DEPARTMENT OF THE INTERIOR

UNITED STATES. GEOLOGICAL SURVEY

CFIARLES D. WALCOTT, DIRECTOR

\title{
THE
}

\section{GRANITES OF MAINE}

BY

T. NELSON DALE

\section{WITH AN INTRODUCTION BY}

GEORGE OTIS SMITH

PREPARED IN COOPLRATION WITH THE MAINE STATE SURVEY COMMISSION

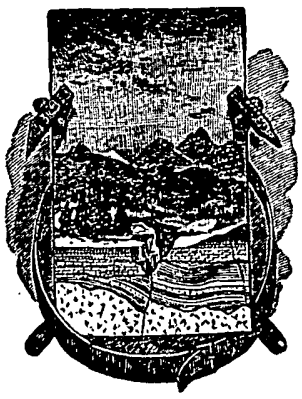

WASHING TON

GOVERNMENT PRINTING OFFICE

1907 



\section{CONTENTS.}

Intronuction-The Occurrence of Granite in Maine, by George Oтіs Sмгтн.

Page.

Geographic distribution......................................... 7

Geologic relations ............................................. 9

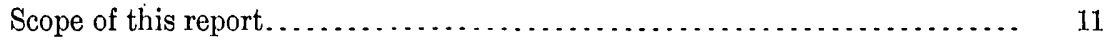

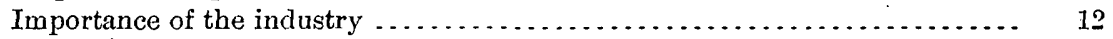

Thę Granites of Maine, by T. Nelson Dale.

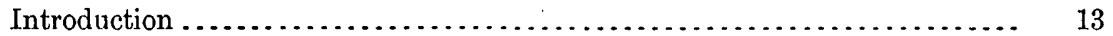

Part I. Scientific discussion ..................................... 14

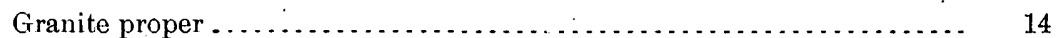

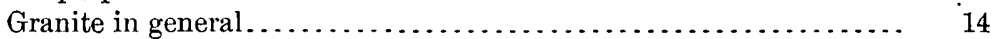

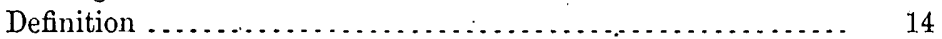

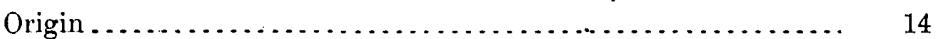

Mineralogical composition.............................. $\quad 16$

Chemical composition ................................. 18

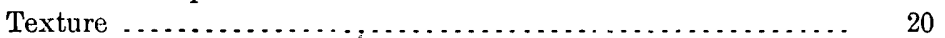

Definition ..................................... $\quad 20$

Character and grade............................. 20

Forms of minerals............................... $\quad 20$

Arrangement of minerals.......................... 20

Physical properties . ................................... 21

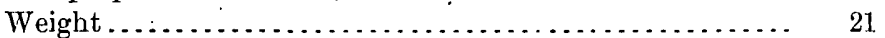

Cohesiveness................................... 21

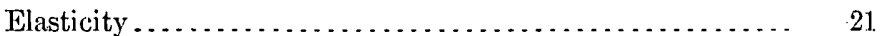

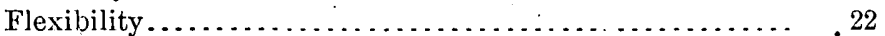

Hardness ...................................... ${ }_{22}$

Expansibility ................................ 22

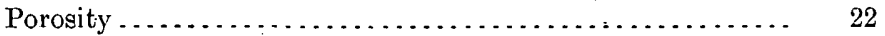

vitreousness ................................... 23

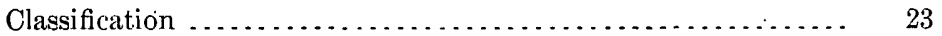

Scientific classification $\ldots \ldots \ldots \ldots \ldots \ldots \ldots \ldots \ldots \ldots \ldots ., 23$

Economic classification .......................... 24

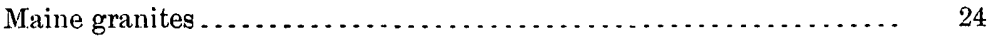

Classification........................................ 24

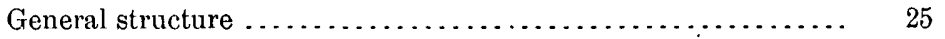

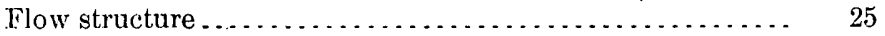

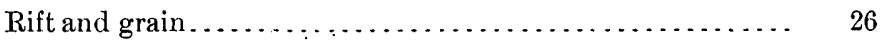

Sheets....................................... 30

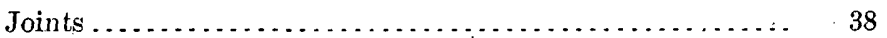

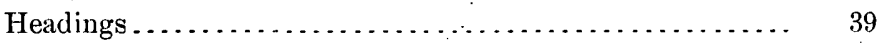

Faults ...................................... 40

Microscopic fractures ("shakes") .................. 40

Subjoints ...................................... 41

Contemporary fractures........................ $\quad 42$ 
Part I. Scientific discussion-Continued.

Granite proper-Continued.

Maine granites-Coutinued.

Rock variations ....................................... 42

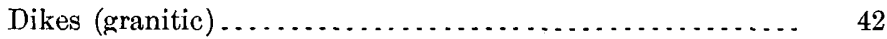

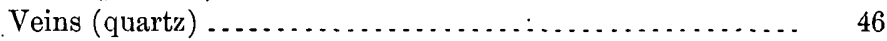

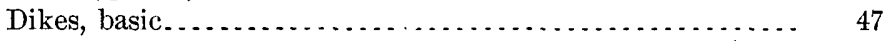

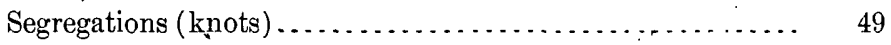

Geodes .......................................... 49

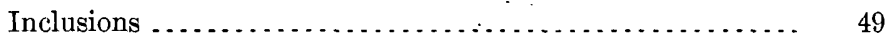

Contacts......................................... 51

Minerals on joint faces.......................... 51

Discoloration ("sap," etc.) ........................... $\quad 52$

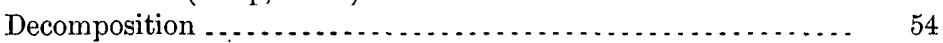

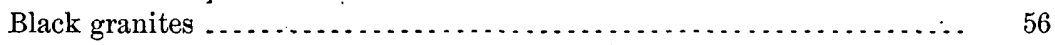

Black granites in general................................. 56

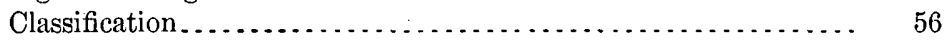

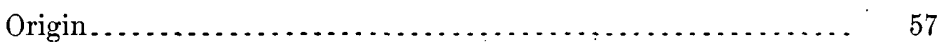

Mineralogical and chemical composition .................. 57

Texture ............................................ 58

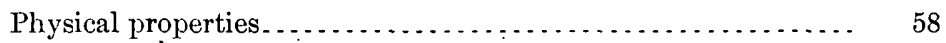

"Black granites" of Maine ............................... 59

Classification........................................ 59

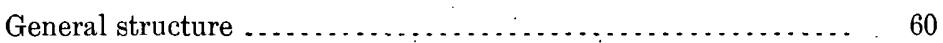

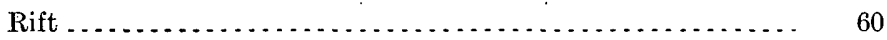

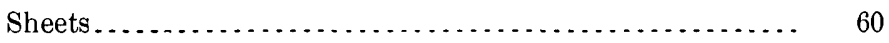

Joints . . . . . . .

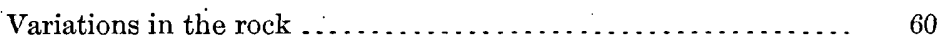

Banding ........................................ 60

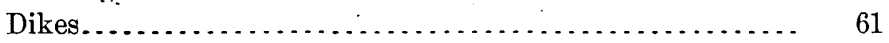

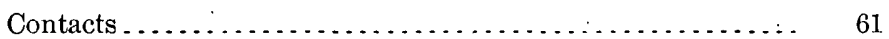

Text-book references on granite and "black granites" ............. 62

Part II. Economic features . . . . . . . . . . . . . .

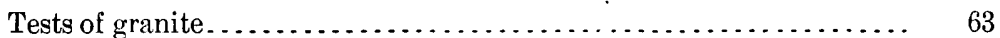

Chemical analysis .................................. 63

Determination of $\mathrm{CO}_{2}$ and $\mathrm{CaO} \ldots \ldots \ldots \ldots \ldots \ldots \ldots \ldots \ldots \ldots \ldots$

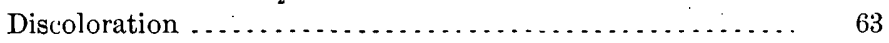

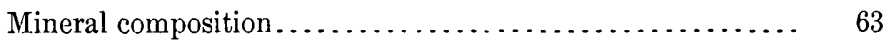

Proportions of minerals .......................... 64

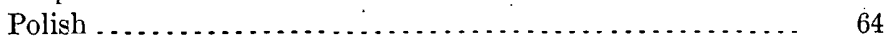

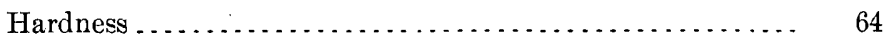

Compressive strength . . . . . . . . . . . . . . . . . . . . . . . 65

Transverse strength, shearing strength, and compressive

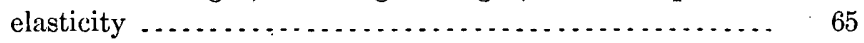

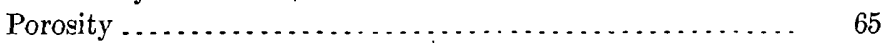

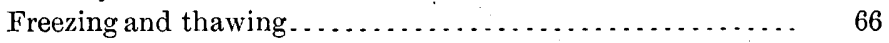

Absorption and compression........................ 66

Behavior under fire .............................. $\quad 66$

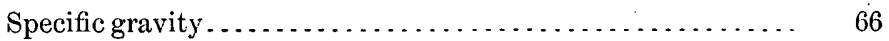

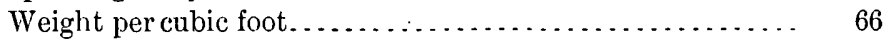

Coefficient of expansion: .......................... 66

Adaptability to different uses............................. 67

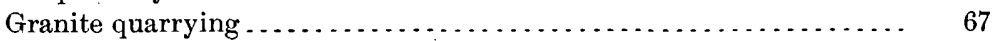

Exploration of surface .............................. 68 
Part II. Economic features-Continued.

Page. Granite quarrying-Continued.

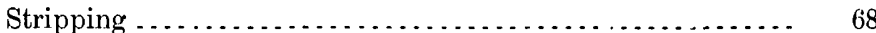

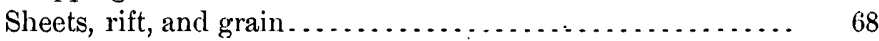

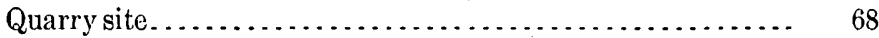

Transportation................................... 68

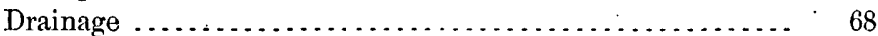

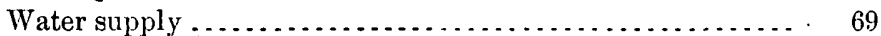

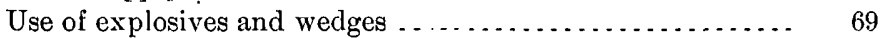

Utilization of waste............................ $\quad 72$

Economic classification of Maine granites .................... 72

Distribution of granite quarries in Maine..................... 75

Quarries of granite proper........................ 75

Quarries of black granite......................... $\quad 76$

Description of the quarries and their product................. $\quad 76$

Cumberland County................................ $\quad 76$

Franklin County ..................................... 80

Hancock County .................................. 84

Kennebec County .................................. 117

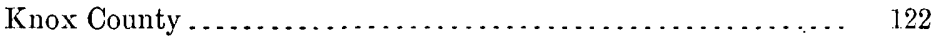

Lincoln County ................................... 139

Oxford County ....................................... 144

Penobscot County ................................. 147

Piscataquis County ................................. 148

Somerset County ................................... 149

Waldo County ................................... 152

Washington County .................................. 159

York County ....................................... 175

Statistics of equipment and investment .................... 183

Statistics of production for 1905 , by Altha $\mathrm{T}$. Coons............. 183

Bibliography of economic geology of granite................. 184

Glossary of scientific and quarry terms................... 186

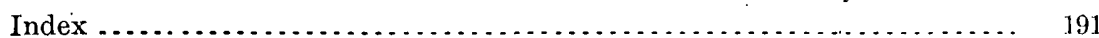

\section{ILLUSTRATIONS.}

Plate I. Map showing the distribution of granite and related rocks in Maine ........................................ Pocket

II. $A$, Joint structure on Heron Neck, Green Island; $B$, Sheet and joint structure on Crotch Island

IIr. $A$, Sheet structure, Ryan Parker quarry, Crotch Island; $B$, Sheet and dome structure, Mosquito Mountain, Frankfort.

IV. $A$, Sheet and joint structure, Hurricane Island quarry; $B$, Sheet and joint structure, Stinchfield quarry, Hallowell ..................

V. $A, B$, Sheet structure, Crabtree and Havey quarry, Sullivan........

VI. $A$, Sheet and joint structure, Sands quarry, Vinalhaven; $B$, Sheet and curved joint, White quarry, Bluehill....................

VII. $A$, Sheets under lateral strain, Rock Chapel Hill, Ga.; $B$, Schist inclusion at Freeport quarry . ...........................

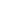

88

(1)

(1)

(1)

(2)

(1)

6

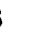

(6)

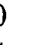

7

9

7

9

2

5

83


Plate VIII. A, Heading, High Isle quarry; $B$, Diabase dike crossing sheets, Allen quarry, Mount Desert...........................

IX. $A$, Granite and schist contact, Waldoboro quarry; $B$, Headings, Longfellow quarry, Hallowell .........................

Page.

X. $A$, Sheet and joint structure, Pleasant River, black-granite quarry, Addison; $B$, Pegmatite dike in black granite, Round Pond quarry ........................................

XI. Round Pond quarry: $A$, Dikes in black granite; $B$, Sheet structure and schist contact.

XII. $A$, Webster quarry, Vinalhaven; $B$, Paving-block quarry, Vinalhaven

XIII. $A$, Carving in coarse granite from Sands quarry, Vinalhaven; $B$, Columns and lathe, Palmer quarry, Vinalhaven............

XIV. $A, B$, Carvings from Stinchfield quarry granite, Hallowell......

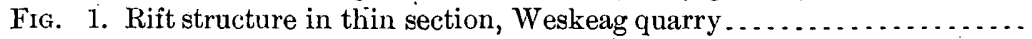

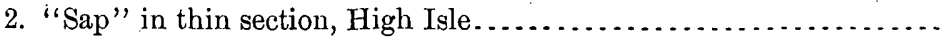

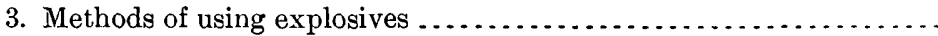

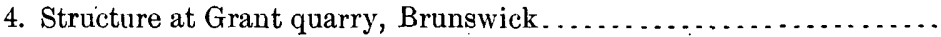

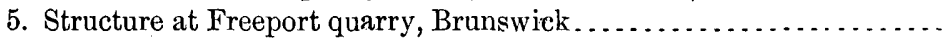

6. Structure at North Jay quarry, Brunswick....................

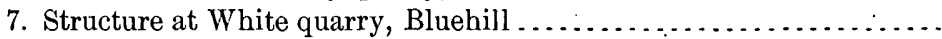

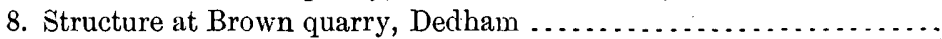

9. Structure at Robertson \& Havey quarry, Franklin . . . . . . . . . . . .

10. Structure at Bragdon, Fernald \& Gordon quarry, Franklin .........

11. Structure at T. M. Blaisdell quarry, East Franklin ...............

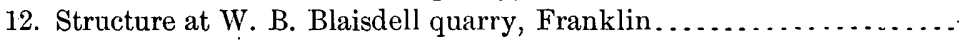

13. Structure at McMullen quarry, Mount Desert Island . .............

14. Structure at Campbell \& Macomber quarry, Mount Desert Island....

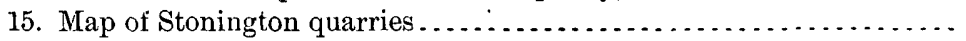

16. Structure at Ryan-Parker quarry, Crotch Island.................

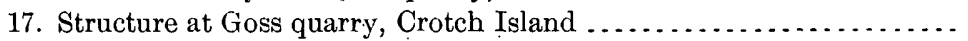

18. Structure at Sherwood quarry, Crotch Island ..................

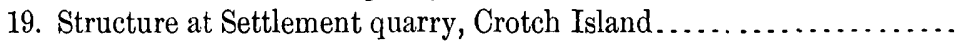

20. Structure at Stinchfield and Longfellow quarries, Hallowell........

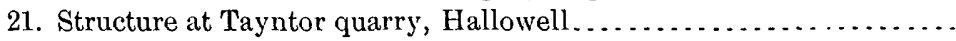

22. Structure at High Isle quarry, Knox County ..................

23. Structure at Sprucehead quarry, St. George ....................

24. Structure at Long Cove quarry, Tenants Harbor................

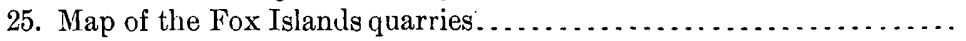

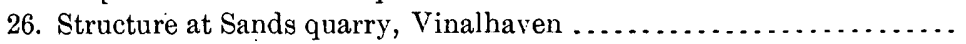

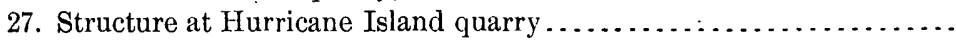

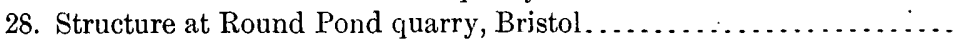

29. Schist inclusions at southwest end of Waldoboro quarry ...........

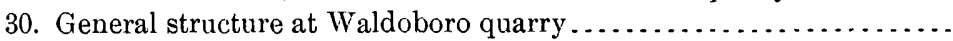

31. Structure at Eagle Gray quarry, Fryeburg ; $\ldots \ldots \ldots \ldots \ldots \ldots \ldots$

32. Flow structure at Dodlin quarry, Norridgewock ................

33. General structure at Dodlin quarry, Norridgewock ..............

34. Structure at Mosquito Mountain quarry, Frankfort...............

35. Structure at Mount Waldo quarry, Frankfort...................

36. Structure at Beaver Lake quarry, Calais . . . . . . . . . . . . . . . . . . .

37. Structure at Bodwell quarry; Jonesboro........................

38. Structure at Gowen Emmons quarry, Biddeford..................

39. Structure at Ross quarry, Kennebunkport................... 


\title{
INTRODUCTION-THE OCCURRENCE OF GraNITE IN MAINE.
}

\author{
By George Otts Smith.
}

\section{GEOGRAPHC DISTRIBUTION.}

Areally, granite is perhaps the most important rock in Maine. Slates, schists, sandstones, and limestones of various types occur in the different sections of the State, but the mountains and hills of the interior and the islands and headlands of the coast for the most part all exhibit slopes and cliffs of massive granite. Even where the exposures are of other rock varieties the notable abundance of granite dikes and quartz veins indicates the presence of granite at no great distance. Not only is this rock most conspicuous, but its importance in both the geology and the industry of the State can hardly be overestimated.

The areal distribution of the granite is somewhat irregular, as may be noted on the map accompanying this report (Pl. I). Three general granitic regions may be distinguished for convenience of description-that of the western tier of counties, that of the eastern part of the State, and the Mount Katahdin area, in the north-central portion of the State. In addition to these larger districts there should also be mentioned three small areas in Lincoln, Kennebec, and Somerset counties, which are intermediate in position between the three main regions.

The granitic areas of the western group are not widely separated, and the largest of these areas as outlined on the map is not all granite, although; as will be explained in a later paragraph, the intrusive granite forms the larger part of the rock exposed within these limits. The northernmost of these granite masses is exposed in the elevated country which forms the divide between the Chaudiere drainage on the Canadian side of the international boundary and the headwaters of Androscoggin and Dead rivers in the northern part of Franklin County. South of this is a much larger area of granite, extending from the western part of Somerset County across Franklin into Oxford County and including prominent peaks, like Mount Bigelow and Saddleback Mountain, as well as the rugged country south of the Rangeley Lakes.

South of this is a large, irregular-shaped area of metamorphic rocks-gneisses and schists-more or less thoroughly impregnated 
with granite, which extends southward and eastward through seven counties, reaching the coast at Casco Bay on the west and Penobscot Bay on the east. Southwest of this area is a mass of granite, which constitutes the eastern extension of the White Mountain massif of New Hampshire and reaches the coast at Casco Bay, Cape Porpoise, and York Cliffs.

The Mount Katahdin granite lies wholly within the forested region of northern Maine, and therefore its exact boundaries are unknown. At the northeastern end of the area is the highest elevation in the State, Katahdin, 5,268 feet above the sea, a typical granite mountain. To the southwest, possibly connected with this area, is the granite near Lake Onawa, where the rock is well exposed in a deep cut of the Canadian Pacific Railroad.

In the eastern counties three extensive granitic areas may be distinguished. Of these the northernmost extends southwestward from New Brunswick across the northern portions of Washington and Hancock counties into Penobscot, and almost wholly is forested country. Southeast of this is the horseshoe-shaped granitic area of Hancock County, which crosses into Washington County near Cherryfield. On the west the outlying Mount Waldo mass may represent an extension of the same granite, although connecting exposures along the Penobscot River below Bucksport have not yet been observed. In the Hancock County area the granite can be traced from the shore of Eggemoggin Reach northward along a line of prominent hills, which are best seen from the Maine Central Railroad near Green Lake. North of Aurora these granite hills have less relief, but east of that place the belt extends southward with increasing ruggedness of topography, Tunk Mountain, near the Washington County Railroad, being characteristic of this southern portion.

The other occurrence of granite in eastern Maine is the belt extending from New Brunswick across the St. Croix, then southwestward to the coast at Addison, and thence along the coast to Penobscot Bay. Within this belt are included several large islands-Swans, Deer, and Vinalhaven-and the mountains of Mount Desert owe their topographic prominence to the massive character of the granite composing them.

Of the smaller areas of granite not included within the three groups described above, that in Lincoln County comprises the town of Waldoboro and islands at the head of Muscongus Bay. The HallowellAugusta area in Kennebec, the North Jay and Phillips area in Franklin, and the Hartland and Norridgewock areas in Somerset County represent the larger of many small intrusive masses of granite in central Maine. With these should be mentioned the granite occurrence in Aroostook County, about 12 miles west of Houlton.

- In the preparation of the map (Pl. I), showing the distribution of 
the granite, as described above, the data used have been largely the results of areal mapping, for folio publication, by E. S. Bastin, C. W. Brown, and the writer, and of general reconnaissance by the writer, assisted by Mr. Bastin. In the more northern areas the work by H. E. Gregory and the earlier mapping by C. T. Jackson and C. H. Hitchcock have been utilized to supplement this recent work. Mr. Brown also contributed the results of recent observations in the vicinity of Mount Katahdin.

\section{GHOLOGIC RELATIONS.}

Wherever the granites of Maine have been studied in any degree of detail, their relations are plainly those of intrusion into part, at least, of the adjacent formations. Evidence that the granite is the younger rock is found in the tendency shown by some of the granite areas (see $\mathrm{Pl}$. I) toward elongation in a northeast-southwest direction, parallel to the general trend of the main structural features of the region, but more conclusive evidence is found in the fact that the granite actually cuts across the bedding of the sedimentary rocks and has in some localities produced in them a very considerable amount of alteration. Bordering the granite in Franklin County, for example, and in some other parts of the State, are andalusite schists which plainly represent sedimentary strata metamorphosed by the granite. In many regions, as will be described later, the granite masses are bordered by gneisses which are formed by a lit-par-lit injection of sedimentary schists by granitic material. Thus the general relations throughout the State point to the granites being relatively the younger rocks.

The feature which is perhaps the most significant in the geologic relations of the granites to the other rocks of the State is the great contrast between the sharpness of certain granite borders and the indefinite character of others. - In the vicinity of Bluehill and Brooksville; for example, in Hancock County, the contact is absolutely sharp, pure granite being succeeded within a foot by schists unmixed with granite. Along such sharp borders, too, the granite usually preserves its normal texture up to the very contact, and the surrounding rocks show almost no effects of contact metamorphism. In striking contrast to this are the broad contact zones which characterize most of the granite masses lying farther westward. In the Rockland region, for example, the Sprucehead-Clark Island granite area is bordered on the northwest by a zone, 3 to 4 miles in width, in which sedimentary slates and schists are intimately associated with injection gneisses, basic granites, fine-grained granite, pegmatite, diorite, gabbro, and diabase. These igneous rocks were plainly derived from the granitic magma and are most abundant in those portions of the contact zone which lie nearest to the areas of pure granite. A granite area near South Penobscot, in Hancock County, 
is almost completely surrounded by a border zone, from one-fourth mile to $1 \frac{1}{2}$ miles in width, in which the rocks are largely diorite and gabbro with small amounts of igneous gneiss and fine-grained granite.

Some hint as to the cause of this contrast in the character of granite borders in different regions is obtained from a study of the rocks in the southwestern part of the State, especially in Sagadahoc, Cumberland, and Oxford counties and the southern part of Kennebec County. Here, as indicated on the map (Pl. I), there are considerable areas from which large continuous masses of normal granite are absent, but in which the prevailing sedimentary schists have been intruded in the most intimate manner by dikelike or irregular masses of pegmatite and fine-grained granite, and in many places have been given a gneissic texture by the lit-par-lit injection of granitic material. The intruded and injected areas pass gradually into the larger areas of nearly pure normal-textured granite shown on the map. To explain such intimate injection and intrusion in areas far removed from any outcropping masses of pure normal granite it seems necessary to assume that a granite mass underlies these rocks at no great distance below the present surface and that such injected areas constitute in reality portions of the " roof" of great granite batholiths.

It seems almost certain that the escape of gases and water vapor and the differentiation of basic rocks from the granitic magma would proceed much more rapidly from the upper surface of a buried magma than from its sides. It is to be expected, therefore, that portions of the "roof" of such granite masses should be particularly characterized by the abundance of pegmatites, diorite, gabbro, etc., and by notable contact metamorphism of the sedimentary rocks through which these forced their way. The sharpness of other granite contacts is readily explained by supposing that they represent the side contacts of the granite batholiths, where the gases and water vapors escaped from the magma laterally in much less volume and where the accompanying metamorphic effects were very much less than at the upper surface.

The geologic history of the great granite intrusions of Maine may be summarized, therefore, as follows:

All of the granite masses now exposed solidified below the surface as it existed at the time they were intruded. The depth at which they solidified varied in different places. Erosion gradually removed the rocks covering some of the masses and has in some places even revealed their deeper portions, so as to show the sharp lateral contacts. In other places all or a part of the "roof" of the granite masses still remains. The present land surface, therefore, truncates the various granite batholiths at different horizons. It is highly probable that a further erosion of 500 to 1,000 feet would expose much larger areas of granite than now appear. 
All of the granites of Maine are believed to belong to the same great period of igneous activity. This conclusion is based on (1) their general lithologic similarity, the differences between granites of different areas being no greater than those observed between different parts of a single area; (2) the nearly continuous extension of certain granite belts for long distances, notably the belt. which extends with slight interruptions from New Brunswick to Jonesport and thence to Mount Desert, Deer Isle, Vinalhaven, and Tenants Harbor; (3) the fact that certain areas of granite are connected by belts that are intensely intruded with granitic rocks, thus suggesting that the granite areas may be continuous beneath the present surface; (4) the fact that most of the granites of the other New England States appear to be of about the same age as those of Maine, thus suggesting a single period of great igneous intrusion throughout the whole New England province.

There can be little doubt at least of the contemporaneity of the granite of the Perry basin, on the eastern border of Maine, with that of Vinalhaven, since the granite forms a practically continuous belt between these two localities, and relations are shown in these two regions which approximately fix the age of the granite. In the Silurian rocks of the Perry region no granite pebbles are found, but such pebbles, plainly derived from the main granite masses of this region, occur abundantly in the conglomerate at the base of the Perry formation, which is of late Devonian age. The granite of the Perry region is therefore late Silurian or Devonian in age. Evidence confirmatory, but less complete, is found in the Vinalhaven region, where the granites intrude surface volcanics of Niagaran age.

\section{SCOPE OF' THIS REPORT.}

This investigation was undertaken at the request of the Maine State Survey Commission, which cooperated with the United States Geological Survey in meeting the expenses of the field work. The plan of this study of the Maine granites provided for both the scientific and the economic phases of the subject, and it is believed that the author has succeeded in making this report an important contribution along both these lines.

Discussion of the granites and associated rocks from a purely petrologic standpoint has been omitted, and no chemical tests have been made except as the chemical composition is believed to affect the durability of the stone. The observations on the relation of the bands of knots to flow structure in the granite, on the parallelism of banding with sheeting and rift, on the relation of sheeting to the surface of the rock, on the cause of the sheeting, and on the spacing and distribution of joints furnish data of high scientific value, which can be used by the geologist interested in the physics of intrusion. Several 
of these same observations can be utilized by the quarry superintendents also. For example, the value of a quarry site is largely dependent on the joint system, and an understanding of the distribution of knots or other imperfections in the stone will guide quarry operations. The discussion of the cause of the discoloration termed "sap" also has a practical value, as well as the suggestion as to the use that can be made of granite so discolored.

The arrangement of the data presented in this report is believed to favor its use by all classes of readers. The broader facts of the classification and description of the Maine granites are separated from the local details of individual quarries. The endeavor has been to present all the essential facts relating to the granites of Maine, so that the report will be of value to geological students as well as to architects, contractors, and quarry owners. It is the plan to follow this publication with similar bulletins by the same author describing the granites of other parts of New England, so that together these will furnish an authoritative report on the granite of this area, which produces over 60 per cent of the granite output of the country.

\section{IMPORTANCE OF THE INDUSTRY.}

The statistics of production given on pages 183-184 of this report indicate the valuation that should be placed upon the granite industry of Maine. In a single county the product of the granite quarries annually reaches the value of $\$ 1,000,000$. For the whole State the output for 1905 exceeded that for any previous year, its value reaching nearly $\$ 2,750,000$.

Vermont and Massachusetts are the only other States whose granite production approaches that of Maine. Both of these, as well as several other States, lead Maine in the value of monumental granite produced, so it is on the output of building stone that the preeminence of Maine depends. The value of Maine granite quarried in 1905 for building purposes was over $\$ 2,000,000$, while in the item of dressed granite of this character the production was valued at $\$ 1,648,687$, or nearly one-third of the output of the whole country. The next most important product of the Maine granite quarries is paving blocks, the amount being over one-seventh of that of the United States, and exceeded only by the output of Wisconsin.

As is shown in this report, the basis of Maine's granite industry is largely the position of quarry sites at tide water. This accessibility of granite of the best grade makes it possible for the Maine product to be an important factor in the markets for building material in the cities of the Atlantic seaboard. Some quarries, both on the coast and inland, furnish building stone and monumental granite of such quality that their product is in special demand. With these advantages the granite industry in Maine deserves consideration as one of the more important assets of the State. 


\title{
THE GRANITES OF MAINE.
}

\author{
By T. Nelson Dale.
}

\section{INTRODUCTION.}

The success of an industry that deals directly with any natural material must involve sooner or later, at some point, a knowledge of the laws pertaining to that material. Moreover, persons engaged in such an industry are led by their very occupation to seek, with an interest that is in proportion to their intelligence, an explanation of the phenomena that daily come before them. For these reasons it has been the writer's aim to make the following report both economic and scientific. Indeed, its scientific part forms to a large extent the basis of its economic part. In the scientific discussion the presentation is succinct. Details that are of interest to the scientific specialist alone have been omitted or very briefly summarized, and technical terms have been, as far as possible, avoided. Such scientific terms as have been necessarily used are explained in the glossary at the end of the report, where, also, some of the quarrymen's terms are given and translated for the benefit of the general reader.

For the general geological knowledge that underlies this report the writer is indebted to a considerable body of scientific literature. The . works of Archibald Geikie, G. P. Merrill, Julien, A. Rosiwal, Buckley, and Watson have been carefully consulted. Other authorities for particular facts or theories will be named at the proper places. The design is to present the subject in the light of present science and in simple form.

The material for the local details and descriptions given in this report was collected in three months in 1905, during which time the writer visited 129 quarries and prospects. Although the complexity of the subject would have justified more extended research at the quarries, it was for several reasons impracticable to extend the season's field work.

Mr. Albert Johannsen, of the United States Geological Survey, has verified or corrected the writer's microscopic determinations of 
53 thin sections of typical rocks for this report; Mr. E. C. Sullivan, of the Survey, has made 10 determinations of carbonate in granite, and Mr. W. T. Schaller, also of the Survey, has determined 2 minerals. Mr. Wirt Tassin, assistant curator of the National Museum, has made an analysis and report on a new mineral from a quartz vein, and Dr. George P. Merrill, head curator of geology of the same institution, has determined a feldspar from the Waldoboro quarry. Mr. G. K. Gilbert, geologist of the United States Geological Survey, has contributed an important photograph (Pl. VII, $A$ ), bearing upon origin of sheet structure in granite, with an explanatory note. Prof. James F. Kemp, of Columbia University, has kindly made some bibliographical contributions. The statistical table of granite production in Maine was prepared by Miss Altha T. Coons, of the Survey.

The word "granites," in the title, is used primarily in its popular and commercial sense, and includes also the so-called "black granites." The proper scientific names of the rocks thus designated are given in the sections devoted to classification and to the descriptions of the quarries and their products.

\section{PART I.-SCIENTIFIC DISCUSSION.}

\section{GRANITE PROPER.}

\section{GRANITE IN GENERAL.}

\section{DEFINITION.}

Granite, in a general sense, is essentially an entirely crystalline igneous rock, consisting mainly of quartz, potash feldspar, and a feldspar containing both soda and lime, also of a small amount of either white or black mica or both, and sometimes of hornblende, more rarely of augite, or both. Where granite has, subsequent to its crystallization, been subjected to pressure sufficient to produce a parallelism in the arrangement of its minerals - that is, a schistosity-it is no longer a true granite, but a gneiss or granitoid gneiss.

\section{ORIGIN.}

Granite is now regarded as the product of the slow cooling and crystallization of molten glasslike matter at a dull-red heat-matter which contained superheated water, and was intruded from below into an overlying mass of rock of sufficient thickness not only to prevent its rapid cooling and its general extrusion at the surface, but also to resist its pressure by its own cohesion and powerfully to compress it by its own gravity. As carbonic acid can be liquefied only under pressure, its presence in liquid form within some of the micro- 
scopic cavities in the quartz of granite is alone evidence that the rock was formed under pressure. The amount of contraction that this inclosed liquid has suffered in cooling has afforded a basis for estimating not only the amount of heat under which the rock began to form, but also the pressure under which it solidified. That the temperature at which granite solidified was comparatively low has been inferred from the fact that it contains minerals which lose their physical properties at temperatures higher than dull-red heat. The relations of the mineral constituents of granite to one another show the order in which they must have crystallized. This order differs from that in which they would crystallize if molten in a dry state, but laboratory experiments have shown that the presence of even a small quantity of water suffices to change that order of crystallization. The presence of superheated water in the formation of granite, inferred from the arrangement of its minerals, and the pressure indicated from a study of the vacuities in the microscopic cavities of its quartz show that the conditions requisite to its formation included not only the pressure of a great overlying mass of rock but also powerful expansive pressure from below. Had this molten matter been extruded at the surface it would have cooled so rapidly that but few of its constituent molecules would have had time to arrange themselves in geometric order. The process of crystallization would have been arrested by the sudden passage of the material into the solid state, and the product would have been a volcanic glass somewhat resembling that which forms cliffs in Yellowstone National Park. In granite, however, the mass has cooled slowly enough to permit the complete crystallization of the originally molten glasslike matter, and no unarranged molecules remain.

The overlying rock mass which furnished so large a part of the pressure required to form granite has at many places been removed from it by erosive processes that operated through great stretches of time. Indeed, it is only by the removal of this mass that granite is anywhere naturally exposed. Although this mass may have measured thousands of feet in thickness, its former presence is at some places attested only by a thin capping on the granite or by fragments which the lacerating action of the intruding granite has incorporated into itself. A remnant of this capping occurs at the Waldoboro quarry and an inclusion of it at the Freeport quarry. (See Pls. IX, $A$; VII, B.)

The lacerating effect of an intrusive eruption and the subsequent erosion of some of the overlying strata have been reproduced experimentally. ${ }^{a}$ The conversion of granite itself back into a material which upon cooling under ordinary conditions has proved to be a

a Howe, Drnest, Twenty-first Ann. Rept. U. S. Geol. Survey, pt. 3, pp. 294-296, Pl. XLIII. 
glass, has been effected in the laboratory, and the chief mineral constituents of granite have been artificially crystallized at high temperature in the presence of water vapor under high pressure, but the conditions requisite for the production of a granitic rock from its chemical constituents have not yet been successfully imitated.

Some granite shows locally a certain alignment of its mica plates and feldspars, due to the flow of the mass while it was in a plastic state-a structure which was probably controlled by the pressure and form of the bordering rock. This "flow structure" should not be confounded with the schistosity which is due to later pressure and which also involves mineral changes and is usually regional rather than local in extent.

The great differences in the grade of texture in granites-the mineral particles ranging from an average diameter of one-fiftieth inch $(0.50 \mathrm{~mm}$.) and even 0.0069 inch $(0.175 \mathrm{~mm}$.) to over half an inchis attributed to differences in the rate of cooling. The portions at the margin of the mass, which cooled rather quickly, crystallized in very small crystals, while the central portions, which cooled more gradually, became coarsely crystalline.

\section{MINERALOGICAL COMPOSITION.}

Feldspar is the most conspicuous and generally the most abundant mineral in granite. By, its color or colors it usually determines to a large extent the general color of the rock; and by the light which it reflects it causes also its brilliancy. It is easily distinguished from the other constituents by its smooth cleavage surfaces and milky, bluish white, or opalescent, or reddish, brownish, or greenish color. Granite usually contains two kinds of feldspar, the most abundant of which is generally potash feldspar, a silicate of alumina and potash. This occurs in one of two crystal forms, orthoclase or microcline, or in both, which, however; can be distinguished only by means of the microscope. The other feldspar (plagioclase), containing both soda and lime, although it may be of the same color as the potash feldspar, can often be distinguished from it by the very fine parallel lines on its surface. Usually it differs greatly in color from the first. The potash feldspar may be reddish or brownish; the plagioclase may be white or greenish. Under the microscope the soda-lime feldspar can be readily distinguished from the potash feldspar by its behavior in polarized light, which brings out its crystalline structure and indicates its particular variety and approximate chemical composition. A granitic rock that contains the two feldspars in equal proportions is distinguished by a special technical name.

Quartz (silica), the next most abundant constituent, is readily known by its glassy luster, uneven fracture, and brittleness. It may 
be colorless, bluish, opalescent or amethystine, or smoky. The quartz in the rock determines in some measure its shade. The vitreousness of the quartz greatly affects the granite.

The next most abundant constituent of granite is mica, which is present in two forms-the white (muscovite, or potash mica), essentially a silicate of alumina with potash, soda, and ferrous oxide, and the black (biotite, or magnesia mica), essentially a silicate of alumina with potash, magnesia, and both ferric and ferrous oxide. Granite may contain one or both of these." The dimensions and number of the scales of black mica largely determine the shade of many granites.

Hornblende, a constituent of many granites, although greenish (rarely bluish), may appear as dark as the black mica, but, unlike that mineral, it does not split into scales. Augite and hornblende resemble each other so closely when in minute particles that they can be distinguished only by means of the microscope. Both may occur.

In addition to these more important minerals, others are usually present in minute or microscopic quantities. Some of these, kaolin, sericite (a potash mica or muscovite), chlorite, epidote, zoisite, and - calcite, as well as paragonite (soda mica), which may possibly be present, are the result of chemical changes in the feldspars or the biotite or hornblende and are therefore called "secondary." Others-like zircon, apatite, titanite, rutile, tourmaline, fluorite, garnet, magnetite, inolybdenite, ilmenite, pyrite, allanite-are regarded as original "accessory constituents." Calcite also occurs in microscopic quantity as an original mineral of some granites. ${ }^{~}$ Of these minor accessories, pyrite (iron disulphide) and calcite (lime carbonate) alone have economic significance, for these may discolor or weaken the stone when dissolved or oxidized on an exposed surface. Ten Maine granites were tested for calcite by Mr. Eugene C. Sullivan at the laboratory of the United States Geological Survey in May, 1906. Under treatment with warm dilute acetic acid they yielded percentages of $\mathrm{CaO}$ (lime), from a trace up to 0.24 . They also showed from 0.014 to 0.218 per cent of $\mathrm{CO}_{2}$ (carbonic acid). Seven of them showed some $\mathrm{MgO}$ (magnesia), two of them showed $\mathrm{CO}_{2}$ in excess of amount required to form $\mathrm{CaCO}_{3}$ (lime carbonate). The calculated result shows the presence of from 0.14 to 0.43 per cent of $\mathrm{CaCO}_{3}$ (lime carbonate), and two of them show from 0.06 to 0.08 per cent of $\mathrm{MgCO}_{3}$ (magnesia carbonate). Mr. Sullivan writes that "the lime extracted by acetic acid is in nearly every case in excess of that required to form calcium cárbonate with the carbon dioxide found. This would indicate that lime and magnesia are present in some easily soluble form,

\footnotetext{
a See Zirkel, Petrographie, vol. 2, p. 13, and Weinschenk, Abhandl. Math.-pbys. Classe k. Bayer. Akad., vol. 18, p. 730, Pl. V.
}

3495-Bull. 313-07-2 
besides the carbonate. It is probably safe to assume that the acetic acid has not attacked the biotite."

During the preparation of this report the accessory minerals garnet, zircon, titanite, magnetite, pyrite, apatite, and molybdenite have been found in Maine granites. Allanite also is reported.

A white silicate which occurs in the Waldoboro granite in isolated more or less incomplete crystals, some of them as much as half an inch in diameter, and which becomes slightly yellowish on weathering, has been determined by Dr. George P. Merrill, of the United States National Museum, as a feldspar between oligoclase and albite. The feldspar of that granite is, however, oligoclase.

The arrangement of the important minerals in the stone will be described under the heading "Texture."

The percentages of the mineral constituents differ within wide limits in granites from different localities. The percentage of muscovite and of the ferromagnesian minerals (biotite, hornblende, augite) is always small, while that of the feldspar and quartz is large. There is considerable variation in the relative amounts of feldspar and quartz and still more in the amounts of each of the feldspars.

The reddish color of the feldspar-a color that plays an important part in the appearance of the stone-is due to an amount of ferrous oxide which rarely exceeds 1 per cent of the mineral and which under the highest powers of the microscope shows no definite form.

\section{CHEMICAL COMPOSITION.}

The chemical composition of granite is of less scientific and economic significance than its mineral composition, for, although chemical analysis shows the percentages of the constituent elements, the process by which these are determined necessarily mingles the elements of several minerals whose proportions vary and whose contribution to the physical properties of the rock differ greatly. When, however, a combination of elements occurs only in one or two of the minerals the chemical analysis serves to corroborate the evidence obtained by microscopic analysis.

Many analyses of granite have been published, but it will suffice here to give the extremes of the percentages shown by some of the more important of these and to refer the reader to works containing complete analyses. ${ }^{a}$ Four analyses of granites from Scotland, Ireland, Italy, and Sweden show the following ranges: ${ }^{b}$

${ }^{a}$ See Washington, H. S., Prof. Papers U. S. Geol. Survey Nos. 14, 1903, and 28, 1904 ; also Clarke, F. W., Bull. U. S. Geol. Survey No. 228, 1904.

${ }^{b}$ Geikie, Archibald, Text-book of Geology, 4th ed., vol. 1, London, 1903, p. 207. 
$\mathrm{SiO}_{2}$ ( silica ) $70.60-74.82$

$\mathrm{Al}_{2} \mathrm{O}_{3}$ (alumina) 14. $86-16.40$

$\mathrm{Fe}_{2} \mathrm{O}_{3}$ (ferric oxide)

$0.10-1.63$

FeO (ferrous oxide)

$0.36-1.64$

Mno (manganese oxide)

$0.00-0.48$

$\mathrm{MgO}$ (magnesia)

$0.23-1.00$

CaO (lime)

$0.89-2.47$

$\mathrm{Na}_{2} \mathrm{O}$ ( sodia)

$3.51-6.12$

$\mathrm{K}_{2} \mathrm{O}$ (potash)

$3.55-5.10$

Ten analyses, made at the laboratory of the United States Geological Survey, of granites from Arizona, California (2), Colorado (4), Maryland, Michigan, and Montana, show the following ranges: ${ }^{a}$

Analyses of American granites.

$\mathrm{SiO}_{2}$ (silicil) 66. $68-77.68$

$\mathrm{Al}_{2} \mathrm{O}_{3}$ (alumina ) -

$\mathrm{Fe}_{2} \mathrm{O}_{3}$ (ferric oxide)

FeO (ferrous oxide) -

MgO (magnesia)

$\mathrm{CaO}$ (lime)

$\mathrm{Na}_{2} \mathrm{O}$ (soda)

$\mathrm{K}_{2} \mathrm{O}$ (potash)

$\mathrm{TiO}_{2} \cdot($ titanium dioxide $)$

$\mathrm{P}_{2} \mathrm{O}_{5}$ (phosphoric acid)

The average of 21 analyses of even-grained Georgia granites made by Watson ${ }^{b}$ yield the following percentages:

Analyses of Georgia granites.

$\mathrm{SiO}_{2}$ (silica)

$\mathrm{Al}_{2} \mathrm{O}_{3}$ (alumina)

$\mathrm{Fe}_{2} \mathrm{O}_{3}$ (ferric oxide)

$\mathrm{CaO}$ (lime)

$\mathrm{MgO}$ (magnesia)

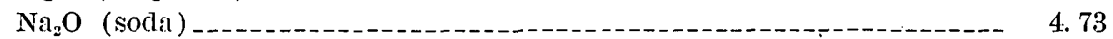

$\mathrm{K}_{2} \mathrm{O}$ (potash) _... 41

It should be noted that in all these analyses most of the lime is to be attributed to the lime-soda feldspar and nearly all the rest of it to apatite (lime phosphate).

It is of interest to note in this connection that certain Scotch and Irish granites contain from 1.6 to 2.8 volumes of gas per volume of rock. This gas is inclosed in microscopic cavities within the minerals, and in the Scotch granite consists of carbon, oxygen,

a See Bull. U. S. Geol. Survey No. 228, p. 54, analysis D; p. 197, analysis D; p. 231, analysis A; p. 232 , analysis $A$; p. 185 , analysis $B$; p. 161 , analyses $A, C, F ;$ p. 78 , analysis $A$; p. 145 , analysis $C$.

b. Watson, Thomas L., Bull. Georgia Geol. Survey No. 9-A, 1902, p. 241.

$c$ Extremes 68.38-72.56. 
hydrogen, and nitrogen in the following combinations and proportions: $\mathrm{CO}_{2}, 23.60 ; \mathrm{CO}, 6.45 ; \mathrm{CH}_{4}, 3.02 ; \mathrm{N}_{2}, 5.13 ; \mathrm{H}_{2}, 61.68 .{ }^{a}$ These gases are probably present in all granites.

\section{TEXTURE:}

Definition.-By the texture of a rock is to be understood those characteristics which are apparent on its surface, or, more exactly, the forms and mutual relations of its minerals as seen without and with a microscope.

Character and grade.-The most important feature of granite is the character of its grain. Some granites are even grained; others contain more or less thinly disseminated and complete crystals of feldspar in a mass of finer, even-grained material-that is, they show what is called porphyritic texture. The next most important feature-perhaps more important-is the relative coarseness or fineness of grain in an even-grained granite. Three grades of texture of this sort may be distinguished: (1) Coarse, in which the feldspars generally measure over $1 \mathrm{~cm}$., or two-fifths inch; (2) medium, in which they measure under $1 \mathrm{~cm}$. (two-fifths inch) and over $0.5 \mathrm{~cm}$. (one-fifth inch) ; (3) fine, in which they measure under $0.5 \mathrm{~cm}$. (onefifth inch). In some coarse-grained granites the feldspars measure one or several inches, and in some fine-grained ones all the particles range from $0.25 \mathrm{~mm}$. to $1 \mathrm{~mm}$. (one twenty-fifth inch) in diameter, and some average as low as $0.50 \mathrm{~mm}$., or one-fiftieth inch. Extremely fine ones average $0.175 \mathrm{~mm}$., or about seven one-thousandths inch.

Forms of minerals.-Even without the aid of the microscope it will be noticed that, except in granites of porphyritic texture, the minerals rarely attain their complete crystalline form. They have interfered with one another's growth. It will also be noticed that some of the crystals of feldspar in some granites are surrounded by a border of a different feldspar. Thus a red feldspar may be bordered by a white or greenish one, or vice versa. Either of these may be the potash feldspar and the other a soda-lime feldspar. It will also be noticed that many of the feldspars are not simple incomplete or complete crystals, but "twins," having the cleavage planes in one half at a different angle from those in the other half, so that when held in the sunlight only one half will reflect the light in one position.

Arrangement of minerals.-A polished surface of any medium or coarse-grained granite shows that the quartz fills up the spaces between the feldspars-that is, was formed after them-also that both feldspars and quartz inclose particles of mica, etc., which must therefore have crystallized before them. Under the microscope the arrangement of the minerals is found to be such that they must

a Tilden, W. H., Proc. Roy. Soc. London, vol. 60, No. 366, Feb. 20, 1897, pp. 454, 455. 
usually have crystallized in the following order: Magnetite, pyrite, apatite, zircon, titanite, hornblende, biotite, muscovite, the feldspars, and, last of all, the quartz. It should be noted, however, that many of the feldspar crystals contain intergrown quartz, so that some of the quartz must therefore have crystallized at the same time as the feldspar. The structure of the potash feldspar in some granites is very intricate, as it contains microscopic intergrowths of a lime-soda feldspar, both having evidently crystallized at the same time or in close alternation. Also, as stated above, the potash feldspar may be rimmed with soda-lime feldspar, or vice versa.

\section{PHYSICAL PROPERTIES.}

Granite derives its physical properties from its mineralogical constitution, particularly from its large content of feldspar and quartz, and from its texture. Among these physical properties the most important are weightt, cohesiveness, elasticity, flexibility, hardness, expansibility, porosity, and vitreousness. Each of these qualities will be taken up in the order in which they are here stated.

Weight.-In order to establish a fixed standard the weight of a rock is compared to that of an equal volume of distilled water. The weight thus determined is called its specific gravity. The specific gravity of granite ranges from 2.593 to 2.731. The average of these extremes is 2.662 , which is equivalent to 2 long tons, or 4,480 pounds, to the cubic yard, or about 165 pounds to the cubic foot. Geikie ${ }^{a}$ calls attention to the change in the weight of granite when immersed in sea water; as given by Stevenson. ${ }^{b}$ A red granite having a specific gravity of 2.71 , or 13.2 cubic feet to the ton in air, will in sea water of a specific gravity of 1.028 measure 21.30 cubic feet to the ton.

Cohesiveness.-The amount of cohesiveness of a rock is ascertained by determining its crushing strength-that is, the weight in pounds required to crush it or to destroy its cohesion. The ultimate compressive strength of granite ranges from about 15,000 to 43,973 pounds per square inch, ${ }^{c}$ but the usual range is from 18,000 to 34,000 pounds. Herrmann ${ }^{d}$ gives the crushing strength of European granites as ranging from 1,100 to over 3,000 kilograms per square centimeter.

Elasticity.-Tests made at the United States Arsenal at Watertown, Mass., to determine the compressive elasticity of specimens of granite from Arkansas, Connecticut, Maine, Minnesota, and New

a Text-book of Geology, 4th ed., p. 568 .

$b$ Stevenson, T., Harbours, p. 107.

- These extremes are from-Wisconsin granites. See Buckley, Ernest B., on the building and ornamental stones of Wisconsin: Bull. Wisconsin Geol. and Nat. Hist. Survey, No. 4, pp. $361,390$.

${ }^{d}$ Herrmann, O., Steinbruchindustrie und Steinbruchgeologie, p. 43. 
Hampshire, show that specimens of granite, in a gaged length of 20 inches and a diameter of 5.5 inches at the middle, when placed under a load of 5,000 pounds to the square inch, suffered compression ranging from 0.0108 to 0.0245 inch, resulting in a lateral expansion ranging from 0.005 to 0.007 inch, and giving ratios of lateral expansion to longitudinal compression ranging from $1: 8$ to $1: 47 .^{a}$

Flexibility.-Although granite contains a large amount of brittle material (estimated at from 30 to 60 per cent) and the interlocking of its various particles give to it great cohesion and rigidity, yet in sheets of sufficient thinness and areal extent it is flexible. Sheets half an inch thick and 4 feet long may be bent, as noted in the description of the Lawton quarry, at Norridgewock, page 151. Whether flexibility in this case was conditioned upon a slight loosening of the grains by chemical and physical change is uncertain.

Hardness.-As will be seen by reference to the tests for hardness described on page 64, granites differ greatly in hardness. This difference is due not merely to differences in the percentage of quartz, but also to variations in the character of the feldspars.

Expansibility.-The expansibility of granite has been variously tested. Bartlett ${ }^{b}$ found that a piece of granite coping 5 feet long, under the effect of a winter temperature of $0^{\circ} \mathrm{F}$. and a summer temperature of $96^{\circ} \mathrm{F}$., expanded 0.027792 inch, or 0.000004825 inch per inch for each degree. The Ordnance Department at the Watertown Arsenal ${ }^{c}$ tested the granites referred to under the heading. "Elasticity," and found that slabs of gaged lengths of 20 inches in passing from a cold-water bath at $32^{\circ} \mathrm{F}$. through a hot-water bath at $212^{\circ} \mathrm{F}$., and back again to cold water at $32^{\circ} \mathrm{F}$., expanded from 0.0017 to $0.0059 \mathrm{inch}$, averaging $0.0040 \mathrm{inch}$.

Porosity.-Granite contains and absorbs water, which is held in microscopic spaces both within and between its constituent minerals. Ansted ${ }^{d}$ states that granite generally contains about 0.8 per cent of water and is capable of absorbing about 0.2 per cent more. In other words, a cubic yard of granite weighing 2 tons contains in its ordinary state about $3 \frac{1}{2}$ gallons of water and can absorb nearly a gallon more on being placed in pure water for a short period. Buckley ${ }^{c}$ found that the pore space or porosity in fourteen Wisconsin granites ranges from 0.17 to 0.392 per cent, and that the ratio of absorption (percentage of weight of absorbed water to the average dry weight of the sample) of the same granites ranges from 0.17 to 0.50 . Mer-

\footnotetext{
a Report of the tests of metals, etc., made with the United States testing machine at Watertown Arsenal, Mass. (1895), 1896, pp. 339-348.

${ }^{b}$ Bartlett, Wm. C., Experiments on the expansion and contraction of building stones by variation of temperature: Am. Jour. Sci., 1st ser., vol. 22, 1832, pp. 136-140.

c Op. cit., p. 322 .

${ }^{d}$ Ansted, D. T., quoted by Edward Hull in A treatise on building and ornamental stones of Great Britain and foreign countries, 1872 , p. 30 .

C Op. cit., p. 400.
} 
rill $^{a}$ has shown that certain Maryland granites absorb from 0.196 to 0.258 per cent of water after drying 24 hours at $212^{\circ} \mathrm{F}$. and then being immersed for 24 hours.

Vitreousness.-The vitreousness of granite is due to that of its contained quartz. Under extreme changes of temperature, as in a city fire, where water is thrown on the stone, granite exfoliates badly. This exfoliation or shelling is attributable to the unequal expansion or contraction of its outer and its inner portions under sudden changes of temperature. It is also probably connected with the vitreousness of the quartz and possibly also in a measure with the liquids contained in microscopic cavities of the quartz. The unequal expansive ratios of the different constituent minerals would result in gereral disintegration, not in exfoliation.

Buckley ${ }^{b}$ subjected 2-inch cubes of five Wisconsin granites to high temperature tests and found that they were all destroyed at $1,500^{\circ} \mathrm{F}$. One of them cracked at $1,000^{\circ}$; two others began to disintegrate at $1,200^{\circ}$. The most notable change was that "when struck with a hammer or scratched with a knife they emitted the sound peculiar to a burnt brick." Cutting ${ }^{c}$ applied a fire test to granites from eighteen quarries in Maine, Maryland, Massachusetts, Minnesota, New Hampshire, Vermont, and Virginia, with the result that after saturation they all stood a temperature of $500^{\circ} \mathrm{F}$. without damage, but showed the first appearance of injury at $700^{\circ}-800^{\circ}$ and were rendered worthless at $900^{\circ}-1,000^{\circ}$. Twenty-three sandstones subjected to the same tests showed the first appearance of injury at $800^{\circ}-900^{\circ}$ and became worthless at $950^{\circ}-1,200^{\circ}$. His general results agree with those of experience as to the relative fire endurance of granite and sandstone. ${ }^{l}$. The behavior of granite under very high temperature is not attributable to any one physical property. The physical properties of granite are further discussed in Part II, under the heading "Tests of granite" (pp. 63-66).

\section{CLAASST FICATION.}

The varieties of granite are so numerous that for either scientific or economic purposes they need to be classified.

Scientific classification.-For scientific purposes granites may be classified according to their less essential mineral constituentsmica, hornblende, and augite. Thus a granite containing white mica is termed a muscovite granite; one containing black mica; a biotite granite; one containing both, a muscovite-biotite granite. A granite

a Merrill, G. P., Maryland Geol. Survey, vol. 2, pp. 94, 95.

${ }^{b}$ Op. cit., p. 411.

$c$ Cutting, Hiram A., Sixth Rept. Agric. Vermont, 1880, pp. 47-54; also, Durability of building stone: Am. Tour. Sci., Bd ser., vol. 21, 1.881, p. 410 .

"Merrill, G. P., Stones for building and decoration, p. 435. 
containing black mica and hornblende is called a biotite-hornblende granite. Granites may also be classified according to both their mineral and their chemical composition. These two form the basis of the latest classification of igneous rocks, which is too complex to be outlined here. ${ }^{a}$

Economic classification.-For economic purposes granites may be classified first as to texture-as even grained, or porphyritic, or as coarse, medium, or fine, according to the scale given on page 20. Those of extra coarse or extra fine texture can be distinguished by the prefix very. This scale gives five grades of texture. Granites should also be classified as to general color and shade-as pinkish, reddish, lavender, or gray or warm gray (that is, a gray showing the presence of a slight reddish, reddish-purplish, or yellowish tinge), and as dark, medium, or light. They may be further classified and designated by the colors of their most conspicuous minerals, the feldspars, quartz, and mica. A stone may thus be called a coarse, even-grained, warm-gray granite, with lavender and white feldspars, smoky quartz, and black mica; or another may be called a fine, evengrained, very light gray granite, with white feldspar, clear quartz, and both white and black mica. This scheme of classification will suffice for general economic purposes. The outline of a complete economic description of granite can be constructed from the tests enumerated in Part II, on pages 63-66.

\section{MAINE GRANITES.}

CLASSIFICATION.

The granites exposed at the Maine quarries fall naturally into six groups:

1. Biotite granite, consisting of the two feldspars, quartz, and black mica.

2. Muscovite-biotite or biotite-muscovite granite, with both black and white mica, the name of the predominating mica being in each case the first.

3. Hornblende-biotite or biotite-hornblende granite, with hornblende and black mica, named according to the predominance of one or the other of these minerals.

4. Quartz monzonite, in which the amount of lime-soda feldspar is so large as to about equal that of the potash feldspar. The monzonites quarried in Maine contain biotite or biotite and hornblende.

5. Hornblende granite, consisting of the feldspars, quartz, and hornblende.

a See Cross, Iddings, Pirrson, Washington, Quantitative Classification of Igneous Rocks based on Chemical and Mineral Characters, with a Systematic Nomenclature, Chicago, 1903 ; also Jour. Geology, vol. 10, 1902, pp. 555 et seq. 
6. Quartz diorite, used for building purposes and not classed commercially as "black granite." This contains only lime-soda feldspar, with quartz, hornblende, and biotite.

The first three groups include nearly all the granite quarried in the State. Quartz monzonite is quarried at Sprucehead, Knox County, and at Norridgewock, Somerset County; hornblende granite is quarried in a small way on Mount Desert Island, and quartz diorite is quarried at Bryant Pond, Oxford County, and has been quarried at Hartland, Somerset County, and for local use at Alfred, York County.

The general appearance and petrographic peculiarities of the stone at each quarry will be briefly stated in Part II, in the descriptions of the quarries and their products, and a classification of Maine granites based upon economic principles will be found on pages 72-75.

Maine granites as exposed at the quarries show a wide range of texture. Some are porphyritic, others even grained, ranging from very fine, in which the size of the particles averages about onefiftieth inch (one-half millimeter) to very coarse, in which the feldspars measure an inch or' more in diameter. They exhibit also considerable variety of color-pinkish, reddish, gray of various shades, and light lavender. The differences in the color of the two feldspars and the variations in the amount of biotite and in the size of its scales produce more or less marked contrasts of color and of shade. The quartz also, if smoky, darkens the general color, and if clear, lightens it.

GENERAL STRUCTURE.

The term "structure" embraces all the divisional planes that traverse the rock. These occur at intervals ranging from a microscopic distance to one measured by scores of feet, and either cross or, very rarely, give a course to the texture resulting from crystallization.

FLOW STRUCTURE.

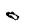

At some of the quarries (as Dodlin Hill, near Norridgewock, and Clinton Sherwood quarry; on Crotch Island) two varieties of granite lie in contact, the dividing line between them being vertical (see p. 109 and figs. 18 and 32 for details). One of the granites at Dodlin Hill also shows a light and dark vertical banding. The direction of the flow of the granite at these quarries must therefore have been vertical. At the Mount Waldo quarry, near Frankfort (see p. 154), vertical flow structure also occurs. At Tayntor \& Company's quarry, near Hallowell (see p. 120), a faint vertical banding is visible in one of the walls, and a thin section of the rock shows a parallelism of the biotite. The same parallelism is seen also at an old quarry near Brunswick (see p. 76). The arrangement of the mica in the granite at both places was doubtless governed by the direction of the flow of 
the material prior to its crystallization. At one of the North Jay quarries (see p. 82) a similar parallelism in the mica occurs, but its course is in horizontal waves 20 feet wide and 3 feet high; while at another of these quarries similar waves pitch $10^{\circ}-40^{\circ}$. At the Pownal Granite Company's quarry, in Pownal (see p. 79), the rock shows a parallelism of the minerals, the planes of structure dipping $10^{\circ}$, and a thin section of the granite does not show any bending of the mica plates or straining of the quartz particles.

In some of the Massachusetts and New Hampshire quarries the writer found flow structure parallel to the surface of the granite at its contact with the overlying rock and also surrounding and parallel to the surface of large blocks of other rock included with the granite. (See "Inclusions," p. 52.)

The very local character of these structural features iridicates that they are not due to pressure which affected the entire region, but that they originated while the granitic masses were still plastic, for they conform to the general direction of the flow or to some local modification of it. A granite that exhibits flow structure is by some writers called a flow gneiss. The courses of the lines of this flow structure in the Maine quarries, when the bands are vertical, are $\mathrm{N}$. $35^{\circ}$ W., N. $20^{\circ}$ W., and N. $45^{\circ}$ E.

RIFT AND GRAIN.

The rift in granite is a feature of considerable scientific interest and of much economic importance. It is an obscure microscopic foliation-either vertical, or very nearly so, or horizontal-along which the granite splits more easily than in any other direction. The grain is a foliation in a direction at right angles to this, along which the rock splits with a facility second only to that of the fracture along the rift. After a little experience an observer can detect the rift with the unaided eye, where it is marked. The only available data on this subject are furnished by Tarr and Whittle. ${ }^{a}$

Tarr presents four figures reproduced from drawings made from enlarged views of thin sections showing the rift in Cape Ann hornblende-biotite granite. These figures and his descriptions indicate that rift consists of microscopic faults, most of which meander across feldspar and quartz alike, although some go around the quartz particles rather than through them. In the feldspars rift usually follows the cleavage. These minute faults are lined with microscopic fragments of the mineral they traverse and some of them send off short, minute diagonal fractures on either side. In examining such

a Tarr, R. S., The phenomena of rifting in granite: Am. Jour. Sci., 3d ser., vol. 41, 1891, pp. 267-272, figs. 1-4; also Economic Geology of the United States, 1895, p. 124. Whittle, Charles L., Rifting and grain in granite: Eng: and Min. Jour., vol. 70, 1900, p. $16 \dot{1}$, figs. 1,2 . 
a structure it is important to make sure that the grinding of the section has not in any way modified the original fractures. Tarr adds that at Cape Ann the rift does not traverse the "knots" or" the basic dikes that cross the granite.

Whittle gives two sketches made from polished surfaces of a wellknown granite quarried by the Maine and New Hampshire Granite Company at Redstone, N. H. One of these sketches, made from a surface running at right angles to the rift, shows quartz and feldspar grains traversed by a generally parallel set of lines corresponding to the rift planes. The lines are more numerous in the feldspar than in the quartz grains. The other sketch, made from another specimen, shows besides the rift lines another less pronounced set intersecting these at right angles. This second set corresponds to the grain. Whittle calls attention to the fact that notwithstanding the marked rift and grain at this quarry the stone stood a compression test of. 22,370 pounds to the square inch, and was, therefore, not appreciably weakened by the microscopic fractures. A visit made by the writer in 1906 to the quarry at Redstone, N. H., has corroborated Whittle's observations. The details of the rift and grain structure observed there will be discussed in a future publication.

Another peculiarity of rift is that the angle of its inclination may at some places be modified by gravity. Thus in some localities a block will split at one angle from the top, but at another from the side; or, again, at one angle where the mass of the block is at the right and at another where it is at the left of the line of fracture. Experienced granite workmen at Concord, $\mathrm{N}$. H., and Quincy, Mass., report that at some places a block that would show a horizontal rift when split from one point of the compass (say the north) acquires an inclined rift if split from the south or the east or west. The cause of this is not apparent. There are also indications that a slight alteration of the feldspars may improve the rift. Finally, as is well known to granite quarrymen, rift and grain are modified by temperature, the effect of winter cold in New England (frost?) being to intensify the rift and grain where they are weak.

A Norwegian geologist, Carl C. Riiber, in a work on the granite industry of Norway ${ }^{a}$ describes an augite syenite with inferior rift and grain, in which the cleavage planes of the individual feldspar crystals are parallel to the two cleavage planes of the rock. No such relationship between rift and mineral cleavage has yet been made out in the Maine granites.

Among the many thin sections prepared for this bulletin there is one from the medium-grained biotite-muscovite granite of C. E. Hudson's Weskeag quarry, near Pleasant Beach, South Thomaston, which

a Norges granit industri, Norges Geologiske undersogelse, Aarbog for 1898, No. 12, p. 45. 
shows the rift; and this is also quite marked in the hand specimen. It consists of exceedingly delicate fractures that meander across the quartz particles and some of the feldspars in a roughly parallel direction. These cracks are filled with a highly refracting mineral (calcite or muscovite?), showing that the fractures are not recent. (See fig. 1.)

Herrmann ${ }^{a}$ states that in Saxony the rift is parallel to the horiontal sheets or joints. That is true for short distances in the

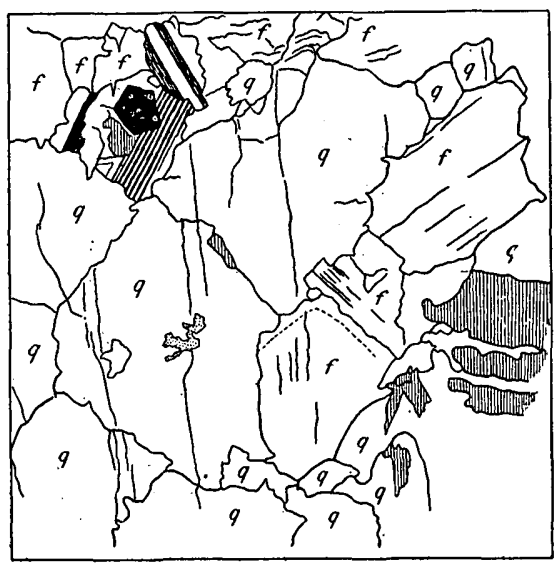

FIG. 1.-Outlines of minerals, in thin section (fourfiftieths inch square) of biotite-muscovite granite from Weskeag quarry, near Pleasant Beach, South Thomaston, showing parallel rift cracks crossing quartz and feldspar particles (marked $q$ and $f$ ). The finely shaded parts are muscovite and biotite; the banded area is oligoclase. The black pentagonal area is a crystal of garnet.
Maine quarries, but where the rift is horizontal and the sheets curve it crosses the sheets, and of course where the rift is vertical it crosses them throughout. Exceptionally, in one of the quarries at Quincy, Mass., a foreman reported to the writer a deflection of the rift in apparent relation to the increasing inclination of the sheets. PI. III, $A$, shows the relations of the rift to the sheets at the Ryan-Parker quarry on Crotch Island. The structural diagrams a c companying the quarry descriptions show the relation of the rift of grain, when vertical, to the various joints.

Rift and grain data were collected at 53 quarries of granite proper. At 29 of these the rift was vertical and at 24 it was horizontal and the grain was vertical. The courses of the rift and grain are distributed as follows:

Courses of rift.

Number of quarries.

N. $10^{\circ}$ W.-N. $10^{\circ}$ E

N. $22^{\circ}-50^{\circ}$ W

N. $30^{\circ}-77^{\circ} \mathrm{E}$

N. $60^{\circ}-70^{\circ}$ W

E. W. to N. $85^{\circ}$ E. and N. $80^{\circ}$ W

a Herrmann, O., Steinbruchindustrie und Steinbruchgeologie, Berlin, 1899, p. 109. 
Courses of grain.

Number of quarries.

$\mathrm{N}$

N. $20^{\circ}-25^{\circ} \mathrm{W}$

N. $45^{\circ}-75^{\circ} \mathrm{E}$

N. $45^{\circ}-72^{\circ} \mathrm{W}$

E. -W. to N. $80^{\circ} \mathrm{E}$

It appears, therefore, that when rift or grain is vertical the eastwest and west-northwest to northwest courses are the most common, and next the north and east-northeast to northeast courses.

Rift and grain are not always pronounced. Either or both may be very feeble or may be absent. At some of the Redbeach quarries, owing to the absence of both, it is difficult to hammer out even a good hand specimen.

At the Armbrust quarry, in Vinalhaven, there is a horizontal rift confined to a 4 -foot mass striking across the hill with a $N$. $65^{\circ} \mathrm{W}$. course.

The presence of fairly good rift or grain is an important economic factor in the granite inclustry, for it diminishes both the amount of labor in drilling for blasts and in splitting.

The cause of rift structure and the relative time of its formation are not yet known. If rift were always vertical it might appear to be closely related to those joints which are nearly parallel to it; but that would not explain the rift when horizontal, and horizontal rift can not be related to the sheets, which it intersects at various angles in many granites. In general it is evident that since it crystallized granite has been subjected to strains that have caused either two sets of vertical microscopic fractures extending at right angles to each other, one more pronounced than the other, or one set of similar horizontal fractures crossed by a.vertical set.

That the rift is a factor in the crushing strength of granite is shown by the results of tests of Mount Waldo granite from Frankfort, blocks of which when placed on the bed-that is, with pressure applied at right angles to the rift-showed an ultimate strength to the square inch of 31,782 to 32,635 pounds (average, 32,208), but when placed on the side-that is, with pressure applied parallel to the rift-showed an ultimate strength of from 29,183 to 30,197 pounds (average, 29,690). In the first test the first crack appeared in the block at a pressure of from 120,000 to 123,300 pounds (average, $121,650)$ and in the second test it appeared at one of 107,400 to 112,600 pounds (average, 110,000 pounds).$^{a}$

a Reilly, J. W., Ordnance Rept., tests of materials, etc. (1900), 1901, p. 1119. 
SHEETS.

The division of granite into "sheets" or "beds" by jointlike fractures which are variously curved or approach horizontally, being generally parallel with the granite surface, attracted the attention of geologists long ago. Although this is the most striking feature in every granite quarry and largely makes the granite industry possible, there is a great diversity of opinion as to its cause. Whitney ${ }^{a}$ writes:

The curves are arranged strictly with reference to the surface of the masses of rock, showing clearly that they must have been produced by the contraction of the material while cooling or solidifying, and also giving very strougly the impression that, in many places, we see something of the original shape of the surface as it was when the granitic mass assumed its present position.

Shaler, a few years later, ${ }^{b}$ attributed the sheet structure to expansion due to solar heat.

C. H. Hitcheock ${ }^{c}$ notices in New Hampshire granite " numerous joints, the planes of which correspond very nearly with the slope of the hill," but does not undertake to explain them.

Vogt ${ }^{d}$ states that the sheets in granites of southeastern Norway measure from 6 inches to 6 feet in thickness and dip from $8^{\circ}$ to $33^{\circ}$ on the sides of the mountains, toward the valleys, but that they are horizontal on top and approximately parallel to the surface. $\mathrm{He}$ shows that they are of preglacial origin, attributes them to the same cause that is postulated by Whitney for those in California, and regards them as parallel to the original surface of the granite masses.

Harris, ${ }^{e}$ referring to the English granite quarries, writes: "In every quarry 'we visited we found that the direction of the 'beds' approximately corresponded with the outline of the hill on which it was situated." He offers no explanation of the phenomenon, however.

J. J. Craw ford $f$ describes the sheet structure at granite quarries in Madera and Tulare counties, California, as consisting of "concentric layers conforming in a general way to the contour of the hills," but suggests no cause for them.

Herrmann, ${ }^{g}$ who made a special economic study of the granites of Saxony, writes:

\footnotetext{
a Whitney, J: D., Geology of California, vol. 1, 1865, Geology, p. 372 ; also pp. 227, 417, and figs. 49-54.

${ }^{b}$ Shaler, N. S., Notes on the concentric structure of granitic rocks: Proc. Boston Soc. Nat. Hist., vol. 12, 1869, pp. 289-293.

${ }^{c}$ Geology of New Hampshire, vol. 2, 1877, pp. 511-512 and plate opposite p. 158, showing sheet structure at the "Flume."

${ }^{d}$ Vogt, J. H. L., Sheets of granite and syenite in their relation to the present surface: Geol. Föreningens i Stockholm, Föhandl., 1879, No. 56, vol. 4, No. 14 ; also Nogle, Bemaerkninger om Granit: Christiania videnskabsselsk. Föhandl., 1881, No. 9.

- Harris, George F., Granites and our granite industries, London, 1888.

$t$ Twelfth .Rept. State Mineralogist of California, 1894, pp. 384-387 and 3 plates.

- Herrmann, O., Technische Verwerthung der Lausitzer Granite: Zeitsch, fuir prakt. Geologie, Nov., 1895, Heft 2, p. 435.
} 
Upon closer inspection it appears that the granite sheets are elongated lenses overlying one another, of which the upper one, as a rule, has its bulging part lying in the depression formed by the two underlying Jenses wbere they come together.

Branner ${ }^{a}$ describes the exfoliation of the granitoid gneisses in Brazil, which he attributes only in part to changes of temperature. $\mathrm{He}$ calls attention to the fact that the linear expansion of a mass of gneiss 300 feet long at a depth of 15 feet from the surface under a surface temperature of $103^{\circ} \mathrm{F}$. would amount to only 0.072 inch; and he quotes the results of Forbes, Quetelet, and others to show that the annual change of temperature can penetrate rock only to a depth of 40 feet in temperate regions and still less in the Tropics.

Merrill ${ }^{b}$ describes Stone Mountain, in Georgia, as a boss of granite 2 miles long by $1 \frac{1}{2}$ miles wide and 650 feet high, which owes its form wholly to exfoliation parallel to preexisting lines of weakness. The mass appears to be made up of imbricated sheets of granite which he regards as the result of torsional strains. The bosslike form is incidental and consequent. Intermittent expansion and contraction from changes of temperature have so affected the sheets that bound the mass at the sides that they have found relief in expansion in an upward direction. These ruptured sheets are rarely more than 10 inches thick, but are 10 or 20 feet in diameter. ${ }^{c}$

Herrmann ${ }^{d}$ sums up his conclusions on the subject substantially as follows: The so-called sheets are thin near the rock surface, generally only a few centimeters thick, but become gradually thicker with increasing depth. This downward increase in the thickness of the sheets is generally more rapid where the texture of the stone is coarser. The course of the sheets is not, as Vogt claims, parallel to the original surface of the consolidating rock. It is not governed by internal strains. The attitude of the sheets corresponds to the form of the present rock surface. The sheet structure is to be looked upon as the effect of the beginning and progress of weathering from the surface inward. These weathering cracks are determined by the form of the rock surface instead of that being determined by them.

a Branner, John C., Decomposition of rocks in Brazil : Bull. Geol. Soc. America, vol. 7, 1896 ; Exfoliation, pp. 269-277 ; Temperature and exfoliation, pp. 285-292:

- Merrill, George P., Rocks, Rock-weathering, and Soils, 1897, p. 245.

c For description and representations of Stone Mountain see Purington, Chester W., Geological and topographical features of the region about Atlanta, Ga.: Am. Geologist, vol. 14, 1894, pp. 105-108 and Pl. IV ; also Watson, Thomas L., Bull. Georgia Geol. Survey No. 9-A, 1902, p. 113, and Pls. I-VIII. See also description of another granite dome-Stone Mountain, in North Carolina-by Watson and Laney, in Bull. North Carolina Geol. Survey No. 2, 1906 ; Pl. XxV.

a Herrmann, O., Steinbruchindustrie und Steinbruchgeologle, 1899, pp. 109-111. 
Turner ${ }^{a}$ calls attention to the sheet structure and exfoliation of Fairview dome in the Yosemite.

Gilbert ${ }^{b}$ shows that sheet structure occurs in synclinal as well as in anticlinal attitude-in other words, is parallel to hollows as well as. hills-which he considers unfavorable to the theory that it is an original structure. He suggests that sheet structure may possibly be due to expansive stress consequent upon relief from compressive stress brought about by the removal of the mass into which the granite was intruded. Subordinately he notes that in the Sierras, at least, the dome structure and the parallel joint structure do not occur in the same place and that the former has resisted general erosion more successfully than the latter.

Dr. G. F. Becker, in a recent conversation with the writer, stated that he had found the granites and gneisses at the bottom of the Colorado Canyon both vertically and horizontally jointed. If these are true granites and are still in contact with the rocks into which they were intruded and show genuine sheet structure the phenomenon would conclusively prove that such structure may occur independently of solar heat and load.

Mr. S. F. Emmons similarly stated that in the Mosquito (Park) Range, in Colorado, the pre-Cambrian granite and schist are cut by horizontal joints to a depth of 50 feet below their contact with the overlying Cambrian, the joints diminishing in number downward. The original load upon the granite here consisted of at least 10,000 feet of Paleozoic and between 5,000 and 6,000 feet of Cretaceous rocks. As the granite, however, was not intruded into Cambrian sediments it must have been exposed to atmospheric erosion before they were deposited. These horizontal joints may therefore have been related to solar temperature.

Mr. G. K. Gilbert has recently studied the granite domes of Georgia and attributes their sheet structure to compressive strains. He finds that the granite in these domes ${ }^{c}$ is not naturally divided into plates, but that the outer parts of the granite-the parts nearest the surface-are in a condition of compressive strain, which results in slow exfoliation and which enables quarrymen, by means of carefully regulated blasts, to develop joints that run approximately parallel to the surface, so that the granite is detached in sheets. As these sheets are divided into blocks in the process of quarrying the blocks expand horizontally as they are released from the general mass. In these granitic domes parting planes also develop naturally

\footnotetext{
a Turner, H. W., The Pleistocene geology of the south-central Sierra Nevada, with especial reference to the origin of the Yosemite Valley: Proc. California Acad. Scl., 3d ser., Geology, vol. 1, No. 9, 1900 ; Formation of domes, pp. 312-315, and Pl. XXXVII.

${ }^{b}$ Domes and dome structure of the high Sierras: Bull. Geol. Soc. Am., vol. 15, pp. 29-36, and pl. 3, 1904.

c Letters to writer dated May 4 and June 11, 1906.
} 


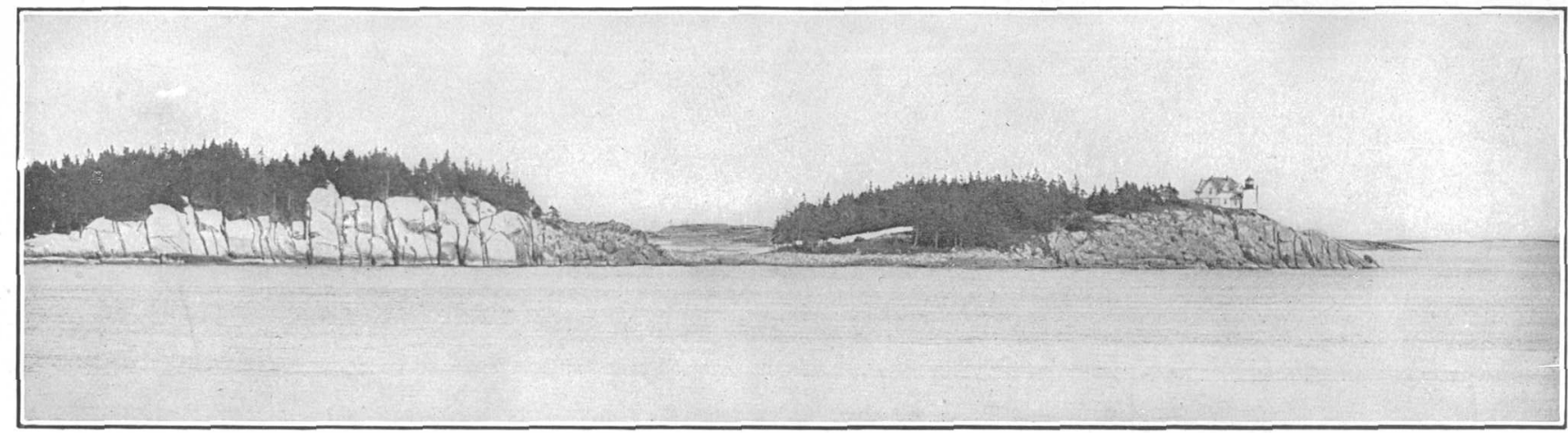

A. EAST-WEST JOINT STRUCTURE IN GRANITE ON HERON NECK AT SOUTH END OF GREEN ISLAND. Looking south-southeast from Hurricane Island. From a photograph.

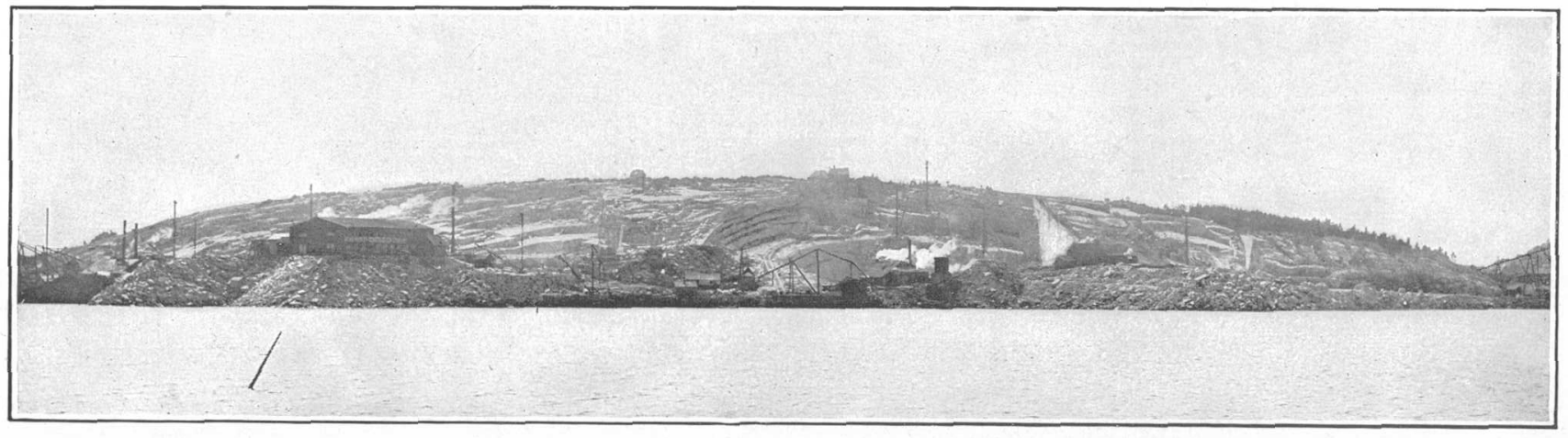

B. SOUTHERN HALF OF CROTCH ISLAND; GOSS QUARRY AT LEFT, RYAN-PARKER QUARRY AT RIGHT.

Showing concentric sheet structure crossed by vertical east-west joints. Looking west from Rock Island. From a photograph. 
within a few inches of the surface, and the expansive force is there so great as to induce conspicuous buckling in the thin sheets thus formed. This buckling is illustrated in Pl. VII, $A$, from a photograph taken by Mr. Gilbert on Rock Chapel Hill, near Lithonia. The jar of blasting precipitates this sheeting action, so that several of the domes at which quarrying is in progress show long lines of freshly formed disrupted arches. Mr. Gilbert found that the horizontal elongation, or rather the elongation coincident approximately with the contour of the dome surface, amounted, by one measurement, to three-fourths inch in a length of 40 feet.

The artificial production of sheets in granite, as practiced at Bangalore, in southern India, shows similar phenomena. It is described by $\mathrm{H}$. Warth ${ }^{a}$ in substance as follows: At the surface there is a horizontal sheet of rather weathered rock 4 feet thick; below this lies a sheet of fresh rock 3 feet thick, but below this lies fresh rock without split. These sheets "are probably due to the variations of temperature, daily and seasonal." By means of wood fires plates 60 by 40 feet by 6 inches in thickness are detached in one piece. A line of fire 7 feet long is gradually elongated and moved over the granite.' The effect of the fire is tested by hammering the granite in front of it, and then the fire is moved forward. The maximum length of the arc of fire is 25 feet. The burning lasts eight hours; the line of fire is advanced 6 feet per hour. The area passed over by line of fire is 460 square feet. The amount of wood used is 15 hundredweight. The average thickness of stone is 5 inches and its specific gravity is 2.62 . These data show that 30 pounds of stone are quarried with 1 pound of wood. Some plates are taken out in inclined position. The action of fire is independent of the original surface of rock and also of the direction of lamination (the granite is gneissose) and of veins. The uniformity in the thickness of the sheets is attributed to the regulating influence of preexisting cracks.

Van Hise, in his treatise on metamorphism, ${ }^{b}$ is inclined to attribute sheet structure to solar temperature.

Before these various views are discussed the sheet structure as exposed at the Maine quarries will be described.

Dome form and sheet structure are most finely exhibited at Crotch Island, near Stonington, and at Mosquito Mountain, near Frankfort. Pl. II, $B$, shows the structure in the southern half of Crotch Island, at Thurlow Head. The dome is oblate, measuring about 1,500 feet from north to south and 140 feet in height.

a The quarrying of granite in India: Nature, vol. 51, 1895, p. 272.

'Mon. U. S. Geol. Survey, vol. 47, pp. 434-439.

3495-Bull. 313-07-3 
Pl. III, $A$, from a photograph of the Ryan-Parker quarry, at the southern edge of the dome, shows that the sheets rapidly increase in thickness downward-from 1 to 25 feet in a depth of 75 feet-and that they dip $20^{\circ}-25^{\circ}$ south. At the next quarry north, the Goss quarry (see p. 104), the excavation has exposed the center of the dome mass. Here the sheets dip both north and south, measure from 1 to 30 feet in thickness, and extend to a depth of fully 140 feet from the surface.

Mosquito Mountain, 2 miles south of Frankfort, in Waldo County, is an oval granite dome 545 feet high, with a north-south axis about 1 mile long and measuring about a half mile across. ${ }^{a}$ It has a steep east face, the sheet structure of which is shown in Pl. III, $B$. On the top of this mountain, where the quarry is situated, the sheets dip gently north, west, and east, tapering out on the sides, and measure from 6 to 15 feet in thickness. At the Mount Waldo quarry, which lies $1 \frac{1}{4}$ miles north-northwest of the top of Mosquito Mountain, the sheets dip $10^{\circ}$ and measure from 8 inches to 8 feet in thickness, and the excavation averages about 20 feet in depth, about 300 feet from north to south, and 400 feet from east to west. The granite here is evidently under compressive strain, for the progress of quarrying resulted in a vertical fissure, running north-northwest by south-soutueast for the entire width of the quarry and across the rift, which is horizontal. The formation of the fissure was accompanied by a dull explosive noise. At several other quarries in the State foremen report a partial closing of vertical drill holes by expansion or compressive strain of the rock. (See pp. 121; 142.)

At the White quarry, in Bluehill, the granite breaks with explosi.. sound when split in large sheets along a vertical rift that extends N. $50^{\circ} \mathrm{W}$. The gradual increase in the thickness of sheets downwar? is well shown at the Stinchfield quarry, near Hallowell (Pl. IV, $B$ ). Their evenness and curvature are shown at the Sands quarry, at Vinalhaven (Pl. VI, $A$ ). At the Hurricane Island quarry $(\mathrm{Pl}$. IV, $A$ ) the excavation is 105 feet deep. The upper sheets measure from 3 to 20 feet in thickness, but the lowest sheet is fully 60 feet thick. A good cross section of granite sheets is seen at the Crabtree \& Havey quarry, in Sullivan, shown in Pl. V, $B$, which brings out their lenticular form and arrangement. The tapering end of one lens lies between the thickest parts of two others. This accounts for the apparent irregularity in the thickness of the sheets in some longitudinal sections, notwithstanding their progressive thickening downward. Compare $\mathrm{Pl}$. $\mathrm{V}, A$, taken at the same quarry, with Pl. V, $B$. Pl. VIII, $B$, also shows the tapering of the sheets, but here there has been some faulting since their formation, as is shown by the dislocation of the dike.

a See Bucksport topographic sheet, U. S. Geol. Survey. 


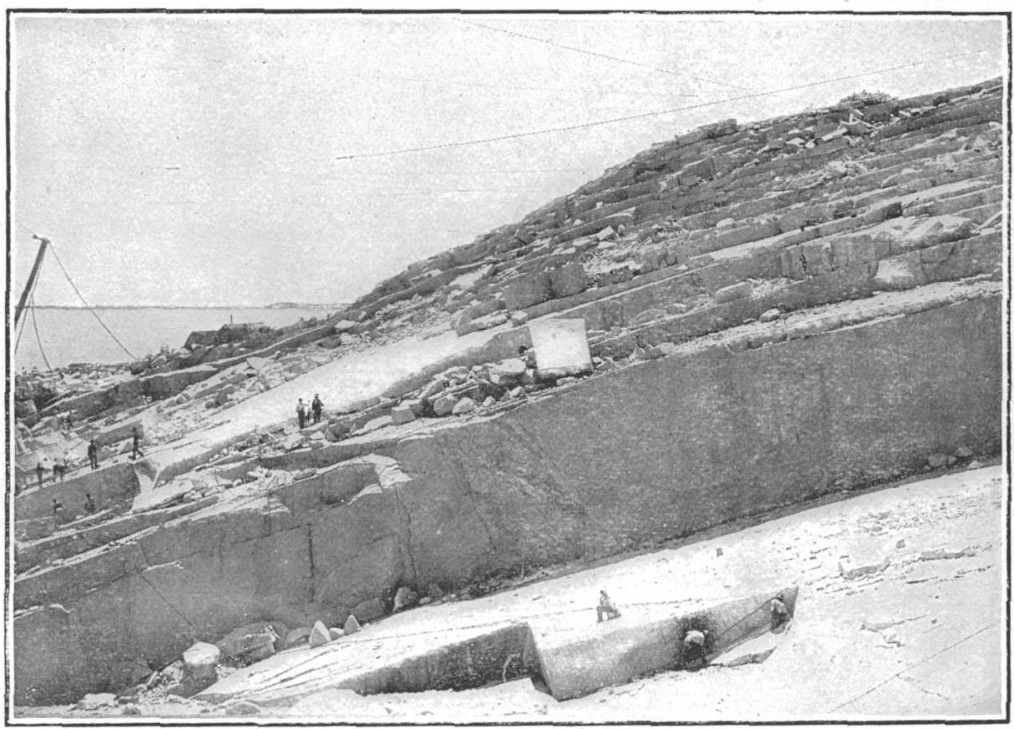

A. RYAN-PARKER QUARRY ON CROTCH ISLAND. LOOKING SOUTHWEST.

Showing sheet structure; the thickest sheet massures 25 feet and is split along the rift.

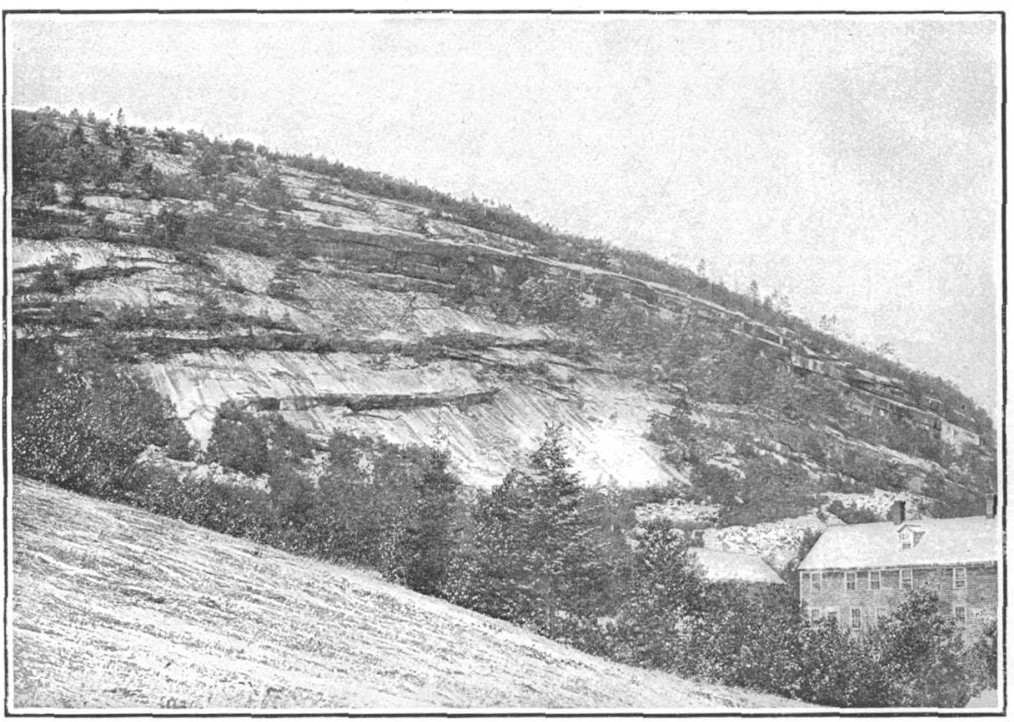

B. EASTERN SIDE OF MOSQUITO MOUNTAIN, TOWN OF FRANKFORT. LOOKING NORTHWEST

Showing sheet and dome structure and the erosion of the sheets. 
Faulting of the sheets is likely to occur also along the steep joints. (See also p. 98.) Pl. IX, $A$, a view taken at the Waldoboro quarry, shows the relation of the sheet structure to the underside of the originally overlying mass of schist, a remnant of which bounds the quarry on two sides at the top. The sheets here are nearly horizontal, while the schist dips $45^{\circ}$.

The observations as to sheet structure made at over 100 granite quarries in Maine are here summarized:

1. There is a general parallelism between the sheets and the rock surface, resulting in a wavelike joint structure and surface over large areas.

2. The sheets increase in thickness more or less gradually downward. In the coarse-textured granites of Crotch and Hurricane islands the increase is abrupt. (See Pls. III, $A$, and IV, A.)

3. The sheets are generally lenses, though in some places their form is obscure. Their thick and thin parts alternate vertically with one another. The joints that separate these superposed lenses therefore undulate in such a way that only every other set is parallel.

4. On Crotch Island the sheet structure extends to a depth of at least 140 feet from the surface.

5. There are indications here and there that the granite is under compressive strain, which tends to form vertical fissures or to expand the sheets horizontally so as to fill up small artificial fissures. (See p. 34.)

The observations, made in Europe and in this country, taken in connection with the various inferences geologists have drawn from them, indicate that sheet or "onion" structure in granite rocks is due to the following possible causes:

1. To expansion caused by solar heat after the exposure of the granite by erosion.

2. To contraction in the cooling of the granite while it was still under its load of sedimentary beds, the sheets being therefore approximately parallel to the original contact surface of the intrusive.

3. To expansive stress or tensile strain brought about by the diminution of the compressive stress in consequence of the removal of the overlying material.

4. To concentric weathering due to original texture or mineral composition. This action would be chiefly chemical and would be aided by vertical joints and by any. superficial cracks due to expansion and contraction under changes of temperature:

5. To compressive strain akin to that which has operated in the folding of sedimentary beds.

6. To the cause named under 1 at the surface, but to the cause named under 5 lower down: 
These propositions will be considered in the order given:

1. Solar heat may produce a certain amount of exfoliation in thin sheets at the surface, as is proved experimentally in the fire method of granite quarrying in India (p. 33), but as it penetrates only to a depth of 40 feet and as sheet structure is known to occur on Crotch Island, Maine, at a depth of 140 feet and at Quincy, Mass., at a depth of 175 feet, it is quite inadequate to account for sheets that are 20 to 30 feet thick and 100 to 175 feet below the surface.

2. In view of the load under which granite was probably formed, as shown by the well-known calculations of Sorby and Ward, ${ }^{a}$ and the very gradual rate at which, therefore, it probably cooled, which is also indicated by the general coarseness of its texture, it is very improbable that the temperature at its contact surface and the temperature at depths 100 or 200 feet below could have so greatly differed as to bring about such a system of joints by contraction.

3. As Gilbert states, in suggesting the theory of fracture by relief of tensile strain through the erosion of overlying masses, we have no distinct knowledge of it. It is a possible explanation.

4. Careful inspection of the rock on both sides of the sheet joints fails to show any difference in texture or mineral composition. The sheet structure traverses both rift and flow structure, and it would be possible to procure specimens showing a sheet joint traversing a single crystal of feldspar. Whatever chemical action has taken place along the sheet joints is of secondary character. Acid waters may have gained access to the joint, but have not caused it. (See matter under heading Discoloration, "Sap," etc., p. 52.)

5. The condition of strain described by Merrill and Gilbert as existing in the granite domes of Georgia and by Niles and. Emerson in the gneiss at Monson, Mass., ${ }^{b}$ and occurring to a lesser extent in some Maine quarries (see pp. 93, 112, 121, 155), shows that granite and gneiss are in places still under compressive strain. Another instance occurs at the quarry of the New England Granite Works, at Concord, $\mathrm{N}$. H., recently visited by the writer. The foreman at this quarry was in the habit of calling certain sheets, marked by the absence of discoloration, "strain sheets," to distinguish them from the others. At one place a northwest-southeast compressive strain had actually extended the strain sheet about 5 feet, and also caused a vertical fracture that extended over 15 feet diagonally from the north-south working face to a point on a vertical east-west channel 5 feet back of the

a Sorby, H. C., On the microscopic structure of crystals, indicating the origin of minerals and rocks: Quart. .Tour. Geol. Soc. London, vol. 14, 1858, pp. 453 et seq.; Ward, J. Clifton, On the granitic, granitoid, and associated metamorphic rocks of the Lake district: Ibid., vol. 31,1875 , pp. 568-602.

$b$ Niles, W. H., Some interesting phenomena observed in guarrying: Proc. Boston Soc. Nat. Hist., vol. 14, 1872 , pp. $80-87$, and vol. 16, 1874, pp. 41-43. Emerson, B. K., Geology of Old Hampshire County, Mass. : Mon. U. S. Geol. Survey, vol. 39, 1898, pp. 63-65. 


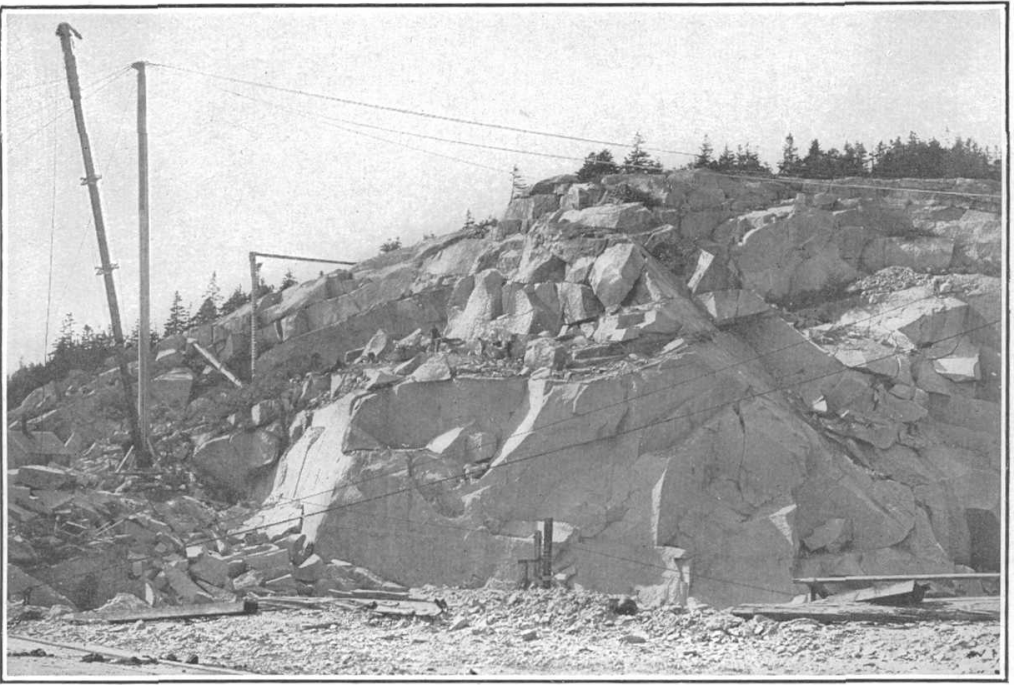

A. HURRICANE ISLE QUARRY; EASTERN END.

Showing the lower 60 -foot sheet overlain by 20 -foot sheet and crossed by vertical east-west joint and by diagonal joint.

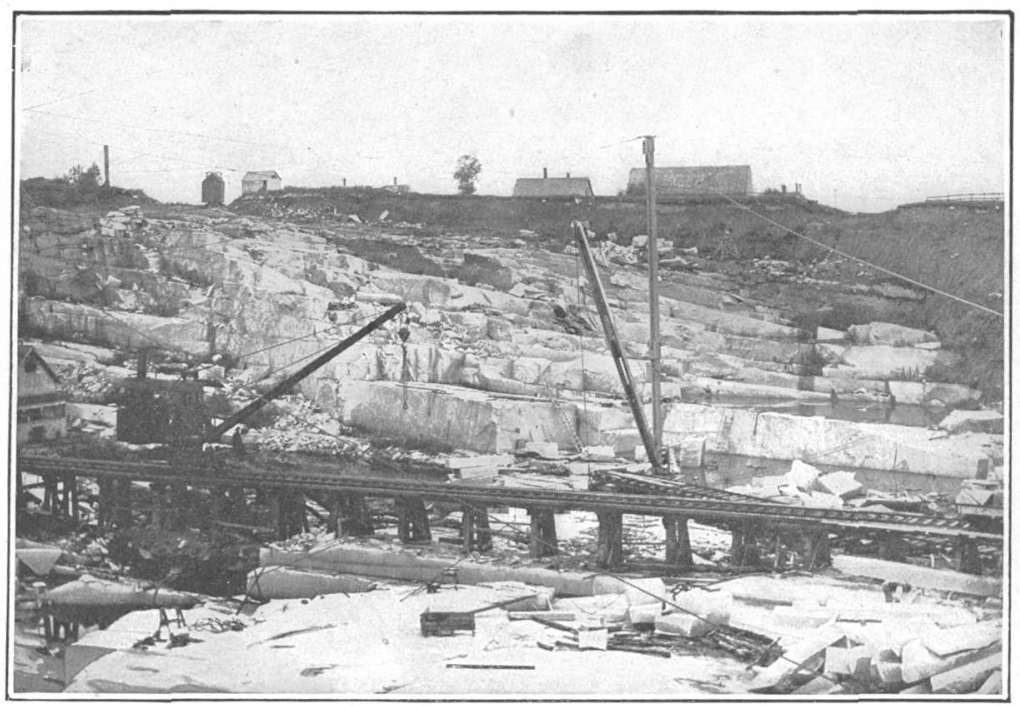

B. STINCHFIELD QUARRY NEAR HALLOWELL LOOKING WEST-NORTHWEST.

Showing the sheets gradually increasing in thickness downward, crossed by joint (C) and overlain by glacial drift. 
face, closing up the channel to half.its original width. The practicability of developing sheet structure by the use of explosives and compressed air, as it is developed in some of the North Carolina granite quarries, shows that the rock is under a compressive strain there. ${ }^{a}$

All these observations bring this theory within the domain of inductive science. If sheet structure is due to compressive strain, it is due to such a strain as would produce a series of undulating fractures extending entirely across a granite mass several miles in diameter and to a depth, as far as observed, of 175 feet from the rock surface.

6. In view of the undoubted sheeting effect of expansion under solar heat within a short distance of the surface and of the fact that some of the sheets near the surface measure but a few inches in thickness, it is quite possible that very thin surface sheets have originated in this way; but in view of what was stated under 5 it seems rather probable that compressive strain is the main factor in producing massive sheets. At the surface both causes may have cooperated. The progressive thickness of the sheets downward indicates that the operation of this strain is evidently also dependent upon distance either from the present surface or from a former surface or contact.

According to this view sheet structure may be said to exert a controlling influence upon surface forms, yet it seems quite admissible that granite domes as conspicuous as Stone Mountain, in Georgia, and Fairview Dome, in California, notwithstanding all the exfoliation that has taken place on them or the erosion they may have suffered, may still retain some degree of parallelism between their present form and the original contour of the granitic intrusions of which they are parts. This may be true, also, of the granite hills of Mount Desert.

The probability being admitted that the general parallelism between the present surface and the sheet structure is the result of erosion that followed the sheeting, the question still remains, What has determined the form and location of the domes? These may possibly be referred to major arches (anticlines) in the folds of the stratified rocks which originally overlay the granite. The crustal movement that produced these folds may also have brought about the intrusion of the material that formed the domes beneath them.

Although the sheet structure and the rock surface are very generally parallel, they are not universally so, as may be seen on the west flank of Mosquito Mountain, shown in Pl. III, $B$, which has evidently been partially eroded, and at the Clark Island (p. 126) and Sprucehead (p. 124) quarries, where the rock surface and the sheet structure were also found to be discordant.

a Watson, T. L., and Laney, F. B., The building and ornamental stones of North Carolina: Bull. North Carolina Geol. Survey No. 2, 1906, pp. 157-160. 
Sheet structure in granite so much resembles the structure of folded stratified rocks that underground water circulates in practically the same way along the fracture planes of one and bedding planes of the other. The exudation of water along sheet joints on vertical rock faces is seen in many of the Maine quarries, and is shown in Pl. V-I, $B$.

That sheet structure is not confined to intrusives is shown at quarries in Niantic, R. I., and Milford, N. H., where it passes indifferently from the granite into the overlying gneiss.

JoINTs.

Herrmann ${ }^{a}$ divides joints into two groups--joints formed by lateral compression, whose distances from one another are related to the coarseness of the rock texture, and joints due to expansion, some of which are parted and filled with calcite, quartz, pegmatite, or volcanic rock. That many joints are due to compressive or torsional strain, and that every such strain resolves itself into two components, resulting in two sets of joints that intersect at an angle of about $90^{\circ}$, each forming an angle of about $45^{\circ}$ with the direction of the strain, are facts now generally recognized. Crosby ${ }^{b}$ has suggested that torsional strains may have been supplemented by vibratory ones in causing joints. Becker, ${ }^{c}$ in a recent paper, shows that four or even more than four systems of joints may be due to a single force. He also shows that subsequent strain on a region thus jointed would tend to produce motion along the previously formed joints rather than a new system of jointing. It is conceivable that if a region had been jointed and afterwards subjected to a tensile strain, some of its joints might be parted, and if they were very deep the openings might become filled with volcanic matter from below, or, if not, with matter from above, infiltrated from overlying rocks. That motion has occurred along some of the joints in the Maine quarries is evident from the polished and striated surfaces of the joints as well as from the faulting of the sheets.

The structural diagrams in Part II, accompanying descriptions of the quarries, show the course and dip of the joints at the Maine quarries. The intersection of sheet structure by joint structure is shown in Pls. IV $A, B ; \mathrm{V}, B$; VI, $A, B$; VIII, $A$; IX, $A$. The conspicuous east-west system of joints as seen on Crotch Island is shown in Pl. II, $B$, and as seen in the region of Vinalhaven, on Heron Neck, at the south end of Green Island, in PI. II, A.

\footnotetext{
"Op. cit., p. 103.

$b$ Crosby, W. O., The origin of parallel and intersecting joints: Am. Geologist, vol. 12, 1893 , pp. $368-375$.

${ }^{c}$ Becker, Geoige F., Simultaneous joints: Proc. Washington Acad. Sci., vol. 7, July, 1905 , pp. $267-275$, Pl. XIII.
} 


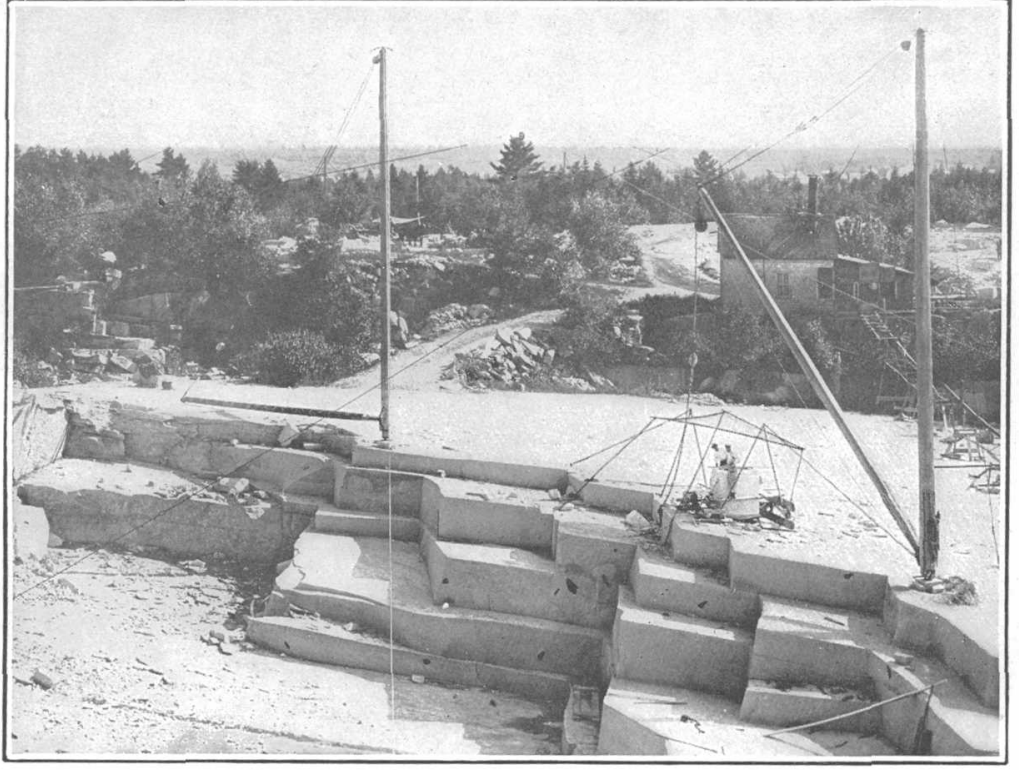

$A$

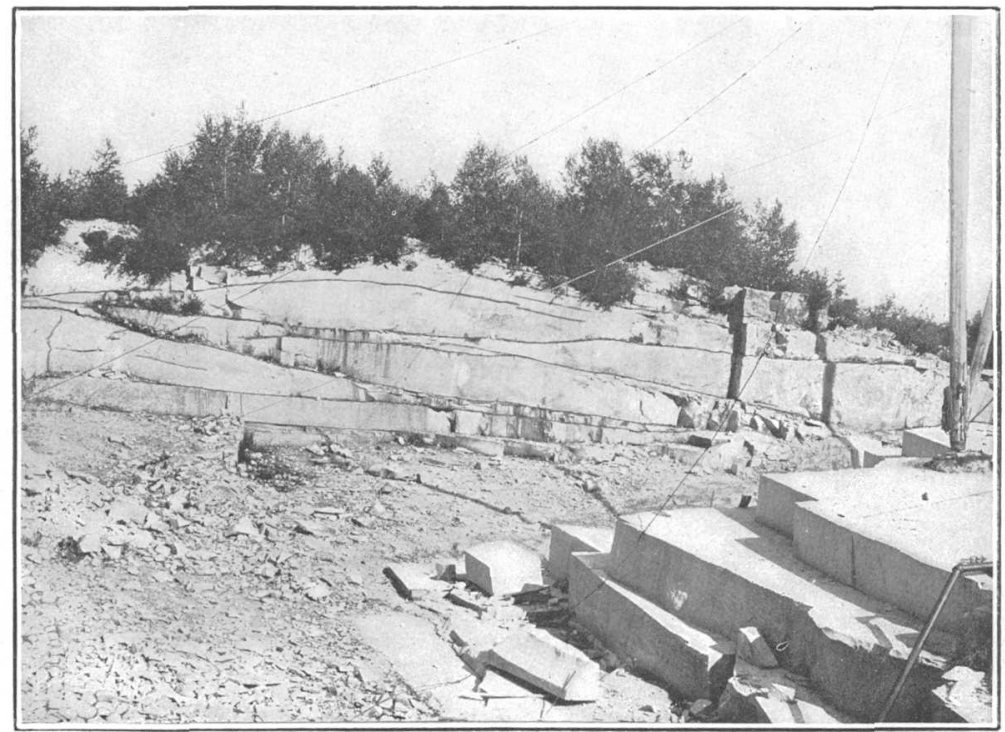

CRABTREE \& HAVEY QUARRY IN SULLIVAN.

A. South side, showing irregularity in thickness of sheets owing to their lenticular form; also 9 black knots. The cuts are along grain and hard way. B. East wall, showing lenticular form of sheets in cross section on a joint face. 
Joints are exceptionally as curved "as the side of a ship." Thus at the White Granite Company's quarry, near Bluehill, there is a curved joint that covers a large segment of a circle and is continuous with two vertical joints, one of which strikes $\mathrm{N}$. $50^{\circ} \mathrm{W}$., and the other $\mathrm{N} .52^{\circ}$. E. This, as well as the sheet structure intersected by it, is shown in Pl. VI, $B$.

Possibly related to such curved joints are what some New England quarrymen term "toe nails." These joints strike with the sheets, but extend only from one sheet surface to the next, and have a curve which sharply intersects that of the sheet structure. Such joints seem to be due to a strain different from that which produced the sheets.

A tabulation of 179 observations of joint courses made by compass at 80 Maine quarries of granite proper yielded the following results:

Courses of joints in granite as determined by 179 observations malle at 80 quarries in Maine.

Direction.

N. $12^{\circ}$ W. N. $15^{\circ}$ E

N. $20^{\circ}-30^{\circ} \mathrm{E}$

N. $20^{\circ}-30^{\circ}$ W.

N. $32^{\circ}-50^{\circ} \mathrm{E}$

N. $35^{\circ}-50^{\circ} \mathrm{W}$

N. $55^{\circ}-70^{\circ} \mathrm{E}$

N. $55^{\circ}-70^{\circ}$ W.

E. - W. to N. $75^{\circ}$ I:. and N. $75^{\circ}$ W.

The joints of the dominant system extend approximately east to west; those of the systems next most common extend approximately northeast and northwest, east-northeast, and west-northwest, and north and south.

The spacing of the joints varies considerably, ranging from 1 foot to 500 feet, but usually from 10 to 50 feet.

In some localities the jointing is very irregular. Thus at the Ellis \& Buswell (Ross) quarry, near Biddeford (fig. 39, p. 182), the granite is broken up into various polygons, which at the surface, where weathering has made inroads, resemble bowlders. Quarries opened in such places are called bowlder quarries. Another sort of irreguIarity in joints consists in their discontinuity or intermittence, their strike and dip for the short spaces in which they occur being uniform.

HEADINGS.

In some places joints occur within intervals so short as to break up the rock into useless blocks. For a space of 5 to 50 feet the joints may be from 6 inches to 3 feet apart. A group of close joints is called by quarrymen a " heading," possibly because, when practicable, 
such a mass is left as the head or wall of the quarry. Pl. VIII, $A$, shows a typical heading on Dix Island. PI. IX, $B$, from a photograph taken at the Longfellow. quarry, near Hallowell, shows the intersection of two headings, one striking about northeast, the other about northwest; also the flexuous course of the northwest set of joints. Headings afford ample ingress for surface water, and consequently the granite within a heading is generally badly stained, if not decomposed. This will be referred to more fully under the heading "Decomposition" (p. 54).

An interesting feature of both headings and joints shown in some of the deeper quarries at Quincy, Mass., which may be found in Maine as the quarries are deepened, is their vertical discontinuity. A heading occurring at the surface may disappear below, or a heading may abruptly appear a hundred feet below the surface and continue downward.

Headings are not easily accounted for. They may be produced by vibratory strains that recur at intervals of time. If they are so caused, the character of the fractures in some headings indicate that the strains are very complex.

The courses of headings at each quarry are given in the descriptions of the quarries in Part II.

FAULTS.

The polished and grooved faces ("slickensides") observed on many of the joints at the quarries show that faulting has occurred along them. The discontinuity of the sheets at some of the joints, causing, where the joints are slightly inclined, what quarrymen call "toeing in," may probably be attributed to faulting. This supposition assumes, of course, that the sheet structure was formed prior to the jointing. There seems to be good evidence of faulting on a considerable scale along the joints at Dodlin Hill, near Norridgewock, the details of which are described on page 150 and illustrated in fig. 33 . Faulting occurs also along sheets, displacing vertical flow structure, at the same quarry (p. 25), as well as displacing vertical dikes, as at the Allen quarry, on Mount Desert, as shown in Pl. VIII, $B$, and referred to on page 100 . The lateral faulting here has occurred both in northeast-southwest and in east-west directions. Another faulted dike is mentioned on page 110 .

\section{MICROSCOPIC FRACTURES.}

In some of the Maine quarries the granite near the surface acquires a marked foliation, which appears to be parallel to the sheet structure, and possibly to the rift. This foliation is known by quarrymen as "shakes." It occures both at the top and at the bottom of 


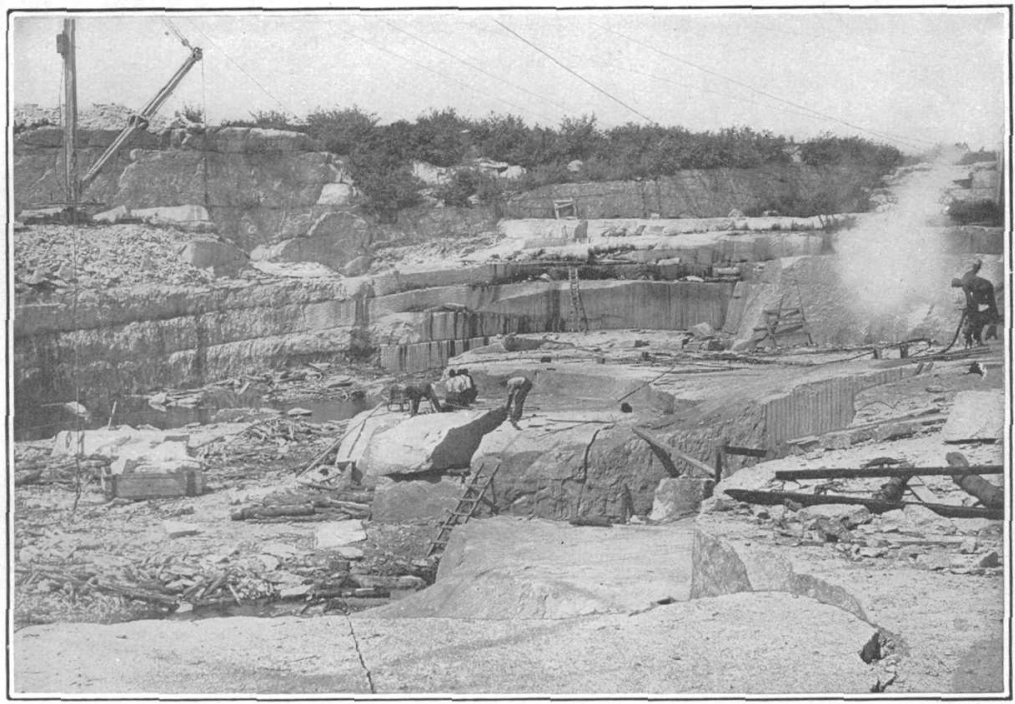

A. SANDS QUARRY IN VINALHAVEN, LOOKING S. $80^{\circ} \mathrm{E}$

Showing the curvature of the sheets, the intersecting joint face, and the N. $10^{\circ} \mathrm{E}$. channeling along the "cut-off."

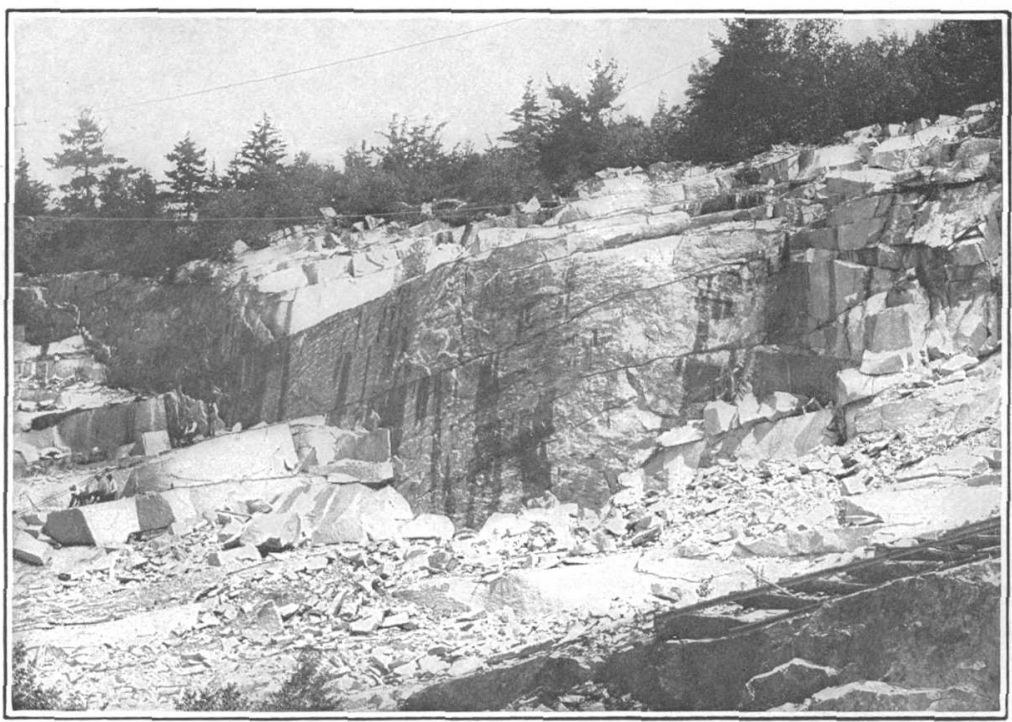

B. WHITE QUARRY IN BLUEHILL. LOOKING N. $10^{\circ} \mathrm{W}$

Showing the lenticular sheets crossed by a vertical joint curving from a N. $50^{\circ} \mathrm{W}$. to N. $50^{\circ}$ E. course. The black vertical streaks are "underground water" issuing from between the sheets. 
the sheet, through a maximum thickness of 6 inches. It $1 \mathrm{~s}$ coextensive with the discoloration known as "sap" and occurs at many places near vertical joints. Under the microscope this structure proves to consist of minute, nearly parallel fissures, of no great continuity, which traverse the mineral particles and which in the thin section examined are especially conspicuous in the quartz and the mica. The distance between these fissures measures from a tenth to a half a millimeter, or from one two hundred and fiftieth to one-fiftieth inch. The parallelism both to the sheets and the "sap" and its relation to the vertical joints indicates that the structure may be due. to the freezing of surface water which has found its way to the sheets through the vertical joints and has entered the rift fissures.

The writer's attention was called to a similar structure in a quarry at Milford, N. H., consisting of short, parallel fractures along the rift, from one-half inch to 2 inches apart, having no apparent connection with joints or discoloration. This is prcbably due to strain affecting part of the granite mass.

SUBJOINTS.

Careful inspection shows that the joint structure in the Maine granites does not everywhere consist of a simple fracture, but that it is at many places complex. Minute fractures branch off from the joint at an acute or right angle and penetrate the rock a few inches, or the rock for a few inches on either side of the joint is traversed by microscopic fissures that are roughly parallel to it. Alt such structural features may properly be called subjoints.

A thin section of North Jay granite across a joint face shows two diverging subjoints that form an acute angle with each other and with the main joint and are filled with limonite and sericite (?). Single subjoints are, however, rarely found, five or six fine parallel fissures generally occurring together. In one of the quarries at Franklin (quarry of W. B. Blaisdell \& Co., p. 94), the subjoints are parallel to the main joint, and as both main and subjoints are filled with calcite, the granite near the joint weathers out vertically in small slablike pieces from one-half inch to 2 inches thick, consisting of a central band of calcite, with one of granite on either side. Under the microscope one of these subjoints, measuring 0.74 $\mathrm{mm}$. across, is seen to be filled with long slivers of quartz and feldspar and scales of biotite, forming a breccia. Another, $0.07 \mathrm{~mm}$. wide, is filled with secondary quartz. At the T. M. Blaisdell quarry in East Franklin, Hancock County (p. 93), a northeast-southwest vertical joint has on one side numerous subjoints that meander off at right angles to it and traverse a cubical mass whose sides measure 1.0 to 15 feet. At the Shattuck Mountain quarry, in Calais (p. 164), 
a joint striking $\mathrm{N} 25^{\circ}$ E. has subjoints striking N. $40^{\circ}$ E., N. $60^{\circ}$ E., and N. $50^{\circ} \mathrm{W}$.

Woodworth has studied analogous and related structures in various rocks and has described them as "joint fringe" and "feather fractures." $"$

CONTENPORARY FRACTURES.

Recent natural fractures have occurred, so far as known to the writer, at only three places in Maine granite quarries. One of these fractures, already referred to in the discussion of the origin of sheet structure (p. 34; see also quarry description, p. 155), occurred at the Mount Waldo quarry, near Frankfort. Here the course of the fractures ran from north-northwest to south-southeast through the center of the quarry for a distance between 200 and 300 feet. The sheets removed from that part of the quarry aggregated about 20 feet in thickness. The fracture was vertical and parallel to the flow structure, but at right angles to both sheets and rift and at an angle of $25^{\circ}$ to the strike of the grain. The other two fractures occurred at the Tayntor quarry, near Hallowell. Their course was east-west. One of these, which was 40 feet long and vertical, passed across a horizontal sheet 4 feet 6 inches thick, extending diagonally between two channel cuts that formed a right angle. Here the rift is horizontal, a faint vertical grain structure strikes $\mathrm{N} .70^{\circ} \mathrm{W}$, and a vertical flow structure strikes N. $35^{\circ} \mathrm{W}$. At Hooper, Havey \& Company's quarry, in North Sullivan, the rock is under a compressive east-west strain, as it tends to fracture north-south across the grain and rift. At many Maine quarries the horizontal movement of the rock crushes the "cores" left between adjacent drill holes in making "channels."

ROCK VARIATIONS.

Under the term "rock variations" are grouped all those variations from typical granite that are due to injection, segregation, infiltration, inclusion, and steam cavities.

DIKES (GRANITIC).

The granitic dikes in the Maine quarries are of three kinds: Extremely fine grained granite (aplite), very coarse grained granite (pegmatite), and fine or medium grained granite.

Aplite differs from ordinary granite by the greater fineness of its texture and its scant content of mica. It is known by quarrymen as "salt horse" or "white horse." The courses of these dikes at each quarry are given in the diagrams or descriptions in Part II. In

a Woodworth, .I. B., On the fracture system of joints, with remarks on certain great fractures : Proc. Boston Soc. Nat. Hist., vol. 27, 1896, pp. 169-173, pls. 1, 2. 


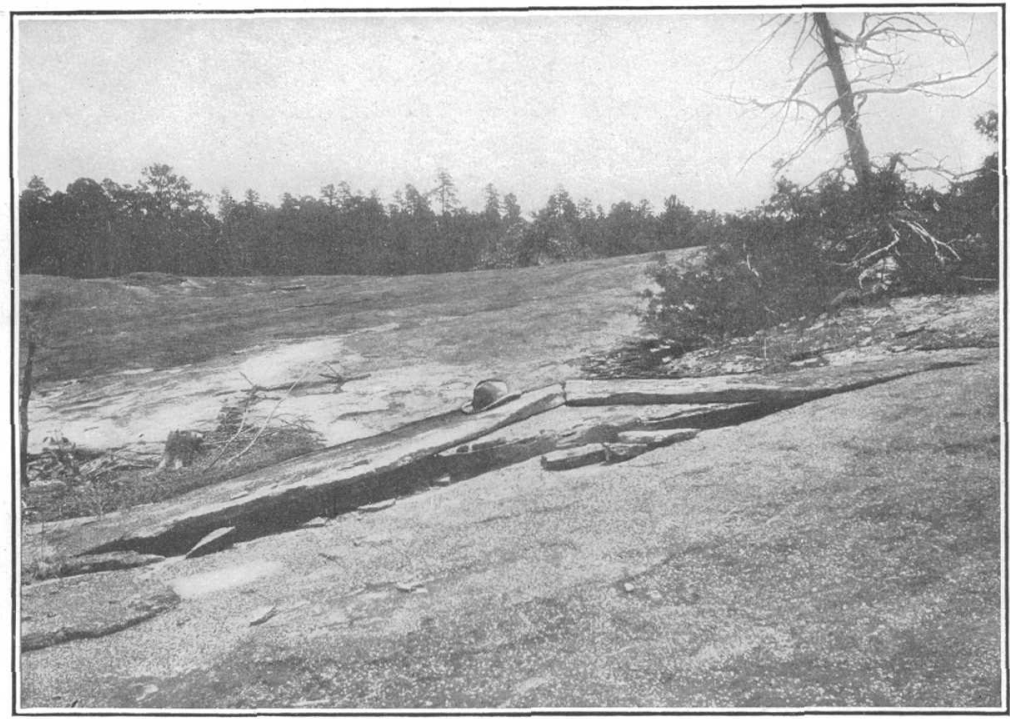

A. ARCH PRODUCED BY THE BURSTING OF A THIN SHEET OF GRANITE-GNEISS, ROCK CHAPEL HILL, NEAR LITHONIA, GA.

Width of arch, 14 feet; height, 9 inches. Photograph by G. K. Gilbert, United States Geological Survey.

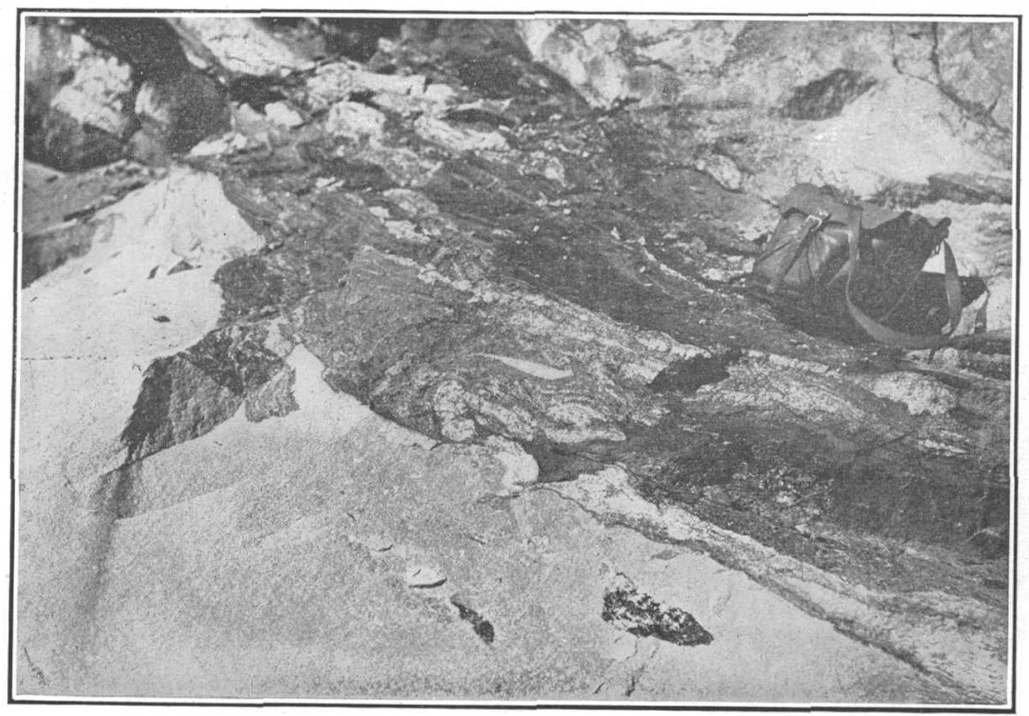

B. LOWER EDGE OF SCHIST INCLUSION IN GRANITE ON WORKING "FACE OF FREEPORT QUARRY.

Showing contact of schist and granite; also schist fragments more or less completely detached from the inclusion. The black streak on the granite is ferruginous stain from the biotite schist. 
thickness they range from a fraction of an inch to 6 feet, but usually from 2 inches to 2 feet.

The courses of 16 aplite dikes are distributed as follows:

Coinses of 16 aplite dikes.

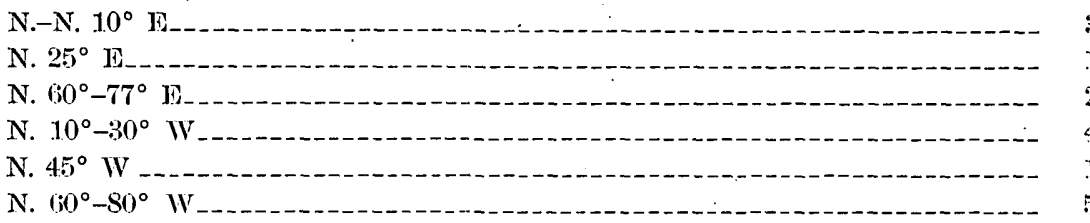

Dikes that strike in the northwesterly-southeasterly quadrants are most numerous.

In color these dikes vary from bluish gray to light and dark reddish. The texture of some aplites is so fine that the mineral particles can not be distinguished with the unaided eye; that of others is so coarse that the feldspar and mica may be thus detected. Under the microscope the dimensions of the particles range from 0.05 to 0.75 $\mathrm{mm}$., the average being about $0.16 \mathrm{~mm}$. for the finer ones and $0.50 \mathrm{~mm}$. for the coarser ones. Some aplites have a porphyritic texture.

Two typical aplites will be described in detail. One, from the John L. Goss quarry, on Moose Island, near Stonington, is from a dike 1.5 inches wide'and over 200 feet long, consists largely of quartz, potash feldspar (microcline), and a soda-lime feldspar (oligoclase) in particles ranging from 0.047 to $0.141 \mathrm{~mm}$. in diameter, a few thinly disseminated particles of the same minerals measuring from 0.55 to 1.45 $\mathrm{mm}$. and a few scales of black mica measuring up to $0.47 \mathrm{~mm}$. Another aplite, from the Sands quarry, at Vinalhaven, consists mostly of quartz, but contains some potash feldspar (orthoclase and microcline), still less soda-lime feldspar (oligoclase), and a few scales of black mica. The particles range from 0.047 to $0.3 \mathrm{~mm}$. in diameter.

The minerals of aplite dikes are so firmly attached to the granite on either side that the rock readily splits across both granite and aplite. Under the microscope the minerals of the dike appear to be welded, so to speak, to those of the granite. In construction the blocks containing such dikes should not therefore necessarily be regarded as places of weakness, but in a quarry at Franklin, Hancock County, the granite is close jointed for a space of a foot on either side of an aplite dike, the joints being parallel to the dike.

At the Bodwell Granite Company's quarry (see p. 168), 2 miles east of Jonesboro, Washington County, the reddish granite is traversed by a 6 -foot dike of rather coarse, dark-reddish aplite, in which the higher: power of the microscope shows that the source of the color lies in exceedingly minute dots of hematite. The aplite contains also muscovite, biotite, and accessory pyrite. This dike crosses the quarry in a N. $20^{\circ} \mathrm{W}$. direction. A similar dike, having a like course, but only 
4 feet wide, occurs at the eastern end of the quarry. A third dike, which ranges in width from 3 to 6 inches, has a N. $75^{\circ}-80^{\circ} \mathrm{E}$. course, and a fourth, of fine-grained material, from one-half to 1 inch wide, crosses the others with a course N. $60^{\circ} \mathrm{W}$. and can be traced for 200 to 300 feet. This is evidently of later date than the others. Aplite dikes are supposed to have originated in the same deep-seated molten mass as the granite they traverse, but they represent a later stage of igneous activity. The fissures they fill were the result of various tensional strains or contractions, possibly consequent upon the cooling of the granite.

Most aplites contain a slightly higher percentage of silica than granite. Five analyses of aplites from the Far West made at the laboratory of the United States Geological Survey ${ }^{a}$ show a range of silica from 71.62 to 76.03 per cent and an average of 74.08 , which is near the maximum of silica for granites generally.

Pegmatite lies at the other extreme. Its mineral constituents range usually from one-half inch to 1 foot or even several feet in diameter. It is reported that the crystals in some pegmatite dikes measure from 10 to 30 feet in length by 1 to 3 feet in width. The chief minerals in pegmatite dikes are the same as in granite, but they occur in different though varying proportions. With these minerals are often associated tourmaline, garnet, beryl, etc. Chemically these dikes generally contain more silica than the granite. Dikes of pegmatite are, as a rule, more irregular in width than those of aplite. They generally range in thickness from 1 inch to 10 feet.

The courses of the pegmatite dikes in the Maine quarries and their relation to the structural features are shown in figs. 4, 6, 20, 21, 24, $28,30,31$, and 33 . Their courses are distributed as follows in 15 quarries:

Courses of pegmatite dikes.

Number of quarries.

N

N. $20^{\circ} \mathrm{F}$

N. $40^{\circ} \mathrm{E}$

N. $60^{\circ}$

N. $15^{\circ}-20^{\circ} \mathrm{W}$

N. $45^{\circ} \mathrm{W}$

N. $65^{\circ}-70^{\circ} \mathrm{W}$

N. $80^{\circ}-90^{\circ} \mathrm{E}$

Horizontal

Pl. X, $B$, shows a pegmatite dike crossing the diorite (black granite) at Round Pond, in Lincoln County. At the Hallowell Granite Works (Longfellow) quarry (p. 119) a 2-foot dike consists of milk-white

a Bull. U. S. Geol. Survey No. 148, 1897, pp. 124, 150, 206, 219. 


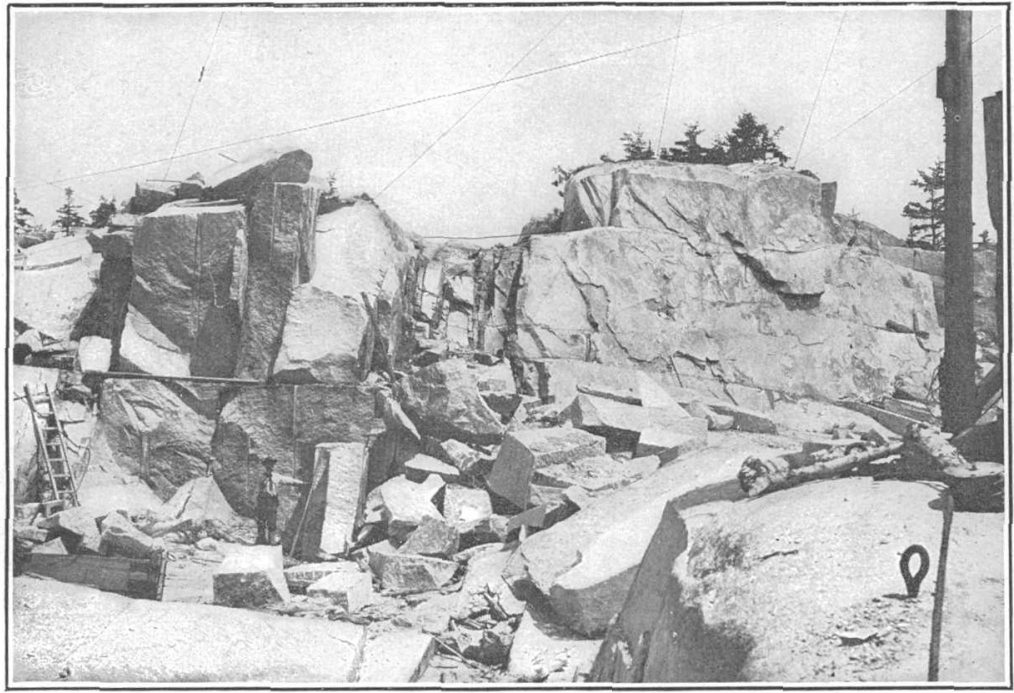

A. HIGH ISLE QUARRY, MUSCLE RIDGE PLANTATION. LOOKING EAST. Showing sheets crossed by a N. $75^{\circ} \mathrm{W}$, heading.

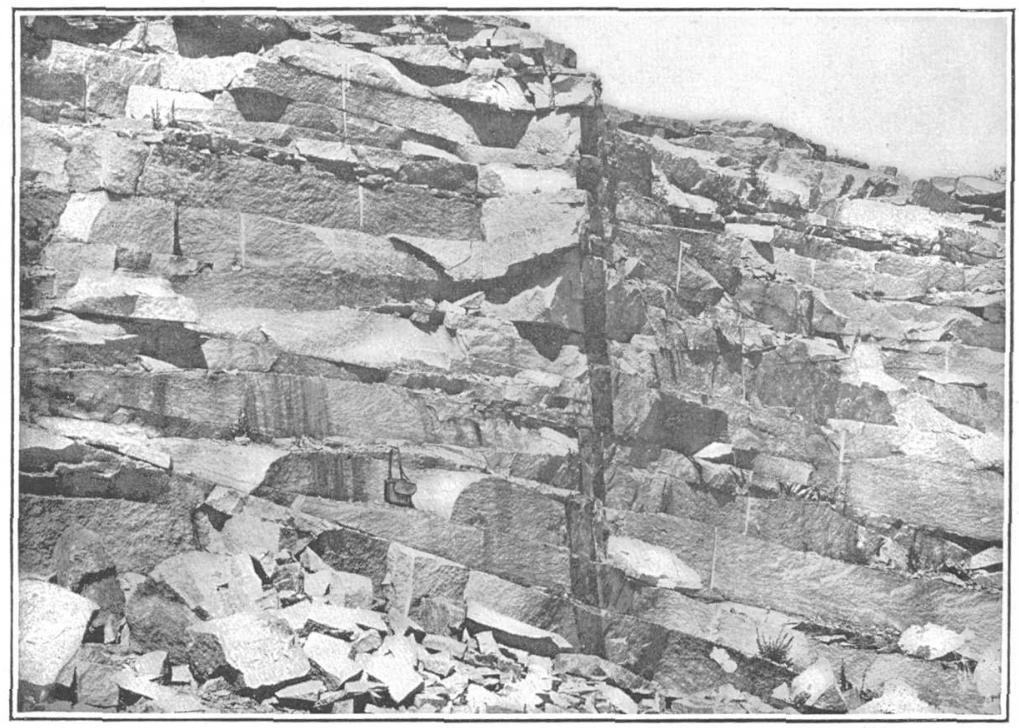

B. ALLEN QUARRY, WEST SIDE OF SOMES SOUND, MOUNT DESERT. LOOKING N. $15^{\circ} \mathrm{W}$. Showing thin lenticular sheets crossed by a vertical diabase dike, faulted on the fourth sheet from bottom of quarry; displacement, 16 inches along the sheet. 
soda-lime and potash feldspars (oligoclase and microcline), smoky quartz, biotite, and muscovite (black and white mica), and garnet. The feldspars, quartz, and micas attain a length of several inches. At the North Jay quarry (p. 82) the pegmatite dikes measure up to 2 . feet 6 inches in width and consist of a milk-white potash feldspar, smoky quartz, biotite muscovite, the constituents measuring several inches in diameter. At the Clark Island (J. C. Rodgers) quarry (p. 126) there are two intersecting pegmatite dikes with similar material of similar dimensions, together with black tourmaline and garnet. The granite at Fryeburg, near the New Hampshire line, abounds in pegmatite. At the Eagle gray granite quarry (p. 144 and fig. 31) two dikes, one 5 feet, the other 10 feet thick, alternate with granite 25 and 60 feet thick. The feldspar masses and crystals attain a length of 12 inches and the biotite and muscovite crystals and the quartz masses a length of 6 inches. Small garnets are abundant. Mingled with the pegmatite is some fine-grained aplitic material. There is also considerable pegmatite at the Waldoboro quarry, in Lincoln County. (See p. 142 and fig. 29.) At the Wild Cat or Willard Point quarry of the Bodwell Granite Company, now abandoned, there is a 12 -inch pegmatite dike of feldspar, quartz, muscovite, and black tourmaline, which has a banded structure. It is crossed by another dike half as thick, with a difference in strike of $20^{\circ}$.

The origin of pegmatite has been much discussed both in Europe and in this country. ${ }^{a}$ The coarseness of its constituent minerals indicates slow crystallization, and the irregularity of the dikes shows tensional rather than torsional strain. The banding of some pegmatite dikes and the isolated lenticular character of others indicate that the dikes were filled from heated solution, while many of them differ in no respect from dikes of igneous origin except by the coarseness of their texture. For these reasons it is thought that pegmatite dikes in granite have been formed in openings and fissures that were due, possibly, to contraction while the granite was still hot and that some of these openings were filled with matter in a state of both molten plasticity and solution under pressure, and others by heated solutions that gathered matter from the adjacent granite. Howsoever derived, this dike material crystallized very slowly.

Granite.-Finally, there are dikes that differ from all those just described, formed simply of fine or medium-grained granite. Thus

a The principal American writings on the subject are: Williams, G. H., The general relation of the granitic rocks in the middle Atlantic Piedmont Plateau; Fifteenth Ann. Rept. U. S. Geol. Survey, 1895 , pp. 675-684 ; Crosby, W. O., and Fuller, M. L., Origin of pegmatite: Techn. Quarterly, vol. 9, 1896, pp. 326-356; Am. Geologist, vol. 19, 1S97, pp. 147-180; Van Hise, C. R., A treatise on metamorphism: Mon. U. S. Geol. Survey, vol. 47,1904 , pp. $720-728$. 
at the Settlement quarry, near Stonington (see p. 108), the coarse granite is traversed by a dike, from 4 to 12 inches thick, of light pinkish-gray granite, in which the feldspars attain a size of onetenth of an inch $(2.5 \mathrm{~mm}$.), but under the microscope some are found that measure as little as 0.025 inch $(0.12 \mathrm{mmi}$.). This rock consists of a pinkish potash feldspar (microcline), a white soda-lime feldspar (oligoclase-andesine), smoky quartz, and black mica (biotite). At the Mosquito Mountain quarry (p. 153), near Frankfort, there is a 10-foot dike of medium-grained gray granite (quartz monzonite), with feldspars up to 0.3 inch. The potash feldspar (microcline) is about equal in amount to the soda-lime feldspar (oligoclase), the quartz is smoky, and the mica is black. At the Mount Waldo quarry (p. 155) there is a dike 200 feet wide of fine biotite granite, with coarse biotite granite on both sides of it. The feldspars of this dike measure up to $0.15 \mathrm{inch}$, but range ordinarily from 0.36 to $1.45 \mathrm{~mm}$. The fine-grained biotite-muscovite granites quarried at the Sherwood quarry, on Crotch Island (spec. 25, $a$, described on p. 105), at East Bluehill (spec. 39, $a$, on p. 87), and at a small opening on Dodlin Hill, near Norridgewock (spec. 117, $a$, described on p. 152), all seem to belong to similar dikes that are not many feet in thickness. At an old quarry near Bluehill (p. 85) there is an 18-inch dike of finegrained muscovite-biotite granite, in which the feldspars are much intergrown with quartz. The courses of these granite veins are $\mathbf{N}$., N. $15^{\circ}$ E., N. $20^{\circ}$ W., N. $55^{\circ}$ E., N. $70^{\circ}$ W. All such dikís represent granitic intrusions.

VEINS.

Quartz veins are exceptional in the Maine quarries. At the old Bodwell Company's quarry on Cook's Mountain, near Redbeach, now abandoned, the red granite is traversed by a banded grayish quartz vein, about 18 inches thick, that has a course N. $25^{\circ} \mathrm{W}$. and a vertical dip. It comprises three, or, in places, four bands, which differ mainly in texture and are separated by more or less pyrite in fine particles. In places this vein divides into three smaller veins, each of which is from 3 to 4 inches thick. The quartz contains some purple fluorite (lime fluoride), as determined by W. T. Schaller at the chemical laboratory of the United States Geological Survey, and a variable amount of a foliaceous.lemon-colored mineral which Wirt Tassin, of the United States National Museum, has analyzed and determined as a new variety of sericite, resulting, possibly, from the alteration of a feldspar, and which is accompanied by another mineral, regarded by him as probably talc. Mr. Tassin's analysis and report are as follows: 


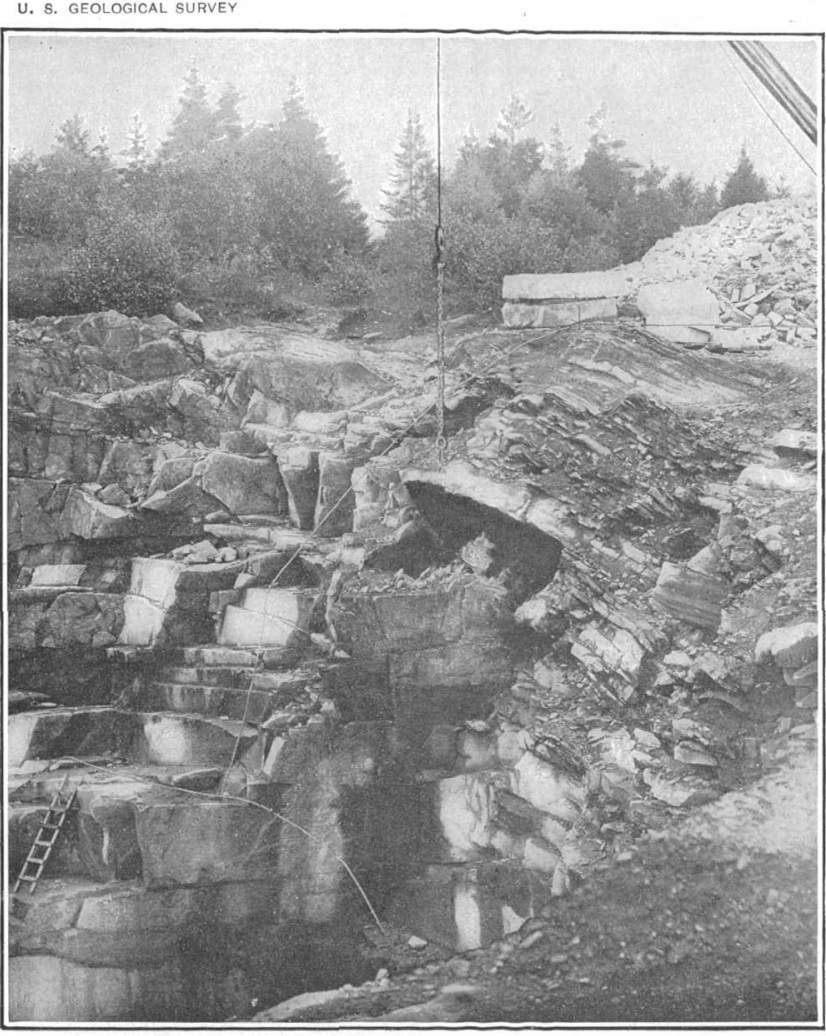

A. EAST CORNER OF WALDOBORO QUARRY.

Showing contact between the granite in horizontal sheets and east-northeast dipping schist strata.

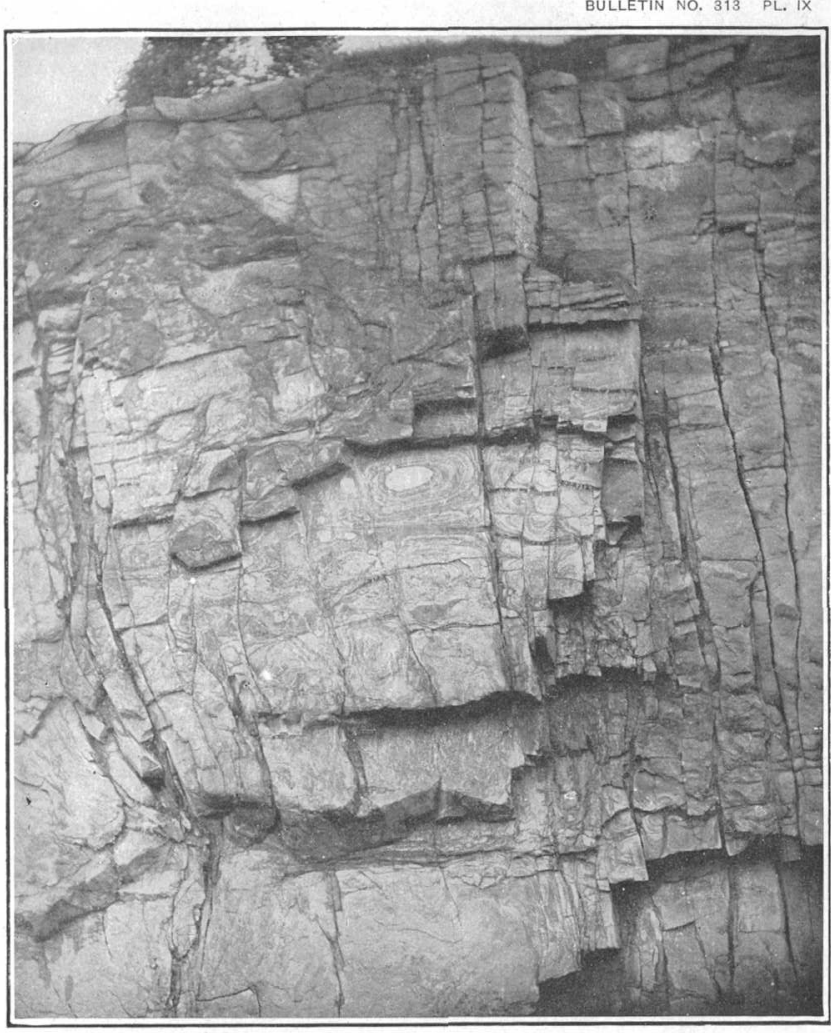

B. NORTHWEST WALL OF LONGFELLOW QUARRY NEAR HALLOWELL.

Showing intersection of two headings, one with a NW., the other with a N. $65^{\circ} \mathrm{E}$. strike; also the progressive concentric ferruginous discoloration ("sap") from the
sheet and joint surfaces. 
Analysis of yellow foliated mineral specimen of guartz marlecd "D. X $\dot{X} \nabla I$, $105 a$, '05."

$\mathrm{SiO}_{2}$ (silica) (-_. 53.28

$\mathrm{Al}_{2} \mathrm{O}_{3}$ (alumina ) ...

$\mathrm{Fe}_{2} \mathrm{O}_{3}$ (ferric oxide)

$\mathrm{FeO}$ (ferrous oxide)

MgO (mianesia) _..._. 409

$\mathrm{Na}_{2} \mathrm{O}$ (soda) _.

$\mathrm{K}_{2} \mathrm{O}$ (potash)

$\mathrm{H}_{2} \mathrm{O}$ (water)

The mineral is secondary mica, probably derived from feldspar (although this is merely a conjecture), and will approximate sericite in composition. It occurs in fine scales, occasionally compacted and then resembling serpentine. Luster, pearly ; color, greenish yellow; hardness, 2.5 ; specific gravity, 2.79 at $20^{\circ} \mathrm{C}$. It is associated in the vein with quartz, pyrite, purple fluorite, and another mineral which hais a greasy luster and contains magnesia, but which it was impossible to separate in a state of sufficient purity for analysis. This last mineral I believe to be talc.

DIKES, BASIC.

Dikes of dark-greenish or black, hard and dense rock (diabase, rarely basalt) are of very common occurrence in the Maine quarries. The courses of some of these dikes and their relation to the joints are shown in figs. $9,10,14,31,34,36,38$, and 39 . The courses of 23 dikes are distributed as follows:

,

Courses of 23 basic dikes at Maine granite quarries.

N. $10^{\circ}-12^{\circ} \mathrm{E}$

N. $22^{\circ}-30^{\circ} \mathrm{E}$

N. $40^{\circ}-50^{\circ}$ E

N. $70^{\circ} \mathrm{E}$

E. $-W_{-}$

N. $15^{\circ}-30^{\circ} \mathrm{W}$

N. $45^{\circ}$ W._-

N. $75^{\circ} \mathrm{W}$

'The northeast, north-northeast, and north-northwest courses are thus the most common. The dikes are vertical, or nearly so, and range in width from 1 inch to 7 feet or more, cutting the granite sheets with mathematical definiteness. Pl. VIII, $B$, shows one of these dikes on Mount Desert, which has a course N. $15^{\circ}$. W., and has been faulted from east to west, or west to east, along a gently inclined sheet with a displacement of 16 inches. A few feet beyond this point the same dike has been faulted along a northeast-sonthwest vertical joint with a displacement of 5 feet. Although it might seem that this dike was injected into the granite before the sheet structure. was formed, it is quite possible that the sheet structure preceded the dike and that at a later time faulting affected both the sheets and the dike, cracking the dike along the sheets when it did not actually fault it. 
Most of these dikes are so firmly welded to the granite that hand specimens that are one-half granite and one-half diabase are readily obtained. Thin sections of the glassy rims of dikes at Bryant Pond and Fryeburg show that the dike sent out microscopic branches for short distances into the granite, in places surrounding some of its quartz particles. A dike at the Dunbar Brothers' quarry, near Sullivan (p. 113), measuring from 16 to 18 inches in width, has a quarterinch border of light-green epidote, derived from the alteration of its glassy rim. These glassy borders are due to the rapid cooling of the material at its contact with the cold granite. A vertical diabase dike in Franklin (see p. 91) has darkened the shade of the granite and filled it with low-dipping close joints for a space of 10 feet on each side. Under the microscope the quartz particles and some of the feldspars show parallel cracks 0.25 to $1.25 \mathrm{~mm}$. apart. . A few typical thin sections of these dikes will be described in detail.

The center of a 7 -foot dike at the Mosquito Mountain quarry near Frankfort (p. 153) shows a network of minute lath-shaped crystals of lime-soda feldspar (labradorite) partly altered to a white mica, in the meshes of which is a green hornblende; also some magnetite in fine particles and pyrite, with accessory titanite, apatite, and secondary epidote.

A 4-inch dike at the W. T. Havey (Whalesback) quarry, in North Sullivan (p. 113), shows a groundmass of fine hornblende and feldspar (plagioclase), in incomplete crystals, with magnetite and thinly dișseminated larger crystals of hornblende and lime-soda feldspar (labradorite), some large quartz particles, and a little pyrite. One feldspar crystal is almost completely altered to a white mica.

A $2 \frac{1}{2}$-foot dike at Campbell \& Macomber quarry, on the west side of Somes Sound, on Mount Desert (p. 99), shows a groundmass of fine hornblende and feldspar (plagioclase) in incomplete crystals, with magnetite (?), pyrite partly altered to limonite, and lime-soda feldspar (labradorite). Some of the particles of the latter measure up to one-tenth inch in length by one-fiftieth inch in width and are largely altered to kaolin and a white mica. The hornblende in all of these dikes is regarded as a product of the alteration of augite.

The geological age of these dikes has not been precisely determined. They are considerably more recent than the granite they traverse or the dikes of aplite and pegmatite which traverse the granite. In Pl. XI, $A$, one of these diabase dikes is shown crossing both a vein of pegmatite and a mass of diorite ("black granite"), at Round Pond, in Lincoln County. ${ }^{a}$ (See p. 139.)

The diabase dikes are the result of an earth movement that either

a Some of the dikes of that part of the coast have been described by 1 . Bascom: On some dikes in the vicinity of Johns Bay, Maine: Am. Geologist, vol. 23, 1897, pp. 275-280, Pls. IX, X, XI. 
opened previously formed joints or made new ones deep enough to be injected with volcanic material. How far this may have penetrated the rocks which overlay the granite or whether it overflowed at their surface can not even be conjectured.

At the granite quarries, wherever this course is possible, the dikes and the headings are left to form the bounding walls of the excavations.

SEGREGATIONS (KNOTS).

Quarrymen know too well that granite is often disfigured by gray or black "knots" of circular" or: oval irregular" curved outline, ranging in diameter from half an inch to 3 feet and exceptionally even 10 feet. These were studied by geologists long ago. ${ }^{a}$ They are finer grained than the granite in which they occur, contain nearly 10 per cent less silica, much more black mica or hornblende (which accounts for their darkness), and a little more soda-lime feldspar, and their specific gravity is about 0.09 per cent higher.

Pl. V, A, shows 12 knots in the vertical cuts at Crabtree \& Havey's quarry, in Sullivan. As the strength and durability of the stone are in no wise affected by the "knots," the blocks containing them are used for curbing, crossings, or other constructions where color and shade are not taken into consideraton.

A thin section of a very dark gray knot from this quarry shows a much greater abundance of biotite than the granite. The feldspar and the biotite particles in the knot measure up to $0.5 \mathrm{~mm}$. (onefiftieth inch), whereas in the granite the feldspar measures up to $2.25 \mathrm{~mm}$. and the biotite up to $0.75 \mathrm{~mm}$.

A knot from the Palmer quarry, on Vinalhaven, is of mediumgray shade, with a very fine grained groundmass inclosing porphyritic buff-pinkish feldspars and smoky quartz particles up to about one-fourth inch in diameter. The groundmass consists of quart\%, potash feldspar (microcline); soda-lime feldspar, black mica, and hornblende in particles ranging in size from 0.075 to $0.5 \mathrm{~mm}$. The porphyritic particles are of quartz, potash feldspar, or soda-lime feldspar, and hornblende, and measure from $0.75 \mathrm{~mm}$. up.

A very dark, almost black, knot from the Sands quarry, on Vinalhaven, consists of crowded particles of hornblende and biotite, which compose one-half the knot, the rest being mostly soda-lime feldspar: and quartz. Among the knots noticed is a spherical one, $2 \frac{1}{2}$ feet in

\footnotetext{
a Phillips, J. A., On concretionary patches and fragments of other rocks contained in granite: Quart. Jour. Geol. Soc. London, vol. 36, 1880, pp. 1-22, FI. I. Merrill, G. P., On the black nodules or so-called inclusions in the Maine granite: Froc. U. S. Nat. Mus., vol. 6, 1883, pp. 137-141. Grimsley, G. P., Basic segregations: The granites of Cecil County in northeastern Maryland: Jour. Am. Soc. Nat. Hist., Apr. and July, 1894. Daly, Reginald A., Basic segregations : The geology of Ascutney Mountain, Vermont: Bull. U. S. Geol. Survey No. 209, 1903, p. 164.
}

$3495-$ Bull. $313-07-4$ 
diameter, at the Sands quarry, and a similar one, $\breve{5}$ feet in diameter, at the Webster quarry, both in Vinalhaven. One at the Mount Waldo quarry measures 6 by 3 feet and consists of a medium-gray groundmass with porphyritic feldspars up to three-fourths inch and biotite scales up to one-twentieth inch. One at the Andrews \& Perkins quarries, near Biddeford (p. 179), is 10 feet long. At another Biddeford quarry the knots are egg-shaped and occur in clusters. At the Tayntor quarry, in Hallowell, there is a belt 5 to 25 feet wide, with a course $\mathrm{N} .10^{\circ}$ E., in which knots are abundant. This crosses the flow structure, which strikes N. $35^{\circ} \mathrm{W}$.

In none of the knots is there a definite boundary separating them from the granite, excepting such as is caused by the change in the proportionate abundance of the darker minerals. The cause of knots is not perfectly understood. They are collections (segregations) of the darker, heavier, iron-magnesia minerals that took place while the rock was in a plastic state.

GEODES.

Small cavities lined with crystals occur in granite. They are uncommon in the Maine quarries, but at the Bodwell Granite Company's quarry, near Jonesboro (p. 169), there are several about a foot in diameter, lined with quartz crystals and epidote. The center of some of these is filled with calcite (lime carbonate) in very obtuse rhombohedra half an inch across. The large aplite vein at the same quarry has many irregular openings lined with crystals of feldspar and muscovite. At the Machias Granite Company's quarry, near Marshfield (p. 174), there are several geodes, up to 6 inches in diameter, lined with crystals of feldspar and amethyst, with the central space filled with chlorite, epidote, and calcite.

Such cavities are attributed to bubbles of steam or gas that were in the rock while it was in a molten state, which gave room for the growth of crystals and later became filled with epidote and calcite.

\section{INCLUSIONS.}

Not to be confounded with "lnots," although some of them are equally dark and occur near them, are irregular or angular particles of various schistose rocks which the granite incorporated into itself during its intrusion. They can usually be distinguished from the knots by their different microscopic structure. Inclusions of this kind occur here and there in the Maine quarries. Thus, at the Stimson quarry, in West Sullivan (p. 111), they measure about 1 inch, more or less, across, and consist of a fine-grained plicated biotite schist with a very little andesine feldspar.

But inclusions also occur on a large scale. Thus, at the Freeport quarry (p. 78), 30 feet below the surface of the granite and completely 
surrounded by it, is a mass of biotite schist between 30 and 40 feet long and 3 feet thick, striking north and dipping $35^{\circ}$ east. In quarrying, this mass has been cut from east to west. Under the microscope this is a coarse biotite quartz and feldspar (oligoclase) schist. It is probably of sedimentary origin. Pl. VII, $B$, shows part of the jagged edge of the lower portion of the inclusion and two isolated fragments of it in the granite. The granite below one of the protruding angles of the inclusion is badly stained by ferruginous water coming from the schist. In some parts of this inclusion there are streaks of pegmatite consisting of feldspar (oligoclase-andesine) and quartz. The period of its formation is uncertain.

CONTACTS.

At the Waldoboro quarry the original contact of the upper part of the granite mass with the lower part of the remnant of the schist mass, which once overlay that region and into which the granite was intruded, is exposed. (See Pl. IX, $A$, and p. 142.) This schist is a hornblende-biotite-quartz schist containing some andesine feldspar, also accessory titanite and zircon. It is a metamorphosed rock, probably of sedimentary origin. At the opposite or southwest end of the quarry (see fig. 29) the relations between the schist and granite are very complex, and a considerable mass of pegmatite intervenes in places. The granite sends. small dikes into the schist and also contains inclusions of it. The granite was erupted after or during the folding of the schist, otherwise it would have become a gneiss.

MINERALS ON JOIN'T FACES.

Joint faces in granite are in some places coated with minerals which do not occur in the granite itself or but very sparsely. At the Sands quarry, in Vinalhaven, one of the joint faces bears very minute crystals of stilbite, a hydrous silicate of alumina, lime, and soda, ${ }^{l}$ also hematite. In other places the face is coated with a film of crystalline calcite from one-tenth to one-fifth inch thick. Calcite occurs also similarly at one of the Redbeach quarries. (See p. 166.) A thin coating of secondary fibrous muscovite or of epidote occurs at several quarries. At the W. B. Blaisdell quarry, in Franklin, certain joints are coated with crystalline calcite to a thickness of one-fourth inch, forming in places banded veins. (See p. 41.) A thin section of the granite away from the joint does not show any carbonate, but Mr. E. C. Sullivan, of the Survey (p. 94), found 0.24 per cent of lime carbonate in a few ounces of the same specimen. Other joints in the same quarry with a different strike are coated with pyrite, and from their rusty appearance are known by the

a Determination by Mr. W. T. Schaller, of the United States Geological Survey. 
quarrymen as "iron seams." At the Bryant Pond quarry (see p. 146) one of the joints is coated with calcite (with a little epidote and pyrite) up to half an inch in thickness, and the granite on either side contains considerable chlorite, derived probably from the alteration of its hornblende. A muscovite-biotite granite quarried at Oxford ( $p$ 146) has considerable secondary muscovite developed along planes which appear to be due to close jointing. At the McMullen quarry, on Somes Sound, Mount Desert, the light buff and white feldspar is altered for the width of a foot along the steep joints to a deep reddish color. This change does not occur along the sheets. A thin section of this red feldspar shows that the color affects both potash and soda-lime feldspars alike and is due to innumerable dots of infinitesimal size; but without definite form or color under the higher powers of the microscope. They are probably hematite.

It seems probable that the calcite and pyrite are infiltrations from calcareous and ferruginous formations that once overlay the granite, but were subsequently eroded. ${ }^{a}$

The presence of epidote, chlorite, muscovite, stilbite, pyrite, and hematite in or near joint faces may be attributed to a process of deepseated mineral alteration aided by percolating waters, which took up some elements and deposited others, and were also probably under pressure. These changes may have occurred subsequent to the intrusion of the diabase dikes, because the dikes also have suffered similar alteration.

DISCOLORATION ("SAP," ETC.).

Rusty (limonite) staining along the upper and lower parts of the sheets and also along the joints and headings is common in granite quarries, although some quarries are almost entirely free from it. The concentric inward growth of "sap" from the close joints of a heading is well shown in Pl. IX, $B$. The zone of discoloration along the sheets in the Maine quarries is from one-half to 12 inches, exceptionally even 18 inches, wide on each side of the sheet parting. Its width, however, decreases gradually from the surface sheets downward. In places the sap consists of two parts-an outer dark brownish zone from three-fourths to $1 \frac{1}{2}$ inches wide and an inner more yellowish zone from one-fourth to one-half inch wide. Generally, however, the discoloration diminishes gradually from without inward. In some quarries there seems to be a connection between the "shake" structure (p. 150) and the discoloration, since these are coextensive.

When the stone is intended for facing or trimming buildings the

a One-fourth of a mile east of Fort Añn, in Washington County, N. Y., Professor Kemp and the writer observed open vertical joints in the pre-Cambrian noncalcareous gneiss filled with calcite. evidently derived from an extraneous source. 
presence of sap is a serious matter, as the stained edge of each block must be split off, which adds somewhat to the cost of production.

This discoloration has been supposed to be always due to the oxidation of the ferruginous minerals of the granite, biotite, hornblende, magnetite, and pyrite, but the Maine thin sections examined by the writer do not bear out this theory. Thus one from the Tayntor quarry, near Hallowell, shows that the stain has insinuated itself into the cleavage planes and cracks of the feldspar and muscovite and in the cracks of the quartz, forming minute deposits of limonite therein, but the biotite scales and magnetite particles are generally untouched by the stain. A section taken from the "top" of the Hopewell quarry, in Sullivan, where the fresh rock has a bluish tinge and the sap a general buff color, shows that the staining extends along the cleavages and fissures and in the spaces between the minerals, but that it does not. appear in connection with the biotite scales, although it is increased by the magnetite particles. A section from the upper part of High Isle, south of Rockland, where the dark sap is an inch wide and an inner lighter part is one-fifth . inch wide, shows a series of roughly parallel cracks crossing the sap vertically, with subsidiary transverse cracks. These cracks and

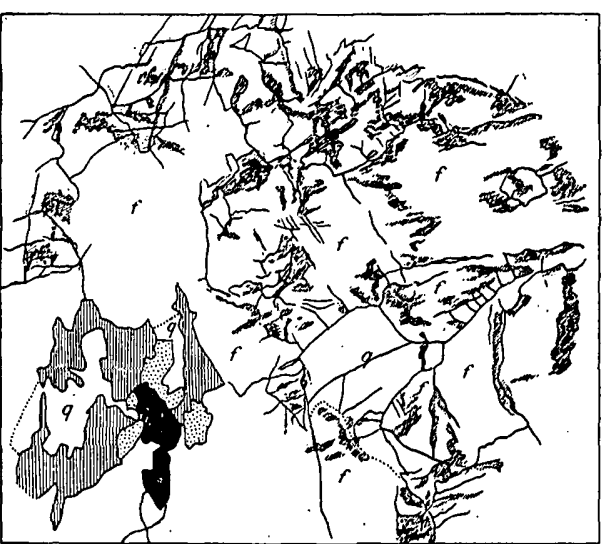

FIG. 2.-Minerals in thin section ( 3.76 by 4.23 millimeters $=0.15$ by 0.17 inch) of biotite granite from High Isle in Knox County, showing "sap." The ramifications of "sap" (limonite stain) across and around feldspar and quartz particles (marked $f$ and $q$ ) are independent of the biotite and magnetite particles. Fine-lined parts are biotite; fine-dotted areas are titanite; large black masses are magnetite. Some of the borders of quartz particles are shown by dotted lines.

the cleavages of the feldspar and the spaces between the minerals are stained, but the staining has no connection with the biotite, and some large particles of magnetite are scarcely touched by it. .(See fig. 2.) In the outer zone the limonite is darker and probably older and thicker than in the inner one. "That "sap" is not generally due to the oxidation of the minerals of the granite is also probable from the fact that no such general discoloration appears on fresh granite surfaces, even after many years of exposure to the weather.

These observations lead to the inference that the discoloration called "sap" is, in the Maine granites, not due chiefly to the oxidation of the ferruginous minerals of the granite by "underground water," but chiefly to the deposition of limonite by ferruginous surface water. The water descended along the vertical joints and then 
flowed along the: sheet partings and permeated the rock above and below them. This staining near the surface is intimately associated with the "shake" structure, which may be the result of frost. Whether the postglacial submergence of the Maine coast had anything to do with the discoloration is not clear.

Another kind of discoloration, which is even more serious in its consequences, appears on fresh faces of granite, either in the quarry or after its removal. This consists of sporadic rusty stains from half an inch to 1 inch in diameter, arising from the oxidation of minute particles of some undetermined ferruginous mineral. In the Maine quarries these limonitic spots are very exceptional.

Daly ${ }^{a}$ describes a bluish-gray syenite (feldspar, quartz, hornblende, augite, biotite) that after twenty-four hours' exposure assumes a greenish tinge, which eventually becomes more or less brownish. He has demonstrated by experiment with oxygen that this change is due to the oxidation of minute blackish granules of ferrous oxide within the feldspar, giving a yellow which, in combination with the original bluish tint of the feldspar, produces a green. The large columns of the library of Columbia University, in New York, are made of this rock. Such changes, however, are uncommon in granitic rocks. The only similar one observed in the Maine granites was in the quartz diorite of Alfred, in York County. (See p. 175.)

Another kind of discoloration occurs on either side of diabase or basalt dikes, consisting mainly of various alterations of the feldspars, and their consequent change in shade or color. (See p. 91.)

Discoloration is thus of four kinds: That due to the infiltration of ferruginous water, that due to the oxidation of sporadic ferruginous minerals, that arising from the oxidation of ferrous oxide within the feldspars, and that due directly or indirectly to dikes and veins. To these should be added a possible fifth-that due to the oxidation of the generally disseminated ferruginous minerals (biotite, hornblende, magnetite) by nonferruginous water.

DECOMPOSITION.

Notwithstanding the strength and durability of granite, it is liable, under certain conditions and in the course of long time, to decompose into a clayey sand. This is the result of its physical, mineralogical, and chemical constitution and properties. One of the most striking illustrations of this is the occurrence in some of the Maine quarries of "beds" of sand or decomposed granite within the fresh granite, either between the sheets away from headings or within the headings

${ }^{a}$ Daly, Reginald A., The geology of Ascutney Mountain, Vermont: Bull. U. S. Geol. Survey No. 209,1903, pp. 51-53. 
and along or across the sheets. Thus at the Palmer quarry, in Vinalhaven, 20 feet below the surface in the face of the quarry there is a bed of granite sand 18 inches thick between two sheets, which at that point dip about $10^{\circ}$ into the hill. On the southeast side of the Longfellow quarry, near Hallowell, some of the sheets within a wide heading include granite sand beds 10 inches thick. At the Shattuck Mountain quarry, near Redbeach (see p. 165) a 6-foot heading includes a vertical layer of granite sand 8 inches thick. Specimens taken from these various sand beds show that the disintegration begins with miscroscopic fractures; in some cases the enlarged rift cracks, producing the "shake" structure described on page 40 , and is followed by more or less kaolinization of the feldspars. This process consists in the loss of alkali and the taking up of water, resulting in the passing of the feldspar into a white clay (kaolin).

The joint and sheet structure affords ingress to surface water, containing its usual percentage of carbonic acid; and the "rift" or "shake" structure facilitates the kaolinization of the feldspar on either side of the sheet parting by this water. As the feldspars pass into clay the rock crumbles into sand consisting of quartz, mica, and kaolin, and of feldspar in various stages of kaolinization. In some places within the range and depth of frost a large part of this work may have been done by frost alone. The sand would there be mainly the product of the "shake" structure.

In regions which have not been swept by a continental glacier any granite masswrould be covered with the products of the decomposition of its own surface. In the Tropics the abundant rainfall. and the organic acids from a luxuriant vegetation materially hasten the decomposition, and granitic rocks in such regions are for these reasons often covered with many feet of sand and soil. ${ }^{a}$ Along the Maine coast the surface of granite ledges bear in protected places an inch or so of granite sand, which represents surface disintegration since the postglacial submergence.

The incipient stage of weathering may be observed in any longexposed granite ledge in the milky whiteness of the feldspars. This change usually attacks the soda-lime feldspars first. The black mica, owing to its content of iron oxide, is also liable to early decomposition. The process of weathering, as it affects the rock as a whole, involves the following chemical changes: A loss of lime, magnesia, potash, and soda; a gain of water, and a relative gain of silica, alumina, and iron oxide-that is, relative to the reduced weight of 
the weathered rock. The subject of weathering of granite is fully treated in the writings of Merrill, Keyes, and Watson. ${ }^{a}$

The changes in granite after it has entered into buildings or other constructions are less marked than those in the natural rock, because the blocks are not then traversed by anything analogous to sheet and joint structure, and also because the years of historic time are few compared to those of geologic time. Much has been written on the decay of granite in monuments and buildings. ${ }^{b}$ Such decay is mainly attributable to microscopic fissures produced by the unequal and repeated expansion and contraction of the different minerals of the granite under changes of solar temperature. In countries where the winter temperature is very low the action of frost within such fissures powerfully assists the process of disintegration. Thus the obelisk now in New York suffered more from three years' exposure to our climate than it had during over three thousand four hundred years in Egypt, although the fissures along which frost operated were started long before it reached this country. A minor factor in decay is the chemical action of water along fissures. ${ }^{\circ}$ It is supposed that these causes of decay operate more effectively in coarse granites than in fine ones. Merrill points out that a sawn or properly prepared polished surface resists weathering more effectively than a cut or hammered one, as the latter is full of minute fractures, parallel to the surface, produced by impact, which facilitate scaling.

\section{BLACK GRANITES.}

\section{BLACK GRANITES IN GENERAL.}

\section{CLASSIFICATION.}

The term "black granites," although sufficient for general commercial purposes, includes a variety of rocks of different character, origin, and appearance-gabbros, diorites, diabase, etc. They have, however, three mineralogical features in common-they contain comparatively little or no quartz, their feldspar belongs entirely or: almost entirely to the series which contains both soda and lime, and

a Merrill, Geo. P., Disintegration of the granitic rocks of the District of Columbia : Bull. Geol. Soc. America, vol. 6, p. 321, 1895; also A treatise on rocks, rock-weathering, and soils, New York, 1897, pp. 206-214, 286, 244, 245, 257. Keyes, Charles R., 'The origin and relations of central Maryland granites: Fifteenth Ann. Rept. U. S. Geol. Survey, 1895, p. 725, and pls. 42-45. See also proc. Iowa Acad.-Sci., vol. 1, pt..3, pp. 22-24, and vol, 2, pp. 27-31, I'ls. II-IV, 1895. Watson, Thomas L., A preliminary report on a part of the granites and gneisses of Georgia, 1902, pp. 299, $300,308,329,331,333$.

${ }^{b}$.Julien, Alexis A., The durability of building stones in New York City : Tenth Censtis, vol. 10, 1884; Granite, pp. 370-371. Merrill, Geo. P., Physical, chemical, and economic properties of building stones: Maryland Geol. Survey, vol. 2, 1898; Granite, pp. 92-94. Also Merrill's Stones for Building and Decoration, 3d ed., 1903; Weathering of granite, pp. 484, 435 .

' See Julien, Alexis A., A study of the New York obelisk as a decayed bowlder: Annals New York Acad. Sci., vol. 8, 1893, pp. 93-166. 
they contain a considerable amount of one of the pyroxenes, or hornblende or biotite, and magnetite, which accounts for the general darkness of their shade or their greenish color.

\section{ORIGIN.}

The gabbros and diorites are more or less granitic in texture, as they crystallized under conditions resembling those which attended the formation of granite. But the diabase was in part erupted through narrow fissures, forming dikes or sheets, and at many places - reached the surface, always crystallizing with comparative rapidity.

Diabase, however, occurs in Vinalhaven, as stated by Dr. George Otis Smith, "in large bodies which have the form of neither dikes nor sheets, being, in fact, part of the same masses as the diorites and gabbros."

Mineralogical aNd CHEMICAL COMPOSITION.

Gabbro consists essentially of a lime-soda feldspar and one or both of the varieties of pyroxene known as diallage and hypersthene. The former is a foliated silicate of iron and lime with about 12 per cent of magnesia; the latter is a silicate of iron with about 24 per cent of magnesia, and each of these minerals crystallizes differently. When hypersthene alone is present the rock is called a norite; when both are present it is a hypersthene gabbro. When the mineral olivine (a greenish silicate of iron with 50 per cent of magnesia) is present also the name olivine may be prefixed to the rock name. The accessory minerals in gabbros are ilmenite (a titanate of iron), magnetite, pyrite, apatite, biotite, garnet, and, rarely, quartz and metallic iron. The secondary minerals - that is, those derived from the alteration of the primary ones-are hornblende, chlorite, epidote, zoisite, analcite, serpentine, a white mica, and calcite. The percentage of silica in gabbros varies a little on either side of 50 . Iron oxides and lime average 9 per cent each; magnesia, 6 per cent.

Diorite consists essentially of feldspar (of the series containing lime and soda) and hornblende with biotite, or biotite alone. Quartz, augite, and potash feldspar may or may not be present. The accessory minerals are magnetite, pyrite, titanite, zircon, apatite, garnet, allanite. The secondary are epidote, chlorite, a white mica, and calcite. When quartz is present the rock is called a quartz diorite. When black mica or augite are the preponderating iron-magnesium silicates the rock becomes a mica diorite or an augite diorite. In diorites the silica ranges from about 49 to 63 per cent, but in quartz diorite it rises to about 69 per cent, which is the minimum in granite. The iron oxides range from 0.52 to 9.70 per cent, the magnesia from less than 1 to over 11 per cent, but usually from 2 to 7 per cent. 
Diabase consists essentially of a feldspar of the series containing lime, or soda and lime, together with a pyroxene or augite (alumina, lime, magnesia, iron), which, however, is frequently altered to hornblende or other secondary minerals; also magnetite or ilmenite or both. Olivine may or may not be present, and some specimens contain a little quartz. The accessory minerals are orthoclase, biotite, pyrite, hypersthene, apatite. The secondary ones are hornblende, a white mica, chlorite, epidote, serpentine, calcite. .The percentage of silica in diabase ranges from about 45 to nearly 57 , of iron oxides from about 9 to 14, and of magnesia from 3 to 9 .

These "black granites," as will be seen by the foregoing description, are distinguished chemically from the ordinary granites by their low percentage of silica ( 45 to 67 per cent), their high maxima of iron oxides (9 to 14 per cent), and of magnesia ( 9 to 11 per cent), and mineralogically by their dominant feldspar not being a potash feldspar, and generally also by their considerable content of the darker iron-magnesia minerals.

\section{TEXTURE.}

The general texture of the black granites corresponds in grade to that of the fine and medium granites. In the diorites the arrangement and order of crystallization of the minerals always correspond to those of the granites, described ${ }^{\prime \cdots}$ on page 20 . In some of the gabbros this is also true, but in others and in diabase the arrangement greatly differs. The feldspars are in needlelike crystals, between which the pyroxene has afterwards crystallized.

\section{PHYSICAL PROPER'TIES.}

Aside from their great toughness, the diorites and the granitic gabbros probably differ but little in physical properties from granites of the same grade of texture. By reason both of their peculiar texture and their mineralogical composition, the diabases and gabbros with "ophitic" texture, described on page 136, should differ considerably in physical properties from the granites. As these stones are rarely used in large buildings, owing to the difficulty of quarrying them either in blocks of sufficient size or at low enough cost, data as to their compressive strength and other useful physical properties are not a vailable.

The specific gravity of gabbro ranges from 2.66 to about 3, that of diabase from 2.7 to 2.98 , and that of diorite averages 2.95 . In these rocks it thus usually exceeds that of granite.

As the black granites are used chiefly for monumental purposes, and particularly for inscriptions, their color, susceptibility to polish, and the amount of contrast between their cut or hammered and 
their polished surfaces are the physical properties of chief economic importance.

Doctor Merrill a explains the cause of these contrasts very satisfactorily :

The impact of the hammer breaks up the granules on the immediate surface, so that the light falling upon it is reflected, instead of absorbed, and the resultant effect upon the eye is that of whiteness. The darker color of a polished surface is due merely to the fact that, through careful grinding, all these irregularities and reflecting.surfaces are removed, the light penetrating the stone is absorbed, and the effect upon the eye is that of a more or less complete absence of light, or darkness. Obviously, then, the more transparent the feldspars and the greater the abundance of dark minerals; the greater will be the contrast between hammered and polished surfaces. This is a matter worthy of consideration in cases where it is wished, as in a monument, to bave a polished die, surrounded by a margin of hammered work to give contrast.

The ordinary granites, while taking a high polish, do not afford such strong contrasts between hammered and polished surfaces as do the "black granites." In some black granites this. seems clearly to be due to their larger" percentage of the black minerals, but in others, as some of the quartz diorites, in which the black minerals do not exceed those in some gray granites, the cause of this marked contrast must be sought in some optical property of the soda-lime feldspar and in its relative abundance.

\section{"BLACK GRANITES" OF MAINE.}

CLASSIFICATION.

The black granites at the quarries and prospects visited by the writer include:

(1) Gabbros: Gabbro, hypersthene-olivine gabbro, norite, olivine norite:

(2) An altered diabase porphyry.

(3) Diorites: Quartz diorite, mica-quartz diorite.

The appearance and the petrographic characteristics of the stone at each quarry will be stated in Part II of this bulletin, in the descriptions of the quarries and of their products, and a classification of black granites based upon economic principles will be found on page 75 . These black granites vary considerably in shade and a little in color. The olivine norite of the Heal quarry, near Belfast, is almost black, but under a side light showis small, brilliant dark-green areas of hypersthene. The Vinalhaven olivine norite is quite black and fine textured. The Addison hypersthene-olivine gabbro is black, with small, irregular white areas of feldspar. The South Berwick

a Merrill, Geo. P., The physical, chemical, and economic properties of building stones : Maryland Geol. Survey, vol. 2, 1898, p. 64. 
gabbro is a very dark olive. The Hermon Hill rock is porphyritic and dark green. A little less dark than these, and without any greenish tinge, are the mica-quartz diorites of Beaver Lake (Calais) and the gabbros from Meddybemps Lake and Mingo Bailey's quarry, in Calais, while the quartz and mica-quartz diorites of Round Pond, East Sullivan, and Calais (Gardner) are all still lighter, and would pass for dark gray. Most of these stones take a beautiful polish, and all of them show very marked contrasts between the polished and cut surfaces. That contrast naturally is still more marked in the darker ones. The polished surfaces of most of these rocks show minute particles of magnetite. Large blocks of the Meddybemps Lake gabbro deflect the magnetic needle, and it is reported that the rock contains a very small amount of gold by assay, while platinum is reported from the Hermon Hill rock.

GENERAL, S'TRUCTURE.

Rift.-The course of the rift at the black granite quarries is given in the quarry descriptions. No other Maine black granite has such a marked rift as that of the Meddybemps Lake gabbro.

Sheets.-The sheet structure is not so well marked in the black granites as in ordinary granites, and herein lies the chief difficulty in quarrying them. Pls. $\mathrm{X}, B$, and $\mathrm{XI}, B$, show the character of the sheets in the Round Pond quartz diorite. Pl. X, A, shows it in the Addison gabbro. The sheets there range from 3 to 17 feet in thickness. In the Meddybemps Lake gabbro the sheets are well developed, being parallel to the banding and the rift, and are spaced from 1 to 6 feet.

Joints.-The courses of the joints are shown in the quarry diagrams. Jointing in the Addison gabbro is shown in $\mathrm{Pl}$. X, $A$, and in the Round Pond diorite its relation to a diabase dike is shown in Pl. XI, A. Generally the spacing of the joints in the black granites is small, which prevents the quarrying of blocks of very large dimensions.

\section{VARIATIONS IN THE ROCK.}

Banding.-The gabbro of Meddybemps Lake is traversed, in at least its upper part, by light-gray bands that range in thickness from one-fourth inch to 2 inches. Their lighter shade is the result of a greater proportion of feldspä. These bands dip at an angle of $15^{\circ}$, and run parallel to both sheet and rift structure. Pl. X, A, shows a similar but less pronounced banding in the Addison gabbro.

This banding represents not only the flow of the eruptive, but also different segregations of the principal minerals of the rock, alternating with one another. This structure resembles that observed in 


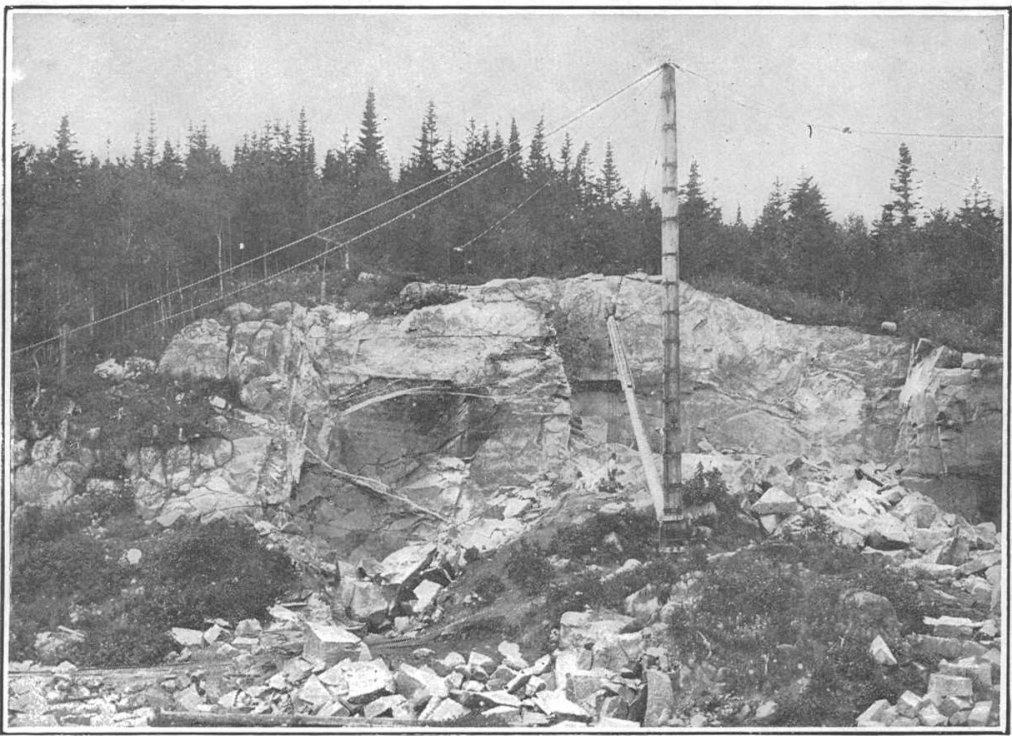

A. PLEASANT RIVER BLACK-GRANITE QUARRY, IN ADDISON. LOOKING NORTH-NORTHWEST. Showing the sheets crossed by frequent joints striking N. $80^{\circ}$ E., the banding of the olivine grabbro, and several dikes of whitish quartz monzonite.

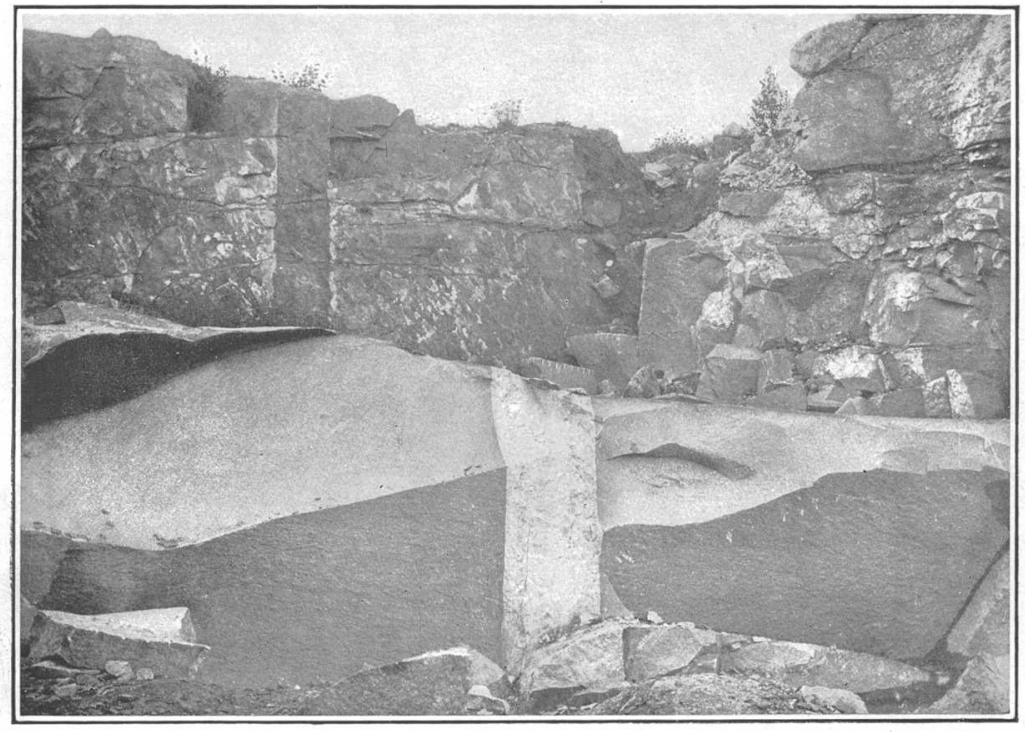

B. ROUND POND BLACK-GRANITE (UPPER) QUARRY, IN LINCOLN COUNTY. LOOKING SOUTH-SOUTHEAST. 
certain Scotch gabbrós, but in them the banding was also contorted prior to crystallization. ${ }^{a}$

Dikes.-The Addison gabbro is traversed by whitish dikes of finegrained quartz monzonite, from 1 to 14 inches thick. (See Pl. X, A.) They have a border, from one-twentieth to three-fourth inch thick, of coarser material, in which the particles measure up to one-tenth inch in diameter. The constituent minerals, in descending order of abundance, are soda-lime feldspar (oligoclase-andesine), potash feldspar (orthoclase) in slightly less amount, clear quartz, biotite, and hornblende, together with accessory magnetite, titanite, and apatite. The texture of this dike rock differs from that of any of the aplite dikes examined from the granite quarries in that the soda-lime feldspar is mostly in lath-shaped crystals ( 0.37 by $0.07-0: 11 \mathrm{~mm}$.), although occasionally also in squarish forms, and makes up an irregular network, the meshes of which are filled with quartz.

In the mica-quartz diorite of the Beaver Lake quarry, near Redbeach (p. 164), there is a dike of grayish pinkish aplite, from 4 to 8 inches wide, which appears to be more recent than a neighboring dike of olivine basalt, as its branches cross it. The particles in this aplite range from 0.11 to $0.91 \mathrm{~mm}$, a veraging roughly about 0.30 mm., and consist of soda-lime feldspar (oligoclase), much less potash feldspar, quartz, and biotite. The aplite is thus a biotite granite.

Dikes of pegmatite and also of aplite traverse the Round Pond (Lincoln County) quartz diorite (see Pls. $\mathrm{X}, B$, and XI, $A$ ), and pegmatites penetrate the overlying sedimentary schists. Miss Bascom has described some schists and pegmatites from points in Johns Bay, about 8 miles south-southwest of Round Pond, which are probably of the same age. ${ }^{b}$ It is uncertain whether the lenses and dikes of pegmatite in the schists were formed prior to the veins in the diorite.

The quartz diorite of Round Pond (Lincoln County) is also traversed by a diabase dike, which also crosses one of the pegmatite dikes and is therefore of later date. (See Pl. XI, A.) The micaquartz diorite of Beaver Lake, near Redbeach, in Washington County, is traversed by a dike of olivine basalt, a very fine-grained black rock consisting of needlelike crystals of feldspar (andesine-labradorite) with pyroxene, olivine, and magnetite, together with accessory biotite and a white mica.

Contacts.-The only contact of black granite with other rocks well exposed at the quarries visited in the preparation of this report is at the Round Pond quarry. (Peter Svensen \& Co., p. 139.) This has

\footnotetext{
${ }^{a}$ See Geikie, after Teall, op. cit., p. 256.

${ }^{b}$ Bascom, Florence, On some dikes in the vicinity of Johns Bay, Maine: Am. Geologist, vol. 23, 1899, pp. 275-280, Pls. IX, X, XI. See also in this connection : Lord, E. C., Notes on the geology and petrography of Monhegan Island, Maine: Am. Geologist, vol. 26, 1900 , pp. $329-347$.
} 
been referred to by Professor Wolff. ${ }^{a}$ At this place there is a finely plicated quartz-feldspar (andesine acid labradorite) hornblende-biotite schist, with accessory pyroxene, titanite, and apatite, striking $\mathrm{N}$. $15^{\circ} \mathrm{E}$., with numerous dikes of pegmatite, up to 2 feet 6 inches thick, parallel in places to the strike of the schist. On the southwest wall of the lower quarry a tongue of this schist 10 to 15 feet thick and 40 feet long lies in the diorite, as shown in Pl. XI, $B$. It reappears on the northeast wall. ${ }^{b}$ The contact of the diabase porphyry of Hermon Hill, near Bangor, is described on page 147.

\section{TEXT-BOOK REFERENCES ON GRANITE AND BLACK GRANITES.}

As the matter contained in the foregoing pages may not fully provide answers to all questions that may arise in the minds of persons interested in tracing the phenomena in granite quarries to their causes, the names of a few reliable general works in English on the subjects considered are here given.

Diller, Joseph S. Educational series of rock specimens collected and distributed by the United States Geological Survey: Bull. U. S. Geol. Survey No. 150.1898.

Granites, pp. 51, 170-180 ; gabbro, pp. 51, 52, 278-288; diorite, pp. 241-244; diabase, pp. 264-278; basalt, pp. 51, 52, 254-256.

Geikie, Archibald. Text-book of geology, fourth edition. London. 1903.

Granite, etc., pp. 89, 90, 203-209, 402-415, 715-809; gabbro, pp. 231, 232, 256 ; diorite, p. 223 ; diabase, p. 233 ; basalt, p. 234.

Harker, Alfred. Petrography for students: An introduction to the study of rocks under the microscope, second edition. 1897.

Granites, pp. 27-41; gabbros, pp. 67-81; diorite, pp. 54-66; basalts, pp. $188-200$.

Hatch, Frederick H. An introduction to the study of petrology; the igneous rocks, second edition. London. 1891.

Kemp, James F. A handbook of rocks for use without the microscope, third edition. New York. 1904.

T'be granites, pp. 33-38; gabbros, pp. 72-74 ; diorites; pp. 60-62 ; diabases, pp. $70-72$.

Luquer, Lea M. Minerals in rock sections, revised edition. New York. 1905.

Merrill, Geo. P. A treatise on rocks, rock weathering, and soils. New York, 1897.

Igneous rocks, pp. 58-64; granites, pp. 65-68; diorites, pp. 81,82 ; diabases; pp. 87,88 ; basalts, pp. 90,91 ; weathering, pp. 170-214. See also the same headings in the revised edition of same work, which has just appeared.

$a$ Wolff, J. E., Details regarding Maine quarries: Tenth Census, vol. 10, 1888, p. 121.

${ }^{b}$ As to the schist and pegmatite, see Bascom, op. cit., p. 61. 

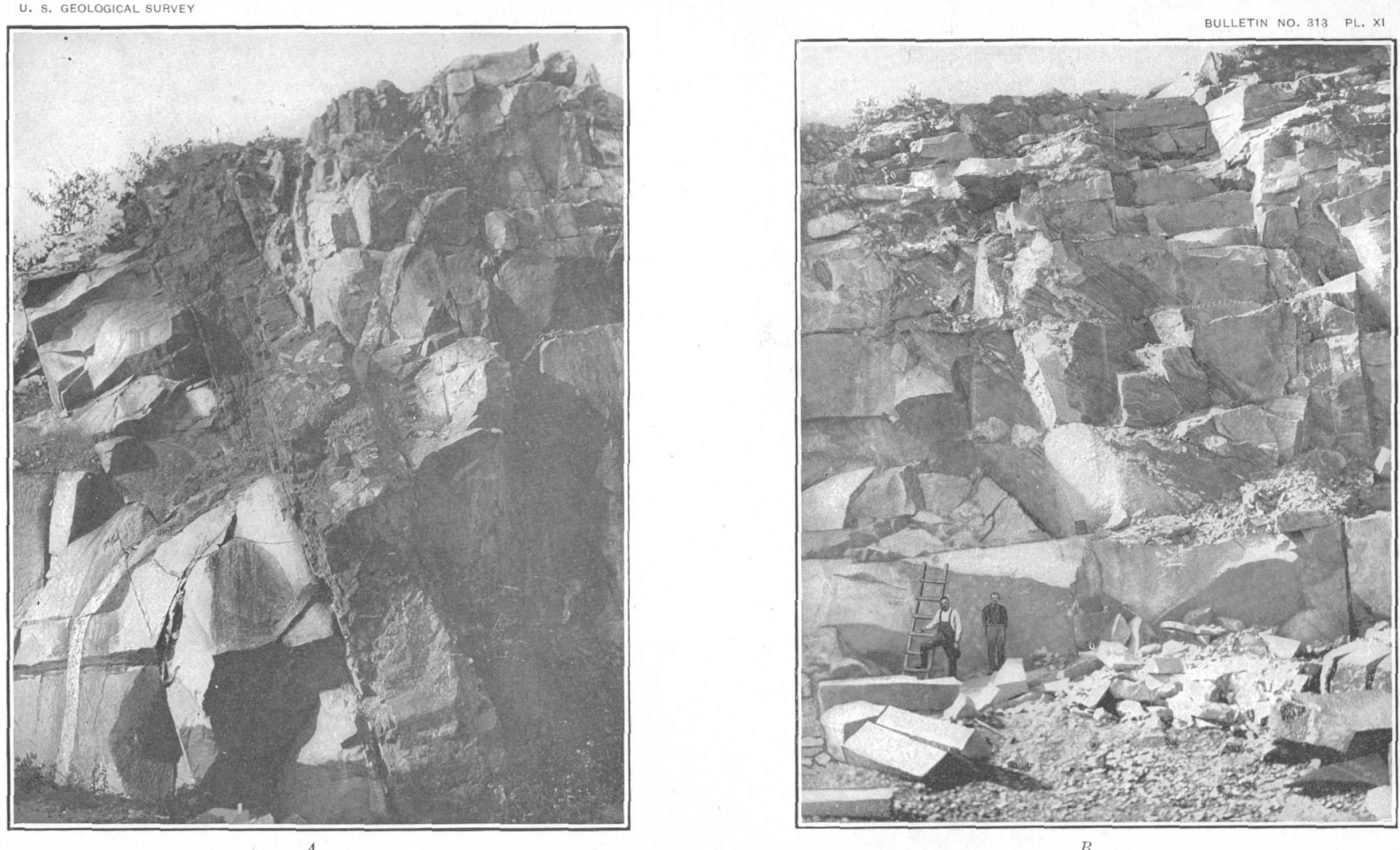

ROUND POND BLACK-GRANITE (LOWER) QUARRY

$A$. Showing the quartz diorite traversed by a small dike of pegmatite, and both crossed by a 2 foot 6 inch diabase dike. Looking west-southwest. The diorite shows joints parallel to the dike. $B$. Southwest wall, showing a tongue of schist within the diorite, crossed by sheet structure; joint (B) at the right. 


\section{PART II.-ECONOMIC FEATURES.}

The practical side of the granite industry will now be considered. The sections on the tests of granite and granite quarrying are of general application, but the rest of the matter has reference only to Maine granites and quarries. A list of the more important works on granite quarries and quarrying and other matters of economic character will be found at the end, together with a glossary of both scientific and quarry terms.

TESTS OF GRANITE.

The testing of granite is a subject of considerable importance, as may be seen by its literature. ${ }^{a}$ As pointed out by Merrill, there is danger of attaching undue importance to tests of compressive strength alone, the results of which in nearly all cases far exceed the generous margin allowed by architects beyond that required by the weightiest structures. On the other hand, there is danger of losing sight of several other important qualities which ought to be carefully tested and upon which the economic value of granite in part depends. The following tests include all the kinds made at European testing institutions or recommended by American authorities, as well as some suggested by the investigation of Maine granites.

Chemical analysis.-Chemical analysis is made in order to determine the amount of iron and lime, or to detect anything abnormal in the composition.

Determination of $\mathrm{CaCO}_{3}$.-Tests are made to determine the presence of lime not combined. with silicates in order to ascertain the percentage of $\mathrm{CaCO}_{3}$ (lime carbonate) present. This is done by powdering and treatment with warm dilute acetic acid. (See p. 94.)

Test for discoloration.-The method applied by Daly (Bull. U. S. Geol. Survey No. 209, p. 52) seëms to be well adapted for this purpose. A piece of fresh rock is immersed in a stream of carbon-dioxide gas for 20 minutes and then kept in an atmosphere of that gas for 24 hours. Another piece of fresh rock is placed in an atmosphere of purified oxygen over night and then exposed for 30 minutes to a temperature of $150^{\circ}$ C. $\left(302^{\circ}\right.$ F.). Any discoloration due to the carbonization or oxidation of the minutest particles of any mineral would be sure to show itself under these tests.

Mineral composition.-This is determined by the microscopic examination of a considerable number of typical thin sections. All the mineral constituents are noted, and the average size of the mineral 
particles in the case of the fine-textured granites is estimated. Any peculiarities of texture, rift, etc., can also be noted.

Proportions of minerals.-A method has been devised by Rosiwal, of the Austrian Geological Survey, ${ }^{a}$ by which the approximate proportions of the chief minerals (feldspar, quartz, mica, hornblende) and their average size can be determined. This consists in tracing a network of lines intersecting one another at right angles upon $\mathbf{a}^{\prime}$ polished granite surface, at intervals so far distint that no two parallel lines will traverse the same mineral particle. The total length of the lines is measured, then the diameters of all the particles of each kind of mineral are added separately and their proportion to the total length of the lines obtained. The average size of the particles of each mineral can be also calculated from the same measurements. Although this method was primarily designed for application to the coarse and medium granites, it can be extended also to the finer ones by drawing the lines upon camera-lucida drawings made from thin sections of such granites under polarized light. As the quartz is the source of the vitreousness of the rock the determination of its amount is important. The incompleteness of the collection of polished specimens of Maine granites and the short limit of time available have alone prevented the application of this method in the preparation of this report, but the method was experimentally applied to a specimen of the coarse reddish granite from Hardwood Island, near Jonesport, and the results are given on page 173.

Polish.-Besides the manifest object of this test it also facilitates exact descriptions of color and comparisons between different granites. The size of the mica plates determines the brilliancy and durability of the polish more than does their number-that is, a considerable number of very minute mica plates is not objectionable.

Hardness.-As pointed out by Hawes ${ }^{b}$ the hardness of certain granites is not due entirely to the quartz, which is always equally hard and brittle and which the tools do not cut but crush, but to the feldspar, which is of variable hardness and, it might be added, has different cleavages, and the proportion of which in relation to quartz also varies. Rosiwal, ${ }^{c}$ adopting a principle established by Toula, takes a piece of smooth unpolished granite of about 2 grams weight and rubs it with emery (of $0.2 \mathrm{~mm}$. diameter of particle) upon a glass or metal plate for 6 or $S$ minutes until the emery loses its effectiveness. The granite is then weighed again and its loss of

a See Rosiwal, August, Ueber geometrisehe Gesteinsanalysen; ein einfacher Weg zur riffermïssigen Feststellung des quantitätsverhältnisses der Mineralbestandtheile gemengter Gesteine: Verhandl. der K.-K. geol. Reichsanstalt, vol. 32, pp. 143-175.

' Hawes, G. W. (edited by Merrill), Granite; Building stones of the United States and statistics of the quarry industry : Tenth Census, vol. 10, 1888, pp. 16-18.

c Neue Untersuchungseigebnisse über die Hirte von Mineralien und Gesteinen : Verbandl. K.-K. geol. Reichsanstalt, 1896, p. 488. 
volume calculated. He found, assigning to emery an arbitrary value of 1,000 as representing its average hardness, that granite from 9 localities showed the following degrees of hardness: $31.7,38.1,41.7$, $44.8,48.4,50.7,52.9,56.6$, and 67.1. The extremes of these figures show that some granites have a general hardness more than twice as great as others.

J. F. Williams ${ }^{a}$ proposed to determine the relative hardness of granites by noting the rate of penetration of a drill of a given diameter, or by measuring the distance to which such a drill will penetrate without being sharpened, or the amount of surface of rough-pointed granite which can be reduced to a bush-hammered surface per hour. Since the introduction of pneumatic drills and surfacers these methods can be easily applied.

Compressive strength.-The methods of testing the strength of building stones have grown in precision. The first requisite is that the cubes to be tested should be sawed by diamond saws and not hammered out. The next is that the direction of both rift and grain should be indicated thereon, and that three cubes should be tested, one with pressure applied parallel to the direction of the rift, one applied parallel to that of the grain, and the third at right angles to rift and grain. Where the rift and grain are pronounced the three results will differ: As in the reports of tests made with the testing machine at the Watertown Arsenal, Mass., the number of pounds pressure at which the first crack is produced should always be given, as well as that at which the cube is crushed. It is assumed that these tests are made in a dry atmosphere.

Transverse strength, shearing strength, and compressive elasticity.It has been found useful for certain architectural purposes to test these qualities in granite. ${ }^{b}$

Porosity.-Buckley points out ${ }^{c}$ that the danger from frost depends not upon the amount of absorption but upon the size of the pore space. Rocks with large pore spaces stand frost better than those with small ones, because they do not retain the water that they absorb. Tests of porosity are therefore important. Buckley used the dry and saturated weights obtained for the samples used in computing the specific gravity.

The difference in these weights was multiplied by the specific gravity of the rock. This amount was added to the dry weight, giving the sum. The difference of the dry and saturated weights multiplied by the specific gravity of the rock was then divided by the sum. This last result is the actual percentage of pore space compared with the volume of the sample tested.

\footnotetext{
a Igneous rocks of Arkansas: Ann. Rept. Geol. Survey Arkansas, vol. 1, 1890, p. 41.

b See Buckley, Building and Ornamental Stones of Wisconsin, pp. 396-398. Also Rept. of tests of metal, etc., Watertown Arsenal (1895), 1896, pp. 319-322, 339-351, 407-411. Some of the results as to elasticity are given on page 21 of this report.

. Buckley, op. cit., pp. 68, 69, 372-376, 400, 413.
}

$3495-$ Bull. $313-07-5$ 
Freezing and thawing.-Buckley's method ${ }^{a}$ consists in drying 1-inch and 2-inch cubes at a temperature of $110^{\circ} \mathrm{C}$. and weighing them. After being saturated in distilled water they were exposed overnight to a temperature below freezing. They were then thawed out and soaked in warm distilled water. This process was continued for thirty-five days, when they, were again dried at $110^{\circ} \mathrm{C}$. and weighed. Finally the same stones were subjected to the tests for compressive. strength and the results compared with those for stones not thus treated.

Absorption and compression.-The complete saturation of a stone and the determination of the amount of absorption are effected by a method described at length by Buckley. ${ }^{b}$ The saturated stone should then be tested for compressive strength and the result compared with that obtained from dry stone.

Behavior under fire.-This test is best applied to saturated specimens, which are then exposed in a laboratory furnace to a temperature up to $1,500^{\circ} \mathrm{F}$. and the effect noted. Some of them can be allowed to cool gradually, but others should be immersed auickly in cold water; or they may be exposed to high temperature while under compression and then cooled slowly or quickly. ${ }^{c}$

Specific gravity.-The specific gravity is the weight of the stone at $16^{\circ} \mathrm{C}$. compared with that of the same volume of distilled water at $4^{\circ} \mathrm{C}$. All air should first be removed from the piece to be tested by boiling in distilled water. The specific gravity is also required for the test of porosity.

Weight per cubic foot.- The weight of the dry store per cubic foot is obtained by multiplying its specific gravity by the weight of a cubic foot of water, but from this there should be deducted "the weight of a quantity of stone of the same specific gravity equal in volume to the percentage of the pore space in the stone." ${ }^{d}$ This gives the actual weight of the stone free from interstitial water.

Coefficient of expansion.-Finally, it may be desirable to obtain the coefficient of expansion of a granite intended for some particular construction. The expansion of certain granites was determined at the Watertown Arsenal by hot and cold water baths. The stones thus tested were afterwards subjected to the test for transverse strength, when it was found that they had lost 16.93 per cent of their original strength. ${ }^{\circ}$

A list of the various tests applied to building stones by German testing institutions is given by Herrmann. $f$

\footnotetext{
a Buckley, op, cit., p. 71 .

${ }^{b}$ Buckley, op. cit., pp. 64-67.

$c$ Buckley, op. cit., pp. 73, 411.

a Buckley, op. cit., p. 70 .

- Rept. of tests of metal, etc., p. 320.

i Steinbruchindustrie und Steinbruchgeologie, p. 10 et seg.
} 


\section{ADAPTABILITY TO DIFFERENT USES.}

The successful use of granite depends upon a careful consideration of its various adaptabilities. The granites proper, as will be seen by the description of the Maine granites alone (pp. 73, 74), include stones which vary greatly in texture, color, and shade. The coarsetextured ones are best adapted to massive structures, while the finetextured ones are better adapted to lighter structures, monuments, and statues. The reason for this is that in coarse-textured granites the large feldspars crossing the various sculptural designs at all sorts of angles produce lines and reflections that interfere with the lights and shades produced by the sculptor's design, and thus mar their effect. The fine granites are well adapted to light structures and to fine sculpture, as is shown in the delicately carved panel and the statue represented in Pl. XIV, $A$ and $B$. Some coarse granites, however, lend themselves well to coarse carvings, especially when these are to be placed in the higher parts of buildings, as was the lintel of Vinalhaven granite shown in Pl. XIII, $A$. Then there is the matter of color and shade. There is large room for the exercise of artistic taste in deciding which colors and shade will best harmonize or contrast with one another in a granite. structure or with the colors of other stones or materials in a composite structure. There is also room for choice between different granites in ornamental work, because of the different amount of.contrast between the polished, hammered, and rough surfaces of stones of different color and texture, although the polished surface is always darkest and the hammered lightest. Tarr ${ }^{a}$ in 1895 wrote of a demand by architects for rustcolored granite (sap) for use in connection with light-colored stone in order to produce pleasing contrasts. (See further p. 72.)

The black granites are obviously best adapted for inscriptions where legibility at a distance is the prime object, and also for all ornamental work in which more marked contrasts are desired than the ordinary granite can furnish. The black granites are sometimes combined with ordinary granite of light shade in monumental work, the die being of black granite.

\section{GRANITE QUARRYING.}

The problems that confront the granite quarryman are numerous. Their solution requires not only capital, but practical experience, judgment, a little geological knowledge, and some mathematics. It is, first of all, assumed that suitably prepared specimens of the fresh rock have been procured and subjected by competent persons, provided with the necessary machines and instruments, to the tests

\footnotetext{
' $a$ Economic geology of the United States, p. 363.
} 
enumerated on pages $63-66$ in order that the quality of the stone may be scientifically determined.

Exploration of surface.-The next step is a careful exploration of the granite surface, if necessary, by stripping in trenches, with a view to determine the areal extent of the quality of stone tested, the character of the jointing, the presence of headings, dikes, and veins, and the frequency of knots.

Stripping.-The thickness of soil or till upon the granite surface and that of the decomposed surface rock should be estimated. In some places the removal of this covering involves large expenditures; in others the expense is so small as to be negligible.

Sheets, rift, and grain.-A sufficient amount of, vertical exploration should be made, possibly by core drilling, in order to determine the thickness of the sheets, the width of the sap, the direction and amount of rift and grain.

Quarry site.-With these preliminaries a quarry site should be selected. In this selection the inclination of the sheets and the locaton of headings and dikes should be considered, as well as the amount of stripping, the location of dumps, the drainage, and the facilities for transportation. The location of a quarry on a level tract, away from streams or shore, may entail insurmountable drainage difficulties.

Transportation.-The cost of transporting the product is obviously one of the great factors in granite quarrying. The basis of the Maine granite industry is the location of its quarries at tidewater. At many quarries schooners of 175 registered tonnagethat is, carrying from $300-350$ long tons-are laden within 500 feet and some within 125 feet of the point where the stone is quarried. (See Pl. XII, A.) . Notwithstanding the greater cost of transportation by rail and the necessity, in many places, of a second handling, Maine granite has found its way far into the interior, as will be seen by reference to the description of the quarries under the heading of "Product." This is supposed to be due to the fact that the completeness of the plants and the ability of the firms in handling large contracts has more than counterbalanced the great distance of the quarry from market. But in any case the transportation of the product any considerable distance by teams to railroad or wharf is a very serious drawback. When the quarry is at a considerable elevation above the railroad or wharf, as at Mount Waldo and Mosquito Mountain, in Frankfort, elaborate systems of gravity rail transportation must be provided. At each of these quarries this has involved about $1 \frac{1}{2}$ miles of railroad track, besides special engines and great lengths of steel cable.

Drainage.-In small and newly opened quarries, drainage is an 


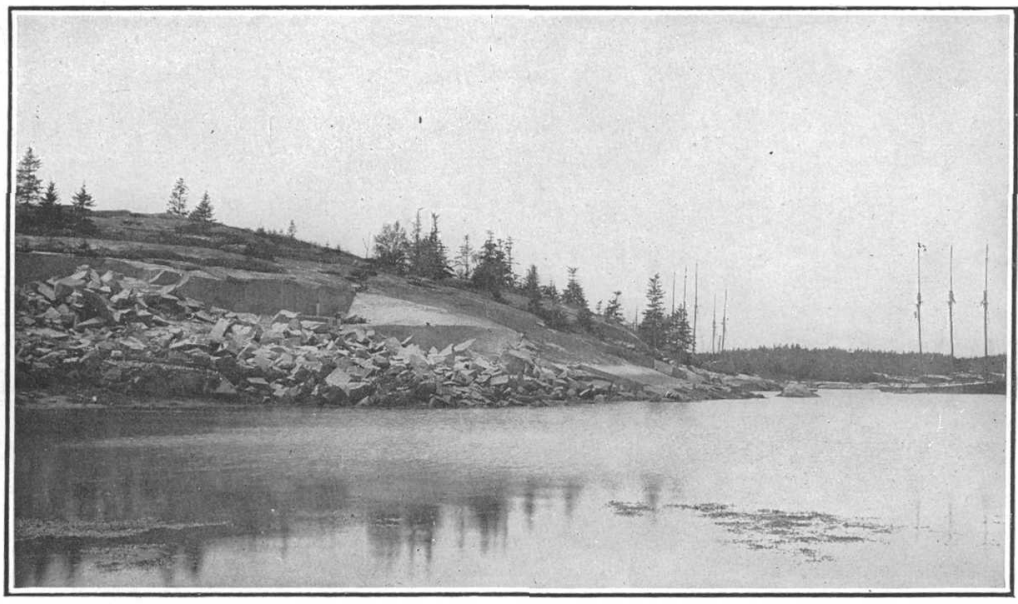

A. WEBSTER QUARRY, ON PLEASANT RIVER, AT END OF WINTER HARBOR, VINALHAVEN. LOOKING WEST.

Granite-laden schooner to right. Photograph by Merrithew.

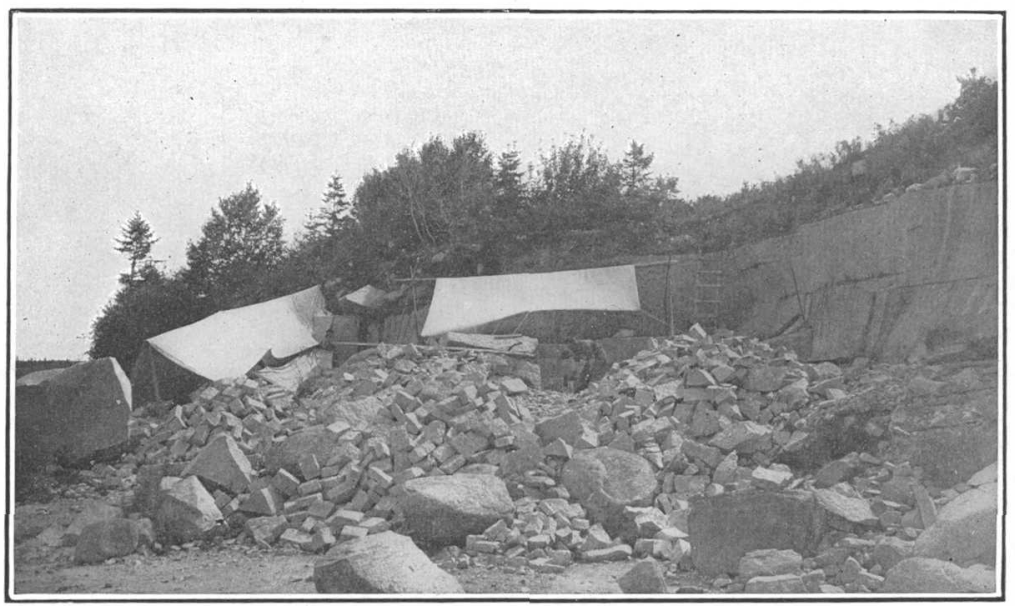

B. PAVING-BLOCK QUARRY AT VINALHAVEN. A "MOTION."

Photograph by Merrithew. 
insignificant matter, but as the quarry deepens it assumes importance. Where the quarry stands at some elevation the drainage is easily disposed of by ordinary piping or siphoning, but if the quarry bottom lies below the level of the surrounding tract and if the drainage exceeds the needs of the boilers, pumping must.be resorted to; but even in such places there must be some available stream or shore to carry off the water. The amount of pumping requisite varies greatly.

Water supply.-When the needs of the boilers exceed the amount supplied by the drainage, neighboring springs or brooks are resorted to. On small islands that are without streams or copious springs the question of water supply in large quarries is a serious one. At one of the Crotch Island quarries water has been brought from Stonington, a mile distant, at an expense of $\$ 110 \mathrm{a}$ month, and at the High Isle quarry water is obtained by pumping from accumulations in the old quarry pits on Dix Island. This required 3,900 feet of 3 -inch pipe. In order to obviate such outlays bored wells are being resorted to, by means of which it is expected that the entire drainage of these islands will be made available. As explained on page 38, it is only the joint and sheet structure that makes granite a source of water. The subject of well boring in granite will be discussed in a paper to be published by the United States Geological Survey. ${ }^{a}$ If well boring should fail to yield an adequate supply to island quarries, the condensation of sea water could still be resorted to, as in ocean navigation.

Use of explosives and wedges.-At no point in granite quarrying is more experience and judgment requisite than in the use of explosives. The selection of the place for blasting, the size and shape of the hole, the selection of the powder, and the size of the charge are all matters requiring careful consideration. The thickness of the sheet, the proximity of joints, the vitreousness of the stone, its rift and grain structure, the physical and mathematical laws governing the action of explosives, and the direction in which the quarryman desires to split the mass are all factors in each problem.

The mathematics of the subject will be found treated in a recent book by Daw, ${ }^{\prime}$ and a general description of quarry methods will be found in a report by Walter B. Smith. $c$

The practice of foremen in the thirty principal granite quarries of Maine, as explained by them to the writer, was found to be as follows: Vertical blast holes almost as deep as the thickness of the sheet are

a Bowman, Isaiah, Well-drilling methods: Water Sup. and Irr. Paper (in preparation).

${ }^{b}$ Daw, A. W. and $Z$. W., The blasting of rocks in mines, quarries, and tunnels, etc., pt. 1, London, 1898.

$c$ Methods of quarrying, cutting, and polishing granite: Minemal Industries; Eleventh Census, 1892, pp. 612-618; also Sixteenth Ann. Rept. U. S. Geol. Survey, pt. 4 (1894-5), pp. 446-456. 
drilled by pneumatic or steam drills along a proposed line of fracture under three sets of conditions. The block to be loosened must be: (A) Bounded laterally by two free ends (consisting either of two artificial channels or two joints or headings or dikes, or else of one of these and one channel) and bounded the other way by one quarried face and the desired line of fracture; or (B) bounded laterally by one channel and the proposed line of fracture and the other way by a heading or joint and a free face; or (C) not bounded laterally by any free end and the other way only by the working face. In this case after the fracture is made the two other sides of the block must be cut either by blasting or splitting. In all these cases the boundaries of the block are the upper and lower surfaces of the sheets, and the lines of frac-

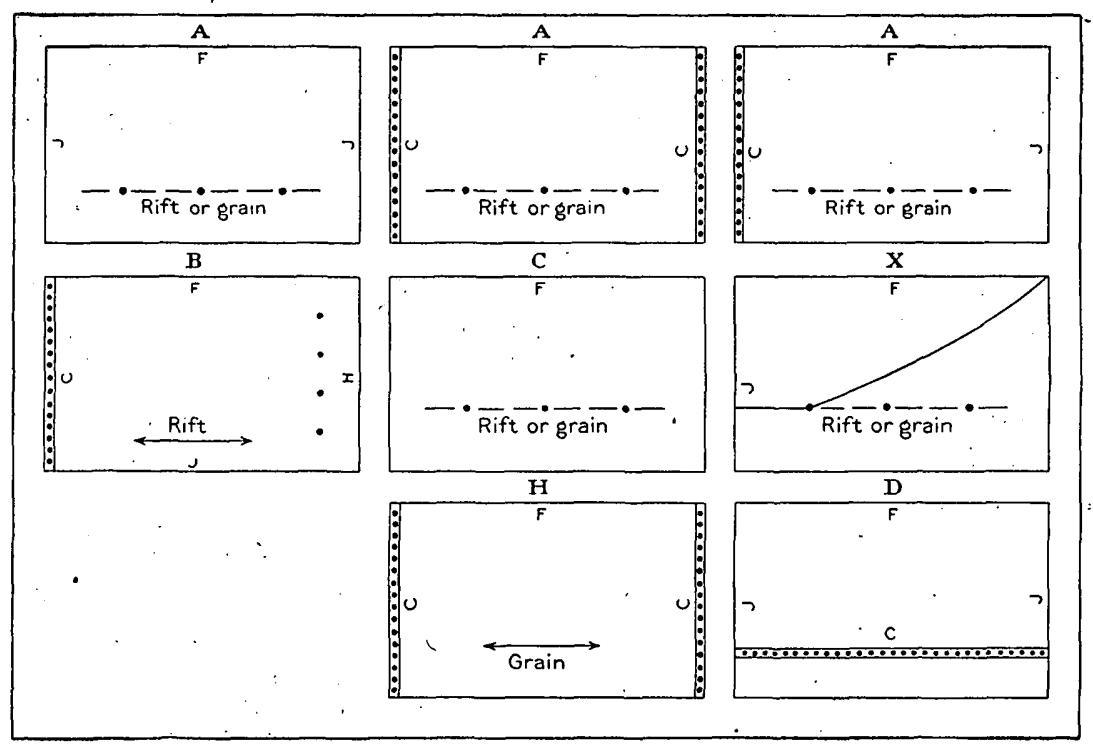

Frf. :- - biagrams illustrating methods of using explosives in Maine granite quaries. $F$, face ; J, joint, heading, of dike ; $C$, channel : $H$, " bard-way " or " cut-off." The round dots represent blast holes. In diagram $\mathrm{X}$ the diagonal crack sbows effect of not cban'- neling on right side. In method shown in diagram $B$ explosives are not used along the rift, and in that of $H$ (Hallowell granite) little or no explosive is used along the grain.

ture must follow either the rift or the grain. Where the grain is weak it requires double the number of blast holes to effect a fracture along it that it does along the rift. Where there is no vertical rift or grain it is impracticable to use method C, and in such cases, even with two free ends, channeling is resorted to.

Exceptionally still another method is in use, which requires only one lateral joint face and one working face (besides the sheet surfaces), the line of fracture forming the third side. But this method is regarded as hazardous by the more experienced men, for the fracture is apt to leave its direction of parallelism to the working face and swerve off diagonally to meet it. Processes A, B, and C are illus- 


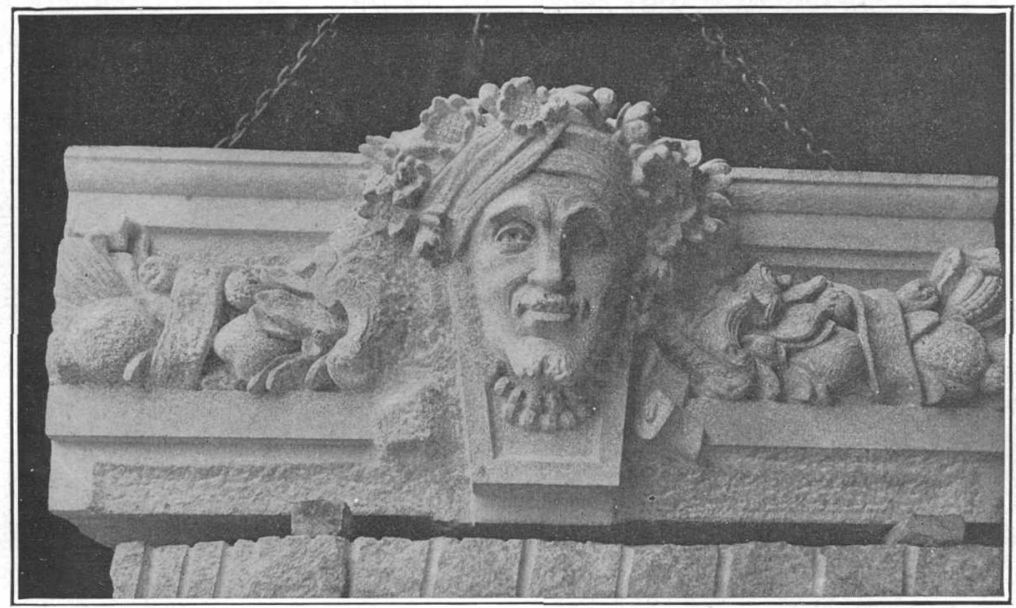

A. LINTEL FOR NEW YORK CUSTOM-HOUSE, CARVED FROM EVEN-GRAINED COARSETEXTURED BIOTITE GRANITE OF SANDS QUARRY, VINALHAVEN.

Showing adaptab'lity for coarser sculpture. Portion at left of head unfinished. Photograph by Merrithew

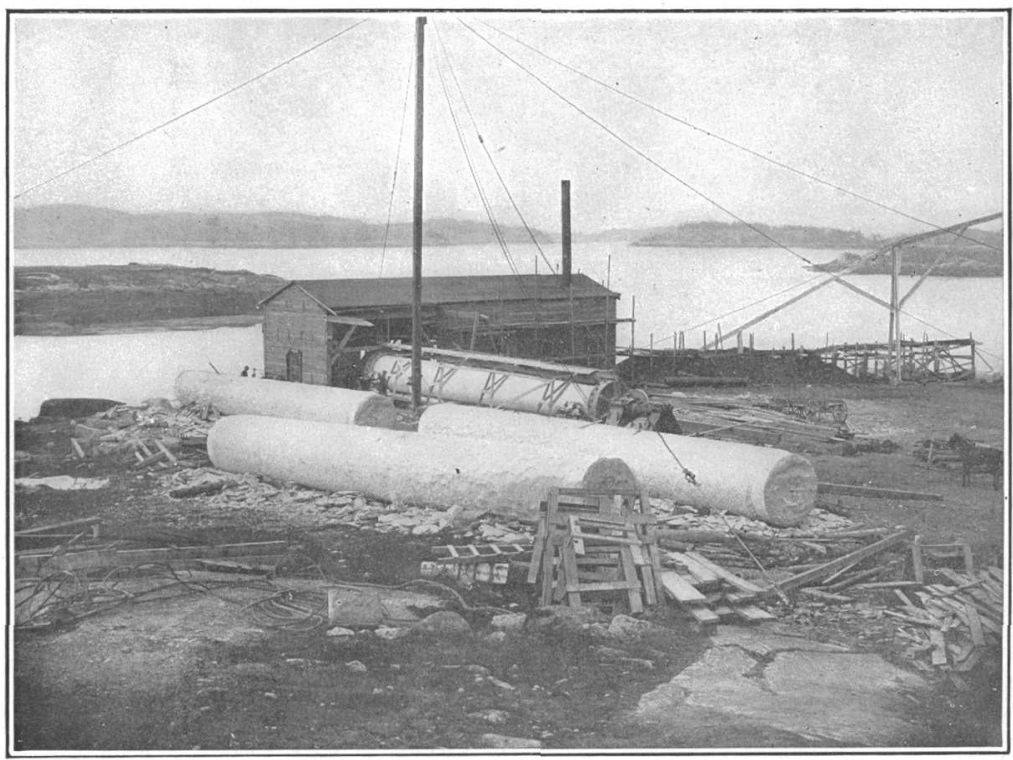

B. MONOLITHIC COLUMNS OF COARSE-TEXTURED BIOTITE GRANITE QUARRIED AT PALMER QUARRY, VINALHAVEN, FOR THE CATHEDRAL OF ST. JOHN THE DIVINE, AT NEW YORK.

Length, 51 feet 6 inches to 54 feet; diameter, 6 feet. One column in lathe. 
trated in fig. 3, diagrams $\mathrm{A}, \mathrm{B}$, and $\mathrm{C}$. The case without rift or grain is marked $\mathrm{D}$, and the hazardous one $\mathrm{X}$.

The blast holes are usually "lewis holes," which consist of two or three contiguous drill holes, with the intervening rock chiseled out, or, where less force is required, "knox holes," consisting of a circular drill hole, with two diametrically opposite lateral vertical grooves. The drill holes may be made divergent below. The "channels" are about 4 feet wide and are made either by drilling blast holes in zigzag order, which are fired singly in diagonal order, or by drilling holes on both sides of the proposed channel in close order; or else the channel consists of a single row of contiguous drill holes. This practice is found more economical than that of using a regular channeling machine. When the stone is delicate, as in the Hallowell quarries, powder is used sparingly or not at all. In the latter case channeling is done in two directions at $90^{\circ}$, and the operation is completed by splitting by wedges in the third. (See fig. 3, diagram H.)

At the Long Cove quarry of Booth Brothers and Hurricane Isle Granite Company (p. 128) mining is resorted to. Shafts and cross tunnels are blasted out on the plan of an inverted $T(T)$ and large quantities of powder are exploded in the ends of the horizontal parts, in order to loosen a great mass of overlying rock.

After the block has been loosened by methods A, B, or C, it is broken up into minor blocks by "splitting." As is well known, splitting is now done almost entirely by the use of pneumatic plug drills. The holes are 3 to 4 inches deep, three-fourths inch in diameter, and a few inches apart. Every few feet a deeper hole is drilled. Iron wedges are then very gradually driven in between steel side pieces called "feathers."

A difference is found in blasting and splitting granite in winter and summer. A low temperature increases its cohesiveness, but, probably in connection with water, increases its fissility where the "rift" is feeble.

It is reported that in quarries in Finland the expansive power of freezing water is regularly used in splitting. This is in line with the ancient Egyptian use of the expansion of wet woody tissue. A method of blasting in use in some of the English coal mines by means of the expansion of slaked lime may be susceptible of adaption to the quarrying of the more delicate granites. ${ }^{a}$

In this connection should be mentioned the method recently adopted in the granite quarries of North Carolina of developing an incipient sheet structure by the use of high explosives followed by the application of compressed air. (See footnote, p. 37.)

\footnotetext{
a See Mosley, Paget, On a new method of mining coal: Jour. Iron and Steel Institute, London, 1882, pp. 53-62.
} 
Utilization of waste.-In most of the Maine quarries the thin sheets and the waste material are worked up into paving blocks, which consume not only the smaller fragments, but blocks which are disfigured by sap or knots. The size of these blocks differs for different cities. The standard in New York is from 11 to 14 by 4 by 7 inches. The flat side is cut parallel to the rift. Paving stones are the only product of some quarries. The drilling at such quarries is generally done by hand. A paving-stone quarry, possibly from its often simple and temporary character, is called a "motion." (See Pl. XII, B.) The magnitude of the paving-stone industry in Maine can be seen from the statistics on page 183. Another use of waste is for crushed stone for macadamizing roads. The only quarry in Maine that is provided with a stone crusher for the utilization of its waste in this way is that at North Jay. The diabase dikes which are so inconvenient in some granite quarries could well be utilized in this way also, and would furnish a kind of crushed stone for which there might be a greater demand than for crushed granite. The architectural use of discolored granite (sap) is in vogue at the Cape Ann, Mass., quarries, where the Rockport public library has been made of it and the unaltered granite used for trimmings. No such thing was encountered in Maine. That sort of waste could be cheaply supplied by many quarries.

\section{ECONOMIC CLASSIFICATION OF MAINE GRANITES.}

A scientific classification of these granites has already been given on pages 24,25. Maine granites, considered in respect to their uses, may be divided into five classes: (a) Constructional, used for bridges, docks, retaining walls, buildings, or the bases of monuments; (b) statuary, for statue and delicate monumental or ornamental work; (c) inscriptional, for inscribed dies and tablets; $(d)$ curbing, for curbstones, straight or circular, and cross walks, and (e) paving, those which are used exclusively for paving blocks. But in order to convey an adequate idea of the great variety of these granites they have been divided into 14 groups. This classification is based upon the most conspicuous economic characteristic, be it either color or texture. The designations of these groups are: (1) Reddish (divided into light, bright, and dark), (2) pinkish-buff, (3) light lavender, (4) gray (black and white, white dominant, the minerals affording strong contrasts), (5) gray, porphyritic, (6) buff, (7) greenish gray, (8) black and white (black dominant), (9) gra?', with weak contrasts, (10) muscovite (white mica conspicuous), (11) fine textured, (12) very coarse, (13) - paving, fine with isolated crystals, (14) black (divided into black, greenish black, and medium gray). In the following table the localities where each of these 

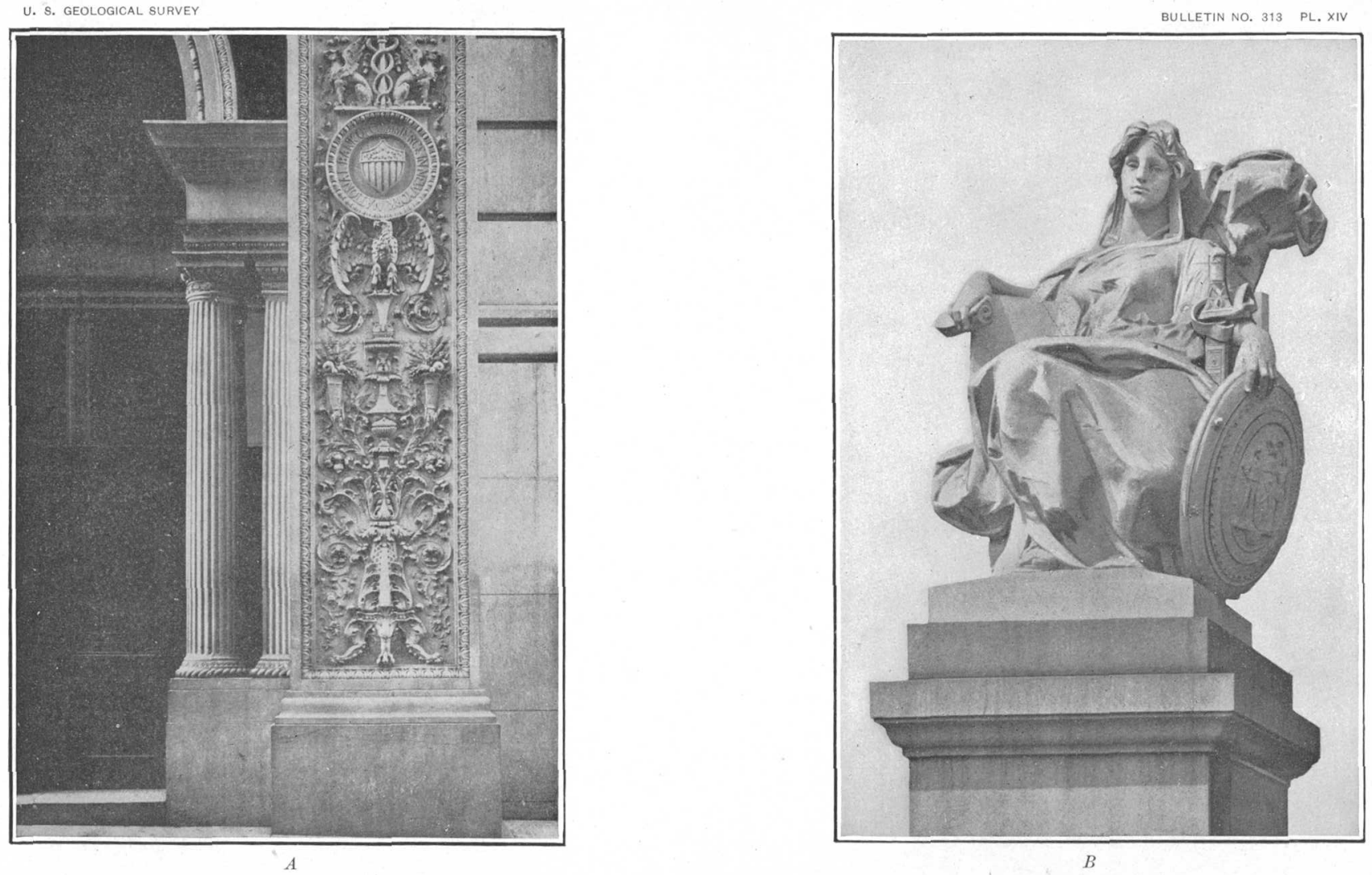

CARVINGS FROM LIGHT-GRAY FINE-TEXTURED BIOTITE-MUSCOVITE GRANITE FROM THE STINCHFIELD QUARRY, NEAR HALLOWELL, SHOWING ADAPTATION TO DELICATE SCULFTURE,

A. Part of panel at side of entrance to New York Bank of Commerce. B. Statue erected in 1906 at the Hall of Records in New York. 
granites is quarried are given, and references are made to the pages on which a complete description of the stone can be found. Connected with those descriptions are particulars as to the quarries and the firms operating them.

Economic classification of Maine granites.

1. Reddish (medium to coarse) :

Light-

Wells (p. 182).

Black Island (p. 96).

Mount Desert: Hall Quarry, Campbell \& Macomber (p. 98).

Swans Island: Toothachers Cove (p. 115).

Bright-

Redbeach: Maine Red Granite Company (p. 165) ; Redbeach Granite Company (p. 167).

Dark-

Sbattuck Mountain (p. 164).

Redbeach: Mingo Bailey \& Co. (p. 165).

Jonesport: Head Harbor and Hardwood Islands (pp. 171, 172).

Marshfield: Machias Granite Company (p. 173).

Black Island: Redcliff quarry (p. 96).

Mount Desert: Southwest Harbor: Carroll quarry (p. 116).

Jonesboro quarries (pp. 168, 169).

2. Pinkish buff (medium to coarse) :

- Vinalbaven: Sands quarry (p. 129) ; Palmer quarry (p. 132) ; Webster quarry. (p. 134) ; Black quarry (p. 134) ; Armbrust quarry (p. 135).

Hurricane Island quarry (p. 122).

High Island (p. 122).

Dix Island (p. 123).

Swans Island; Baird quarry (p. 115).

Biddeford: Marcille \& Wormwood (p. 178).

Stonington: Deer Isle: Hagan \& Wilcox quarry (p. 109). Crotch Island: Sherwood upper quarry (p. 106). Green Island: Latty Brothers (p. 106).

3. Light lavender (medium to coarse) :

Stonington: Crotch Island: Ryan-Parker quarry (p. 102) ; Goss quarry (p. 104). Deer Isle: Settlement quarry (p. 108). Moose Island (p. 107).

Jonesboro: Fish quarry (p. 167).

4. Gray (medium to coarse); black and white, latter dominant, strong contrasts. Feldspar in some rocks, slightly bluish:

Biddeford : Ricker (p. 176) ; Gowen Emmons \& Co. (p. 177) ; Andrews \& Perkins (p. 179).

- Kennebunkport: Ross quarry (p. 181); Day quarry (p. 181).

Bluehill: White quarry (p. 84) ; Chase quarry (p. 86) ; Howard quarry (p, 88).

South 'Thomaston: Weskeag quarry (p. 127).

Guilford (p. 148).

Norridgewock: Dodlin quarry, light (p. 149).

South Brooksville: Bucks Harbor quarry (p. 88) ; Maine Lake Ice Company quarry (p. 89). 
5. Gray, with isolated lighter crystals:

Frankfort: Mosquito Mountain (p. 152) ; Mount Waldo (p. 154).

Searsport: Mount Ephraim (Bog Hill) (p. 157).

Bluehill : Collins Granite Company (p. 87).

Dedham: Brown (p. 90).

6. Buff (medium to coarse) :

Millbridge (p. 174).

Mount Desert: Hall Quarry, McMullen \& Co. (p. 97).

Brooksville: Wilson quarry (p. 88).

Sedgwick (p. 101).

7. Greenish gray (medium texture) :

Mount Desert: Seal Cove (Herrick) quarry (p. 116).

Alfred: Bennett Brothers (p. 175).

8. Black and white (medium texture, black dominant) :

Sprucehead: Bodwell quarry (p. 124).

Hartiand (p. 149).

Woodstock: Bryant Pond (p. 146).

Norridgewock: Dodlin quarry, dark (p. 149).

9. Gray, weak contrasts (medium to coarse texture) :

Sullivan : Crabtree \& Havey (p. 110) ; Taylor quarry (p. 113) ; Hopewell quarry (p. 111); Stimson quarry and other quarries (p. 111).

Franklin: W. B. Blaisdell (p. 94) ; T. M. Blaisdell (p. 93) ; Robertson \& Havey, and other quarries (p. 90).

10. Muscovite, white mica conspicuous (medium texture) :

Fryeburg (p. 144).

Oxford (p. 146).

Bradbury (Hollis Center) (p. 180).

11. Fine textured (light to medium gray):

Jay (p. 80).

Pownal (p. 79).

Swanville: Oak Hill (p. 158).

Lincoln (p. 156).

Hallowell (p. 117).

Freeport (p. 77).

Frankfort: Mount Waldo (p. 154).

Bluehill. Chase (p. 87).

Clark Island (p. 125).

Long Cove (p. 128).

Brunswick (p. 76).

Crotch Island: Sherwood lower quarry (p, 105).

Waldoboro (p. 140).

Norridgewock: Emmons Taylor quạrry (p. 152).

12. Very coarse (gray or pinkish buff) :

Stonington: Spruce Island (p. 107).

Dedham: Brown (p. 90).

Franklin: Bradbury quarry (p. 95).

13. Paving (fine, with isolated crystals) :

Vinalhaven: Fequoit quarry (p. 135); Duschane Hill quarry (p. 135).

Mount Desert: Hall Quarry, Allen (Snowflake) quarry (p. 99). 
14. Black (fine to coarse) :

Black and black speckled-

Vinalhaven: Bodwell (p. 136).

Addison : Fleasint River (p. 159) ; Thornberg. (p. 160).

Calais: Mingo Bailey \& Co. (p. 163).

Greenish black-

Belfist: Heal quarry (p. 157).

South Berwick: Spence \& Coombs (p. 176).

Fermon: Fermon Hill (p. 147).

Dark gray-

Sullivan: Pettee (p. 114).

Baileyville: Meddybemps Lake, Hall's quarry (p. 161).

Redbeach : Beaver Lake quarry (p. 163).

Calais: Gardner (p. 162).

St. George: McConchie quarry (p. 126).

Round Pond quarry (dark) (p. 139).

Medium gray-

Round Pond quarry (light) (p. 139).

Whitefield: Jewett quarry (p. 143).

\section{DISTRIBUTION OF GRANITE QUARRIES IN MAINE.}

The map (Pl. I) shows the location of the principal quarries and groups of quarries and prospects, which include 133 separate openings, and also the relation of these to the rock areas which are described in the introductory chapter. Of these openings 92 are quarries operated in 1905: A number of unimportant paving block and underpinning quarries have been overlooked or. intentionally omitted.

Quarries of granite proper.-With the exception of the important quarries at Hallowell in Kennebec, North Jay in Franklin, and the minor ones at Fryeburg and Bryant Pond in Oxford County, Pownal in Cumberland County, Norridgewock in Somerset County, Oak Hill and Lincolnville in Waldo County, and Dedham in Hancock County, all the granite quarries of Maine are along the seaboard, either on islands or on bays or navigable rivers, or within 4 miles of them. The inland quarries are all on railioads or within a short distance of them. The distance to rail from a few quarries is 3 miles, from one 5 miles, but as the product of these quarries is used entirely for monumental work the cartage is a matter of less moment. The Maine granite industry may be said to have its center in Penobscot and Blue Hill bays and the islands about them. A. line drawn from Clark Island, south of Rockland, north-northeast to Frankfort, and thence about east to Franklin, in Hancock County, thence south through Bar Harbor, and thence around the islands in a southwesterly course back to Clark Island, would embrace an area of about 1,200 square miles, which would include the bulk of the granite industry. 
Quarries of black granite.-There are 12 quarries of black granite, although a few obscure ones may have been overlooked. Their location is shown by a separate symbol on the map. They are in York, Lincoln, Waldo, Penobscot, and Washington counties. Of these only the Addison (in Washington County), Vinalhaven (in Knox), and Round Pond quarries (in Lincoln) are at tidewater, but as these granites are used only in small quantities for expensive work the cost of transportation is a minor consideration.

\section{DESCRIPTION OF THE QUARRIES AND THEIR PRODUCT.}

The quarries will be here described in detail by counties. The particulars in regard to each quarry come under the following heads, which will be taken up in the order given:

1. Name and location of quarry; name and office address of operator.

2. The granite-its name, color, texture, minerals, chemical composition, and physical qualities as shown by any tests. The number of the specimen collected in the preparation of this report precedes the description in each case. The words "coarse," "medium," and "fine" as applied to texture are to be understood as defined on page 20.

3. The quarry: Date of its opening, size, drainage, stripping.

4. Rock structure and rock variations under the one head "Rock. structure," comprising general features, sheets, joints, headings, rift and grain, dikes, veins, knots, sap, etc.

5: The plant, with enumeration of all machines and pneumatic tools.

6. Transportation, including distance from dock or railroad, and method of transport.

7. Product, its uses and market, and the names of specimen buildings or monuments and contracts undertaken in 1905.

The counties will be taken up in alphabetic order: Cumberland, Franklin, Hancock, Kennebec, Knox, Lincoln, Oxford, Penobscot, Piscataquis, Somerset, Waldo, Washington, and York, and the towns in each county will be taken up in like order.

\section{CUMBERLAND COUNTY.}

The Granite quarries in Cumberland County are in the towns of Brunswick, Freeport, Pownal, and Westbrook.

The Grant quarry is in the town of Brunswick, 3 miles west of Brunswick village, on the south side of the Maine Central Railroad, on the Merriman farm. This quarry was not in operation in 1905 .

The granite (specimen 110,a) is a biotite granite of medium-gray shade and fine, even-grained texture, in which the particles of quartz 
measure up to about $0.4 \mathrm{inch}$, those of feldspar and mica up to 0.15 inch. Its minerals, in descending order of abundance, are potash feldspar (both microcline and orthoclase), quartz, a feldspar with both lime and soda (oligoclase-albite), and biotite, with rarely a scale of muscovite. The orthoclase has inclusions of quartz, circular in cross section, and the second feldspar is greatly altered. The rock contains accessory zircon.

The quarry opening measures about 75 by 50 by 5 feet in depth.

Rock structure: The sheets range from 2 to 12 inches in thickness and dip not higher than $5^{\circ}$. The joints are shown in figure 4 . A marked flow structure is indicated by alternating light and dark bands, due to varying amounts of black mica and also by the parallelism of the longer axes of the larger feldspar crystals and biotite plates. The granite is traversed by a pegmatite dike, 2 to 3 inches

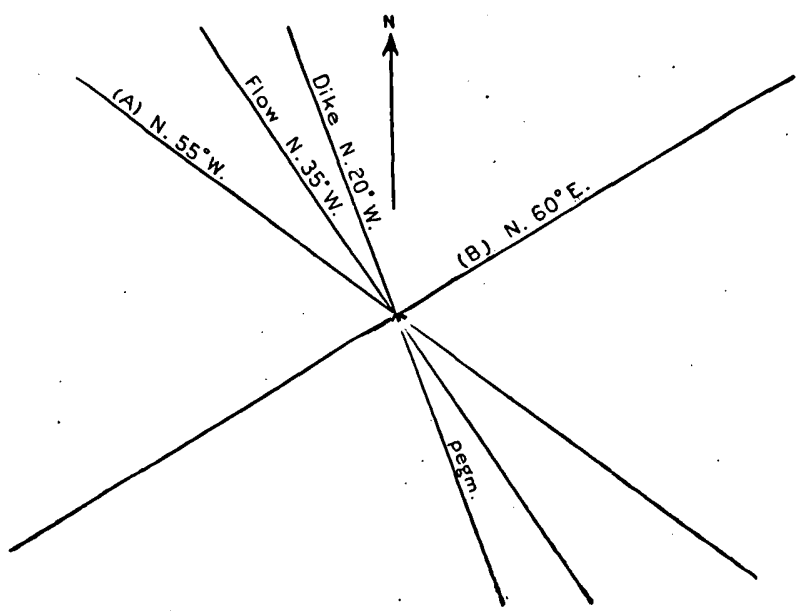

FIG. 4.-Structure at Giant quarry, Brunswick.

thick, with a course N. $20^{\circ}$ W. The upper sheet shows considerable discoloration.

Plant, none. Transportation by team to railroad near by.

Product: The chapel of Bowdoin College, at Brunswick, was built of the same granite, but the stone was taken from another opening, near this one, which is referred to by George P. Merrill as also furnishing the stone for the First Parish Church, in Portland. ${ }^{a}$

The Freeport quarry is one-half mile southeast of Freeport station, on the Maine Central, on the eastern side of a hillock 80 feet high, with northeast-southwest axis. The Freeport Granite Company is. now in the hands of a receiver, Wilford G. Chapman, 396 Congress street, Portland, Me.

The granite (specimen 127, $a$ ) is a biotite-muscovite granite of a 
medium-gray shade with a slight bluish tinge and very fine, evengrained texture, with particles ranging from 0.36 to 1.28 and, exceptionally, from 0.18 to $2.5 \mathrm{~mm}$. in diameter. Its minerals, in descending order of abundance, are potash feldspar (microcline, orthoclase), smoky quartz, soda-lime feldspar (oligoclase), black mica; and white mica. The soda-lime feldspar is considerably altered to kaolin and a white mica and both feldspars often have intergrowths of quartz circular in cross section. The rock contains accessory apatite. It takes a fine polish. The specific gravity was reported by F. L. Bartlett, of the Maine State assay office, as 2.627. ${ }^{a}$ It is free from pyrite.

The quarry, first opened in 1886, now measures about 600 feet from northeast to southwest by 100 feet across, and has a working face 55 feet high. It is not below the general surface at the road

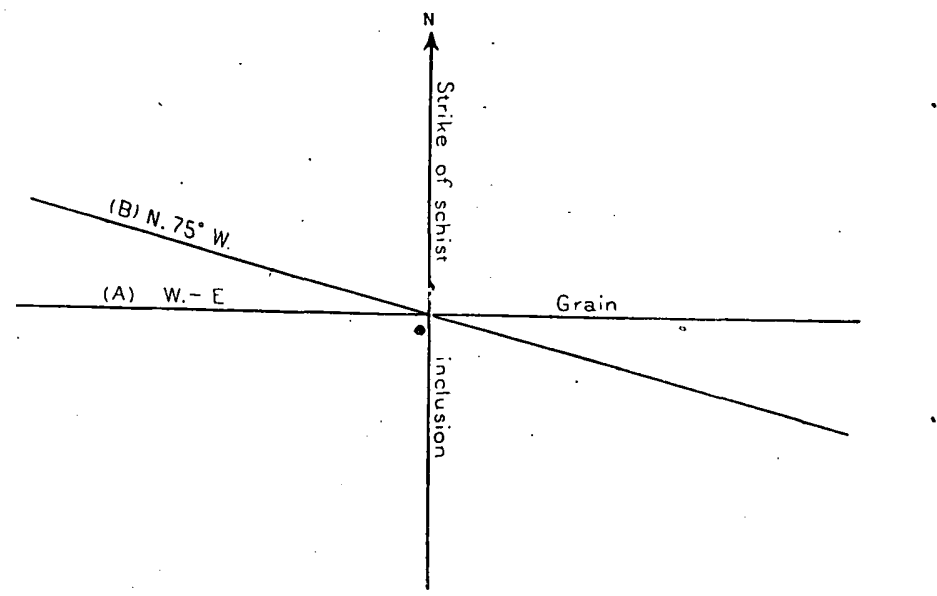

FIG. 5.-Structure at freeport quarry, Brunswick.

that passes in front of it. The drainage offers no difficulites. 'The stripping consists of 2 to 5 feet of loam and sand.

Rock structure: The granite at the northeast end of the quarry is capped by about 5 feet of schist, and in its center the excavation, in proceeding in a direction parallel to the axis of the hill, has bisected an inclusion of this same schist 3 feet thick and about 40 feet long, dipping $35^{\circ}$ E. to a point 30 feet below the surface of the granite. This schist inclusion is described on page 51. (See also Pl. VII, B.) About 150 feet southeast of it is another inclusion of similar material. The presence of these inclusions necessarily involves some dead work and waste. The sheets are from 1 to 8 feet thick, increasing in thickness downward, and dipping up to $10^{\circ} \mathrm{SE}$. and $10^{\circ} \mathrm{NW}$. Joint courses are given in fig. 5. A forms the northeast wall of quarry and recurs every 20 to 50 feet; $\mathrm{B}$, at southwest end of

a See Twentieth Ann. Rept. U. S. Geol. Survey, pt. 6, continued, 1898-9, p. 389. 
quarry, recurs at distances of 3 to 30 feet. The rift is horizontal and the grain is vertical, extending east-west. There are a few knots, up to 12 inches across, of muscovite, quartz, and feldspar. There is no sap.

The plant consists of 3 derricks; 1 hoisting engine, and 3 polishers.

Transportation is by cartage, one-half mile to railroad or three. fourths mile to dock. In 1905 the quarry was idle.

The fine texture of the stone makes it particularly well adapted for monuments. It has found its way chiefly into Massachusetts and the West. Among the monuments made of it are the Humboldt monument in Chicago and the Scott monument in Pittsburg, Pa. The front of the Maine building at the Chicago World's Fair, afterwards removed to Poland Springs, Maine, and the polished tanks at Poland Springs also came from this quarry.

The Pownal Granite Company's quarry is in the southern corner of the town of Pownal, $2 \frac{1}{2}$ miles north-northeast of Yarmouth junction on the Maine Central and Grand Trunk railroads. Operator, Pownal Granite Company, No. 1 Madison avenue, New York.

The granite (specimen 123,a) is a biotite granite of light-gray shade and very fine, even-grained texture, most of the particles ranging from 0.25 to $0.75 \mathrm{~mm}$. in diameter. It consists, in descending order of abundance, of very slightly smoky quartz, potash feldspar (microcline), soda-lime feldspar (oligoclase), and black mica with accessory zircon, apatite, and magnetite. The oligoclase is much altered to a white mica and the microcline has intergrowths of quartz, circular in cross section. The polish is inferior to that of the Freeport stone.

The quarry, opened in 1880 , measures 300 by 200 feet, and averages. 3 feet in depth. There are from 2 to 3 feet of clay and soil stripping.

Rock structure: Flow structure at one point results in a lamination dipping $10^{\circ}$ east, with thin black streaks of matted biotite scales. The sheets measure from 4 inches to 4 feet 8 inches in thickness and dip $10^{\circ}-15^{\circ}$ SE. in broad undulations. They have been tested with core drills to a depth of 60 feet and the lowest sheets found to be 6 feet thick. Vertical joints, striking N. 50 $0^{\circ}$ E., recur every 30 or 35 feet. The rift is horizontal and the grain is vertical, extending east-west. A 12-inch basic dike crosses the northwest half of the quarry with a course N. $50^{\circ}$ E. A 1-inch pegmatite dike, with ferruginous staining, strikes N. $80^{\circ}$ E. and dips $20^{\circ} \mathrm{SE}$. Another, 4 inches thick, occurs at the west end of the quarry, dipping $10^{\circ} \mathrm{W}$. There are neither knots nor rust stains nor sap.

The plant consists of 4 derricks, 2 engines, 2 steam drills, 1 steam pump, 1 compressor with a capacity of 80 cubic feet of air per minute, 4 pneumatic hand tools, 1 surfacer. The cutting plant is in New York. 
Transportation is effected by cartage of $2 \frac{1}{2}$ miles to dock or railroad.

Product: Monuments and superior class of buildings. Market: New York. Specimen monuments and buildings: Baker mausoleum at Woodlawn Cemetery, New York; hotel at corner of Seventieth street and Central Park, and Van Norten Trust Building, corner of Sixtieth street and Fifth avenue, New York. Contracts in 1905: The French monument, Calvary Cemetery, and a building at corner of Eighty-first street and Ninth avenue, New York.

Pride's quarry is in the town of Westbrook, $3 \frac{1}{2}$ miles northeast of Westbrook (Saccarappa) and one-fourth of a mile north of Prides Corners. Operator, James H. Pride; address, R. F. D., Woodford, $\mathrm{Me}$.

The granite (specimen $140, a$ ) is a biotite granite of medium-gray color with conspicuous black mica and fine even-grained texture (particles measuring up to one-tenth of an inch across) consisting, in descending order of abundance, of potash feldspar (microcline and orthoclase), smoky quartz, a little soda-lime feldspar (oligoclase), and biotite with accessory apatite. The biotite scales are generally parallel. This stone does not fit into any of the groups described on pages 73,74 .

The quarry, opened in 1898 , is 200 by 100 feet, and averages about 6 feet in depth.

Rock structure, etc.: There is a marked flow structure, dipping in places $30^{\circ}$ eastward, which gives the granite the appearance of a gneiss. The sheets are from 6 inches to 2 feet 6 inches thick, and dip up to $5^{\circ}$. A heading on the east side strikes N. $10^{\circ}$ E., and dips $55^{\circ} \mathrm{W}$. The rift is horizontal and grain vertical, trending east to west. A 12-inch thick basic dike, striking N. $50^{\circ}$ E., forms the west side of quarry. Sap from 1 to 3 inches wide in upper sheets, but none 5 feet down.

The plant consists of 3 derricks, 1 engine, and 1 polisher.

Transportation: The nearest railroad is at Westbrook, $3 \frac{1}{2}$ miles away. Product: Curbing and bases of monuments. Market: Local; Westbrook and Portland.

FRANKLIN COUNTY.

The granite quarries in Franklin County are in the town of Jay.

The Maine and New Hampshire Granite Corporation quarries are at North Jay. The company's office is in the Baxter Building, Congress street, Portland, Me.

The granite (specimen $118, a$ ) is a biotite-muscovite granite of very light gray shade ("white granite"), and fine, even-grained texture, in which the particles range from 0.36 to $3 \mathrm{~mm}$. in diameter, and consist of the following minerals, arranged in descending order 
of abundance: Potash feldspar (microcline and orthoclase), clear quartz, soda-lime feldspar (oligoclase), black mica (biotite), and white mica (muscovite), together with accessory garnet, magnetite, and apatite. The general whiteness of this rock is due to the quartz not being smoky as in most granites, and also to the whiteness of the feldspars, which is thus visible through the quartz. The feldspars are mostly unaltered. The following chemical analysis. of this granite, made by E. T. Rogers, was reported by Prof. John E. Wolff, of Cambridge, Mass., in $1892:^{a}$

\section{Analysis of aranite from quarry at North Jay.}

$\mathrm{SiO}_{2}($ silici $)$

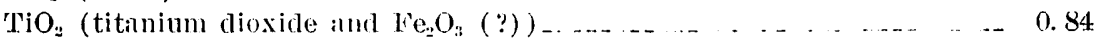

$\mathrm{Al}_{2} \mathrm{O}_{3}$ (aluminia) _... 14.24

$\mathrm{Fe}_{2} \mathrm{O}_{3}$ (ferric oxide) ... . . . . . . . . . .

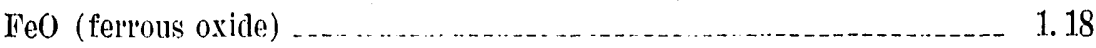

CaO (lime) -

MgO (magnesia) _..... 0.34

$\mathrm{Na}_{2} \mathrm{O}$ (soda) - 3.39

$\mathrm{K}_{2} \mathrm{O}$ (potash)

$\mathrm{H}_{2} \mathrm{O}$ (water, at red heat)

$\mathrm{S}$ (sulphur) -

$\mathrm{CO}_{3}$ (carbon dioxide)

98.59

The same analyst finds the specific gravity 2.639. A test of the compressive strength of this granite, made for the company at the Watertown Arsenal in 1892, shows that the cube cracked at 15,720 pounds per square inch and was destroyed at 16,310 pounds per square inch. An earlier test of the same granite with somewhat different results was made at that arsenal on May 6,1882. ${ }^{\circ}$ It does not take a very good polish, owing to the abundance of mica and the large size of its plates. The North Jay granite was also described by M. E. Wadsworth in $1878 .^{\circ}$

The quarry, opened in 1872, consists of three openings, known by the name of "Upper," "Lower," and "Bowlder." The upper quarry measures about 425 feet from north to south by 200 feet from east to west and has an average depth of 20 feet. The lower one, adjacent to it on the west, measures 500 feet from north to south and 350 feet from east to west, with an average depth of about 35 feet. These openings are on the west side of a north-south ridge. The bowlder quarry, a little north of the other two, is about 150 feet square and 20 feet deep. The upper and lower quarries are separated by a mass

a See Nineteenth Ann. Rept. U. S. Geol. Survey, pt. 6, continued, 1898, pp. 218, 219.

- Eighteenth Ann. Rept. U. S. Geol. Survey, pt. 5, continued, p. 961.

- Proc. Boston Soc. Nat. Hist., vol. 19, pp. 237-238. 3495-Bull. $313-07-6$ 
10 feet thick, consisting of two large aplite dikes that have a northsouth course. The drainage is natural. There are from 6 inches to 3 feet of loam on the granite surface, but in places it is bare.

Rock structure: In the center of the lower quarry there is a lamination in folds 20 feet broad and 3 feet high, occasioned by the parallelism and abundance of biotite plates along certain planes. Some of these planes show evidence of friction along them. There is also a north-south vertical structure associated with the dikes of aplite between the two quarries. The sheets range from 4 inches to 6 feet in

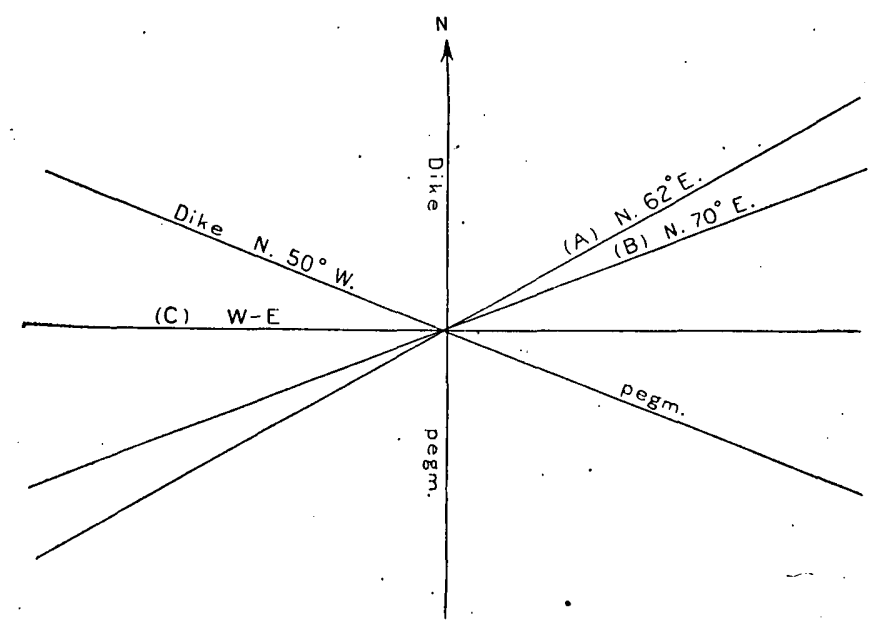

Fig. 6.-Structure at Maine and New Hampshire Ganite Company's quarry at North Jay.

thickness. In the upper 25 feet the sheets are thin, but below that they become gradually thicker. In cross section they feather out alternately, or "toe in," as described on page 35 . At the top of the hill and at the east side of the upper quarry they are horizontal, but on the west side they curve over westward, dipping $5^{\circ}-10^{\circ}$, and possibly a little more in the lower quarry, governing the slope of the hill. At the north side of the lower quarry is a heading striking N. $50^{\circ}-60^{\circ} \mathrm{E}$., dipping $60^{\circ}$ and also $90^{\circ}$. The courses of the various joint systems and dikes are shown in fig. 6 . Of joints $B$ there are four discontinuous ones in a space of 50 feet in the upper quarry. The rift is horizontal and there is no grain. The pegmatite dikes consist of milk-white potash (microcline) and soda-lime (oligoclase) feldspar, smoky quartz, biotite, and muscovite, and measure up tó 2 feet 6 inches. Knots are exceptional and measure up to 12 inches across. Heading $\mathbf{A}$ is covered with limonite from oxidation of pyrite. Ferruginous discoloration (sap) is noticeably absent from the sheets.

The plant consists of 8 power and 2 hand derricks, 8 engines, 2 locomotive cranes, 1 compressor (capacity, 762 cubic feet per minute), 4 steam or air drills, 8 pneumatic plug drills, 2 surfacers, 14 
pneumatic hand tools, 3 steam pumps, and 2 steam crushers- 1 of 200 tons capacity a day, the other of 75 tons.

Transportation is had by gravity track to the Maine Central Railroad, 1,300 feet distant and 300 feet down. This company has devised an ingenious mode of adapting an ordinary platform freight car to the transportation of thin granite blocks 12 feet square.

The product is used for monuments and buildings, and the chief market is the West. Specimen monuments and buildings: General Grant's tomb, Riverside drive, New York; Richard Smith soldiers' and sailors' memorial gateway at Fairmount Park, Philadelphia; entrance to Union Mutual Life Insurance Company's building at Portland, Me.; the Hahnemann monument, in Washington, D. C. the Chicago and Northwestern Railway building, in Chicago; the Western German Bank, Cincinnati, Ohio, and the Union County court-house, at Elizabeth, N. J.

Rough stone, paving blocks, and crushed stone are important byproducts.

Contracts in 1905: The Westmoreland County (Greenbush) courthouse, Pennsylvania, and an addition to the Marshall Field store in Chicago.

T'he American Stone Company's quarry is at North Jay, on the east side of the same hill on which the quarry above described is located. Address, Pierce V. C. Miller, secretary American Stone Company, 49 Wall street, New York.

The granite is identical with that of the Maine and New Hampshire Granite Corporation's quarry. (Specimen 118,a.)

The quarry measures about 300 feet from north to south by 200 feet east to west and is of varying depth. A little occasional pumping is necessary for drainage. Stripping, up to 8 feet of till.

Rock structure: An undulating flow structure like that in the previously described quarry, but with a northerly pitch of $10^{\circ}$ to $4.0^{\circ}$, occurs in the northern part of quarry. The sheets are from 6 inches to 3 feet thick and dip $5^{\circ}-10^{\circ} \mathrm{E}$. Vertical joints strike N. $65^{\circ}-70^{\circ} \mathrm{E}$.; also $\mathrm{N}$. $75^{\circ}-80^{\circ} \mathrm{W}$. The latter form a discontinuous heading in middle of quarry: Coarse pegmatite dikes up to 2 feet thick have courses of N. $60^{\circ} \mathrm{E}$., north to south, and N. $20^{\circ} \mathrm{E}$.

The plant consists of 3 derricks and 3 engines, 4 steam drills, 2 pumps, and 1 gas engine for same.

Transportation is effected by gravity to railroad seven-eighths mile distant.

This quarry produced the stone for all but the basement of Senator W. A. Clark's residence on Seventy-seventh street and Fifth avenue, New York. It is now idle, but not abandoned. 
HANCOCK COUN'TY.

The granite quarries in Hancock County are in the towns of Bluehill, Brooksville, Dedham, Franklin, Long Island, Mount Desert, Sedgwick, Stonington, Sullivan, Swans Island, and Tremont.

The White quarry, in the town of Bluehill, $1 \frac{1}{4}$ miles east of Bluehill village. Operator, The White Granite Company, West avenue and Newton Creek, Long Island, N. Y.

The granite (specimen $36, a$ ) is a biotite granite of medium-gray, slightly bluish color and of coarse (on the medium side) even-grained texture. The feldspars measure as high as one-half inch, and some of them a little over. The rock consists, in descending order of abundance, of potash feldspar (microcline and orthoclase), smoky quartz, soda-lime feldspar (oligoclase), and black mica (biotite),

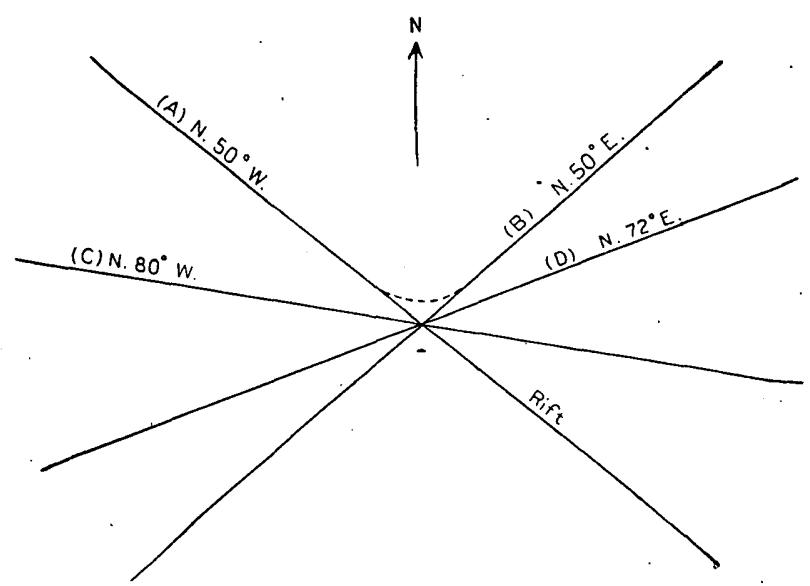

Fig. 7.-Structure at White quarry, Bluebill. The rectangular joint is shown by the dotted line.

together with accessory zircon and magnetite. The feldspar is slightly bluish. The contrast in shade between the polished and rough surface is marked, but the mica plates are sufficiently large and numerous to prevent a perfect polish. Although the texture of this stone is coarsish, it is sufficiently fine to be well adapted for fluted columns and capitals. A test of its compressive strength made at the United States Arsenal at Watertown (test No. 9087, 1893) gave an ultimate strength of 29,420 pounds per square inch, the pressure being applied at right angles to the rift. A similar test made by the engineering department of the School of Mines of Columbia University, in New York, gave an ultimate strength of 29,681 pounds.

The quarry, opened about 1855 , measures 300 by 350 feet and from 15 to 45 feet in depth. The drainage that is not required for the boilers is effected by a channel to the harbor. There is no stripping. 
Rock structure: The striking geological feature is the rectangular curved joint described on page 39) and shown in Pl. VI, $B$. The sheets are from 3 to 10 feet thick and dip from $10^{\circ}$ to $15^{\circ} \mathrm{W}$. and SW. The joint courses are shown in fig. 7. Joints A recur every 100 feet and form a heading at right of curved joint, as shown in Pl. VI, $B$. The rift is vertical, with a course N. $50^{\circ} \mathrm{W}$, not very pronounced. There are small dikes and thick lenticular knots of very fine grained bluish-gray aplite. Dark-gray knots measure up to 10 by 4 inches. Sap is confined to the upper sheets, and does not exceed 2 inches in width. There are no rust stains.

The plant consists of 3 polishing machines, hoisting engines, 3 derricks, and 1 steam drill.

Transportation is effected by team to docks, one-third mile off.

The product is used for buildings and monuments, and the waste goes. into paving blocks. The chief market is New York. Specimen buildings: Woman's Hospital, in New York; Mercantile*'Trust Company's and Caledonia Insurance Company's buildings, in St. Louis. Contracts in 1905: Part of extension to House of Representatives; part of District of Columbia municipal building; First Day ${ }^{*}$ and Night Bank, New York; Delamar and Brokaw residences, New York; chemical laboratory of Pratt Institute, Brooklyn, N. Y.; chemical laboratory of Stevens Institute of Technology, at Hobolien, N. J., and a fountain with a large monolithic bowl for Deep River, Conn.

The Bluehill Granite Company's quarries are $1 \frac{1}{2}$ to 2 miles east of Bluehill village. The company is no longer in existence. The property is now owned by L. D. Willcutt \& Son, 166 Devonshire street, Boston, but the quarries are not operated.

The granite is identical with that of the White quarry.

The quarries consist of three openings, one south of the White quarry, near the harbor; another south-southeast of that quarry, about 150 feet square and from 10 to 30 feet deep, and the third about one-half mile east of White quarry and 100 feet above it. This opening, known as the "doorstone quarry," is about 200 feet square and from 5 to 10 feet deep.

Rock structure: At the second opening the sheets are from 1 to 10 feet thick and undulate horizontally. At the third they are thinner, but have the same attitude. At the second opening a granite dike (described on p. 46) 18 inches thick strikes N. $55^{\circ}$ E. and dips $80^{\circ}$ NW. A joint and a heading strike N. $80^{\circ}$ E. and dip $90^{\circ}$. At the third opening a vertical heading strikes $\mathrm{N} .40^{\circ} \mathrm{E}$. and a vertical joint strikes N. $70^{\circ} \mathrm{W}$.

The product: The Eastport, Me., post-office and part of the Pittsburg, Pa., post-office and the Washington, D. C., Loan and Trust Company's building, corner of $F$ and Ninth streets, are of granite 
from the first two of these quarries. The product of the third was used only for doorsills, "platforms," and paving blocks.

The Chase granite quarry is in the town of Bluehill, 3 miles east of Bluehill Village, and north of Woods Point. Operator, Chase Quarries Company, 11 Broadway, New York. The quarries are not in operation at present.

The granite (specimen $38, a$ ) is a biotite granite of medium to light-gray shade and coarse, even-grained texture, the feldspars measuring up to 0.8 inches in length. It consists, in descending order of abundance, of potash feldspar (microcline and orthoclase), smoky quartz, soda-lime feldspar (oligoclase), and black mica (biotite), with accessory magnetite. The feldspars are milky white with a slight bluish tinge. The contrasts between the feldspar, quartz, and biotite are marked, more so than in the White quarry stone, becanse the feldspar is whiter, the quartz more smoky, and the biotite a trifle coarser. The following chemical analysis of this granite, made in 1896 by Ricketts and Banks, of New York, is inserted here merely for reference :

Analysis of granite from Chase granite anary, near Bluehill, Me.

$\mathrm{SiO}_{2}$ (silica)

FeO (ferrous oxide)

$\mathrm{Al}_{2} \mathrm{O}_{3}$. (alumina ) _

MnO (manganous oxide)

$\mathrm{CaO}$ (lime)

$\mathrm{MgO}$ (magnesia) _....... Trace.

$\mathrm{K}_{2} \mathrm{O}$ (potash)

$\mathrm{Na}_{2} \mathrm{O}$ (soda)

S (sulphur) _...

Loss and undetermined

The same firm also made a test of this granite (test No. 16606, 1899) which showed that it has an ultimate compressive strength of 23,400 pounds per square inch.

The quarry, opened in 1872 , consists of several openings on the top and eastern slope of a hill rising 220 feet above the sea in a distance of three-fourths mile. Drainage is effected by occasional use of siphon and pump.

Rock structure: The sheets are up to 8 feet thick and either lie horizontal or dip at a low angle. Vertical joints strike N. $50^{\circ} \mathrm{W}$. and N. $40^{\circ} \mathrm{E}$. The rift is vertical, with a north strike. There are some small dikes of aplite and dark-gray knots. Sap occurs in the upper sheets to a thickness of several inches. In one of the openings the stone has occasional light rust spots half an inch in diameter, which are due to the oxidation of some ferruginous mineral in very minute particles.

The plant consists of 9 derricks and 5 hoisting engines, 1 cable 
engine, 1 locomotive crane, 1 compressor, 4 steam drills, 3 pneumatic plug drills, 2 surfacers, and 2 pumps.

Transportation is effected by a cable road 1,400 feet long from the main quarry to the cutting shed and by locomotive and track, 650 feet more, from shed to dock.

The product is used for buildings. Specimen buildings made of this granite are the New York Stock Exchange, Lying-in Hospital, Manhattan Trust Building, and Grand Union Hotel, Forty-second street, New York, the General Thomas monument, and the trimmings to the Bureau of Engraving and Printing, Washington, D. C.; the League Island dry dock, and the post-office at Harrisburg, Pa. Paving blocks are a by-product.

The Chase Quarries (monumental granite) are in the town of Bluehill. About 350 feet east of the upper opening of the Chase quarries is an area not less than 200 feet square, of a medium bluish-gray fine-textured, porphyritic biotite-muscovite granite (specimen $39, a$ ). The particles range in general size from 0.07 to $1.1 \mathrm{~mm}$. in diameter, a veraging about $0.37 \mathrm{~mm}$. The isolated feldspars measure up to onefourth inch across. The minerals, arranged in descending order of abundance, are potash feldspar (orthoclase and microcline), smoky quartz, soda-lime feldspar (oligoclase), black mica (biotite), and white mica (muscovite), with accessory magnetite. The feldspars are bluish gray. They have considerable intergrown quartz and the rock is generally harder.than the adjacent granite, which it probably traverses as a large dike. It has been quarried occasionally by the company for local monumental use.

The Collins Granite Company's quarry, in the town of Bluehill, three-fourth mile east of East Bluehill, has not been operated since 1888 or 1889.

The granite (specimen $40, a$ ) is a biotite granite of medium-gray shade and porphyritic texture, with feldspar crystals up to one-half inch in length, in a fine-textured matrix in which many particles measure down to 0.05 to $0.25 \mathrm{~mm}$. The minerals, in descending order of abundance, are potash feldspar (microcline and orthoclase), smoky quartz, soda-lime feldspar (oligoclase), generally altered to kaolin and a white mica, and black mica (biotite), with a very little muscovite.

The quarry is 150 by 60 feet and from 15 to 30 feet deep.

Rock structure: The sheets lie flat and are up to 10 feet thick. The joints strike N. $5^{\circ}$ E. and N. $60^{\circ}$ W., with steep or vertical dip. The first set is spaced 20 feet and the other forms a heading.

Transportation: The stone was carted two-fifths mile to the cutting buildings and dock.

Part of the Pittsburg, Pa., post-office was built of material from this quarry. 
The Howard quarry is in the town of Bluehill, 1 mile southeast of top of Bluehill and $1 \frac{1}{4}$ miles northeast of Bluehill village. Owner, William M. Howard, Bluehill.

The granite is a biotite granite like that of the White quarry.

The quarry is about 50 feet square and from 5 to 15 feet deep.

The sheets, 8 feet thick, dip $40^{\circ} \mathrm{N}$. The rift is vertical with a strike of N. $10^{\circ} \mathrm{W}$. Sap is 3 inches thick on each side of sheets.

The plant consists of one hand derrick. The stone is carted onehalf mile, where it is cut and polished. The product is used locally for monuments.

Some of the stone of the gate house to High Bridge, in New York, came from this quarry, and also several soldiers' monuments.

The Bucks Harbor quarries, Bucks Harbor, South Brooksville, are operated by the Bucks Harbor Granite Company.

The granite (specimen $46, a)$ from opening one-half mile southeast of South Brooksville, is a biotite granite of light grayish-buff color with conspicuous black mica, and is of coarse (inclining to medium) even-grained texture. It consists, in descending order of abundance, of a light cream-colored potash feldspar (microcline and - orthoclase), smoky quartz, a milk-white soda-lime feldspar (oligoclase), and black mica (biotite) with accessory magnetite. The oligoclcase is partially altered to kaolin and a white mica. A little pyrite was found at the quarry.

The granite (specimen 47,a) from opening one-fourth mile northeast of South Brooksville, is of medium-gray shade, with conspicuous black mica and coarse, even-grained texture, and consists, in descending order of abundance, of a very light gray potash feldspar (microcline and orthoclase), slightly smoky quartz, a little sodalime feldspar (oligoclase), and black mica (biotite). Both of these granites are bright from the contrasts of their minerals.

The quarries consist chiefly of two openings-one formerly operated by the Wilson Granite Company, and lying one-half mile southeast of the village, measuring 200 feet by 100 feet, and from 5 to 20 feet in depth; the other, one-fourth mile northeast of the village, is about 200 by 100 feet, and from 5 to 10 feet deep.

Rock structure: The sheets at these quarries are from 2 to 8 feet thick and are either horizontal or $\operatorname{dip} 10^{\circ}-15^{\circ} \mathrm{W}$. Joints at the first opening strike N. $40^{\circ} \mathrm{W}$, dip $75^{\circ} \mathrm{S}$. W., and recur at intervals of 15 feet or more; also N. $50^{\circ}$ E., dipping $75^{\circ} \mathrm{S} .50^{\circ} \mathrm{W}$. to $90^{\circ}$. The rift is vertical, striking N. $30^{\circ}$ E. The sap is confined to the uppermost sheets.

The plant consists of 3 derricks and 1 hoisting engine.

Transportation: The company owns two granite wharves, which afford 12 feet of water at low tide. 
The product of these quarries is adapted to building purposes. In 1905 , pending a reorganization of the company or an enlargement of its capital, the quarries had not yet resumed operations.

The Westcott quarry is at Bucks Harbor, in the town of Brooksville, about three-fourths mile southeast of South Brooksville village. Owners, Maine Coast Granite Company, South Brooksville. The granite of this quarry is said to be like that of the more eastern quarry of the Bucks Harbor Granite Company, which is very near: it, and to have been used for pillars in the bridge over the Mississippi at St. Louis.

T'he Maine Lake Ice Company's quarry lies 500 feet north of the company's dock. It is 'operated by Foster and Sargent, of Sargentville, for paving blocks, but is now idle.

The granite (specimen $43, a$ ) is a biotite granite of medium to light gray shade and coarse even-grained texture, with slightly bluish milk-white feldspars up to an inch in length. It consists of these minerals, in descending order of abundance: A potash feldspar (microcline and orthoclase), rather dark smoky quartz, sodalime feldspar (oligoclase), black mica (biotite), and accessory zircon. The oligoclase is considerably altered to a white mica. The contrasts in this granite are more marked than in that of specimen $47, a$ (p. 88), for the quartz is darker. It was found to be hard in working.

The quarry measures about 200 by 30 feet and 10 feet in depth. The sheets are up to 5 feet thick and lie flat or dip $10^{\circ} \mathrm{N}$. Vertical joints with headings strike N. $67^{\circ} \mathrm{E}$. and N. $67^{\circ} \mathrm{W}$. The rift is vertical, and its course is $\mathrm{N} .60^{\circ} \mathrm{W}$.

There is a track 500 feet long to the dock.

Herrick's quarries, in the town of Brooksville, consisting of several small openings, about one-third mile northwest of "Herrick" post-office, worked by E. H. Herrick for paving blocks, curbing and rough stone, give employment to three men. The stone (specimen $44, a)$ is a biotite granite of medium-gray color and medium evengrained texture.

Sargent's quarry, in the town of Brooksville, is a small opening, less than one-fourth mile northeast of Herrick's, belonging to Henry W. Sargent, but not worked in 1905 . The stone is a gray evengrained coarse-textured granite, resembling that of the Maine Lake Ice Company's quarry. In contact with it is also one of slightly finer texture, but with poor contrasts (specimen $45, a$ ).

The Brown quarry is in the town of Dedham, $1 \frac{1}{2}$ miles east of Holden station (East Holden post-office) on the Maine Central Railroad, on the northeast side of a hill reaching an altitude of 840 feet above sea level and having a northwest and southeast axis: Operator, David Brown, East Holden. 
The granite (specimen 108, a) is a biotite granite of dark-gray matrix with light-grayish feldspars and of very coarse porphyritic texture, with some evidence of distortion and crushing of its feldspars. These measure up to $1 \frac{1}{2}$ inches in diameter and the black mica up to three-tenths inch. The feldspars are generally twinned and often of oval or roundish outline. The rock consists, in descending order of abundance, of potash feldspar (orthoclase and microcline) smoky quartz, soda-lime feldspar (oligoclase) and black mica (biotite), together with accessory zircon, apatite, and secondary magnetite and chlorite. The quartz contains needles of rutile (?). The orthoclase crystals contain zonally arranged quartz grains and biotite scales and are sometimes thinly rimmed with oligoclase or intergrown with it. Many small grains of quartz in the matrix indicate crushing. The oligoclase is partially altered to kaolin and a white mica. The rock takes a fine polish, but the durability of the

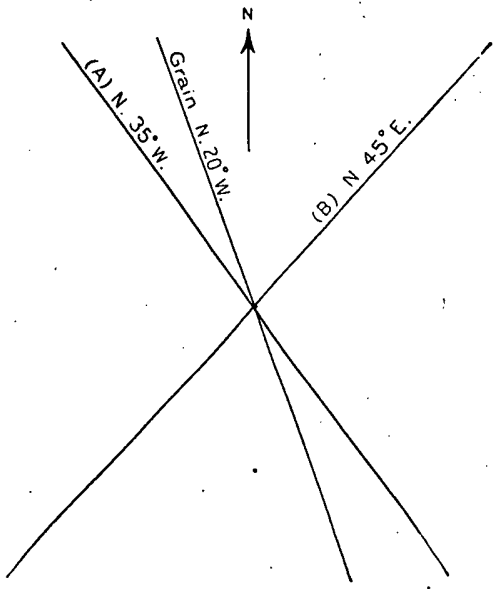

Fig. 8.-Structure at Brown quarry, Dedham. polish under outdoor exposure is doubtful, owing to the large size of the mica scales.

The quarry, opened in 1892 , is 200 feet north - northwest to south-southeast by 20 feet across and from 4 to 9 feet deep. The stripping consists of drift up to 6 feet thick, but in places there is none.

Rock structure: The sheets, from 2 to 6 feet thick, dip $15^{\circ}$ SSE. Joint courses are given in fig. 8. A recur at intervals of 100 to 200 feet; B at intervals of 75 feet or more. The rift is horizontal. Aplite dikes, from 1 to 4 inches thick, cross the grain at high angle. No knots are in sight. Sap, from 1 to 2 inches thick, is confined to the topmost sheet.

The plant consists of 5 derricks, worked by horses and oxen, and 1 engine.

Transportation is had by cartage $1 \frac{1}{2}$ miles to Holden station, where the cutting shed is.

The product is used for bridge work. Contract in 1905: Maine Central Railroad bridge and station improvements at Bangor.

The Robertson \& Havey quarry in the town of Franklin, owned and operated by Robertson \& Havey; address, North Sullivan.

The granite (specimen $71, a$ ) is a biotite granite of medium-gray shade and of coarse (inclining to medium), even-grained texture, with whitish feldspars up to one-half inch in diameter, consisting, 
in descending order of abundance, of potash feldspar (orthoclase and microcline), slightly smoky quartz, soda-lime feldspar (oligoclase), and black mici (biotite), with accessory magnetite and pyrite. The slight contrast between the shade of the quart: and that of the feldspar and the small size of the biotite scales produce a general lack of brilliancy in the rock.

The quarry, opened in 1892, measures 300 feet from north to south by 300 feet from east to west, and from 5 to 15 feet in depth. It is drained by two siphons ( $2 \frac{1}{2}$ and $3 \frac{1}{2}$ inch pipes) 800 and 1,000 feet long. The stripping consists of 3 to 4 feet of loam and bowlders.

Rock structure: The sheets, from 2 to 8 feet thick, are horizontal, but on the west side dip $10^{\circ} \mathrm{W}$. The courses of joints and dikes are given in fig. 9. Joints A recur at irregular intervals. The rift is

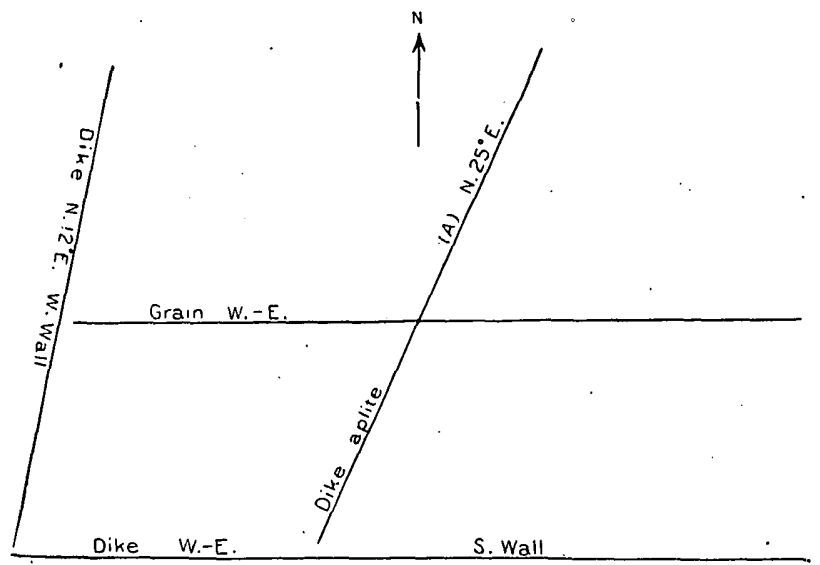

Fia. 9.-Structure at Robertson \& Havey quarry, Franklin.

horizontal and the grain is vertical, striking east-west. Aplite dikes measure from 2 to 8 inches in width, and the granite for about a foot on each side of them is close jointed. Knots are rather abundant and up to 2 feet across. The north-south joint face carries some pyrite. Sap measures from 2 to 3 inches in width along the sheets. No rust spots were detected. A 1-foot diabase dike, with its rim altered to epidote, forms the west wall of quarry, and a $2 \frac{1}{2}$ to 3 foot dike forms the south wall. For a space of 10 feet on each side of this dike the shade of the granite has been changed to a dark gray, and the rock is filled with close joints that dip at low angles: The microscope fails to reveal the nature of this change, but shows that the quartz particles and some of the feldspars are crossed by more or less parallel cracks, from $0.25 \mathrm{~mm}$. to $1.25 \mathrm{~mm}$. apart.

The plant consists of only one derrick and the siphon pipe.

Transportation is effected by cartage $1 \frac{3}{4}$ miles to dock in bay.

The product is used for curbing, both straight and circular, and 
for paving blocks and "random" stone. The principal markets are Boston, New York, and Philadelphia.

The Bragdon, Fernald, \& Gordon quarry is in the town of Franklin. The firm's address is Franklin.

The granite is a biotite granite of medium-gray shade and medium, even-grained texture like that of the Crabtree \& Havey quarry (specimen 69,a) in Sullivan (p. 110). Molybdenite was found in it.

The quarry measures 300 feet from north to south by 150 feet from east to west and from 10 to 20 feet in depth, and is drained by a 3 -inch siphon pipe 600 feet long.

Rock structure: The sheets, from 2 to 6 feet thick, dip $10^{\circ}$ to $15^{\circ} \mathrm{W}$. Joint and dike courses are shown in fig. 10. Joint A recurs 1.50

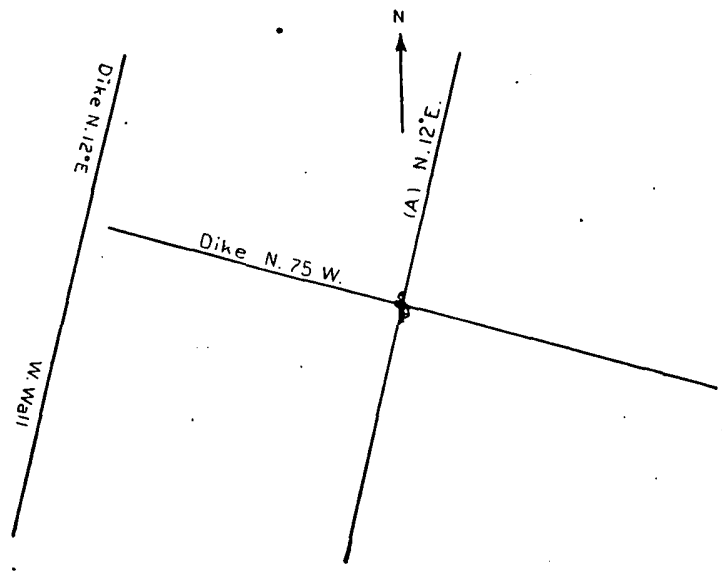

FIG. j0.-Structure at Bragdon, Fernald, \& Gordon quarry. Franklin.

feet away. The north-south dike is 6 inches thick and tapers out. The other is up to 12 inches thick. Knots measure up to 12 inches across.

The plant consists of 3 derricks, worked by horses, and of 600 feet of siphon pipe.

Transportation is effected by cartage of 2 miles to wharf.

The product is used for curbing (both straight and circular), paving blocks, and "random" stone. The markets are Philadelphia, New York, and Boston.

The Alonzo Abbott quarry is in the town of Franklin. Address, Alonzo Abbott, Hancock, Me.

The granite is a biotite granite of medium-gray shade and coarse (inclining to medium), even-grained texture, identical with that of specimen $71 ; a$, Robertson \& Havey (p. 90).

The quarry, opened about 1885, measures 200 feet from east to west by 150 feet from north to south and from 2 to 8 feet in depth, and is drained by siphoning. The stripping consists of 3 feet of loam and bowlders. 
Rock structure: Sheets from 2 to 8 feet thick dip both east and west at $5^{\circ}-10^{\circ}$. Vertical joints with a N. $25^{\circ}$ E. course recur at irregular intervals. The rift is horizontal.

The plant consists of 2 derricks, worked by horses, and a siphon pipe.

Transportation is effected by cartage of a mile to wharf.

*. The product consists of curbing, flagging, paving, and random, and goes to Boston, New York, and Philadelphia.

The T. M. Blaisdell quarry is in East Franklin, 1 mile above the head of navigation. Address, T. M. Blaisdell, East Franklin.

The granite (specimen $76, a$ ) is of a darkish medium-gray shade and medium even-grained texture, with feldspars up to one-fourth inch in length, and consists, in descending order of abundance, of

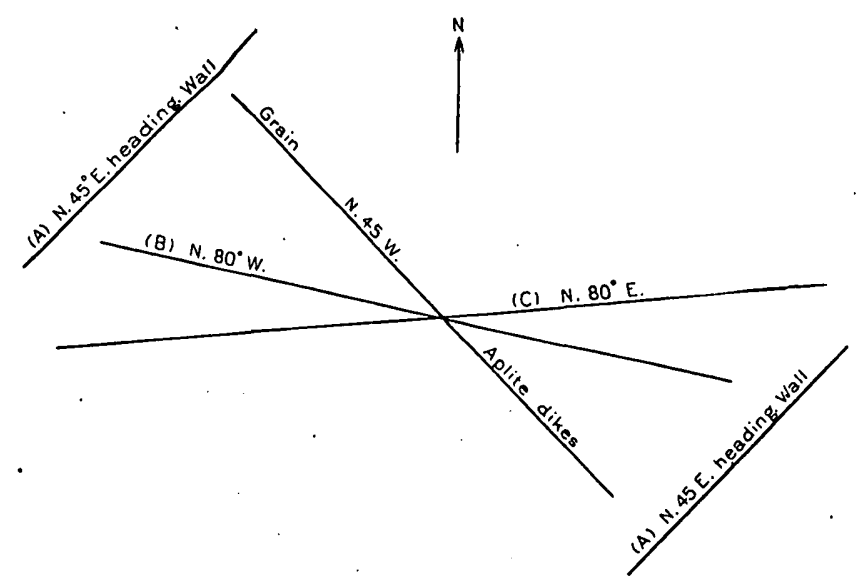

FrG. 11.-Structure at T. M. Blalsdell quarry, East Franklin.

potash feldspar (microcline and orthoclase), slightly smoky quartz, lime-soda feldspar (oligoclase to oligoclase-albite), black mica (biotite), together with accessory magnetite and zircon. The effect of the slightly bluish gray color of the feldspar and the light smokiness of the quartz is to prevent any contrast of shade between these two minerals and also to darken the general color of the stone.

The quarry, opened about 1875 , measures 200 by 300 feet and is of varying depth. The working face on the north is 53 feet high. Neither drainage nor stripping is required.

Rock structure: The sheets, from 2 to 13 feet thick, dip $10^{\circ} \mathrm{NE}$. Owing to compressive strain, on the removal of load in quarrying, the bottom sheet rises half an inch from the underlying one. The joint courses are shown in fig. 11. A forms a heading on the northwest and southeast sides. C dips in places $45^{\circ} \mathrm{N}$. The rift is horizontal and grain vertical, trending northwest-southeast. Several parallel dikes of aplite up to 2 inches thick dip southwest at a 
low angle. In one 5-foot mass there are five of these. Sap is confined to the upper sheets. Black knots measure up to 8 inches across.

The plant consists of 4 derricks, worked by horses or men.

Transportation is effected by carting a few hundred feet and loading on a lighter, which is propelled by poles a mile to a wharf where the blocks are laden onto schooners by means of a derrick. It is proposed, however, soon to propel the lighter by an engine, by which also the stone will be hoisted onto the schooners.

The product is used for curbing, paving, bridges, docks, and "random," and finds market in Boston, Philadelphia, New York, and Washington.

The W. B. Blaisdell \& Company quarry is in the town of Franklin, on the southeast side of Sullivan River. Address, Franklin, Me.

The granite (specimen $78, b$ ) is a biotite granite of medium-gray

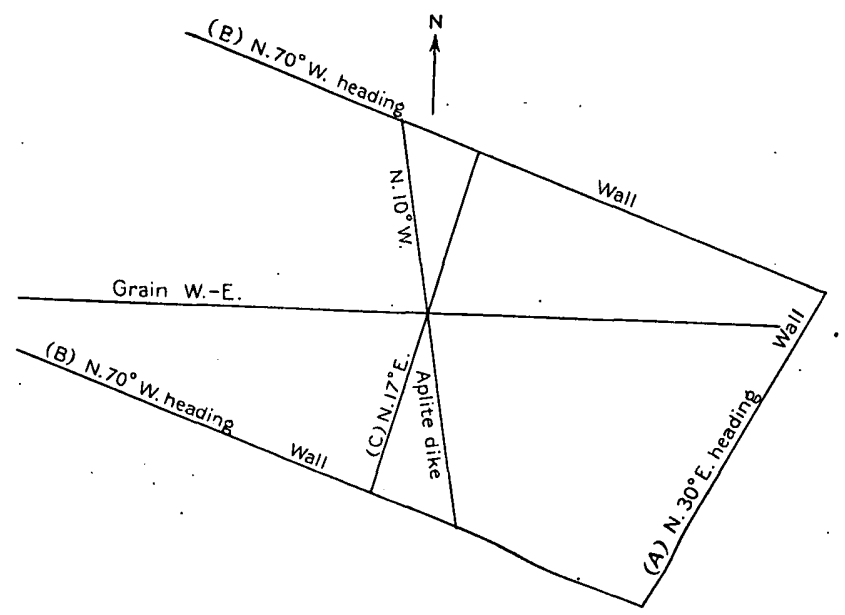

Fig. 12.-Structure at W. B. Blaisdell quarry, Last Franklin.

shade and medium (inclining to coarse) even-grained texture, consisting, in descending order of abundance, of potash feldspar (microcline and orthoclase), smoky quartz, soda-lime feldspar (oligoclase), and black mica (biotite), together with accessory magnetite, zircon, apatite, and secondary epidote and chlorite. The oligoclase is partially altered to a white mica. The feldspars are grayish, and are therefore of almost the same shade as the quartz, which deprives the rock of marked contrasts. It is a little lighter than specimen $76, a$, of the T. M. Blaisdell quarry, and is said to be a little softer. Mr. E. C. Sullivan has tested the granite $(78, b)$ with warm dilute acetic acid at the chemical laboratory of the United States Geological Survey and finds that it contains 0.15 per cent of $\mathrm{CaO}$ (lime), much $\mathrm{MgO}$ (magnesia), and 0.104 per cent of $\mathrm{CO}_{2}$ (carbon dioxide). 
If all the $\mathrm{CO}_{2}$ were allotted to $\mathrm{CaO}$ it would give 0.24 per cent of $\mathrm{CaCO}_{3}$ (lime carbonate) as the cöntent in the granite.

The quarry, opened about 1875 , measures 300 by 250 feet, and from 15 to 35 feet in depth. It is drained by siphoning. The stripping consists of 3 feet of clay and bowlders.

Rock structure: The sheets are from 6 to 7 feet thick and generally dip northwest at low angles. There is some "toeing in," owing to the overlapping of lenses. Joint and vein courses are given in fig. 12. A forms a heading on the east side of quarry; $\mathbb{B}$ is on the north and south sides and is coated with lime carbonate (calcite), as described on page 4.1. The heading on the south has four joints 3 feet apart. $\mathrm{C}$ is coated with pyrite, and hence is called by workmen the "iron seam." The rift is horizontal and grain vertical east-west. The sap measures from 1 to 3 inches in thickness. There are some knots up to 6 inches across.

The plant consists of 2 derricks and siphon pipes.

Transportation is effected by "lifters" drawn by horses 1,000 feet to schooners at dock.

The product is used for curbing (both straight and circular) and paving in Boston, Philadelphia, and New York.

F. Bradbury \& Ś Sons quarry is in West Franklin, near north end of Grape Pond; address, West Franklin.

The granite (specimen 77, a) is a biotite granite of dark-grayish, slightly purplish color, of very coarse, somewhat porphyritic texture, with feldspars up to an inch in diameter and black mica plates up to one-tenth inch. It consists, in descending order of abundance, of a grayish-purplish potash feldspar (orthoclase and microcline), smoky quartz, yellowish-white soda-lime feldspar (basic oligoclase), and black mica (biotite), together with accessory magnetite, apatite, zircon, and secondary chlorite. Many of the grayish-purplish potash feldspars are rimmed with the yellowish oligoclase, and are also intergrown microscopically with a plagioclase feldspar and with quartz. This granite is very striking in the contrasts of its minerals. Its quartz and feldspars take a high polish, but the large biotite scales are not favorable to the durability of the polish under outdoor exposure.

The quarry is triangular in area, each side of the triangle measuring about 75 feet, and its depth reaches in places 15 feet, which is the height of the working face.

Rock structure: The sheets are 10 feet thick and about horizontal. Joints striking $\mathrm{N} .70^{\circ} \mathrm{W}$. and dipping high east recur at intervals of 5 feet or more. There are a few knots.

The plant consists of 2 derricks.

Transportation is effected by cartage to railroad about 900 feet away. 
The product has been thus far used for culverts and similar structures on the Maine Central and Washington County railroads.

The Black Island quarries are in the northeastern part of Black Island, which lies south of Mount Desert, in the town of Long Island. Operators, Black Island Granite Company, J. E. Dutton, president, 42 East Twenty-third street, New York.

The quarries, opened in 1892, consist of two openings. The upper one, about one-fourth mile south of dock at northeastern corner of island, measures 500 by 300 feet and from 10 to 40 feet in depth, and the lower one, known as the "Redcliff," a little south of the dock, is about 100 feet square. There is no drainage to contend with.

The granites taken from these two openings differ. Specimen 31, a, from the upper quarry, is a biotite granite of pale pinkish-gray color and medium (inclining to coarse) even-grained texture, consisting, in descending order of abundance, of potash feldspar (microcline and orthoclase), smoky quartz, soda-lime feldspar (oligoclase), and very little black mica (biotite), together with accessory titanite and magnetite. Both feldspars are light pink. The potash feldspar is sometimes rimmed with oligoclase. The latter is often partially altered to kaolin and a white mica. The rock presents but faint contrasts of color and, owing to the small quantity of its mica, must needs take a very fine polish.

The granite (specimen 39, a) of the Redcliff quarry is a biotite granite of grayish-pink color and medium (inclining to coarse) evengrained texture, consisting, in descending order of abundance, of potash feldspar (microcline and orthoclase), smoky quartz, soda-lime feldspar (oligoclase), and very little black mica (biotite), together with accessory titanite, magnetite, and zircon. Both feldspars are pinkish. The oligoclase is largely altered to kaolin and a white mica. Its small content of mica must make this granite susceptible of high polish.

Rock structure: At the upper quarry the sheets, from 8 inches to 5 feet thick, are horizontal, with minor undulations. Vertical joints strike N. $70^{\circ}$ W., recurring at intervals of 100,200 , and 250 feet. The rift is parallel to these, but feeble. Sap, 3 inches thick, is confined entirely to the upper sheets. At the Redcliff quarry the sheets, up to 6 feet in thickness, bend over from the horizontal to $25^{\circ} \mathrm{N}$. and NE. Vertical joints, striking N. $77^{\circ}$. E., recur at intervals of 50 feet. Another set, striking N. $35^{\circ}$ E., abounds at the sides of the quarry, but is scarce in center. Joints of this strike are numerous along the north shore of the island. The rift is vertical, with a $\mathrm{N}$. $77^{\circ} \mathrm{E}$. course.

The plant consists of 3 derricks, 2 engines, and 3 steam drills at the upper quarry; 1 derrick at the wharf; 2 derricks and engine and polisher run by the same at the lower quarry. 
Transportation is effected by a track and cable one-fourth mile long from upper quarry to the wharf and a short one from the lower: quarry.

The product of the upper quarry is used for buildings, and its thin sheets are used for paving. That of the Redcliff quarry is used particularly for monuments and columns. The markets are Boston, New London, New York, and Baltimore. A contract for the Park Building, in Brooklyn, N. Y., was being executed in 1905.

The McMrullen quarry is in the town of Mount Desert, southeast of village of "Hall Quarry," and four-fifths of a mile north of Robinson Mountains. Operators, Arthur McMullen \& Co., Paịk Row building, New York. (In hands of a receiver in August, 1905.)

The granite (specimen $55, a a)$ is a biotite granite of general lightgrayish buff color and coarse (inclining to medium), even-grained texture, consisting, in descending order of abundance, of buff-colored potash feldspar (orthoclase intergrown with plagioclase), smoky quartz, milk-white soda-lime feldspar (oligoclase); and black mica (biotite), together with accessory apatite and a little secondary calcite within the oligoclase. The contrasts resulting from the different shades and colors of the four minerals are attractive and must come out still more strongly on the polished surface. Mr. E. C. Sullivan has examined this granite at the chemical laboratory of the United States Geological Survey and finds that it contains 0.014 per cent of $\mathrm{CO}_{2}$ (carbon dioxide) and that warm dilute acetic acid dissolves traces of $\mathrm{CaO}$ (lime) and $\mathrm{MgO}$ (magnesia). This percentage of $\mathrm{CO}_{\text {., }}$, if all allotted to $\mathrm{CaO}$, would imply the presence of 0.03 per cent of $\mathrm{CaCO}_{3}$ (lime carbonate). The microscope also shows the presence of a carbonate in very minute quantity.

The quarry, opened in about 1880 , measures 250 feet from north to south by 250 from east to west and attains a depth of 50 feet at the - west side. A little pumping is necessary at times to drain it. The stripping consists of $3 \frac{1}{2}$ feet of drift and bowlders.

Rock structure: The sheets are from 2 to 12 feet thick and dip from $5^{\circ}$ to $10^{\circ}$ north to south and east. They are faulted along some of the $\mathrm{N} .25^{\circ} \mathrm{W}$. joints, resulting in a toeing in of the sheets, which necessitates quarrying from west to east-that is, toward the hade of the faults, as shown in fig. 13. The courses of the joints are shown in the same figure. A forms a heading on the west, dipping $80^{\circ}$ W.; B, dipping $65^{\circ} \mathrm{S}$., forms a heading on the north and recurs at middle of quarry; C, dipping $75^{\circ}$ to $80^{\circ} \mathrm{NW}$., forms a heading on the south and recurs at irregular intervals. The rift is horizontal and the grain strikes about east-west. Sap along some of the sheets is 3 inches thick and exceptionally 18 inches. The granite along joints $\mathrm{A}$ and $\mathrm{B}$ for the space of a foot is bright reddish. (See p. 52.) The faces are 3495-Bull. $313-07-7$ 
greenish, probably from presence of chlorite and epidote. Dark-gray knots measure up to 6 inches in diameter.

The plant consists of 12 derricks, 12 hoisting engines, 1 hanging electric crane (capacity 15 tons), 1 locomotive; 2 compressors (capacity 750 and 1,400 cubic feet per minute), 5 steam drills, 25 pneumatic plug drills, 18 surfacers, and 36 pneumatic hand tools.

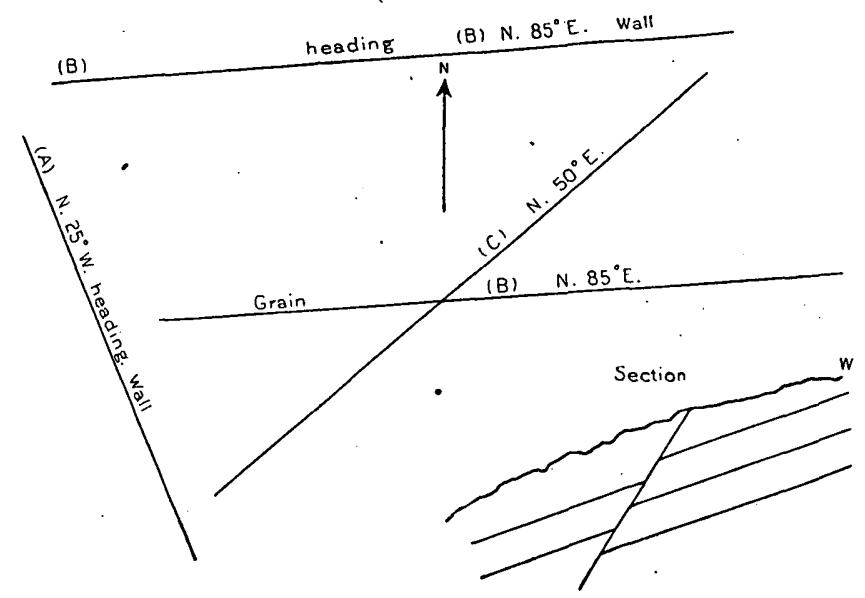

FIG. 13.-Structure at McMullen quarry, Mount Desert Island. The section shows the " toeing in" of sheets, probably by faulting along the joints.

Transportation is effected by track to wharf, 800 feet off, which is accessible to schooners of 20 feet draft.

The product is used for construction in New York and Washington. Specimen buildings made of this granite are the United States mint in Philadelphia, the basement of the New York custom-house, and the new bridge over the Potomac at Washington. Contracts in 1905: Brooklyn anchorage to Manhattan Bridge.

The Campbell \& Macomber quarry is in the town of Mount Desert, one-half mile north of top of Robinson mountain, at its foot, and two-fifths of a mile south of "Hall Quarry" village. Office address, Hall Quarry, Me.

The granite (specimen 56, a), known commercially as "Somes Sound Pink," is a biotite granite of light pinkish-gray color and medium, inclining to coarse, even-grained texture, consisting, in descending order of abundance, of a delicate pink potash feldspar (orthoclase, with very little microcline), smoky quartz, milk-white soda-lime feldspar (oligoclase), and black mica (biotite), together with accessory magnetite, zircon, and apatite. It takes a fine polish, This stone differs from the McMullen quarry stone in the tint of its orthoclase.

The quarry, opened in about 1880, measures 150 by 200 feet by 20 
feet in depth. Drainage is effected by siphoning and pumping in spring and fall. No stripping.

Ročk structure: The sheets, from 2 to 6 feet thick, dip $10^{\circ}$ to $15^{\circ}$ E., and exceptionally are thinner at the bottom than the top of quarry. Joint and dike courses are shown in fig. 14. All are vertical. B forms a heading at the south side, $\mathrm{C}$ one at the north. The rift is horizontal and grain N. $75^{\circ}$ E. A diabase dike, $2 \frac{1}{2}$ feet wide, tapering toward the north, occurs at the west side of quarry. This is described on page 48. There are a few knots, but sap does not occur.

The plant consists of 5 derricks, 1 hoisting engine, 125 -horsepower compressor, 2 pneumatic plug drills, 1 surfacer, 12 pneumatic hand tools, and 1 pump.

Transportation is effected by cartage of 1,600 feet to wharf on Somes Sound.

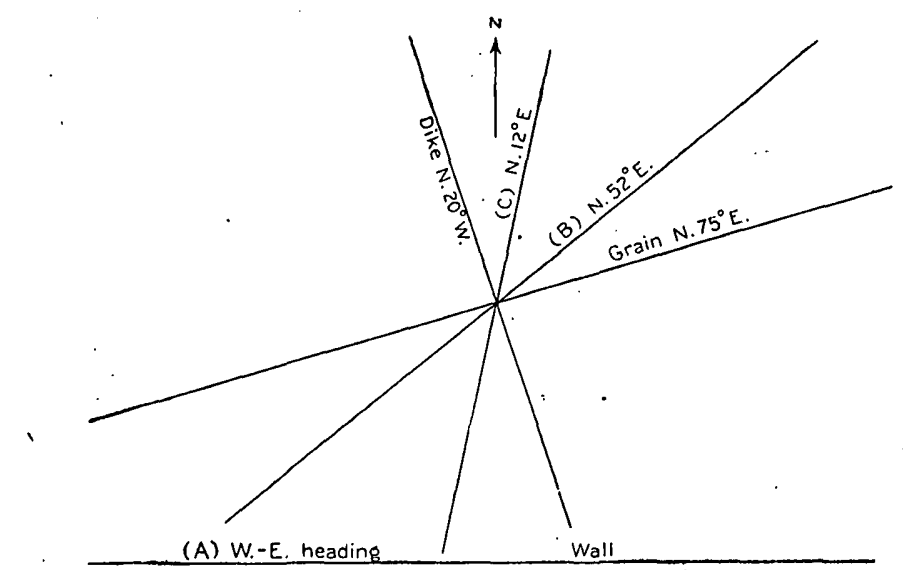

Fra. 14.-Structure at Campbell \& Macomber's quarry, Mount Desert Island.

.The product is used for buildings, chiefly in New York. Specimen buildirgs: The Crocker residence at Darlington, N. J.; the Danforth Library at Paterson, N. J.; the First National Bank at Baltimore, Md. Contract in 1905: The Phœnix National Bank at Hartford, Conn.

The Snowflake quarry, on Mount Desert, about one-fourth mile northwest of Hall Quarry village, is operated by the Allen Granite Company. Address, M. L. Allen, Mount Desert, Me.

The granite (specimen $58, a$ ) is a biotite granite of medium-gray shade and fine texture, with porphyritic pinkish feldspars up to 0.4 inches in diameter. It consists, in descending order of abundance, of pinkish potash feldspar (orthoclase), smoky quartz, white translucent soda-line feldspar (oligoclase), and black mica (biotite), together with accessory magnetite. The orthoclase is intergrown with a plagioclasé. 
The quarry is about 200 feet square and from 5 to 10 feet deep.

Rock structure: The sheets, from 6 inches to 3 feet thick, are horizontal. Joints forming a heading on east side strike N. $20^{\circ} \mathrm{W}$ : and $\operatorname{dip} 75^{\circ} \mathrm{W}$. A diabase dike, 6 to 10 inches thick; with course N. $20^{\circ}$ $W$., traverses the entire quarry.

The product is confined to paving blocks, which are carted about one-half mile to the wharf.

The Allen quarry belongs to the same concern as the "Snowflake," and lies one-fourth mile east of it. It is no longer worked. The granite closely resembles that of the "Snowflake." The sheets are from 6 inches to 3 feet thick. Pl. VIII, $B$, shows the sheets crossed by a diabase dike, which has a N. $15^{\circ} \mathrm{W}$. course, and is faulted in two directions. (See p. 47.) There are geodes of pink feldspar, quartz, and epidote in the granite.

The Babbadge quarry, on Mount Desert, about one-third mile southwest of Hall Quarry village, is operated by Seth Babbadge; address, Hall Quarry post-office. The granite is a coarse-grained biotite granite. The quarry is 50 by 50 feet and from 5 to 10 feet deep. The sheets, which are up to 6 feet thick, lie horizontal. A diabase dike on the east side strikes N. $20^{\circ} \mathrm{W}$. There is one derrick. The product is sold to the McMullen Company.

The Richardson Brothers quarry, on Mount Desert, lies nearly onehalf mile southwest of Hall Quarry village; address, Hall Quarry post-office. The rock is a coarse biotite granite. The quarry is 100 feet square and 5-10 feet deep. The sheets are spaced from 1 to 6 feet. There is one derrick. The product is also sold to the McMullen Company.

The Fernald Brothers and Higgins quarry is on Mount Desert, one-fourth mile north of Sound, on the east side of Somes Sound; address, Mount Desert post-office.

The granite is a coarse biotite granite resembling that of the McMullen quarry. There are several small openings, first worked in 1888. The one worked in 1905 is 50 feet square and a few feet in depth. There is one derrick. The sheets are up to 6 feet thick. The product is all used for paving and is carted about one-fourth mile to wharf.

The Graves Brothers quarry is on Mount Desert, in the northern part of village of Northeast Harbor; address, Northeast Harbor. This quarry is worked only occasionally, for underpinning. It is mentioned here on account of the exceptional character of the stone among Maine granites, which (specimen $64, a$ ) is a hornblende granite of general dark-gray color and medium even-grained texture, consisting, in descending order of abundance, of greenish-gray and pinkish potash feldspar (orthoclase and microcline), with inter- 
grown soda-lime feldspar '(oligoclase-andesine,, smoky quartz, and dark-green hornblende, together with accessory magnetite, apatite, and secondary chlorite. The feldspar is largely altered to a white mica. A similar granite occurs also $1 \frac{1}{2}$ miles west-northwest of it, at the Carroll quarry, in the town of Tremont, at the south foot of Dog Mountain. (See p. 116.)

The quarry measures 100 by 50 feet and 10 feet in depth at the deepest point. The sheets are up to 6 feet thick and dip $5^{\circ}-10^{\circ} \mathrm{W}$. There is much discoloration.

The Sedgwick quarries consist of 6 small openings in the town of Sedgwick, about three-fourths mile northwest of Sedgwick village, operated by the W. G. Sargent Company, of Sargentville.

The granite (specimen $42, a$ ) is a biotite granite of coarse to medium even-grained texture, like that of one of the Bucks Harbor quarries (specimen 46, a, p. 88), consisting of light cream-colored feldspars, smoky quartz, and black mica, all in marked contrast. The feldspars measure up to three-fourths inch in length and the biotite plates one-tenth inch.

The rift is vertical, with a strike of N. $22^{\circ} \mathrm{W}$. The plant consists of 2 hand derricks. The product, consisting entirely of paving blocks, is carted $1 \frac{1}{4}$ miles to the wharf at Sedgwick.

The Stonington quarries.-The granite industry which centers in Stonington is distributed over an area of about 4 miles square. (See map, fig. 15.) Some of the quarries are on Deer Isle, others are south of it, on Crotch Island, so named from the inlet which divides it, and the rest are on neighboring islets. Of the latter, however, only those on Moose, Green, and Spruce islands were in operation in 1905 .

The southern half of Crotch Island, which measures about 1,500 feet from north to south, shows sheet structure very clearly. (See PI. II, B.) The sheets slope off to the northwest and the southeast at angles of $10^{\circ}, 15^{\circ}, 20^{\circ}$, and $25^{\circ}$ from its central part (140 feet above sea level), where they are horizontal. The east-west vertical joints are conspicuous from a distance. The Goss quarry has cut into the center of the arch and also on either side of it, while the Ryan-Parker quarry (PI. III, A), on the south, is on the southeast slope of the sheets and of the hill. In the northern half of Crotch Island, at the lower quarry of the Sherwood Company, the coarse granites are in contact with a fine-textured one, which is also exploited. The contact line is vertical, but the sheets traverse both granites indifferently. The Stonington quarries, as will be seen from the descriptions, embrace several varieties of granite.

The Ryan-Parker quarry is on Crotch Island, in its southeastern part, at Thurlow Head. (See Pl. II, B, and fig. 15.) Operators, 
Ryan-Parker Construction Company, Park Row building, 13-21 Park Row, New York.

The granite (specimen 20, $b$ ) is a biotite granite of lavender, medium-gray color and coarse, even-grained texture, consisting, in descending order of abundance, of very light lavender-colored potash feldspar (orthoclase and microcline), smoky quartz, milk-white sodalime feldspar (oligoclase), and a little mica (biotite), rarely a plate

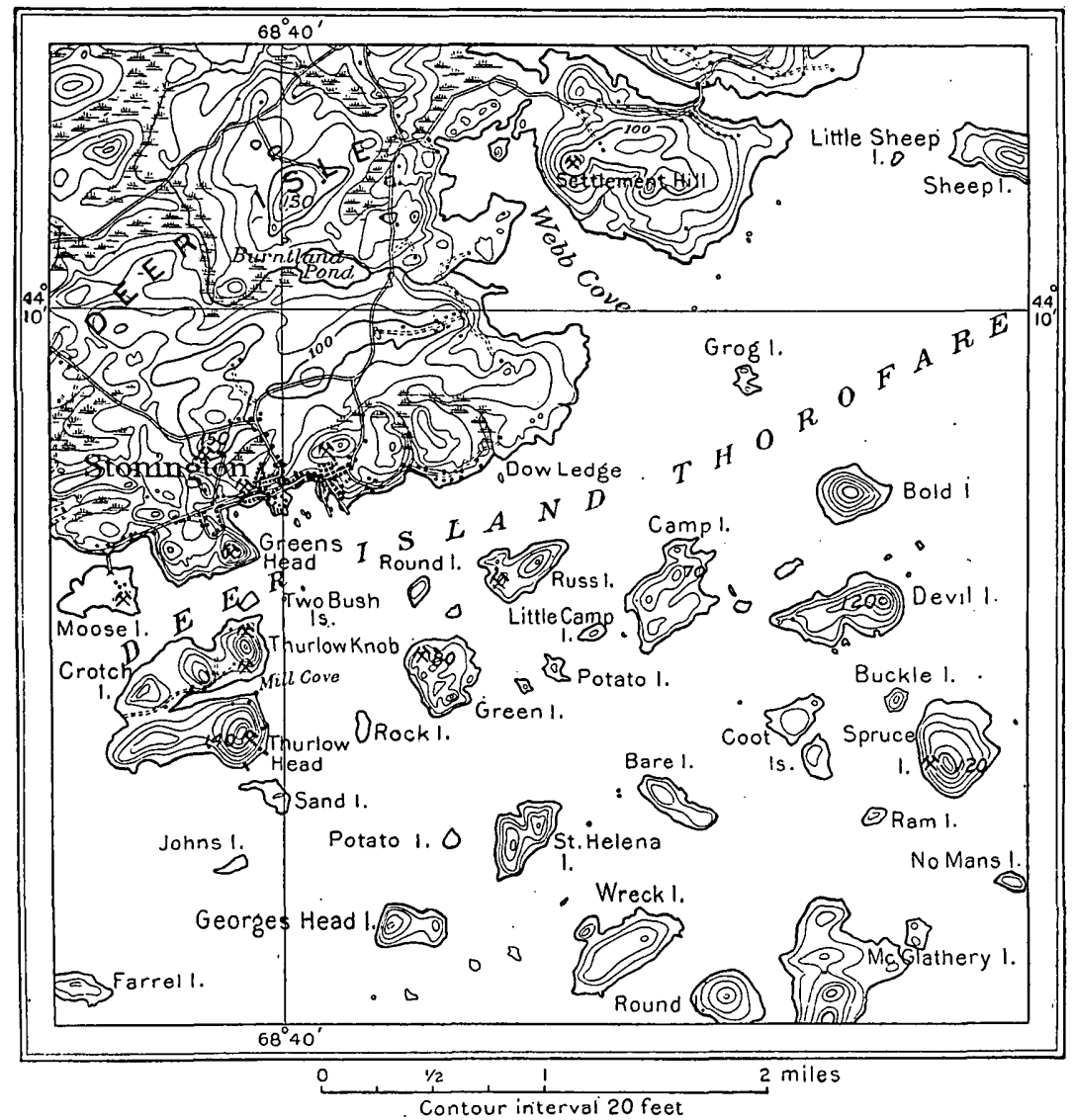

Fig. 15.-Maip showing location of quarries about Stonington, Me. (Reduced from Deer Isle Sheet, Topographic Atlas U. S., U. S. Geol. Survey.)

of muscovite, together with accessory magnetite, titanite, zircon, and pyrite, partially altered to limonite. The potash feldspars measure up to 1 inch and many of them are twinned and intergrown with a plagioclase. The biotite plates do not exceed 0.1 inch across. The oligoclase is generally much altered to a white mica and kaolin.

Mr. E. C. Sullivan, of the United States Geological Survey, determined the presence in this granite of 0.044 per cent of $\mathrm{CO}_{2}$ (carbon dioxide) and of 0.08 per cent of $\mathrm{CaO}$ (lime) and a little $\mathrm{MgO}$ (mag- 
nesia) extractable with dilute acetic acid. . To allot all the $\mathrm{CO}_{2}$ to the $\mathrm{CaO}$ would give 0.10 per cent of lime carbonate in the granite.

The quarry, opened about 1880 , measures about 700 by 300 feet, and from 20 to 75 feet in depth, averaging about 35 feet. (See Pl. II, A.) The drainage from its upper half flows seaward, but that from its lower half must be pumped after heavy rains. Water for steam purposes was brought in a "water boat" a mile from Stonington at an expense of $\$ 110$ per month, but a well that was being bored in the granite near the shore was expected to yield a supply sufficient to save this large expenditure. Little or no stripping has been required.

Rock structure: The sheets vary in thickness downward, and dip from $20^{\circ}$ to $25^{\circ}$. SE. Joint courses are shown in fig. 16. A dips $80^{\circ}$

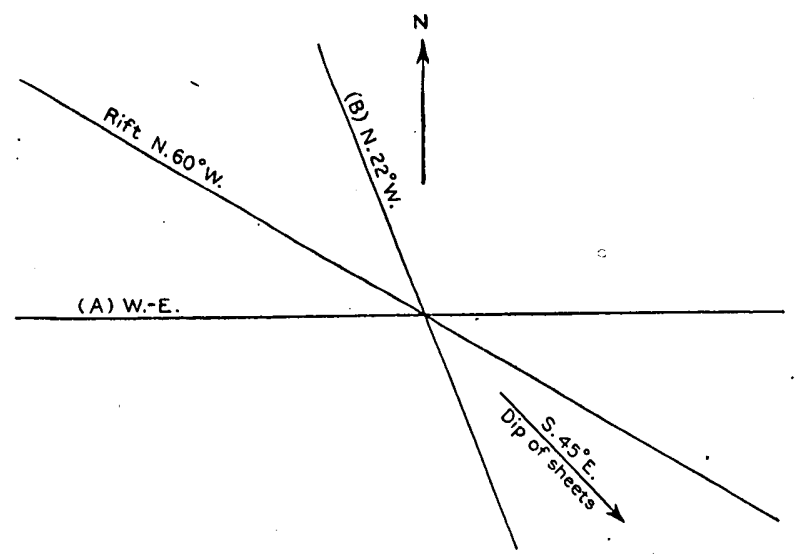

Fig. 16.-Structure at Ryan-Pàrel quarry, Crotch Island.

and forms a heading on the north, and $\mathrm{B}$ also forms one. Both $\mathrm{A}$ and $\mathrm{B}$ are infrequent. The rift is vertical and trends $\mathrm{N} .60^{\circ} \mathrm{W}$. Sap occurs from 6 to 12 inches on either side of joint B.

The plant consists of 9 derricks, worked by 9 hoisting engines; a traveling crane of 20 tons' capacity; one compressor of 900 cubic feet capacity per minute; 8 large pneumatic drills; a number of pneumatic plug drills; 4 surfacers; one lathe carrying stones 8 feet by 2 feet 6 .inches; and two steam pumps.

Transportation to the wharfs is effected by means of gravity on tracks 75 and 100 feet long.

The product is used chiefly for massive construction and for buildings, and its market is New York, where the firm is engaged in building enterprises. Among the public structures made of this granite are the piers of the Blackwells Island bridge in New York. In 1905 this quarry was furnishing the stone for the retaining wall of the Riverside Drive in New York. 
The Goss quarry is on Crotch Island, adjacent to and north of the Ryan-Parker quarry, on Thurlow Head. .(See fig. 15 and Pl. II, B.) Operator, John L. Goss; office, Stonington, Me.

The granite is a biotite granite, identical with that of the RyanParker quarry: (specimen 20, a), described on page 102. The firm reports that a test of this stone made by the New York Dock Department showed a breaking weight of 18,000 pounds to the square inch.

The quarry, opened in about 1872 ; measures about 350 feet square; has a maximum depth of 120 . feet and a minimum depth of 10 feet. Pumping is necessary in rainy weather. Little or no stripping has been required.

Rock structure: The sheets vary from 1 to 30 feet in thickness,

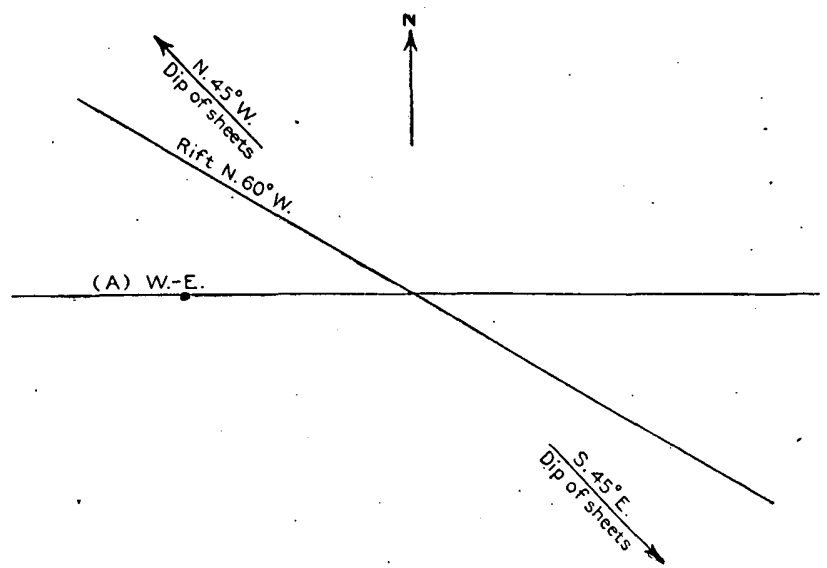

FIG. 17.-Structure at Goss quarry, Croteh Island.

increasing rapidly in thickness downward. They are horizontal in the center of the quarry, but south of it dip up to $20^{\circ}$. SE. and north of it as steeply to the northwest. The joint courses and rift are shown in fig. 17. Of $\mathrm{A}$ there are only two or three in the quarry. Their faces are coated with epidote. There is no sap, but pyrite occurs in small particles rarely.

The plant consists of 8 derricks and 8 hoisting engines, 2 cable engines for drawing cars, 1 compressor (Ingersoll \& Sargent, compound), with a capacity of 350 cubic feet of air per minute, 5 steam drills, 16 pneumatic hand tools, and 2 pumps.

Transportation is effected by means of three tracks-one 100 , one 4.00 , and one 500 feet long-from the quarry to the dock, the cars being propelled by cable engines.

The product is used chiefly for bridges and buildings. The small beds are worked into paving blocks. New York is the chief market. Specimen buildings of granite from this quarry are the post-office in Lowell, Mass.; the court-house at Dedham, Mass.; the Cadet armory at Boston; the public library at Laconia, N. H., and the Ninth Regi- 
ment armory in New York. In 1905 this quarry was supplying the rough stone for the Brooklyn approach to East River Bridge, No. 3, New York, and the cut stone for the Manhattan approach to the same bridge, the trimmings for the University Heights Bridge, New York, and the stone for the Flushing, Long Island, Bridge.

The Sherwood quarries are north of Mill Cove, Crotch Island. Operators, S. Clinton Sherwood Company, No. 1 Madison avenue, New York. (See fig. 15 for location of quarries.)

The granite of the lower and. northern quarry (specimen 25,a) is a biotite-muscovite granite of light-gray shade, with a very slight yellowish tinge, and of very fine texture, most of its particles ranging in size from 0.11 to $1.1 \mathrm{~mm}$., the average diameter being about $0.45 \mathrm{~mm}$. There are, however, occasional quartz particles and feldspar crystals one-fourth inch across, and of the latter rarely one a half inch in length, so that the rock has a porphyritic texture. The constituents, arranged in descending order of abundance, are potash feld-

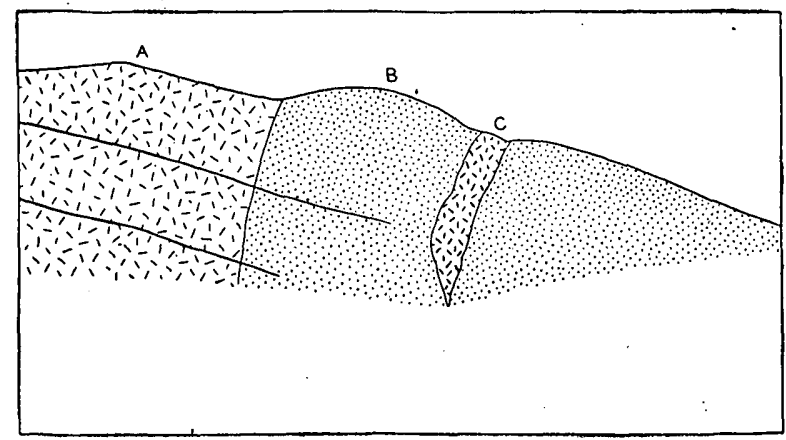

Fra. 1.8.-Relations of fine biotite-muscovite granite (B) to coarse biotite granite (A and C), and of sheet structure to both at north end of Sherwood quarry, Crotch Island. Length, 9 feet.

spar (microcline and orthoclase), smoky quartz, soda-lime feldspar (oligoclase), black mica (biotite), and white mica (muscovite), together with accessory magnetite and secondary epidote. The oligoclase is largely altered to a white mica and kaolin, and all the feldspars are in places intergrown with quartz circular in cross section.

The lower quarry, opened in 1889, is triangular in area, each side being 75 feet long and 40 feet deep, two of which are working faces. The drainage supplies the boilers.

Rock structure: The sheets, which are from 2 to 8 feet thick, dip $5^{\circ}$ to $10^{\circ} \mathrm{W}$. Joints, dipping $70^{\circ} \mathrm{S}$. to $90^{\circ}$. and striking N. $75^{\circ}$ E., recur: at intervals of 1 to 10 feet. The rift is vertical, with a course $\mathrm{W} .60^{\circ} \mathrm{N}$., as at the quarries south of the cove. The relations of this fine granite at the north end of the quarry to the coarse granite of the island are shown in fig. 18. The fine granite probably represents a later eruption through the coarser. (See p. 46.) 
The plant consists of 1 derrick and 1 hoisting engine.

Transportation is had by track to wharf, 100 feet distant.

This quarry was idle in 1905 and is worked only on special orders.

The product is used for monuments, bases, etc., and finds its way usually to New London, Conn. The minor sheets and remnants are worked up into paving blocks.

The granite of the same firm's upper quarry, opened in 1890 (specimen 26,b), is a biotite granite of general pinkish buff-gray color and coarse even-grained texture, consisting of pinkish-buff potash feldspar, smoky quartz, cream-colored soda-lime feldspar and black mica. The potash feldspar measures up to an inch or more in length, and the biotite scales one-tenth inch. This stone appears to be identical with that of the Latty quarry on Green Isle (specimen 28, $a$ ).

The upper quarry is 200 by 100 feet, and averages about 15 feet in depth. The quarry drainage supplies the boiler.

Rock structure: The sheets are from 1 to 5 feet thick, and dip $5^{\circ}$ to $10^{\circ} \mathrm{E}$. and $\mathrm{W}$. Vertical joints strike N. $50^{\circ}-60^{\circ} \mathrm{W}$. and parallel to the rift. For a space of 50 feet across the middle of the quarry these recur at intervals of from 2 to 8 feet. Another set, less numerous, strikes N. $25^{\circ} \mathrm{W}$. and dip $60^{\circ} \mathrm{E}$. There is an irregular tapering dike of pegmatite, with pink and white feldspar, biotite, and muscovite. The sheets in upper part of quarry have "shakes" for 2 to 3 inches from their surface.

The plant consists of 1 derrick and 2 steam drills.

Transportation is effected by cable and engine along a track 900 feet long to a dock on east side of the island.

The product consists of random stone and goes to New London, Conn.

The Latty Brothers quarry is in the southeast part of Green Island, which lies 1 mile southeast of Stonington. (See map, fig: 15.) Operators, Latty Brothers, Stonington, Me.

The granite (specimen 28,a) is a biotite granite of pinkish-buff color and coarse, even-grained texture, consisting of a pinkish-buff potash feldspar, smoky quartz, cream-colored soda-lime feldspar, and black mica. The potash feldspar measures up to an inch, and the biotite up to 0.15 inch in diameter. The stone appears to be identical with that of the upper quarry of S. Clinton Sherwood Company, on Crotch Island.

Rock structure: The sheets are from 6 feet to 6 feet 8 inches thick and dip gently southeast. There are vertical joints striking $N$. $45^{\circ} \mathrm{W}$., spaced 6 to 12 feet, also forming a heading. The rift is vertical, with course $\mathrm{N} .60^{\circ} \mathrm{W}$.

The quarry was opened in the spring of 1905 . The plant consists of 3 derricks, 2 engines, and 1 steam drill.

Transportation is effected along a track 100 feet long to wharf. 
The product is random stone for bridges and buildings and goes to New York and Boston.

The Stonington granite quarry is on the west shore of Spruce Island, $3 \frac{1}{4}$ miles east-southeast of Stonington. (See map, fig. 15.) Operator, E. L. Waite, Stonington.

The granite (specimen $27, a$ ) is a biotite granite of pinkish buff gray color and very coarse semiporphyritic texture. It consists of a pinkish-buff potash feldspar in crystals measuring up to $1 \frac{1}{t}$ inches in diameter, smoky quartz, cream-colored soda-lime feldspar. (oligoclase) in particles and crystals up to one-half inch in diameter, and black mica in scales measuring up to 0.15 inch across. The contrasts between the two feldspars and the mica are strong. The smoky quartz is a little darker than the potash feldspar. Some of the pinkish-buff feldspar is rimmed with the cream-colored one.

Rock structure: The sheets, 5 to 8 feet thick, dip about $40^{\circ} \mathrm{W}$. Vertical joints strike N. $45^{\circ}$ E., N. $45^{\circ} \mathrm{W}$., and N. $80^{\circ} \mathrm{E}$.

The plant consists of 3 derricks and 2 engines.

The quarry was being opened in July, 1905.

The Moose Island quarry is in the southeast part of Moose Island, three-fourths mile west-southwest of Stonington. (See map, fig. 15.) Operator, John L. Goss, Stonington.

The granite is a biotite granite identical with that of the Goss and Ryan-Parker quarries on Crotch Island (specimen 20, a), for descriptions of which see page 102 .

The quarry, opened in 1873 , measures 600 by 200 feet and averages about 17 feet in depth. One corner of it is 4 feet below low-tide level, so that sea water enters, which, to the amount of 300 to 400 gallons, has to be pumped out daily.

Rock structure: The sheets, from 1 to 7 feet thick, dip from $5^{\circ}$ to $10^{\circ} \mathrm{E}$. Vertical joints striking N. $80^{\circ}$ to $85^{\circ} \mathrm{W}$. recur at intervals of 200 feet and form a heading on north side of quarry. There is no perceptible rift, and the rock does not split well when frozen. The 15-inch aplite vein, described on page 43 , has a course N. $80^{\circ} \mathrm{W}$. Sap, from 1 to 2 inches thick, is confined to the upper sheets.

The plant consists of 4 derricks and 4 engines, 2 locomotive cranes of 10 and 20 tons capacity, 1 compressor of 800 cubic feet capacity per minute, 2 steam or pneumatic drills, 8 pneumatíc plug drills, 3 surfacers, 2 pneumatic hand tools, $\cdot 1$ steam pump, and 1 . windmill pump.

Transportation is effected by cars on track 200 feet to wharf.

The product is used for bridges and buildings, and goes chiefly to New York.

Specimen structures: The gate house at Central Park and the steps of Columbia University, in New York; trimmings of the Hampton Dormitory at Cambridge, Mass. 
Contracts in 1905: University Heights Bridge and part of the stone for No. 3 anchorage for Manhattan. Bridge, New York.

The Settlement quarry is on Deer Isle, on Settlement Hill east of Webb Cove, 2 miles northeast of Stonington. (See map, fig. 15.) Operator, John C. Rodgers, 1909 Amsterdam avenue, New York.

The granite (specimen 22,a) is a biotite granite of medium gray slightly lavender tint, blotched with white, and of coarse texture, consisting, in descending order of abundance, of a very light lavender-colored potash feldspar (microcline and orthoclase), smoky quartz, slightly cream-colored soda-lime feldspar (oligoclase), and black mica (biotite), together with accessory magnetite, titanite and apatite, and secondary chlorite. The potash feldspar is sometimes rimmed with oligoclase. The feldspars measure up to 1 inch and the biotite plates are under one-tenth inch. The contrast between the two feldspars and the mica is strong, but that between the quartz and the potash feldspar is feeble.

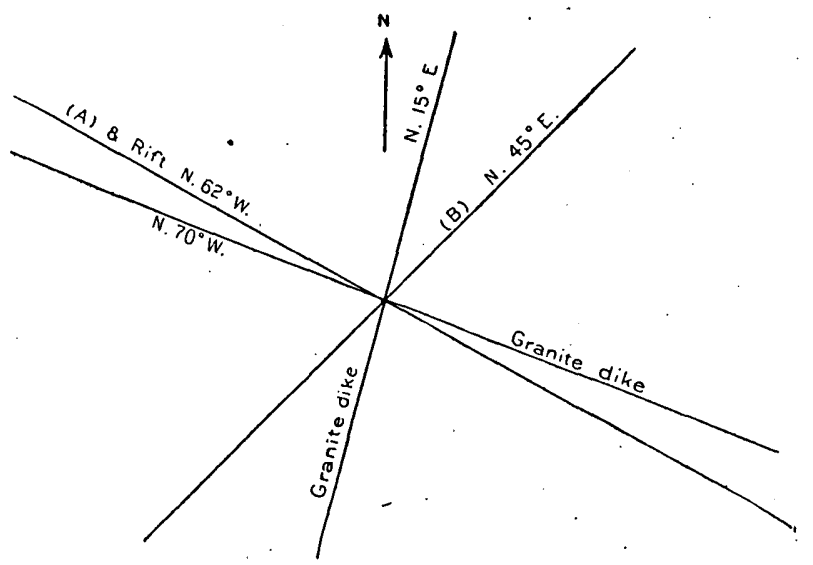

Fir. 19.-Structure at Settlement quarry, on Deer Isle, near Stonington.

The following test of the crushing strength of this stone was made by the Pittsburg Testing Laboratory (Limited) and is given here merely for reference:

T'est of crushing strength on 3-inch cubes of granite from Deer Isle.

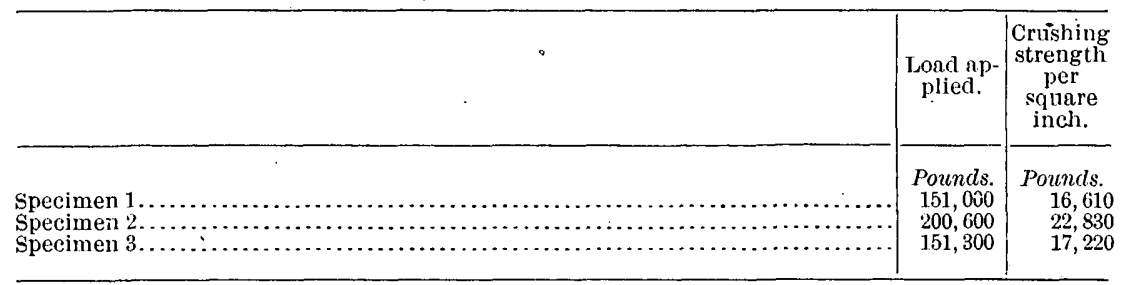

Laboratory No. 17858, April 7,1903 ; signed, John M. Bailey, Secretary. 
Mr. Oren, United States inspector of building stone for Government contracts, stationed at Stonington in 1905, stated to the writer that he had tested this granite by immersing it in commercial hydrochloric acid for over three months without any bad effects.

The quarry, opened in 1900 , consists of two openings, one near the top of the hill, 500 by 400 feet and from 10 to 18 feet in depth, the other on its west side, 600 by 60 feet and up to 14 feet in depth. Drainage requires occasional pumping. There is little or no stripping.

Rock structure: The sheets, from 6 inches to 16 feet thick, dip $10^{\circ}$ to $15^{\circ}$ north and south away from the top of the hill. Joint courses are shown in fig. 19. A occurs but once; B recurs at intervals of 500 feet. The rift is vertical with a course of N. $60^{\circ}-65^{\circ} \mathrm{W}$. There are granite dikes from 4 to 12 inches thick. (See description on p. 46.) Knots are rare and small. Pyrite occurs but very rarely.

The plant consists of 9 derricks and 3 engines, 1 traveling crane of 10 tons' capacity, 1 locomotive, 2 compressors each of 750 cubic feet capacity, 16 steam or pneumatic drills, 9 surfacers, 19 pneumatic plug drills, 8 pneumatic hand tools, and 2 steam pumps.

Transportation is effected by locomotive and 2,500 feet of track. The distance from upper quarry to cutting shed is 1,000 feet, and from cutting shed to wharf 600 feet.

The product is used for massive structures in New York and Norfolk, Va. The small sheets and waste are used in paving. Specimen structures: The approach to Williamsburg Bridge and the piers to Manhattan Bridge, New York. Contracts in 1905: Retaining wall for Riverside Drive, New York, and the dry dock in Norfolk, Va.

Hagan and Wilcox quarry is on Deer Isle, in Stonington village. Operators, Hagan and Wilcox, Stonington.

The granite is a coarse-textured, even-grained biotite granite like that of Green Island.

The quarry has two nearly adjacent openings, one 75 by 75 feet, the other 50 by 50 feet, and from 25 to 50 feet deep. Drainage is effected by occasional pumping.

Rock structure: The sheets, from 2 to 20 feet thick, are horizontal. Vertical joints, striking N. $80^{\circ}$ E., recur at intervals of from 2 to 40 feet and also N. $20^{\circ} \mathrm{W}$., recurring at intervals of from 10 to 20 feet. The rift is vertical, with course N. $30^{\circ}-35^{\circ}$. W. From the small spacing of its joints, this is technically a "bowlder quarry."

The plant consists of 3 derricks and 3 hoisting engines, 2 steam drills, and 1 pump.

Transportation is effected by cartage 1,000 feet to. wharf.

The product is random stone, which is shipped to Philadelphia and cut there. Structure: A lace mill in Philadelphia.

The Calvin Ames quarry is on Deer Isle, 1 mile east of Stonington. Operator, Calvin Ames, Stonington. 
The granite is a coarse-textured, even-grained biotite granite like that of Green Island (p. 106).

The quarry measures 75 feet square by 12 feet in depth.

Rock structure: The sheets, which are from 1 to 5 feet thick, are horizontal but irregular. Vertical or steep joints strike N. $80^{\circ}$ E. N. $60^{\circ} \mathrm{W}$, and N. $30^{\circ} \mathrm{W}$. There is a foot of sap and "shakes" at the top.

The plant consists of 2 hand derricks at quarry and 2 more at the wharf, which is connected with the quarry by a 400 -foot track.

The product is random and cellar stone, and is shipped to Boston and New York.

The Crabtree \& Havey quarry is in the town of Sullivan, threefourths mile from Sullivan River. Operators, Crabtree \& Havey, North Sullivan.

The granites of the Franklin and Sullivan quarries, with but one or two exceptions, are of the general character described under group 9 (in page 74.

The granite of the Crabtree \& Havey quarry (specimen 69, $b$ ) is a biotite granite of medium-gray shade and fine to medium evengrained texture, consisting, in descending order of abundance, of milk-white potash feldspar (microcline and orthoclase), smoky quartz, a milk-white soda-lime feldspar (oligoclase), and black mica (biotite), together with accessory magnetite. The stone from the lower sheets is a trifle darker than that described above, which represents that of the upper ones. The difference lies in the feldspar.

The quarry, opened in 1865, measures 300 feet from north to south and 200 feet from east to west and ranges in depth from 10 to 50 feet. It is drained by occasional pumping. The stripping consists of 2 to 3 feet of drift.

Rock structure: The sheets, from 3 to 8 feet in thickness, dip $10^{\circ}$ $W$. and northwest. They are not very regular in the center of the quarry owing to their lenticular form, shown in $\mathrm{Pl}$. V, $A$ and $B$. Vertical joints strike $\mathrm{N} .80^{\circ}-85^{\circ} \mathrm{W}$., forming a heading on the north, also N. $10^{\circ}-20^{\circ}$ E., bounding the quarry on the east. A diabase dike $\delta$ feet wide occurs on the west side, faulted in two places with a displacement showing a thrust from the east. The rock contains manny knots, some of them as large as 6 inches and a few 3 feet in diameter. Sap occurs along the sheets, but not invariably.

The plant consists of 3 derricks, 1 hoisting engine, and 1 pump.

Transportation is effected by cartage three-fourths mile to wharf.

The product is used for building, curbing, and crossings in Boston, Providence, and New York. The small beds go into paving blocks. A private residence in Chicago has been constructed of the granite. Contracts in 1905 were for random stone, curbing, and paving in Boston, New York, and Philadelphia. 
The Hopewell quarry is in the town of Sullivan, on Sullivan River above the "falls." Operator, Hopewell Stone Company, 36 Main street, Bangor, Me.

The granite (specimen $68, a$ ) is a biotite granite, of light to medium-gray shade and fine to medium even-grained texture, consisting, in descending order of abundance, of milk-white potash feldspar (microcline and orthoclase), smoky quartz, translucent white soda-lime feldspar (oligoclase), and black mica (biotite), together with accessory magnetite. Many slender oligoclase crystals, most of them unaltered, measure between one-tenth and one-fifth inch. The contrasts are not strong. The stone takes a good polish, and the contrast between polished and cut face is fair. The general shade of this granite is but a trifle darker than the so-called "white granite" of North Jay, described on page 80, but its mineral particles are coarser and its biotite is more conspicuous.

The quarry, opened about 1855 , is triangular in area, each side being about 200 feet long; the depth of the working face on the east is 40 feet, and the depth at front 20 feet. There is no drainage problem. The stripping consists of 2 feet of drift besides 6 feet of "top" or poor stone.

Rock structure: The sheets, from 2 to 12 feet thick, dip southwest at a low angle. Vertical joints strike N. $25^{\circ}-30^{\circ}$ E., forming a heading on the north, and also N. $60^{\circ} \mathrm{W}$., the last recurring at irregular intervals and more or less discontinuously. The rift is horizontal and the grain vertical, with course N. $60^{\circ} \mathrm{W}$. There is very little sap. Knots are few and small.

The plant consists of three derricks and two engines.

Transportation is effected by gravity tracks and cable to wharf 500 feet off. Schooners of 13 feet draft can pass the falls at high tide during one-half hour.

The product is random blocks, curbing, and crossings for Philadelphia, Boston, and New Jersey. The thin sheets and waste go into paving blocks. Contract in 1905: Base course of manual training school building, corner Broad and Jackson streets, Philadelphia.

The Stimson quarries are in the town of Sullivan. Owner, Mrs. C. A. Stimson, Sullivan. Leased by Hopewell Stone Company, but not operated in 1905 . Reported as sold since the writer's visit.

The granite (specimen $67, a$ ) is a biotite granite of medium-gray shade and fine to medium even-grained texture, consisting, in descending order of abundance, of gray potash feldspar (orthoclase and microcline), smoky quartz, grayish soda-lime feldspar (oligoclase), and black mica (biotite), together with accessory magnetite. The biotite plates measure up to 0.15 inch across. The general shade of: this granite is darker than that of the Hopewell quarry. Contrasts are slight, owing to similarity in shade of quartz and feldspar. 
The quarries consist of three openings, the main one of which is 200 feet square and from 15 to 30 feet deep.

Rock structure: The sheets, from 1 to 5 feet thick, are horizontal, with slight undulations. Vertical joints strike N. $65^{\circ} \mathrm{W}$., forming headings on the north and south side, also north, and coated in places with pyrite. The rift is horizontal. A vertical dike of aplite 1 foot 7 inches thick has a N. $10^{\circ}-15^{\circ} \mathrm{W}$. course. The amount of sap is small. Dark-gray knots up to 2 inches and exceptionally 7 inches in diameter occur.

The product was carted to a wharf a half mile off and shipped to New York.

Hooper, Havey a Co.'s quarry is in North Sullivan. Office, North Sullivan.

The granite is a biotite granite of medium-gray shade and fine to medium even-grained texture, like that of the Crabtree \& Havey quarry (specimen $69, a$ ) described on page 110.

The quarry, opened in about 1894, measures 300 by 150 feet by $15-$ 20 feet in depth. As the bottom of the quarry is about 15 feet below the general surface there is much inflow of water along the sheets, as well as direct collection of rain water. Its drainage requires considerable pumping. After being idle in winter it requires three weeks' steady pumping to reopen it.

Rock structure: The sheets, from 6 inches to 6 feet thick, are gently undulating and horizontal. Vertical joints strike N. 20$25^{\circ} \mathrm{E}$., forming the west side of quarry, and also east-west, forming a heading on its north side. The rift is horizontal, and the grain vertical, east-west. The rock is evidently under a compressive eastwest strain, as it tends to fracture in a north-south direction across the grain, without regard to knox holes. The knots are small.

The plant consists of 3 derricks (horse) and 1 steam pump.

Transportation is by cartage of one-half mile to wharf.

The product is random stone and street material, mostly for Boston. Contracts in 1905: Curbing (straight and circular), crossings, and paving blocks for Philadelphia.

The Whalesback quarry, in North Sullivan, is operated by W. T. Havey, jr., \& Son, of Franklin.

The granite is a biotite granite of medium-gray shade and fine to medium texture, like that of the Crabtree and Havey quarry described on page 110 .

The quarry, opened in about 1868 , is 200 feet square and from 8 to 30 feet deep. It is drained by a $2 \frac{1}{2}$-inch siphon pipe, 250 feet long. The stripping consists of 3 to 8 feet of drift. On one side the glaciated granite surface has a $2 \frac{1}{2}$-foot bowlder, excavated from the overlying drift, resting on it. 
Rock structure: The sheets, from 2 to 8 feet thick, dip $5^{\circ}$ to $10^{\circ}$ SE. Vertical joints strike N. $85^{\circ}$ E., forming headings at the north and south sides; also N. $10^{\circ}$ E., parallel with a 4-inch diabase dike. A microscopic description of this dike will be found on page 48 . The rift is horizontal and the grain vertical with east-west course. Knots are rare.

The plant consists of 2 derricks and siphon pipe.

Transportation is effected by cartage three-fourths mile to wharf.

The product is used for curbing and random stone in Philadelphia, New York, and Boston.

The Dunbar Brothers' quarry (leased from Crabtree and Havey) is $2 \frac{1}{2}$ miles northwest of Sullivan village, in the town of Sullivan. Address, Sullivan.

The granite is a biotite granite of medium-gray shade and coarse (inclining to medium), even-grained texture, like that of the Robertson \& Havey quarry, in Franklin, described on page 90.

The quarry, opened in 1901, measures 250 by 100 feet and is from 4 to 8 feet in depth. Its drainage requires occasional pumping. The stripping consists of 2 feet of drift, with small bowlders.

Rock structure: Sheets, from 2 to 12 feet thick, undulate with a general easterly dip of $10^{\circ}$. Vertical joints strike N. $80^{\circ}-85^{\circ} \mathrm{E}$, forming a heading on south side of quarry, and N. $60^{\circ} \mathrm{E}$. with a heading; also exceptionally N. $5^{\circ}-10^{\circ}$ E. The rift is horizontal. A diabase dike from 8 to 16 inches thick has a course N. $20^{\circ}-25^{\circ}$ E., and rims of epidote, as described on page 48. There is little or no sap; and knots are few.

The plant consists of 2 derricks (horse) and 1 pump.

Transportation is effected by cartage $1 \frac{1}{4}$ miles to wharf.

The product is random, curbing, and paving, which go to Boston, New York, and Philadelphia.

The Harvey Dunbar quarries consist of several small. openings in West Sullivan, operated by Harvey Dunbar (address, Sullivan), who employs 8 men in getting out paving blocks.

The Taylor quarry is in the town of Sullivan, on the west side of a north-south ridge, 2 miles from Sullivan village. Owner, Harry Taylor, North Sullivan. Quarry not operated in 1905.

The granite (specimen $79, a$ ) is a biotite granite of medium-gray shade and fine to medium even-grained texture, consisting, in descending order of abundance, of grayish potash feldspar (orthoclase and microcline), smoky quartz, grayish soda-lime feldspar (oligoclase), and black mica (biotite), together with accessory magnetite. The feldspars measure from 0.1 to 0.25 inch and the biotite scales up to 0.1 inch. The rock is identical with that of the Stimson quarry, described on page 111.

$3495-$ Bull. $313-07-8$ 
The quarry, opened recently, measures 50 by 25 feet and 5 feet in depth. The sheets, from 2 to 5 feet thick, dip $20^{\circ}-30^{\circ} \mathrm{W}$. Vertical joints strike N. $25^{\circ}-30^{\circ}$ E. There is one derrick.

The Pettee black-granite quarry is three-fourths mile north of East Sullivan, on the road to Tunk Pond. Owner, J. A. Pettee, East Sullivan.

This rock (specimen $80, b$ ) is a mica-quartz diorite of very dark gray shade and fine to medium texture with occasional porphyritic whitish feldspars up to one-fourth and more rarely one-half inch. It consists, in descending order of abundance, of white translucent soda-lime feldspar (oligoclase-andesine), black hornblende, opalescent quartz, black mica (biotite), and magnetite, together with accessory titanite, apatite, and pyrite. It takes a fine polish, and the contrast between polished and cut surfaces is marked. The diorite of East Sullivan is referred to by W. O. Crosby in a paper on the Geology of Frenchmans Bay. ${ }^{a}$

The quarry, which is only 15 by 15 feet and 8 feet deep, is on the west side of a knoll 20 to 25 feet high.

Rock structure: Vertical joints striking N. $25^{\circ}$ W. and N. $85^{\circ} \mathrm{W}$. recur at intervals of 1 to 5 feet. The rock splits in these directions also horizontally. There are whitish bands. or veins one-half inch thick, consisting almost entirely of the feldspar and quartz.

Thiis stone is quarried occasionally in small blocks for monumental purposes.

The Sinclair Ulack-granite prospect is $1 \frac{1}{2}$ miles north of East Sullivan, on Herbert and Thaddeus Sinclair's (formerly Smith Bean's) farm, near Charles Dowel's sawmill.

This rock (specimen $82, a$ ) is a quartz monzonite of almost black shade, with white blotches, of medium to coarse (porphyritic) texture, consisting, in descending order of abundance, of bluish opalescent quartz, whitish soda-lime feldspar (oligoclase-andesine), and potash feldspar (microcline and orthoclase), black hornblende, and black mica (biotite), together with accessory magnetite, pyrite, titanite, and apatite. Some of the feldspars measure nearly an inch in length. This is closely related to the true granites, as it contains nearly as much potash feldspar as soda-lime feldspar, although it is among the darker of the "black granites."

The ledge is exposed for a length of 50 feet north-south and a height of 20 feet. A vertical joint strikes N. $20^{\circ}$ W. An opening 10 by 5 feet and 5 feet deep was made here in 1902 .

The Baird quarry is on Swans Island, east side of old harbor, not quite 1 mile east of Swans Island village and three-fourths mile southeast of Mintum. Operators, The Mathew Baird Contracting Company, 433 East Ninety-second street, New York. 
The granite (specimen $34, a$ ) is a biotite granite of medium pinkish-buff gray color and of medium, inclining to coarse, even-grained texture, consisting, in descending order of abundance, of a pinkishbuff potash feldspar (orthoclase and microcline), smoky quartz, a milk-white soda-lime feldspar (oligoclase) and black mica (biotite), together with accessory magnetite, and, rarely, a little greenish hornblende. The potash feldspars are intergrown with plagioclase and measure up to over one-half inch, but most of the biotite is considerably under one-tenth inch. The stone takes a good polish, but the contrast between the polished and rough surface is feeble, owing to the smallness of the biotite scales. The contrasts are mostly between the quartz and the feldspars. The company reports a test of crushing strength of between 18,000 and 19,000 pounds per square inch.

The quarry, opened in 1901, measures 500 by 250 feet and has an average depth of 15 to 18 feet. The drainage supplies the boilers. There is no stripping.

Rock structure: The sheets, from 1 to 7 feet thick, dip $15^{\circ}$ south. Vertical joints, striking N. $45^{\circ}$ E., recur at intervals of 50 feet; others, striking $\mathbf{N}$. $80^{\circ} \mathrm{W}$., recur but twice as continuous joints. The rift is vertical, north-south. Sap is confined to the sheets of the upper 3 feet. No knots or veins.

The plant consists of 3 derricks, 3 engines, a steam drill. and a steam pump.

Transportation is effected by gravity and cable on a track to wharf, 1,200 feet off.

The product is random, dimension, and paving stone, which go to New York, where the firm has its cutting works.

The Toothachers Cove quarry is near end of that cove, in the western part of Swans Island, $1 \frac{1}{2}$ miles north-northwest of Swans Island village. The property is owned by B. E. Rowe, of Swans Island. The mineral right was leased to Wilbur and Havey, address, Swans Island, but is now held by C. J. Hall of the same place. In the fall of 1905 a company was being formed to operate the quarry.

The granite (specimen $33, a$ ) is a biotite granite of medium pinkish-gray color and coarse, even-grained texture, with feldspars up to three-fourths inch and biotite fully one-tenth inch. It consists, in descending order of abundance, of light-pink potash feldspar (orthoclase), smoky quartz, cream-colored soda-lime feldspar (oligoclase), and black mica (biotite), together with accessory magnetite and titanite. The orthoclase is intergrown with plagioclase. The oligoclase is altered to a white mica. The contrasts between the four minerals are marked.

The quarry is 50 by 25 feet, and the working face is 20 feet high. There are two other small openings. 
Rock structure: The sheets are from 5 to 12 feet thick and horizontal. Vertical joints, striking N. $60^{\circ} \mathrm{W}$., recur at intervals of 10 feet. There are veins of aplite and of quartz.

In July, 1905, the plant consisted of a horse windlass and derrick. An inclined track leads to the wharf, 400 feet off.

Product: Random and paving blocks.

The Seal Cove quarries are in the town of Tremont, on Mount Desert Island, about one-half mile southeast of Murphy Hill. Operator, S. W. Herrick, Southwest Harbor, Maine.

The granite (specimen 57, a, from lower opening, collected by writer) is a biotite granite of dark-gray shade and medium (inclining to fine) even-grained texture, with feldspar up to one-fourth inch and black mica generally under one-tenth inch. It consists, in descending order of abundance, of bluish-gray soda-lime feldspar (oligoclase) and a little black mica (biotite), together with accessory magnetite. The difference in the amount of the two feldspars appears to be less than in specimen $57, c$, and this granite thus approaches a quartz monzonite. There is little contrast between the quartz and feldspars, and the biotite plates are small and thinly disseminated. The granite (specimen 57, c, probably from the upper quarry, collected by the operator) is like specimen $a$, except that its color is dark greenish, in consequence of the feldspars being greenish gray, and that the two feldspars occur in their usual proportions. It contains some secondary epidote and takes a fair polish.

The quarries, opened in 1903 , consist of several small openings, none of which exceed 25 feet square.

Rock structure: The sheets, from 1 to 3 feet thick, are horizontal at the upper quarry, but dip $10^{\circ}$ to $25^{\circ} \mathrm{W}$. at the lower one. Vertical joints strike $10^{\circ}$ to $15^{\circ} \mathrm{W}$. and also N. $90^{\circ} \mathrm{W}$. The rift is horizontal. Sap from 2 to 3 inches thick occurs along the sheets. Dark-gray knots, up to 2 inches across, occur occasionally.

The product, paving blocks thus far, is carted three-fourths mile to wharf in Seal Cove.

The Carroll quarry is in the town of Tremont, on Mount Desert Island, at Southwest Harbor. Owned by estate of Jacob W. Carroll. Address, John Carroll, Southwest Harbor.

The granite (specimen.65,a) is a hornblende granite, of pinkishgreenish medium-gray color and medium even-grained texture, consisting, in descending order of abundance, of pinkish-greenish potash feldspar (microcline), smoky quartz, very dark green hornblende, and very little black mica (biotite), together with accessory magnetite and zircon and secondary chlorite. The microcline is intergrown with quartz and soda-lime feldspar (oligoclase-andesine), and is largely altered to kaolin and a white mica. This granite is like that 
of the Graves quarry (specimen 64, a), page 100, except that the feldspars are more pinkish.

The quarry is 100 feet from north to south by 30 feet from east to west, and has a working face on the east 15 feet high. The sheets, from 6 inches to 3 feet thick, are horizontal at the north end, but dip $10^{\circ} \mathrm{S}$. at south end. Vertical joints strike N. $75^{\circ}$ E. and N.50 $-55^{\circ}$ W. Knots are abundant and are up to 2 feet in diameter.

The quarry is only. worked occasionally, and the stone is used locally for foundations.

The Orland quarries, situated in the vicinity of Orland, in Hancock County, were reported as not in operation in 1905 and were not visited.

\section{KENNEBEC COUNTY.}

The quarries in Kennebec County are in the town of Hallowell.

The Stinchfield and Longfellow quarries are in the town of Hallowell, $2 \frac{1}{2}$ miles northwest of the city of Hallowell, on the southern part of Lithgow Hill: (See map, Pl. I.) Operator, Hallowell Granite Works, Hallowell.

The granite (specimen $111, a$ ) is a biotite-muscovite granite of light-gray shade and fine texture, with porphyritic feldspars usually about one-fourth inch in diameter. It consists, in descending order of abundance, of slightly bluish translucent potash-feldspar (orthoclase and microcline), smoky (light) quartz, soda-lime feldspar of same colors as the other (oligoclase), black mica (biotite), and white mica (muscovite), together with accessory garnet, zircon, and apatite. The oligoclase is usually undergoing alteration to kaolin and a white mica and contains intergrowths of quartz circular in cross section. Leaving the porphyritic feldspars out of consideration, the general diameter of the particles ranges from 0.25 to $1.0 \mathrm{~mm}$., averaging about 0.65 . The micas are thickly disseminated. The stone takes a fine polish, and the polished face has a slight bluish tinge. A microscopic description of Hallowell granite will be found in Merrill's Stones for: Building and Decoration, pages 63,64 .

Mr. E. C. Sullivan, as a result of tests at the chemical laboratory of the United States Geological Survey in May, 1906, found that this granite contains 0.060 per cent of $\mathrm{CO}_{2}$ (carbon dioxide) and that warm dilute acetic acid dissolves 0.08 per cent of $\mathrm{CaO}$ (lime) and a trace of $\mathrm{MgO}$ (magnesia). If all of this $\mathrm{CO}_{2}$ is assigned to the $\mathrm{CaO}$, the rock contains 0.14 per cent of $\mathrm{CaCO}_{3}$ (lime carbonate). The lime extracted by this process is in addition to that combined with silica in the soda-lime feldspar. The thin sections from the Tayntor quarry stone, which is essentially the same, show a little carbonate (see p. 120), and the same mineral must occur also in the 
stone from the Stinchfield and Longfellow quarries, but in very minute quantity.

A test of the crushing strength of this granite made by Ricketts and Banks yielded the following results:

First cube

Second cube 15,730

Average 17,495

The difference in the two cubes is attributed to some imperfection in the second one.

The quarries were opened about 1826. The Stinchfield quarry measures 600 feet from northeast to southwest by 400 across and from 30 to 60 in depth. (See Pl. IV, B.) The Longfellow quarry (not in operation, but:filled up to 20 feet with water); southwest of

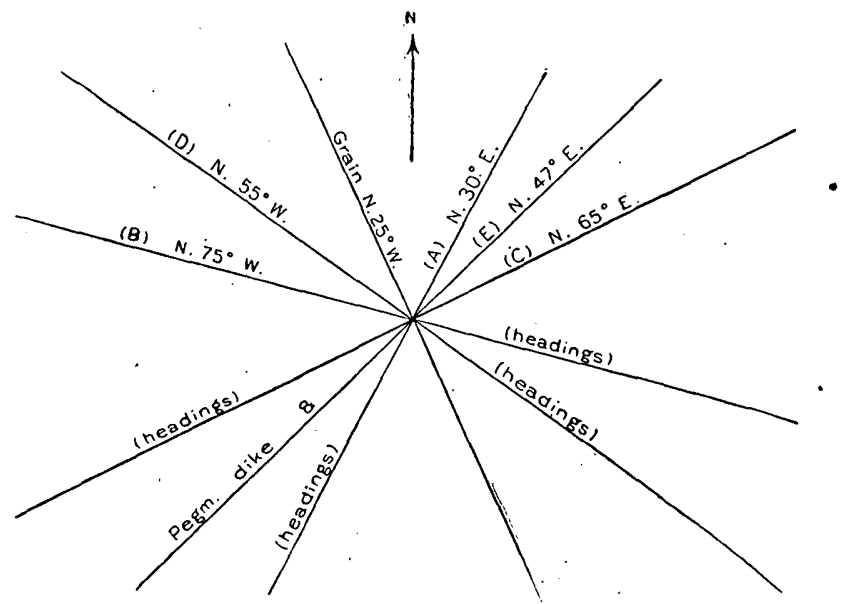

Fíg. 20.-Structure at Stinchfield and Longfellow quarries, near Hallowell.

the above and communicating with it, measures about 400 by 200 feet and from 50 to 70 feet in depth. The drainage of the Stinchfield quarry requires pumping for a few hours after.heavy rains, and that drainage supplies the boilers. The stripping consists of from 1 to 20 feet (increasing northwestward) of yellowish sandy clay with small bowlders near the top. (See Pl. IV, B.)

Rock structure: The most striking features in these quarries are the gradual increase in the thickness of the sheets downward (partly shown in Pl. IV, B), which ranges from 4 inches to 14 feet, and the evidence of strain afforded by the numerous headings and joint systems shown in fig. 20; also the evidence of weathering afforded by the decomposition and discoloration along these headings. The sheets range from, a horizontal position to an inclined one of $15^{\circ}$ NE. Many of them stop at the joints, probably owing to faulting; 
some taper out and overlap. Pl. IX, $B$, a view of a part of the northwest wall of the Longfellow quarry, shows the intersection of headings of joint systems $\mathrm{C}$ and $\mathrm{D}$. Joints $\mathrm{A}$ are spaced from 10 to 50 feet. B forms a heading 50 feet wide on the southeast wall, weathered yellow to a depth of 50 feet from the rock surface. Joints $\mathrm{C}$ are spaced from 5 to 70 feet. In a 2 -foot heading of $\mathrm{C}$ on the southwest wall the joints recur at intervals of 2 inches to one-half: inch and are coated with quartz crystals. Joints $\mathrm{D}$ form two headings, 10 feet wide, on the southeast wall, containing a bed of sand a foot thick and 30 feet deep or long. Joints $\mathrm{E}$ are discontinuons and grooved and polished from motion. Large areas of some of the joint planes in the Longfellow quarry are covered with frost-like crystallizations of oxides of iron and probably of manganese. The rift is horizontal; the grain is vertical N. $25^{\circ}$ W., but feeble. A 2-foot pegmatite dike contains milk-white oligoclase, smoky quartz, muscovite, biotite, and 1-inch garnets. Knots occur up to threefourths inch across, exceptionally 1 by 3 inches. The sap is very marked along the joints and up to a foot in thickness. The concentric growth of ferruginous discoloration is shown in the heading Pl. IX, $B$.

The plant (including both that at the quarries and at the Hallowell cutting sheds) consists of 18 derricks, of which 3 are worked by electricity, 3 by hand, and the rest by 6 engines; 2 traveling cranes, of 10 and 20 tons capacity; 2 compressors, of 180 and 900 cubic feet per minute capacity; 14 pneumatic plug drills; 2 1-foot plug drills; 5 surfacers; 3 polishers; 56 pneumatic hand tools; 1 lathe for: stone 16 by 2 feet, 2 for stone up to 6 by 2 feet; 2 polishing lathes for: stone 16 by 2 feet, and 3 steam pumps.

Transportation is effected by cartage $2 \frac{1}{2}$ miles to railroad or to wharf on the Kennebec River at Hallowell, accessible to schooners of 12 -foot draft.

The product is used for buildings and sculpture. It lends itself remarkably well to statuary and delicate ornamental work, as is shown by Pl. XIV, $A$, a reproduction of a photograph of a panel at the entrance to the Bank of Commerce in New York, and by Pl. $\mathrm{XIV}, B$, representing a statue recently finished for the Hall of: Records in the same city. About seven-eighths of the product go into building and one-eighth into carved work. The principal markets are Chicago and New York. Specimen buildings: Albany capitol, Hall of Records (including its statuary), New York; Brooklyn Savings Bank, New York; Masonic Temple, Boston; academic and library buildings at United States Naval Academy, Annapolis, $\dot{M} d$.; Illinois Trust Company's building, Chicago; Northwestern Insurance Company's building, Milwaukee; post-office at 'Allegheny, 
Pa. Specimen monuments and statues: Statuary on Plymouth monument, Massachusets; National monument at Yorktown, Va.; New York State monument at Gettysburg, Pa.; Soldiers' monument at New Haven, Conn.; Richard M. Hunt monument in Central Park, New York; Battlefield monument at Trenton, N. J. Contracts in 1905: Suffolk Savings' Bank building, Boston; several mausoleums for New Orleans, Pittsburg, and Chicago; ex-Governor Cleaves's monument at Portland, Me.

The Tayntor quarry (formerly known as the Melvin quarry) is in the town of Hallowell, 2 miles north-northwest of the city of Hallowell. Operator, C. E. Tayntor \& Co.; office, Hallowell (C. E. Tayntor, 239 Broadway, New York).

The granite is a biotite-muscovite granite of light-gray shade and fine (but porphyritic) texture, identical with that of the Longfellow and Stinchfield quarries (specimen 111,a) described on page 117. The general diameter of particles, excluding the porphyritic crystals, ranges from 0.25 to $1.25 \mathrm{~mm}$. One of the small porphyritic oligoclase crystals measuring $2.25 \mathrm{~mm}$. in diameter shows calcite between its cleavage planes. Calcite appears also independently in plates up to $0.5 \mathrm{~mm}$. acrosi. Mr. E. C. Sullivan, of the United States Geological Survey, tested granite from the Tayntor quarry and found that it contained 0.146 per cent of $\mathrm{CO}_{2}$ (carbon dioxide) and that warm dilute acetic acid extracted 0.24 per cent of $\mathrm{CaO}$ (lime) and no magnesia. The $\mathrm{CO}_{2}$ found corresponds to 0.33 per cent of $\mathrm{CaCO}_{3}$ (lime carbonate). The difference in the result of the test of this and the test of the Stinchfield quarry stone may not hold good of the stones in general. The average of both tests or 0.235 per cent for the lime carbonate of both stones may be nearer the truth.

The quarry, opened before 1840 , measures 520 feet N. $30^{\circ}$ W. to S. $20^{\circ}$ E., by 275 feet across and from 10 to 40 feet in depth. The deeper part of it is 275 by 150 and 40 feet deep. It is drained by pumping after rain. In places the glaciated granite surface is covered with 5 feet of sand and bowlders.

I Rock structure: In places there is a vertical flow structure with course $\mathrm{N} .35^{\circ} \mathrm{W}$., and where it occurs it is the direction of easiest fracture. The sheets measure from 1 foot to 6 feet 6 inches (the thicker being the lower ones), and are horizontal. The joint and dike courses are shown in fig. 21. A recurs at intervals of 20 to 200 feet, and forms one heading, which does not extend beyond a depth of 15 feet from the rock surface. B sometimes dips steep north, recurs at intervals of 10 to 40 feet and forms headings in the northern half of quarry. The rift is horizontal and grain vertical, N. $70^{\circ} \mathrm{W}$, but feeble. Fig. 21 shows the courses of the pegmatite dikes. $a$ dips $45^{\circ} \mathrm{N}$. and is 4 inches thick, $b$ dips $65^{\circ} \mathrm{E}$. and is 3 inches thick, $c$ dips N. and is 3 inches thick. Pegmatite lenses 2 feet thick also 
occur. In the north part of quarry there is a band of dark knots, from 5 to 25 feet wide, with a N. $10^{\circ} \mathrm{E}$. course, but the rest of the quarry is free from knots. The glaciated surfaces and the sheet surfaces are free from sap except near the headings, where it extends for 6 inches from each sheet and joint face. The granite is here under compressive strain, for the cores between the contiguous borings made in channeling become crushed, and on two occasions spontaneous vertical east-west fractures 40 feet long occurred through a sheet 4 feet 6 inches thick, and diagonal to two rectangular " channels."

The plant consists of 3 derricks, operated by 1 engine (Ledgerwood hoist, triple drum) ; 1 compressor (capacity 180 cubic feet of air per minute), driven by a 30 -horsepower Westinghouse electric motor; 4

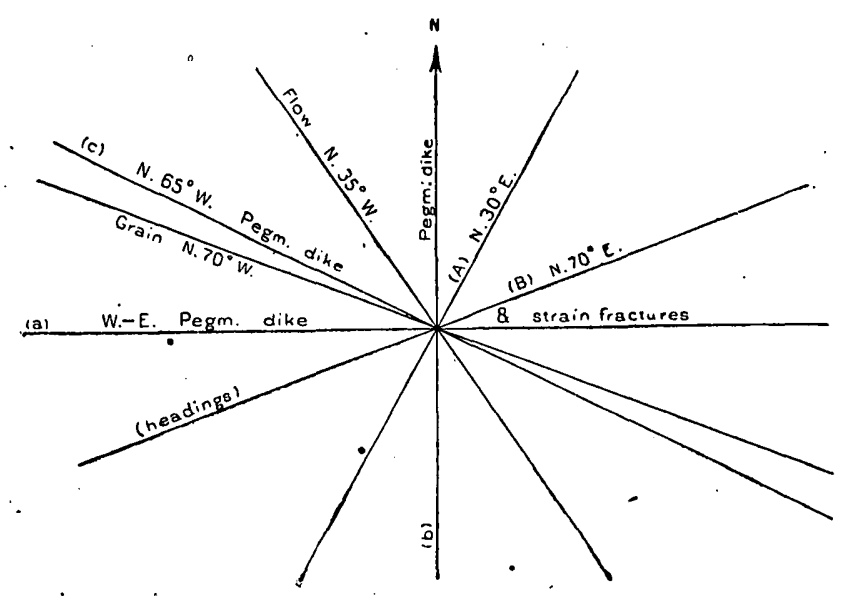

Fia. 21.-Structure at Tayntor (Melvin)-quarry, near Hallowell.

steam drills; 1 pneumatic plug drill; 1 surfacer; 1 polisher; 9 pneumatic hand tools, and 2 steam pumps. New machinery is to be put into the new building, which is in process of construction.

Transportation is by cartage, $1 \frac{3}{4}$ miles to the cutting shed and onefourth mile farther to wharf or railroad. The company's new works will have a dock at one end and railroad at the other.

The product is used for monumental work. Specimen monuments: The General Slocum monument at Gettysburg, Pa.; the State of Maine monument at Andersonville, Va.; the New .York State monument at Lookout Mountain (Craven House), Tennessee; the soldiers' monument at Pittsfield, Me.; the Dunlap mausoleum (Corinthian style, 16 by 28 feet); and the Ziegler mausoleum (Grecian Doric style, 25 by 34 feet, after the temple at Paestum), both at Woodlawn Cemetery, New York. Contracts in 1905: The General Miles mausoleum at Arlington, Va., and the Latham mausoleum at Hopkinsville, $\mathrm{Ky}$.

About 100,000 paving blocks are made annually from waste and thin sheets. 
KNOX COUNTY.

The quarries in Knox County are in Muscle Ridge Plantation and the towns of St. George, South Thomaston, Tenants Harbor, and Vinalhaven.

The High Isle quarry is in Muscle Ridge Plantation, $9 \frac{1}{2}$ miles southsoutheast of Rockland. Operator, William Gray \& Son ; office, Thirtieth street, below Walnut, Philadelphia, Pa.

The granite (specimen $18, a$ ) is a biotite granite of slightly pinkish medium-gray color, with conspicuous black mica and of medium to coarse, even-grained texture, the feldspars measuring up to one-half inch and most of the biotite scales up to one-tenth inch, but some onefifth inch. It consists, in descending order of abundance, of a delicate pink potash feldspar (orthoclase and microcline), smoky quartz, milk-white (very slightly bluish) soda-lime feldspar (oligoclase), and black mica (biotite), together with accessory magnetite, apatite, and secondary chlorite. The oligoclase is in some places partially altered to a white mica. The contrasts between the minerals are rather marked, but the polish is not very satisfactory, owing to the large size of the biotite scales.

The following chemical analysis and determination of specific gravity were made for the firm by Prof. James F. Kemp, E. M., of Columbia University :

\section{Analysis of granite from quarvy at High Isle quarry.}

$\mathrm{SiO}_{2}$ ( silica)

$\mathrm{Al}_{2} \mathrm{O}_{3}$ (alumina)

13. 30

$\mathrm{FeO}$ (ferrous oxide)

0. 79

$\mathrm{Fe}_{2} \mathrm{O}_{3}$ (ferric oxide)

0.92

$\mathrm{CaO}$ (lime)

1. 26

$\mathrm{MgO}$ (magnesia)

0.009

Mn (manganese)

0.51

$\mathrm{S}$ (sulphur)

$\mathrm{Na}_{2} \mathrm{O}$ (soda)

3. 69

$\mathrm{K}_{2} \mathrm{O}$ (potash)

5. 01

100.067

Loss on ignition, 0.55 .

Specific gravity, 2.641, equal to 165.06 pounds per cubic foot.

The results of four crushing tests on cubes (2-inch) bedded with plaster of Paris, made at the engineering laboratory of Columbia University for the firm, are as follows: First crack at 100,000 to 126,300 pounds. Ultimate strength in pounds per square inch, 25,880 , $32,360,32,495,33,085$. (Laboratory Nos. 1759 to 1761.)

The quarry, opened about 1894, consists of five openings, each about 100 feet square, with a maximum depth of 50 feet and an average 
depth of about 17 feet. The drainage requires pumping. The stripping is insignificint, but in places is from 5 to 10 feet thick.

Rock structure: The sheets, which are from 2 to 14 feet thick, are lenticular, tapering, and curve over to the northwest and southeast at low angles. (See Pl. VIII, A.) Joint courses are shown in fig. 22. System $\mathrm{A}$ is prominent and forms a heading on the south side of the island, shown in Pl. VIII, A. B dips $40^{\circ}$ SE., occurs but occasionally, and is discontinuous. C also forms a heading. D dips $65^{\circ}$ $\mathrm{SW}$. and is also prominent. The rift is vertical, with east-west course. Irregular horizontal dikes of pegmatite, up to 2 inches thick, consist of the same minerals as the granite-a pink orthoclase and microcline, smoky quartz, cream-colored oligoclase, and biotite. Sap occurs along the sheets and joints $\mathrm{A}$ and $\mathrm{C}$, and markedly at the surface in places up to a foot in thickness. (For details see p. 53 and

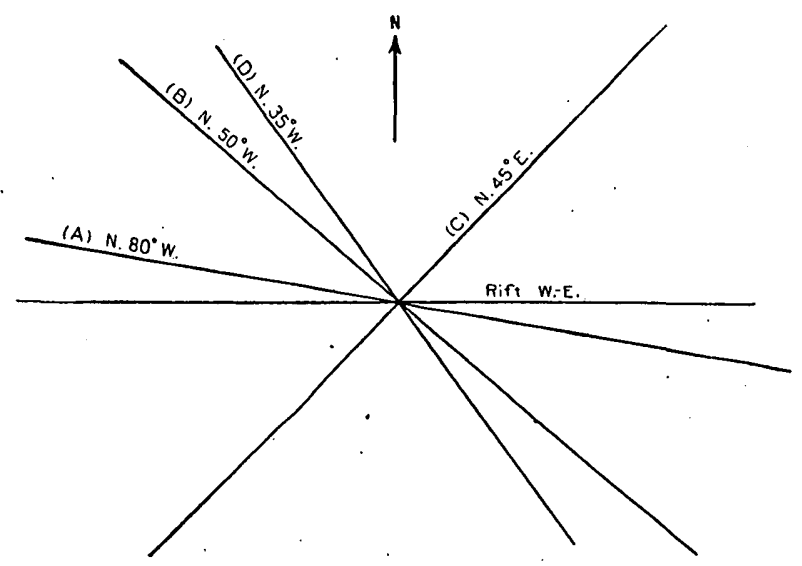

FIo. 22.-Structure at Figh Isle quarry, Knox County.

fig. 2.) Along some of the headings of A the granite is weathered to a sand at a depth of 20 feet.

The plant consists of 9 derricks, worked by 8 engines; 2 locomotive cranes, 2 compressors (with a capacity of 862 cubic feet per minute), 15 large pneumatic drills, 28 pneumatic plug drills, 13 surfacers, and 20 pneumatic hand tools.

Transportation is effected by gravity and track 650 feet to wharf.

The product is used for buildings, chiefly in Philadelphia. Sundry small buildings and bridge seats for the Pennsylvania Railroad have been made of this stone. Contract in 1905: The new Wanamaker store in Philadelphia.

Dix Island quarries, Muscle Ridge Plantation, one-half mile southwest of High Isle. Owner, Thomas Dwyer, 1613 Amsterdam avenue, New York.

Six openings were operated extensively in 1880 by the Dix Island 
Granite Company, which employed 1,400 men when filling large contracts. These quarries furnished material for the United States Treasury Department extension at Washington, the basement of the Charleston custom-house, the New York and Philadelphia post-offices, and the trimmings for the New York Metropolitan Museum of Art. Only an occasional block is now quarried. There is a wharf with 12 feet of water at low tide. These quarries are referred to by J. E. Wolff in Tenth Census, vol. 10, 1888, pp. 119, 120, and by G. P. Merrill in Ann. Rept. Smithsonian Inst., pt. 2, 1889, p. 416.

The granite (specimen 19, $a$ ) is a biotite granite of somewhat dark gray shade and of medium to coarse even-grained texture, with feldspars up to one-half inch and numerous fine biotite scales rarely exceeding one-tenth inch. It consists, in descending order of abundance, of delicate pink potash feldspar (orthoclase and microcline), smoky quartz, a very slightly bluish white soda-lime feldspar (oligoclase), and black mica (biotite), together with accessory magnetite and apatite. The oligoclase is partly altered to a white mica and rarely contains a little calcite. The biotite is here and there interleaved with muscovite. The chief difference between this and the High Isle granite is that in this the biotite scales are generally smaller and much more abundant, which darkens the shade of the rock and diminishes the contrast between the minerals.

Rock structure: The sheets are from 2 to 10 feet thick and dip $20^{\circ}$ to $40^{\circ} \mathrm{S}$. in places. Headings strike N. $80^{\circ}$ E. and N. $35^{\circ} \mathrm{W}$.

The Sprucehead quarry is on Sprucehead Island, in the town of St. George, about 10 miles south of Rockland. Operator, Bodwell Granite Company, Rockland, Me.

The rock (specimen $10, a$ ) is a quartz monzonite, with conspicuous black and white particles and medium to coarse even-grained texture, consisting, in descending order of abundance, of translucent white soda-lime feldspar (oligoclase), milk-white potash feldspar (microcline), smoky quartz, black mica (biotite), and black hornblende, together with accessory titanite, magnetite, pyrite, zircon, apatite, and secondary epidote. Zonal structure is common in the oligoclase. The contrasts between the black minerals, the smoky quartz, and the feldspars are very marked.

The quarry is about 275 feet by 250 feet and has a maximum depth of 55 feet and an average depth of about 27 feet. Those parts of the quarry that lie below sea level require pumping. No stripping is necessary.

Rock structure: The sheets, which range in thickness from less than a foot to 13 feet, lie horizontal or dip from $10^{\circ}$ to $15^{\circ}$ northwest and southwest, intersecting the surface, which dips gently southeast. The sheets are irregular in thickness, owing to the tapering out of the lenses, but in general increase in thickness downward. Joints 
and dike courses are shown in fig. 23. A recurs frequently on the north side of the quarry, but two joints are 50 feet apart and have greatly facilitated the opening of the quarry. B dips $70^{\circ} \mathrm{N}$., traversing the entire quarry. The rift is vertical with a N. $60^{\circ}$ E. course. Knots and dikes occur. Sap is 3 inches thick on the sheet surfaces.

The plant consists of 4 derricks, operated by 4 engines; 1 compressòr, with a capacity of 527 cubic feet of air per minute; 2 steam drills; 3 surfacers. Pneumatic drills and tools were about to be added.

Transportation is effected by cartage 300 feet to wharf.

The quarry was idle in July, 1905, but preparations were being made for resuming work.

The product, consisting chiefly of building stone and some random and paving blocks, finds a market mostly in the West and South. Specimen buildings, etc.: Carnegie Library at Alleghany, Pa.; the

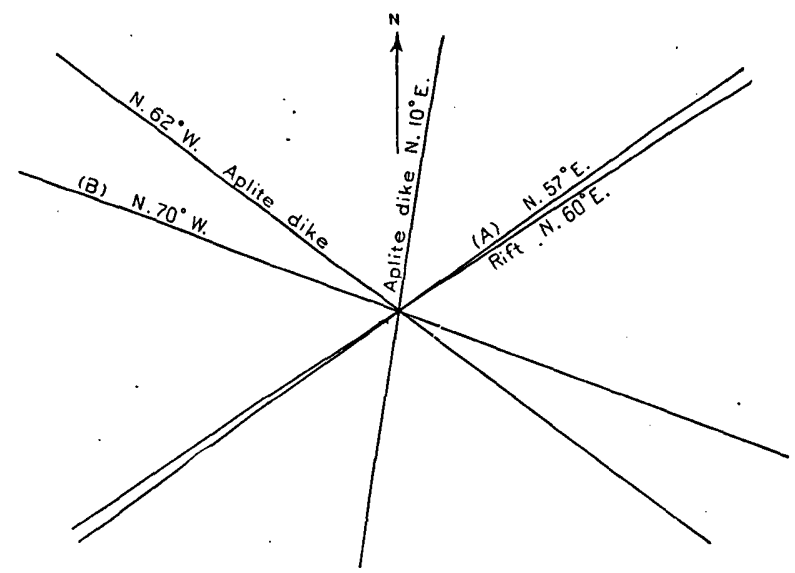

Fia. 23.-Structure at sprucehead quarry, st. Cieorge.

new post-office and custom-house at Atlanta, Ga.; the columns of the Auditorium building, Chicago, Ill.; the Mutual Life Insurance Company's building, New York.

T'he Clark, Island quarry is on Clark Island, in the town of St. George, about 12 miles south-southwest of Rockland. Operator, John C. Rodgers; office, 1909 Amsterdam avenue, New York,

The granite (specimen 12, a) is a biotite-muscovite granite of bluish, medium-gray color and of fine to medium even-grained texture, with feldspar up to one-fourth inch and mica under one-tenth inch. It consists, in-descending order of abundance, of light-bluish potash feldspar (microcline and orthoclase), clear: or very slightly smoky quartz, light-bluish soda-lime feldspar (oligoclase), black mica (biotite), and white mica (muscovite), together with accessory garnet, zircon, apatite, and secondary chlorite. The oligoclase is partly 
altered to a white mica and includes a little carbonate. The quartz contains hairlike crystals of rutile (?). In general, as the quartz is so nearly clear, the bluish tint of the feldspar dominates and the contrast is mostly between it and the thickly disseminated black mica. It takes a very fine polish.

Mr. E. C. Sullivan, of the United States Geological Survey, finds that this granite contains 0.218 per cent of $\mathrm{CO}_{2}$ (carbon dioxide), and that warm dilute acetic acid extracts 0.24 per cent of $\mathrm{CaO}$ (lime), and much $\mathrm{MgO}$ (magnesia). Figuring the $\mathrm{CO}_{2}$ to both $\mathrm{CaO}$ and $\mathrm{MgO}$, this would give 0.43 per cent of $\mathrm{CaCO}_{3}$ (lime carbonate) and 0.06 per cent of $\mathrm{MgCO}_{3}$ (magnesium carbonate). As. stated above, the thin section also shows carbonate.

Two tests of the crushing strength of this stone, made by the Pittsburg Testing Laboratory (Limited) in March, 1899 (laboratory No. $13396,13397)$, yielded 13,000 and 15,175 pounds per square inch, and are given here merely for reference.

The quarry, opened about 1870 , is 500 by 300 feet, and has a maximum depth of 50 feet and an average depth of 25 feet. A very little pumping suffices for drainage. There is no stripping.

Rock structure: The sheets, from 2 to 10 feet thick, strike N. $30^{\circ}$ W. and dip $20^{\circ} \mathrm{E}$., and on the east side of the quarry $20^{\circ}-30^{\circ} \mathrm{W}$. They do not conform to the topography of the surface. Vertical joints strike N. $65^{\circ}-7.0^{\circ} \mathrm{W}$., recurring at intervals of 10 to 20 feet. The rift is vertical, with a $\mathrm{N} .85^{\circ} \mathrm{W}$. course. There are two dikes of coarse pegmatite, up to 6 inches thick, one striking $\mathrm{N}$. $15^{\circ} \mathrm{W}$., the other N. $40^{\circ}$ E. They consist of feldspar, quartz, muscovite, biotite, black tourmaline, and red garnet. The usual sap occurs along the sheets.

The plant consists of 8 derricks and 8 hoisting engines, 1 overhead traveling electric crane of 16 tons capacity and 1 hand crane of 2 tons capacity; two compressors (capacity 850 and 300 cubic feet of air per minute), 4 steam drills, 7 pneumatic plug drills, 8 surfacers, 2 polishers (Jenny Lind), 2 small polishing lathes, 22 pneumatic hand tools, and 2 steam pumps, throwing 6 -inch and 4 -inch streams.

Transportation is effected by horse power on track $900-1,200$ feet long, extending to wharf.

The product is used for building and ornamental work. Specimen buildings: The Hartford, Conn., and Buffalo, N. Y., post-offices; the Standard Oil building in New York. In 1905 the cutting plant was working on Stonington granite for the United States dry dock at Norfolk, Va.

The McConchie black-granite quarry, in the town of St. George, about three-fourths mile north of Long Cove quarry. Operator, George McConchie (Crown Granite Works) ; office, South Thomaston. 
The rock (specimen 16;a) is a norite of very dark gray shade and fine to medium texture, consisting, in descending order of abundance, of an unaltered colorless to smoky feldspar containing both soda and lime (andesine to labradorite), hypersthene partly altered to brown hornblende, black mica (biotite) in scales up to $0.2 \mathrm{inch}$, and magnetite, together with accessory pyrite.

The quarry, opened in 1888, is about 50 feet square and from 10 15 feet deep and is provided with one derrick.

The stone has to be carried 10 miles to the cutting works at South Thomaston, although the quarry itself is within one-fourth mile of seaboard.

The product is used entirely for monuments. Specimen structures: The soldiers' monuments at Warren and Union, in Maine.

The Flat Ledge quarry, in the town of St. George, north of Clark Island, consists of several small openings ("motions") operated by Edwin Edwards. Address, Clark Island.

The granite (specimen 13,a) is a biotite-muscovite granite of clarkgray color and fine, even-grained texture, with flow structure, consisting, in descending order of abundance, of a white potash feldspar (microcline and orthoclase), clear or barely smoky quartz, white sodalime feldspar (oligoclase), black mica (biotite), and white mica (muscovite). But for its fine texture and less abundant muscovite this granite would belong in group 10, page 74 .

The paving blocks are carted $1 \frac{1}{4}$ miles to wharf.

The Weskeag quarry is in the town of South Thomaston, 1 mile west of Pleasant Beach, which is 7 miles south of Rockland. Operator, C. E. Hudson, South Thomaston.

The granite (specimen $142, a$ ) is a biotite-muscovite granite of slightly bluish medium-gray color and of medium to coarse, evengrained texture, with feldspars up to one-half inch and mica 0.15 inch. It consists, in descending order of abundance, of light-bluish potash feldspar (orthoclase and microcline), smoky quartz, bluish or white soda-lime feldspar (oligoclase), black mica (biotite), and white mica (muscovite), together with accessory garnet, magnetite, and apatite. The oligoclase is partly altered to kaolin and a white mica. Thin sections show a marked rift, described on page 27 and shown in fig. 1 (p. 28). The stone takes a fine polish, but the abundance and size of the mica plates are not favorable to the durability of the polish under outdoor exposure.

The quarry, reopened in 1905, and still in process of development, covers about an acre of ground and has an average depth of 20 feet. The sheets are horizontal and tapering, lenticular. Joints strike N. $80^{\circ}$ E. and $\operatorname{dip} 80^{\circ}$ south. Rift is vertical and strikes N. $80^{\circ} \mathrm{E}$. Grain is horizontal. (Quarry data collected by Mr. E. S. Bastin, of the United States Geological Survey.) 
The plant consists of 2 derricks, 1 hoisting engine, 1 steam drill, and 1 steam pump.

Transportation is effected by cars and horsepower on a track onehalf mile long to wharf near Birch Point.

The Long Cove quarry is in the town of Tenants Harbor, on Long Cove, St. George River, about 13 miles southwest of Rockland. Operator, Booth Brothers \& Hurricane Isle Granite Company; offices, Rockland, Me., and 207 Broadway, New York.

The granite is a biotite-muscovite granite of bluish medium-gray color and of fine to medium even-grained texture like that of the Clark Island quarry, described on page 125. Tests of its compressive

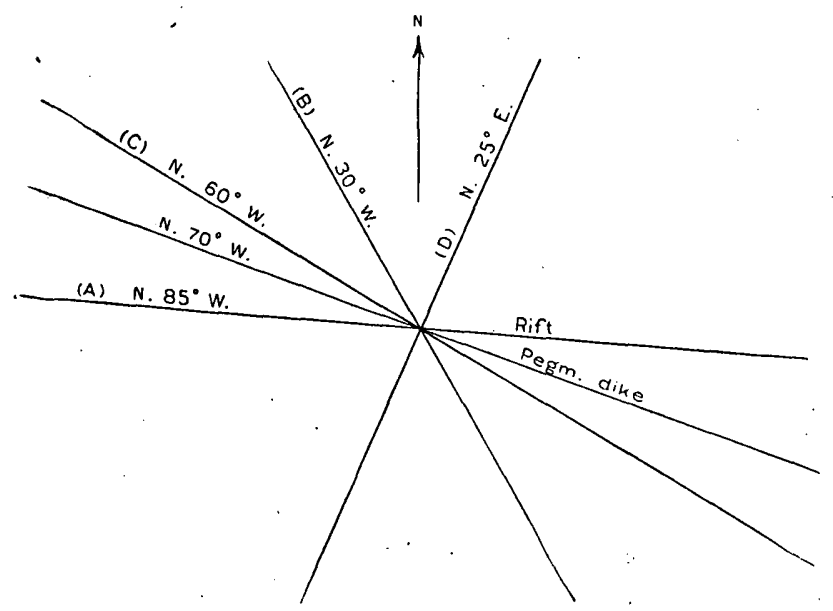

Fig. 24.-Structure at Long Cove quarry, Tenants Harbor.

strength made by the Columbia School of Mines are reported by the firm to have shown an ultimate crushing strength of 22,000 pounds per square inch, but the original report of these tests has been misplaced.

The quarry, opened about 1873 , measures about 1,000 feet from north to south by 500 feet from east to west, and ranges in depth from 20 to 75 feet, averaging about 40 feet. Its drainage involves pumping with 4-inch pipe during rainy season. This is the only quarry in the State in which tunneling is resorted to in the use of explosives. (See p. 71.)

Rock structure: The sheets, from 6 inches to 13 feet thick, are horizontal; or dip $10^{\circ}$. Joints and dike courses are shown in fig. 24. A recurs at intervals of from 2 to 30 feet, $\mathrm{B}$ dips $25^{\circ}, \mathrm{C}$ dips $65^{\circ} \mathrm{N}$. E. The east end of the quarry is much broken up by the closeness of joints $\mathrm{A}$ and the thinness of the sheets for a considerable distance below the surface. The rift is vertical with $\mathrm{N} .80^{\circ}-90^{\circ} \mathrm{W}$. course. There is a horizontal dike of pegmatite up to 9 inches thick 
at the north end of the quarry; another, divided into many parallel ones, strikes N. $70^{\circ} \mathrm{W}$. and dips $70^{\circ} \mathrm{N}$. These dikes all consist of white feldspar, quartz, muscovite, black tourmaline, and garnet. Sap occurs up to 18 inches thick along sheets and joints.

The plant consists of 1 derrick and 1 hoisting engine, 1 Blondin carrier, 1 locomotive crane, 1 compressor (capacity 560 cubic feet of air per minute), 3 steam drills, 3 pneumatic plug drills, and 1 steam pump.

Transportation is effected by inclined track 900 feet to wharf.

The product is used chiefly for monumental work, being specially aaapted to rough face and fine work. It goes chiefly to Greenwood and other cemeteries near Brooklyn, N. Y. The small beds and waste are worked into paving blocks. Specimen buildings, etc.: Albany post-office, Bates Building, Philadelphia, and part of Saratoga monument.

\section{THE QUARRIES OF VINALHAVEN AND HURRICANE ISLANDS.}

These and the adjacent islands have been known collectively as the Fox Islands and their granite as Fox Island granite. The granite industry of these islands is distributed over an area about 5 miles from east to west by 4 miles from north to south. The locations of the quarries are shown on the map fig. 25. Some of them are near the center of Vinalhaven Island. The Palmer quarry is on the west shore; the Black and Webster quarries are on the east shore; the Sands, Harbor, and Armbrust quarries are on the south shore, near: Vinalhaven village, while the Pequoit and Duschane Hill quarries lie east of the village near the east shore. There are some minor quarries ("motions") on Barton, Gundelow, and Green islands, and, finally, there is the important quarry on Hurricane Island. As will be seen from the descriptions, there is little difference between the coarse granites of the Hurricane Isle, Sands, Harbor, Armbrust, Black, Webster, and Palmer quarries, but the. Duschane Hill and Pequoit quarry granites are fine textured, as is also that from an abandoned opening in Vinalhaven village.

PI. II, $A$, shows the conspicuous east-west jointing in the granite on Heron Neck at the south end of Green Island. The same system of joints recurs on Hurricane Island and at the Sands and Armbrust quarries.

The Sands quarry is in the town of Vinalhaven, at the northeast side of the head of Sand Cove (see maps, Pl. I and fig. 25). Operator, Bodwell Granite Company ; office, Rockland, Me.

The granite (specimen $1, b$ ) is a biotite granite of general pinkishbuff, medium-gray color and of coarse, even-grained texture, the feldspars measuring up to three-fourths inch (rarely 1 inch) and the 3495-Bull. 313-07-9 
biotite scales up to two-tenths inch. It consists, in descending order of abundance, of a pinkish-buff potash feldspar (chiefly orthoclase with some microcline), smoky quartz, milk-white soda-lime feldspar (oligoclase), and black mica (biotite), together with accessory magnetite, zircon, and apatite. The orthoclase here and there contains irregular areas of carbonate, is intergrown with a plagioclase, or

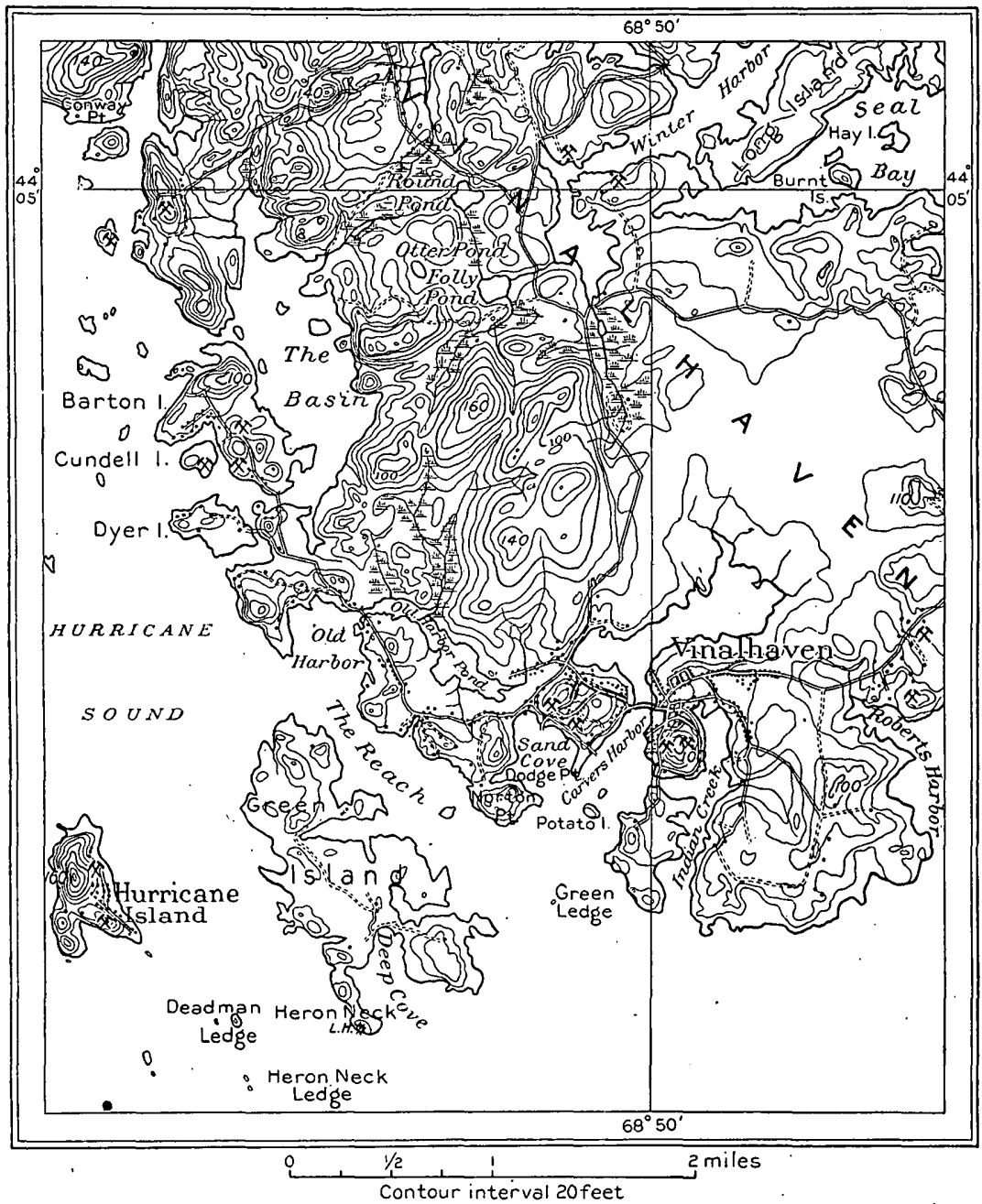

Fla. 25.-Map showing location of guarries in Fox Islands. (From Vinalhaven sheet of Topographical Atlas of the United States, U. S. Geol. Survey.)

rimmed with oligoclase. The oligoclase is partially altered to kaolin and a white mica. Pyrite is found by the quarrymen in rare and minute particles, and molybdenite occurs occasionally in half-inch scales. Mr. E. C. Sullivan, of the United States Geological Survey, finds that this granite contains 0.034 per cent of $\mathrm{CO}_{2}$ (carbon diox- 
ide), and that warm dilute acetic acid extracts 0.07 per cent of $\mathrm{CaO}$ (lime), and a trace of $\mathrm{MgO}$ (magnesia). This, if the $\mathrm{CO}_{2}$ is allotted to the $\mathrm{CaO}$, shows a percentage of 0.08 of $\mathrm{CaCO}_{3}$ (limecarbonate), the presence of which mineral is also indicated by the microscope. The stone takes a fine polish, but the size of the mica plates does not favor the durability of the polished face under continued exposure. The contrasts of color and shade are chiefly between the two feldspars and the black mica.

The quarry, opened before 1860, now measures about 500 feet from northeast and north-northeast to southwest and south-southwest and about the same distance from northwest to southeast, and ranges in depth from 20 to 75 feet, averaging about 40 feet. The excavation has not only cut down a granite hillock, but has extended below the general land level. Pl. VI, $A$, shows the south-southeast end of the

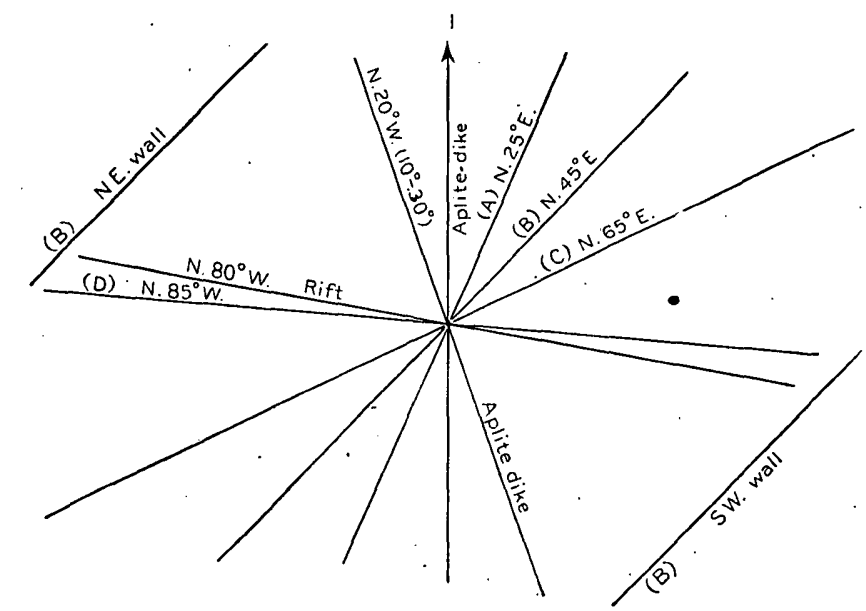

FIG. 20.--Structure at Sands quarry, vinalhaven.

quarry. The surface drainage, as well as the water that exudes from between the sheets, is collected in the deeper, now unused parts of the quarry and supplies the boilers. No stripping seems to have been necessary.

Rock structure: The sheets, from 1 to 20 feet thick-generally, however, from 2 to 10 feet-lie flat along an east-west axis for a width of about 200 feet, but on either side curve over gently to the north and south, with dips of $5^{\circ}, 10^{\circ}$, and $20^{\circ}$. The joint and vein courses are shown in fig. 26. Joints $\mathrm{B}$ form the northwest and southeast walls of quarry. Joints $\mathrm{C}$ are coated in places with crystalline calcite to the thickness of one-fourth inch, or with hematite, chlorite, and stilbite in microscopic films. (Determination of stilbite by Mr. W. T. Schaller, of the United States Geological Survey.) The rift is vertical, with a N. $80^{\circ}$. W. course. The "hard-way" or 
"cut-off" is N. $10^{\circ}$ E. Blocks 65 and 120 feet long have been obtained by splitting along the rift. The thickness and curvature of the sheets, the intersecting joint face, and the channeling along the "cut-off" are shown in Pl. VI, A. Dikes of grayish aplite, described in detail on page 43, measure from 1 to 7 inches in thickness. There are occasional dark-gray knots (see p. 49 for description) of more biotitic granite, measuring up to 2 feet in length and 4 inches in width, and some of spheroidal form, with a diameter of $2 \frac{1}{2}$ feet. Sap is 4 inches wide on either side of joints A, B, D, and also along the sheet surfaces, but is there less marked. The unhewn weathered surface about the quarry passes into a granite sand, with little or no staining by limonite.

The plant consists of 5 derricks, operated by 3 engines, 2 surface traveling cranes (of 20 and 10 tons capacity), 2 Ingersoll \& Sargent steam-driven compressors (each of 850 cubic feet per minute capacity), 4 large pneumatic drills, 8 pneumatic plug drills, 1 channeler, 8 surfacers, 6 polishers, 2 granite lathes (one for 30 -foot columns, 5 feet in diameter, the other for small columns and balusters), 6 polishing lathes, 35 pneumatic hand tools, and several steam pumps.

Transportation is effected by railroad 500 feet long to wharf, which admits schooners of 200 to 800 gross tons capacity.

The product is used for docks, bridges, piers, buildings, and monuments. The thin sheets and much of the waste are made into paving blocks 12 by 4 by 7 to 8 inches. Pl. XIII, A, shows how the granite of this quarry lends itself to coarse sculpture. The principal markets are New York, Philadelphia, and Washington. Specimen structures made exclusively of Sands quarry granite: New post-office, Washington, D. C.; Masonic Temple, Philadelphia; savings bank, Wilmington, Del.; new board of trade building, Chicago; new post-office and custom-house, Brooklyn, N. Y.; Manhattan Bank, New York; General Wool monument, Troy, N. Y. The Sands quarry and the Palmer quarry together furnished all the stone for the new custom-house in New York.

In 1905 the following contracts were undertaken: The Altman Building, Thirty-fourth street and Fifth avenue, and the West Street office building, West, Cedar, and Albany streets, in New York, and some docks in the same city.

The Palmer or Wharfi quarry, in the town of Vinalhaven, west side, opposite Leadbetter Island. (See map, fig. 25.) Operator, Bodwell Granite Company, Rockland, Me.

The granite (specimen $2, b$ ) is a biotite granite of general pinkishbuff medium-gray color and of coarse texture, the feldspars measuring up to three-fourths inch and the biotite scales up to two-tenths inch. It is identical with that of the Sands quarry (see p. 129), 
except that the potash feldspar is a little more pinkish buff and the white soda-lime feldspar is of a slightly greenish tinge. The general tone of the color is "warmer." The thin section shows rarely a little hornblende.

The quarry is on the west side of a 100 -foot high ridge. It measures about 500 feet square and has an average depth of 25 feet. No stripping or pumping is necessary.

Rock structure: The sheets dip $10^{\circ} \mathrm{W}$. in the front (western) part of the quarry, but gradually turn at the back or working face to $10^{\circ} \mathrm{E}$. They range in thickness from 4 to 15 feet. About 20 feet below the top of the quarry face is a bed of granite sand, 18 inches thick, parallel to the sheets, already referred to on page 55. The principal joints strike N. $80^{\circ} \mathrm{W}$. and dip $80^{\circ} \mathrm{S}$., forming a 5 -foot heading at the south end of quarry, and recurring but once or twice. The rift is vertical, trending N. $10^{\circ} \mathrm{E}$. Owing to the structure here, it is usual to blast by lewis holes along the grain (eastwest) and then to split by plug drilling along the rift; in this way thick sheets can be split along the grain a distance of 200 feet. One block loosened measured 300 feet along the grain by 120 feet along the rift and was 15 feet thick. Dikes of aplite are rare. A knot from this quarry is described in detail on page 49. Sap measures up to 6 inches in thickness along the sheet and joint surfaces. It is intense in color at the surfaces.

The plant consists of 5 derricks, 2 hoisting engines, 2 steam drills, 1. Ingersoll \& Sargeant Duplex steam-driven air compressor (capacity, 525 cubic feet of air per minute), 1 channeler, 7 pneumatic plug drills, and 1 granite lathe, capable of carrying columns 70 by 7 feet, made by Cheney \& Spiller, of Boston.

Transportation is effected by cartage of 700 feet to wharf, where the blocks are laden on schooners and taken either to the cutting sheds at the Sands quarry or directly to market.

The product is used chiefly for bridges and buildings, and the waste is made into paving blocks. This quarry, in common with the Sands quarry, furnished the material for the new New York customhouse. It supplied also 8 columns, $51 \frac{1}{2}$ to 54 feet long by 6 feet in diameter, for the cathedral of St. John the Divine in New York. It was intended that they should each be of one piece, but as both the direction of the rift at the quarry and architectural principles required that they be cut with their long axes at right angles to the rift, the strain in the great lathe came upon the weakest part of the stone. However, as the first stone put into the lathe broke with a long diagonal fracture, it became evident that the chief difficulty was that the stone had been subjected to too great a torsional strain by the application of rotary power from one end only. It therefore 
became necessary to make each column of two sections, each about 26 feet long. Pl. XIII, $B$, shows the lathe with the first full-length column in it and three others as originally prepared for it.

The Webster quarry is in the town of Vinalhaven, on the north shore of "Pleasant River," at end of Winter Harbor, in the northern part of Vinalhaven Island. Operator, A. M. Webster \& Co., Vinalhaven.

The granite is a biotite granite identical with that of the Palmer quarry, described on page 132.

The quarry, opened in 1899, is 150 feet N. $30^{\circ} \mathrm{W}$. by 200 feet across and between 10 and 20 feet deep. The tide reaches its lower part. There are $2 \frac{1}{2}$ feet of stripping.

Rock structure: The sheets, from 5 to 10 feet thick, dip $10^{\circ}$ to $15^{\circ}$ N. $30^{\circ}$ E. Vertical joints strike N. $30^{\circ}$ W. and N. $60^{\circ}$ E. The rift is vertical, with $\mathrm{N}$. $30^{\circ} \mathrm{W}$. course. There are some knots. A spherical one measures 5 feet in diameter. Sap is 3 inches thick along sheets and joints.

The plant consists of 3 derricks and 3 hoisting engines.

Transportation is effected on a graded track 200 feet to wharf that admits schooners of 300 to 350 long tons. Pl. XII, $A$, shows the quarry, and a schooner laden with granite.

The product is used for buildings in New York and Boston. It is shipped in the rough.

The Black (Pleasant River) quarry is in Vinalhaven town, on the south shore of Pleasant River, at end of Winter Harbor, in the northern part of Vinalhaven Island. Operator, Joseph S. Black, Vinalhaven. .

The granite is a biotite granite, identical with that of Webster quarry and Palmer quarry, described on page 132.

The quarry, opened in 1896, measures 300 feet in a N. $40^{\circ} \mathrm{W}$. direction by 200 across and has a working face 45 feet high. The drainage is used to supply the boiler. There is 1 foot of stripping in places.

Rock structure: The unworked surface above the quarry is very free from joints, knots, and veins. The sheets, from 10 to 12 feet thick, are horizontal at the working face or back of the quarry, but at the front dip $10^{\circ}-15^{\circ} \mathrm{W}$. Vertical joints strike N. $20^{\circ} \mathrm{E}$. The rift is vertical, with course N. $40^{\circ} \mathrm{W}$. Knots are from 6 inches to 2 feet 6 inches in diameter. No dikes.

The plant consists of 3 derricks, 2 engines, and 2 steam drills.

Transportation is effected by a 350 -foot track, with a grade of 10 feet to wharf.

The product is used for building, the waste for riprap. It is marketed in New York, Philadelphia, and Boston. The quarry has 
furnished material for the dry dock at Portsmouth, N. H., and the Rain Island light-house. In 1905 it was supplying blocks for a private residence at Gladstone, $\mathrm{N}$. Y.

The Pequoit quarry is in the town of Vinalhaven, $1 \frac{1}{4}$ miles eastnortheast of Vinalhaven village, on Vinalhaven Island. Operator, Booth Brothers \& Hurricane Isle Granite Company, Rockland, Me.

The granite (specimen $7, a$ ) is a biotite-hornblende granite of medium-gray shade and fine even-grained texture, with porphyritic feldspars up to one-fourth inch in length. It consists, in descending order of abundance, of a whitish, translucent potash feldspar (orthoclase, with a very little microcline), smoky quartz, a whitish soda-lime feldspar (oligoclase), black mica (biotite), and dark hornblende, together with accessory magnetite, titanite, apatite. The orthoclase is here and there intergrown with a plagioclase. The orthoclase is in places altered to kaolin and a white mica and includes occasionally some carbonate. The porphyritic crystals are orthoclase.

The quarry, opened in 1887, consists of two openings, each about 250 feet square and about 10 feet deep. Drainage is effected by a 2-inch siphon, 240 feet long.

Rock structure: The sheets, from 1 to 6 feet thick, dip $10^{\circ}-15^{\circ}$ N. $80^{\circ}$ W. Vertical joints strike N. $80^{\circ}$ W. and N. $5^{\circ}-10^{\circ}$ E. The rift is vertical, striking $\mathrm{N} .5^{\circ}-10^{\circ} \mathrm{E}$.

There is no machinery. The product is carted one-third mile to the narrows and there shipped.

The product consists entirely of paving blocks (10 to 14 by 4 to 5 by 6 to 7 inches) which go to New York and Philadelphia. In 1905 an order was being filled for New Jersey.

The Duschane Hill quarry, in the town of Vinalhaven, $1 \frac{1}{4}$ miles east of Vinalhaven village, on Roberts Harbor. Owned by Bodwell Granite Company, but no longer operated. Office, Rockland, Me.

The granite (specimen $8, a$ ) is a biotite granite of medium buffgray color and of fine to medium porphyritic texture, with most of the feldspars about one-fifth inch long, but some one-third or onehalf inch long. The rock consists, in descending order of abundance, of a buff-gray potash feldspar (orthoclase), smoky quartz, a buffgray soda-lime feldspar (oligoclase), and black mica (biotite), together with secondary chlorite. The orthoclase is intergrown with plagioclase and the oligoclase is partly altered to kaolin and a white mica.

This stone was used for paving blocks.

The Armbrust quarry is in the town of Vinalhaven, between Carvers Harbor and Indian Creek, south of Vinalhaven village. Operator, J. P. Armbrust, Crown Hill Granite Works. Office, Vinalhaven.

The granite is a biotite granite similar to that of the Sands quarry described on page 129 . 
The quarry consists of numerous openings on several sides of a hillock 100 feet high.

Rock structure: The sheets, 3 to 15 feet thick, are horizontal, but on the east side of the hill dip $10^{\circ} \mathrm{S}$. Vertical joints strike N. $75^{\circ}-$ $80^{\circ}$ W., and also N. $30^{\circ}-35^{\circ}$ E. There is no marked rift, but a vertical mass 4 feet thick, striking N. $65^{\circ}$ W. across the hill, has a horizontal rift and greatly facilitates quarrying, as it serves the purpose of a channel.

'The plant consists of 3 hand derricks, 2 steam derricks, 1 horse derrick, and 3 big wagons. Pl. XII, $B$, shows the character of this work.

Transportation: The product is carted in 7 to 10 ton loads onefourth to one-half mile to wharf on Carvers Harbor.

The product consists entirely of paving blocks, which find a market in New York, Newark, and Philadelphia.

The Harbor quarry is in the town of Vinalhaven, on the east side of Sand Cove; near Vinalhaven village. Operator, Bodwell Granite Company, Rockland, Me.

The granite is a biotite granite like that of the Sands quarry, described on page 129, but is harder and is therefore discarded for structural uses and employed only for paving, according to demands.

The quarry is about 450 feet from northeast to south west by about 300 feet from northwest to southeast and from 10 to 40 feet deep.

The sheets, from 2 to 5 feet thick, lie horizontal on the top of the hill, but dip southeast and northwest up to $15^{\circ}$ at the sides. The joints are like those at the Sands quarry (fig. 26), but an additional set strikes N. $25^{\circ} \mathrm{W}$.

The Bodwell black-granite openings are in the town of Vinalhaven, in the diabase area west of Sand Cove. Operator, Bodwell Granite Company, Rockland, Me.

This rock (specimen $1 \frac{1}{2}, a$ ) is an olivine norite, of almost black color and of fine texture, consisting, in descending order of abundance, of a network of usually slender crystals (from 0.37 to $1.66 \mathrm{~mm}$. in length) of grayish unaltered lime-soda feldspar (labradorite to bytownite) filled with hypersthene, greenish olivine, black mica (biotite), and magnetite. It takes a very fine polish and cuts white. It is not obtainable in very large blocks. This stone is referred to by George P. Merrill. $^{a}$

The Gundelow quarry is on Gundelow Island, south of Barton Island, west of Vinalhaven Island. It produces paving blocks, but was not in operation in 1905 .

The George Gins quarry is at the north end of Green Island, between Vinalhaven Island and Hurricane Island. It produces paving 
blocks, but was reported as not in operation in 1905 and was not visited by the writer. The product of this quarry is purchased by Booth Brothers \& Hurricane Isle Granite Company.

The Hurricane Island quarry is in the town of Vinalhaven, in the southeast. part of Hurricane Island. (See map, fig. 25.) Operator, Booth Brothers \& Hurricane Isle Granite Company; office, 207 Broad. way, New York, and Rockland, Me.

The granite (specimen $4, a_{0}$ ) is a biotite granite of general pinkishbuff, medium-gray color, and of coarse, even-grained texture, the feldspars measuring up to three-fourths inch and the biotite scales up to two-tenths inch. It is identical with that of the Sands quarry, described on page 129. The potash feldspar is perhaps a trifte more pinkish buff than that of the Sands quarry, but not quite so much so as that of the Palmer quarry. These distinctions, however, are small, and may not hold throughout the quarries, although they do characterize the typical specimens selected for the writer by the superintendents of the respective quarries.

The following chemical analysis of Hurricane Island granite was made by Ricketts \& Banks, of New York, for the firm (No. 16073), and is inserted here for reference merely:

Analysis of granite from Hurricane Island.

' Per cent.

$\mathrm{SiO}_{2}$ (silica) -

$\mathrm{Al}_{2} \mathrm{O}_{3}$ (alumina) -

$\mathrm{FeO}$ (ferrous oxide) -

$\mathrm{CaO}$ (lime) -

MgO (magnesia) _._._._._. 0.19

MnO (manganese oxide) _... 0.13

$\mathrm{Na}_{2} \mathrm{O}$ (soda)

$\mathrm{K}_{2} \mathrm{O}$ (potash)

$\mathrm{S}$ (sulphur) total_... 0.05

CO.: (carbon dioxide) -

ross and undetermined....... 0.37

100.00

The following compression test was made by Prof. Ira H. Woolson, of the Columbia School of Mines. ${ }^{a}$ Ultimate crushing strength, 19,583 pounds per square inch.

The quarry, opened about 1876 , measures 500 feet along the rift $\left(\mathrm{N} .85^{\circ} \mathrm{W}\right.$.) and has an average width of 150 feet. It lies on the south side of a ridge 100 feet high with a west-northwest to eastsoutheast axis. The greatest depth of working face is 105 feet, and its average is about 50 feet. The drainage is saved to supply the boilers. There is no stripping.

\footnotetext{
"Published by William C. Day in Twentieth Ann. Rept. U. S. Geol. Survey, pt. (6, continued, 1899, p. 391 . ('Test No. 1709.)
} 
Rock structure: The sheets, from 3 to 20 feet thick, curve over on both the north and the south side of the ridge, with a dip of not less than $10^{\circ}$. Seen from the western spur of the island, two 20 -foot sheets form the upper part of the hill; beneath these, however, is a much thicker sheet, which at the east-southeast end of the hill and quarry measures fully 60 feet- - too thick for economic working. These sheets are shown in $\mathrm{Pl}$. IV, $A$, as seen looking northwest. This abnormally thick sheet is referred to by Merrill. ${ }^{a}$ The sheets are traversed by three sets of joints, as shown in figure 27 . A dips $50^{\circ}$ to $55^{\circ} \mathrm{W}$.; $\mathrm{B}$ is vertical, and $\mathrm{C}$, which is diagonal to $\mathrm{A}$ and $\mathrm{B}$, dips $40^{\circ} \mathrm{NE}$. The rift is vertical, with N. $85^{\circ} \mathrm{E}$. course. The eastwest system (B), which is parallel to the rift, reappears on Heron Neck, as shown in Pl.II, $A$. B and $\mathrm{C}$ are both shown on Pl. IV, $A$.

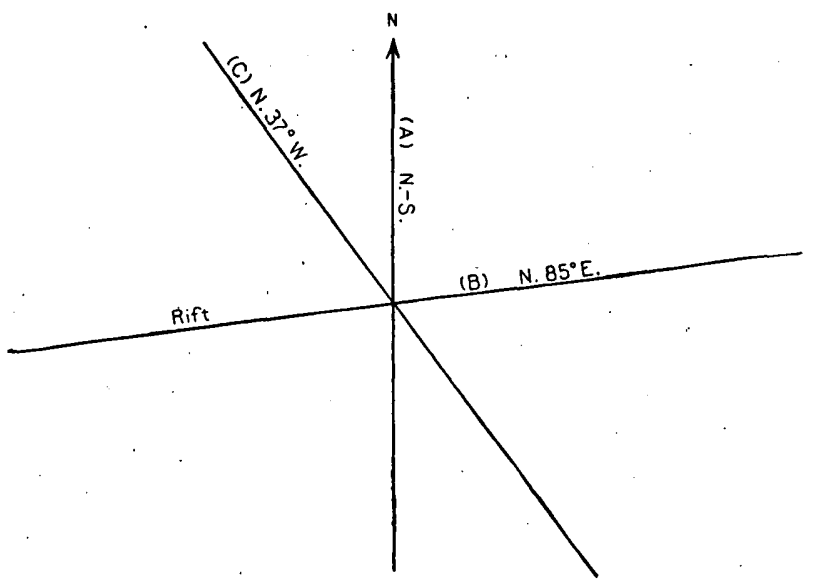

FIG. 27.-Structure at Furricane Island quarry; Knox County.

The B surfaces are, in places, coated with epidote. Occasional knots occur.

The plant consists of 8 derricks, run by 5 engines; 2 traveling steam cranes, 1 compressor (with capacity of 900 cubic feet of air per minute), 1 channeler, 6 steam drills, 23 pneumatic plug drills, 7 surfacers, 5 . polishing lathes ( 2 small and 3 for stones, 30 feet by 5 feet), 1 steel saw for sawing granite with chilled iron shot, 32 pneumatic hand tools, and 2 steam pumps.

- Transportation is effected by track, 400 feet long, to dock.

The product is used for buildings and monuments. The waste goess into paving blocks. The chief markets are New York, Philadelphia, and the interior. Specimen buildings: The Suffolk County court-house at Boston; the St. Louis post-office and custom-house; two buildings for the Naval Academy at Annapolis, Md.

"Ann. Rept. Smithsonian Inst., pt. 2, 1889, p. 415. 


\section{LINCOLN COUNTY.}

The quarries in Lincoln County are in the towns of Bristol, Waldoboro, and Whitefield.

The Round Pond quarry is in the town of Bristol, one-fourth mile east of Round. Pond village, and west of Muscongus Island. Operator, Peter Swensen \& Co., Round Pond, Me.

The rock (specimens $126 a, 126 \mathrm{~b}$ ) is a quartz diorite of very dark gray and medium-gray shades and of fine, even-grained texture, with feldspars up to one-fifth inch: The darker variety consists, in descending order of abundance, of bluish-white soda-lime feldspar: (oligoclase-andesine), clear quartz, black mica (biotite), potash feldspar (orthoclase and microcline), and magnetite, together with accessory titanite, zircon, apatite, and secondary calcite. The lighter consists of the same minerals, but with less biotite, so that it changes place with the potash feldspar in order of abundance. Both varieties take a fine polish and offer a very marked contrast between the polished and cut or hammered surface. Granite of the same shade affords no such contrast.

The quarry, opened in 1885, consists of two adjacent openings along a northwest-southeast line. The upper or northwestern one is 100 feet square; the lower is 400 feet (northwest-southeast) by 100 feet across, but with a central part 37 feet wide on each side-that is, 175 feet wide. These openings range in depth from 10 to 65 feet. Drainage is natural, the excavations not having gone below high-tide level.

Rock structure: Considerable scientific interest attaches to the geological relations at this quarry, as may be seen by the references to them on pages $44,48,60-62$. This quarry has been described by J. E. Wolff. ${ }^{a}$ The diorite underlies a mass of schist which strikes $\mathrm{N} .15^{\circ} \mathrm{E}$., and is traversed by dikes and lenses of coarse pegmatite. It also includes a tongue of this schist, as shown in Pl. XI, $B$, and is traversed by dikes of pegmatite, as shown in $\mathrm{Pl}$. $\mathrm{X}, B$, and $\mathrm{XI}, A$, and itself, in turn, is traversed, as is also its pegmatite, by a diabase dike. Thus the schists are older than the diorite, and the dike is later than the diorite and its pegmatite. The joint and dike courses are shown in fig. 28. The sheets, from 1 to 12 feet thick, dip $10^{\circ}$ south and also $10^{\circ}$ east, and are traversed by joints $\mathrm{A}$, which recur at intervals of 5 to 42 feet, and $B$, which recur but once or twice. There are bad headings on the northeast side of the quarry. The pegmatite dikes send out small branches. Sap, only 1 inch thick, occurs along the sheets. Knots measure up to 6 by 2 inches, but are rare. These sheets, joints, and dikes are shown in the plates referred to. The general result of this complex structure is that it is difficult to obtain many large blocks. 
The plant consists of 3 derricks, worked by oxen, and 2 steam polishers.

Transportation is by cartage of about 300 feet from the lower. quarry, and of possibly 800 to 1,000 feet from the upper one, to the wharf in Muscongus Bay.

The product is now used exclusively for monuments, and finds a market in New York, Pennsylvania, and the West. The waste goes into paving blocks.

Specimen monuments: The die of the Maine monument at Andersonville, Ga.; the base and die of the General Sheridan monument in the National Cemetery at Arlington, Va.

In 1905 finished monuments were being sent to New York, where the lettering was added.

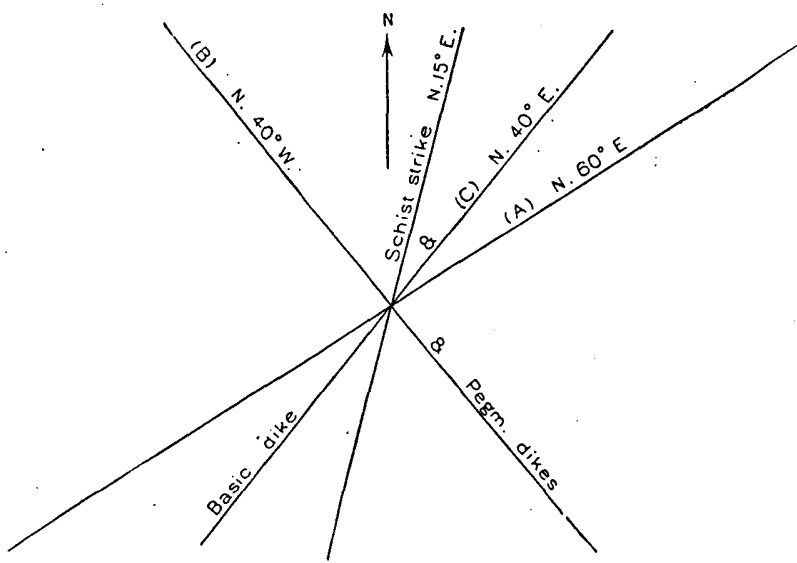

Fig. 28.-Structure at Round Pond diorite quarry, Bristol.

The Waldoboro quarry is in the town of Waldoboro, $1 \frac{1}{2}$ miles north of Waldoboro village, on the Boston and Maine Railroad. Operator, Booth Brothers \& Hurricane Isle Granite Company, 207 Broadway, New York, and Rockland, Me.

The granite (specimen 109,a) is a muscovite-biotite granite of medium-gray shade (a trifle darker than Hallowell granite, and still darker than North Jay granite) and of fine (inclining to medium) even-grained texture, some of the feldspars measuring up to onefourth inch, but the particles generally ranging from 0.36 to 2.56 $\mathrm{mm}$. in diameter: It consists, in descending order of abundance, of a whitish translucent potash féldspar (orthoclase and microcline), smoky quartz, whitish soda-lime feldspar (oligoclase), white mica (muscovite), and black mica (biotite), with accessory garnet. The feldspars are often intergrown with quartz in particles that are circular in cross-section. Some of the mica plates are bent, indicating slight (secondary) motion. Mr. E. C. Sullivan, of the United States 
Geological Survey, finds that this granite contains 0.045 per cent of $\mathrm{CO}_{2}$ (carbon dioxide) corresponding to a content of 0.10 per cent of $\mathrm{CaCo}_{3}$ (lime carbonate), and that warm dilute acetic acid extracts from it 0.11 per cent of $\mathrm{CaO}$ (lime). This granite contains sporadic particles or crystals, up to one-fourth or even one-half inch in diameter, of a milk-white mineral, which weathers readily, becoming yellowish and powdery, and finally leaves cavities. Dr. George P. Merrill, head curator of geology at the United States National. Museum, has examined this mineral, and finds it to be a feldspar lying between albite and oligoclase-that is, containing between 6 and 11 per cent of soda, therefore a little more soda than the sodalime feldspar of the granite itself, which is 5 to 5.5 per cent, and that the powdery material is very near kaolin. But he does not regard his results as perfectly satisfactory, nor does he understand why such a feldspar should weather so readily. The slightly higher percentage of soda indicated does not seem to him an adequate cause for the weathering, although minerals rich in soda do weather with comparative facility. Workmen report that when first decomposing this mineral protrudes beyond the granite surface.

The following analysis of the granite was made by Ricketts \& Banks, of New York, for the firm (No. 16074), and is given merely for reference:

\section{Analysis of granite from Waldoboro quarry.}

Per cent.

$\mathrm{SiO}_{2}$ (silica)

73.48

$\mathrm{Al}_{2} \mathrm{O}_{3}$ (alumina)

15. 26

FeO (ferrous oxide)

1. 42

$\mathrm{CaO}$ (lime)

0.88

$\mathrm{MgO}$ (magnesia)

0.09

MnO (manganese oxide)

$\mathrm{Na}_{2} \mathrm{O}$ (sodal)

$\mathrm{K}_{2} \mathrm{O}$ (potash)

S (sulphur) total _... Trace.

$\mathrm{CO}_{2}$ (carbon dioxide)

100. 01

The following test of compressive strength of Waldoboro granite was made by Prof. Ira H. Woolson of the Columbia University School of Mines: ${ }^{a}$ Number of test, 1714; crushing strength, 23,111 pounds per square inch.

The quarry, which was opened in 1860 , measures 400 . (N. $52^{\circ}$ E. to S. $52^{\circ}$ W.) by 140 feet across, and is of 60 to 85 feet deep. Its drainage requires pumping for about two hours a day and this supplies the boilers. There is no stripping.

a Published by William C. Day in Twentieth Ann. Rept. U. S. Geol. Survey, pt. 6, continued (1899), p. 391 . 
Rock structure: The geological relations at this quarry are of no little interest, as will be seen by the references to it on pages $15,4.5$, and by Pl. IX, A, and fig. 29. The granite is here in contact with the schist mass, which originally covered it and which at all the other Maine quarries, except those at Freeport and Round Pond, has been removed. On the northeast side of the quarry a mass of schist striking N. $72^{\circ} \mathrm{W}$. and dipping $45^{\circ} \mathrm{N} .72^{\circ}$ E. and also $90^{\circ}$, overlies the granite, which sends small dikes into it. The contact between the two rocks appears at the east corner of the quarry and is shown in Pl. IX, A. At the southwest end of the quarry two schist masses are partially included in the granite, and a large pegmatite mass intervenes, as is shown roughly in fig. 29. The sheets, from 1 to 7 feet thick, lie horizontal and $\operatorname{dip} 55^{\circ} \mathrm{W}$. in the upper part of quarry. The joint and dike courses are shown in fig. 30 . Joints A dip $60^{\circ}$

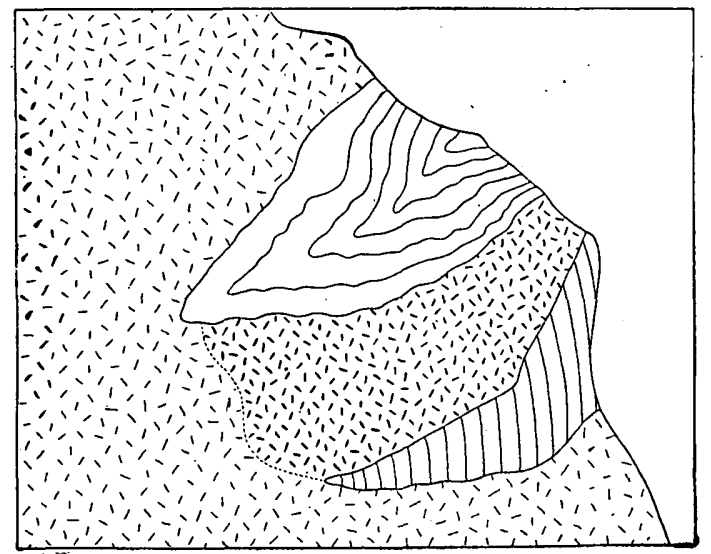

FIG. 29.-Schist inclusions at southwest end of Waldoboro quarry. Total height, 45 feet. The coarse material, between the two inclusions, is pegmatite. The finer is muscovitebiotite granite.

SE., and form both longitudinal walls of the quarry, a heading on the northwest side, and recur at intervals of 40 feet. Joints B dip $85^{\circ} \mathrm{N}$. and recur at intervals of 100 feet. The rift is horizontal and the grain is vertical, with course N. $60^{\circ} \mathrm{W}$. Pegmatite dike $a, 5 \frac{1}{2}$ inches thick, dips $60^{\circ} \mathrm{SE}$; dike $b, 12$ inches thick, dips S. $60^{\circ} \mathrm{W}$., at an angle of $45^{\circ}$. A dike of aplite, an inch thick, dips $45^{\circ} \mathrm{NE}$. Sap is confined to the upper sheets. Knots are very exceptional.

That the granite is under compressive strain is shown by the closing up of the channels when the cores are taken out, and also by spontaneous north to south fissuring.

The plant consists of 3 derricks, operated by 3 engines (one of these derricks is 108 feet 4 inches high with a 90 -foot boom), 3 overhead traveling cranes (of 3 and 2 tons capacity), 1 compressor (ca- 
pacity about 400 cubic feet of air per minute), 3 large steam drills, and 1 small one, 14 pneumatic plug drills, 6 surfacers, 23 pneumatic hand tools, and 2 steam pumps ( 5 inch and one-half inch).

Transportation is effected by cartage 1,300 feet (and 120 feet down) from quarry to mill, then by cars 19 miles to wharf at Rockland. The distance from quarry to tidewater at Waldoboro is only $1 \frac{1}{2}$ miles, but the water there is only 11 feet deep at high tide.

The product is used for buildings and monuments, but not for polished work. The small sheets and waste are used for paving and road ballast. About 250,000 paving blocks are shipped annually, mostly to Philadelphia. The chief markets for this stone are. New York and Philadelphia. Specimen buildings: The Buffalo Savings Bank, the armory, boat house, and cadets' quarters at the United States Naval Academy, Annapolis, Md.; the Crockett monument at

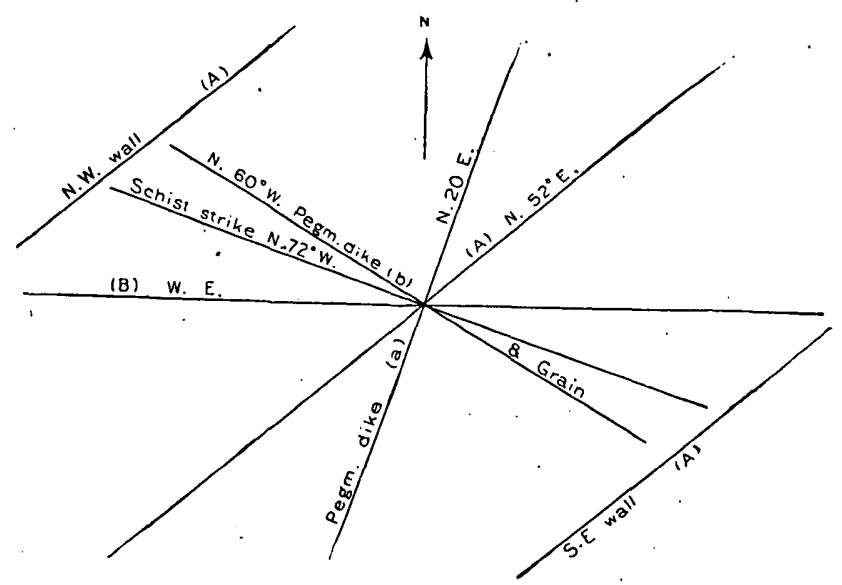

FIG. 30.-General structure at .Waldoboro quarry.

Acorn Cemetery, Rockland, Me. Contracts in 1905: The Chemical National Bank in New York; "platforms" for sidewalk around Schwab Building, Seventy-fourth street and Riverside Drive, New York. In September, 1905, two fluted columns, 25 - feet long, were being cut for a block in New York, and some fine carving on keystones, etc., for one of the buildings at the United States Naval Academy.

Jewett's black-granite quarry is in the town of Whitefield, $1 \frac{1}{2}$ miles southeast of Whitefield village (Kings Mills). Operator, E. C. Jewett, Whitefield, Me.

The rock (specimen 113,a) is a quartz diorite of very dark gray shade with a bluish tinge, and of fine to medium even-grained texture and flow structure, with feldspars up to one-fourth inch in diameter. It consists, in descending order of abundance, of bluish milk- 
white soda-lime feldspar (oligoclase-andesine), black hornbleṇde, quartz in amount almost, if not quite, equal to that of the hornblende, black mica (biotite), and accessory magnetite, titanite, zircon, apatite, and secondary epidote. The stone takes a fair polish.

The quarry, which was opened in 1885 for monumental work, consists of two adjacent openings, one 50 by 25 feet and up to 6 feet in depth; the other 60 by 30 and 5 to 8 feet in depth, besides 4 feet of clay loam stripping.

Rock structure: The sheets, 3 to 8 feet thick, dip $25^{\circ}-30^{\circ} \mathrm{NE}$. Vertical or steep joints strike N. $10^{\circ} \mathrm{W}$. and N. $42^{\circ} \mathrm{W}$. The rift is vertical with $\mathrm{N} .10^{\circ} \mathrm{W}$. course, and the grain is parallel to the sheets. The sap is 3 inches thick along the joints. There is one aplite dike $2 \frac{1}{2}$ to 4 inches thick. Biotite knots occur occasionally.

The product is used for monuments locally.

OXFORD COUNTY.

The granite quarries in Oxford County are in the towns of Fryeburg, Oxford, and Woodstock.

The Eagle Gray quarry is in the town of Fryeburg, at the northeast foot of Starks Hill, about $1 \frac{1}{4}$ miles south of Fryeburg village. Operator, Eagle Gray Granite Company, Fryeburg, Me.

The granite (specimen 124,a) is a muscovite-biotite granite of general medium even-grained texture, with feldspar one-fourth inch in length and mica up to one-fifth inch. It consists, in descending order of abundance, of slightly cream colored potash feldspar (orthoclase), smoky quartz, slightly cream colored soda-lime feldspar (oligoclase), white mica (muscovite), and black mica (biotite), together with accessory garnet and zircon. The contrasts are chiefly between the cream-colored feldspar and the smoky quartz and the brilliant muscovite plates. The large size of the mica plates is unfavorable to the durability of its polish under outdoor exposure.

The quarry, opened in 1903, is about 150 feet square by 3 to 12 feet deep.

Rock structure: The sheets, from 1 to 10 feet thick and becoming thicker southwest, dip less than $10^{\circ} \mathrm{NE}$. There are no joints, but there are several pegmatite and diabase or basalt dikes, already referred to on page 45 and shown in fig. 31. These generally have a northwest-southeast course. The pegmatite is very coarse, affording incomplete crystals of orthoclase 1 foot long and biotite crystals 3 inches long. Mingled with the pegmatite are irregular bands of whitish garnetiferous aplite. The absence of joints and the abundance of dikes are the chief obstacles here. The rift is horizontal and marked, but there is no grain. Sap, one-half inch thick, is confined to the top sheet. 
The plant consists of 2 hand derricks.

Transportation is by cartage two-fifths mile to Maine Central Railroad.

The product is used for buildings ana for bases to monuments, and finds a market at widely scattered points in the West and South. Specimen building: The granite part of the Conway, N. H., problic library. In 1905 the quarry was supplying bases to private monuments.

The Hodsdon quarry is in the town of Fryeburg, at the northeast foot of Starks Hill, a little over $1 \frac{1}{4}$ miles south of Fryeburg village. Operator, W. I. Hodsdon, Brownfield, Me.

The granite (specimen 125, $a$ ) is a muscovite-biotite granite of general medium-gray shade and medium even-grained texture, identical with that of the Eagle Gray granite quarry described on page 144.

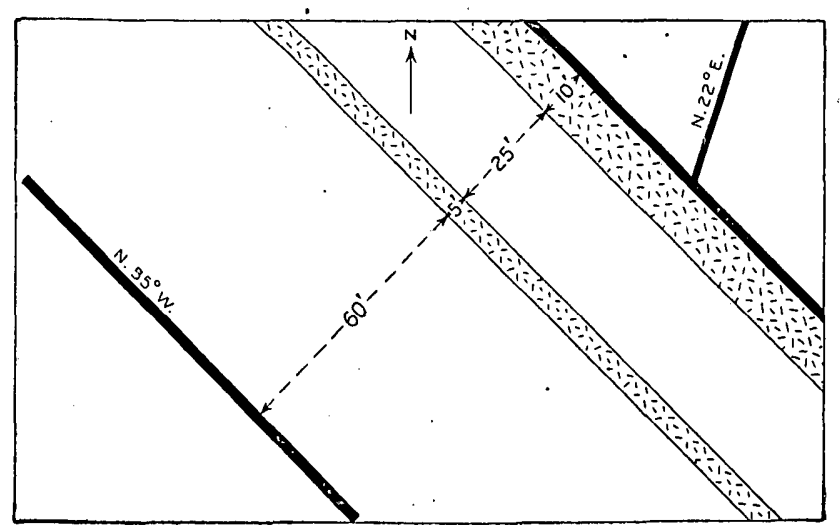

Fig. 31.-Structure at Eagle Gray quarry, at Fryeburg. The black bands are basic dikes, and those with a pattern are pegmatite.

The quarry, opened in 1905 , measures 120 by 30 feet and averages 8 feet in depth. The stripping is less than 2 feet.

Rock structure: The sheets, from 1 to 4 feet thick, dip $10^{\circ}$ NE. but taper, "growing on." There are no joints but 3 vertical basic dikes, from 16 to 24 inches wide, with courses of N. $30^{\circ}$ W., N. $30^{\circ}$ E., and N. $70^{\circ}$ E. The rift is horizontal and the grain is vertical, trending north-south. Sap is confined to a space of several feet on each side of the dikes. Knots are infrequent.

The plant consists of 3 derricks.

Transportation involves a cartage of about one-half mile to Maine Central Railroad.

The product is used for bases of monuments, curbing, and paving blocks, and finds a market mostly within the State.

3495-Bull. 313-07-10 
The Roy quarry is in the town of Oxford, three-fourth mile from Oxford village. Operator, Elie Roy; office, 94 Chestnut street, Lewiston, Me.

The granite (specimen 121,a) is a muscovite-biotite granite of medium cream-gray color and of medium (inclining to coarse) evengrained texture, with feldspars up to four-tenths inch in diameter. It consists, in approximate descending order of abundance, of a cream-colored potash feldspar (orthoclase and microcline), smoky quartz, cream-colored soda-lime feldspar (oligoclase), white mica (muscovite), and black mica (biotite), together with accessory apetite. Some of the joint planes are coated with coarse fibrous muscovite in parallel arrangement.

This quarry, opened in 1898 , covers about 5 acres and has a working face 40 feet deep. It is worked only occasionally. The product is used for rough foundations and also for trimmings. The trimmings on the Catholic Church at Berlin, Me., and the McGillicuddy Block at Lewiston are of this granite.

The Bryant Pond quarry is in the town of Woodstock, one-half mile south of Bryant Pond station, on east side of the Grand Trunk Railway. Operator, Grand Trunk Railway; address, Master of Bridges and Buildings, Grand Trunk Railway, Montreal, Canada.

The rock (specimen 122,a) is a quartz diorite with conspicuous black particles on a more bluish-white rather than a yellowish-white ground, and of medium even-grained texture and flow structure, with feldspars and black minerals up to three-tenths inch in diameter (rarely four-tenths). It consists, in descending order of abundance, of white translucent soda-lime feldspar (oligoclase to oligoclaseandesine), clear quartz, black mica (biotite), and black hornblende, together with accessory garnet, titanite, zircon, apatite, and a little secondary epidote. Some of the feldspars are partially altered to a white mica and some have borders that are radially intergrown with quartz. $^{a}$ The clearness of the quartz and the translucent whiteness of the feldspar result in the apparent merging of the two minerals, and as the biotite and hornblende are both black the only contrast in the rock is that between black and white. There is a marked contrast between the hammered and rough surface, which is attributable to the presence of soda-lime feldspar alone. (See p. 59.) The flow structure, where marked, gives the rock a gneissoid aspect.

The quarry, opened about 1864, is 150 feet from north to south by 250 feet from east to west and from 10 to 50 feet deep. It is on the west side of a north-south ridge. There is no drainage problem. The stripping consists of 5 to 12 feet of bowlder drift.

${ }^{a}$ Michel Lévy's "structure vermiculee: Bull. Carte géol. de France, No. 36, vol. 5 . $1893-4$, pp. $27-28$, fig. 5 . 
Rock structure: There is a marked flow structure in places horizontal and parallel to the rift, but in others quite irregular. The sheets, from 1 to 6 feet thick, are horizontal or slightly undulating on the quarry face, but at the west side dip $20^{\circ}$ to $30^{\circ}$ west. They increase in thickness downward and at the bottom of the quarry appear to run out ("grow on"), making quarrying in that direction increasingly difficult. A vertical joint, striking N. $35^{\circ}$ E., is coated with crystalline calcite and epidote. The rock adjacent to it for an inch or two contains much pyrite and also chlorite, probably derived from alteration of hornblende. The rift is horizontal and the grain vertical north-south, but dișappears on the west side. Vertical basalt or diabase dikes, with northeast-southwest courses, form the north and south walls of the quarry, 4 feet and 22 inches thick, respectively. A 5 -inch one occurs 25 feet north of the south wall. A thin section of a half-inch branchlet from this dike is described on page 48. Sap is confined to the upper sheets. There are some knots.

The plant consists of 3 derricks and 1 hoisting engine.

Transportation: Derricks lift the blocks from the quarry. to the cutting shed and from that to the cars of Grand Trunk Railway.

The product is used entirely for bridges and stations on the Grand Trunk Railway. Specimen buildings: The vestibule, first story, and trimmings of Grand Trunk Railway station at Portland, Me.; the Grand Trunk Railway station at Battle Creek, Mich.

PENOB̈SCOT COUNTY.

The quarries in Penobscot County are in the town of Hermon.

The Hermon Hill quarry is on Hermon Hill, $5 \frac{1}{2}$ miles northwest of Bangor. Operator, Dr. H. F. Hanson, Bangor, Me.

This black granite (specimen $106, c$ ) is an altered diabase porphyry of dark-green color and fine texture, with porphyritic crystals of black hornblende up to three-fourths inch in diameter. The rock consists, in descending order of abundance, of hornblende, calcite, a much-altered feTdspar (plagioclase), and magnetite, together with secondary actinolite, fibrous serpentine, and chlorite. It contains sufficient calcite (lime carbonate) to make it effervesce with cold dilute hydrochloric acid. It takes a very fine polish and cuts very light, but the presence of the calcite exposes it to attack by the carbonic acid of the atmosphere. It is therefore more suitable for indoor work. Ora W. Knight, State assayer of Maine, reports that it contains a very small amount of platinum, which is very irregularly and unevenly distributed. ${ }^{a}$

The quarry, opened in 1900 , measures 25 by 20 feet and from 5 to 12 feet in depth. 
Rock structure: The outcrop is about $200^{\circ}$ feet from northeast to southwest by 40 to 50 feet across, and occurs in a chloritic-quartzose shale, striking N. $45^{\circ}$ E. In places, however, there intervenes a granite porphyry containing crystals of orthoclase largely altered to muscovite, chlorite, and biotite. The sheets are from 6 inches to 6 feet thick and dip S. $60^{\circ}$ E. at an angle of $30^{\circ}$. Vertical joints strike N. $60^{\circ} \mathrm{W}$., forming a heading on the northeast, and recur at 20 -foot intervals, also striking N. $20^{\circ} \mathrm{W}$. and spaced from $2 \frac{1}{2}$ to 8 feet. Both the above show marks of slippage. There is also a diagonal set striking N. $45^{\circ} \mathrm{W}$. and dipping $45^{\circ} \mathrm{SW}$., recurring irregularly. The rift seems to be parallel to the sheets. Sap occurs along the joints. There are quartz veins parallel to the sheets and rift.

There is no machinery.

Transportation involves cartage of 1 mile to the new Maine Northern Seaport Railroad, or $5 \frac{1}{2}$ miles to Bangor.

The quarry is worked only occasionally.

The product is used for dies, memorial tablets, and wainscoting. Specimen monuments: Die on soldiers' monument at Hermon; about 20 dies in Mount Hope and Mount Pleasant cemeteries at Bangor; dies at cemetery at Springfield, Me.; cornerstone of Catholic Church at Orono; keystone, etc., at Lord Hall at University of Maine.

\section{PISCATAQUIS COUNTY.}

One quarry in Piscataquis County is in the town of Guilford.

The Queen City Granite quarry is $3 \frac{1}{2}$ miles from Foxcroft. Operator, Queen City Granite Company; office, Oak street, Bangor, Me.

The granite (specimen 107,a) is a biotite-muscovite granite of light-gray shade and medium to coarse, even-grained texture, with feldspars up to one-half inch in diameter and biotite scales up to 0.15 inch. It consists, in descending order of abundance, of very slightly bluish white potash-feldspar (microcline), smoky quartz, a whitish soda-lime feldspar (oligoclase), black mica (biotite), and much less white mica (muscovite), together with accessory magnetite. The oligoclase is partly altered to a white mica. As the feldspars are of similar shade and the muscovite is present in small amount the contrasts are between the feldspar, smoky quartz, and biotite, and they are marked.

The quarry measures 100 by 50 feet and has a maximum depth of 70 feet, the average being about 35 . It had not been worked for two years.

The stone is used for building. The trimmings of a brick building erected in 1899 for Bangor Theological Seminary and those of the Stetson Block at Bangor are made of it. 
The granite quarries in Somerset County are in the towns of Hartland and Norridgewock.

The Hartland quarry is in the town of Hartland, near Hartland village, on the Sebasticook and.Moosehead Railroad. The quarry was not operated in 1905 , but was formerly operated by Joseph $\mathrm{H}$. Baker. Property reported as owned by the Linn estate.

The rock (specimen 141, a, collected by Dr. George Otis Smith), is a quartz diorite with conspicuous black particles on a more bluish than yellowish white ground, and of medium to coarse, even-grained texture with flow structure. It consists, in descending order of abundance, of a translucent milk-white soda-lime feldspar (oligoclase), very.slightly smoky quartz, black mica (biotite), black hornblende, and accessory titanite and magnetite. Some of the feldspars are cloudy from incipient alteration.

The Dodlin quarry is in the town of Norridgewock, on the northeast side of Dodlin Hill, which lies $2 \frac{1}{2}$ miles south of Norridgewock village, and has a north-northeast-south-southwest axis and a height of 350 feet above the general level and of 650 feet above sea level. Operator, Dodlin Granite Company; office, Oakland, Me.

The rock (specimens 116, $a$, and 116, $b$ ) is a quartz monzonite of two shades. Specimen $116, a$, is a general medium gray with conspicuous black particles on a white ground, and specimen $116, b$, is a general light gray with much finer black particles on a ground of mixed white and gray. Both rocks have a like texture, medium inclining to fine, with porphyritic crystals of white feldspar up to one-half inch. In the darker rock $(116, a)$ the biotite scales measure up to one-tenth inch, while in the lighter they rarely attain onetwentieth inch. Both varieties consist, in descending order of abundance, of a slightly bluish milk-white soda feldspar (oligoclase) and, in equal or slightly less amount, of a whitish potash feldspar (microcline), quartz, almost clear in the darker rock $(116, a)$ and light smoky in the lighter one $(116, b)$, and black mica (biotite) (considerable in $116, a$, but much less in $116, b$ ), with accessory magnetite, titanite, zircon, pyrite, and secondary epidote and white micas. Some of the feldspars are radially intergrown with quartz. ${ }^{a}$ In the darker variety, owing to the clearness of the quartz and the abundance and coarseness of the biotite, the contrast is simply between the black mica and the white feldspar, but in the lighter variety, owing to the smokiness of the quartz and the smallness of the biotite scales, the contrast, although not very marked, is between the gray quartz, white feldspar, and black mica.

a "Structure ver'miculee" of Michel Levy : Bull. Carte géol. de France, No. 36, vol. 5, 1893-4, pp. 27-28, fig. 5 . 
The quarry, opened about 1885, measures 400 feet from northnorthwest to south-southeast by 250 feet across, and has an average depth of 30 feet. There is no drainage problem. Stripping up to 4 feet thick.

Rock structure: There is a vertical northeast-southwest flow structure indicated by the dividing line between the dark and light granite (shown in diagram sketch of upper part of quarry, fig. 32), and also in the light and dark banding of some of the lower sheets. The sheets, from 2 inches to 16 feet thick, dip about $5^{\circ} \mathrm{E}$. In the south part of the quarry they measure up to 2 feet only, but in the northern part from 2 feet to 16 feet. Joint and dike courses are shown in fig. 33. A recurs at intervals of 200 feet. From the relation of the thickness of the sheets to the joint spaces, both in this quarry, as shown in fig. 32, and in two adjacent abandoned openings, known as the "Mink Hole" and "Bank quarry," it appears that in

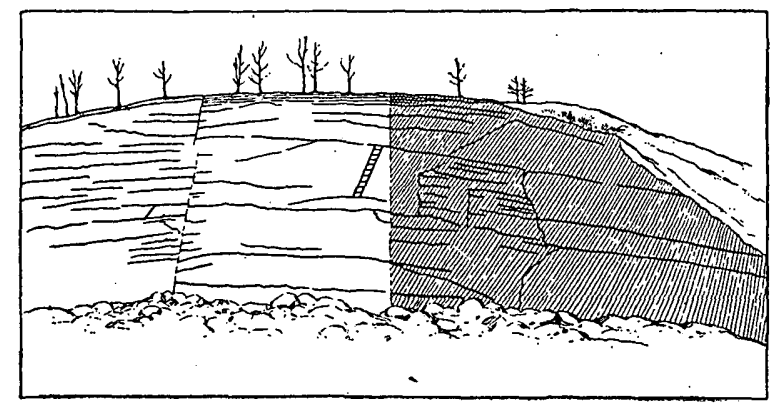

Fig. 32.-Diagram sketch showing junction of light and medium gray granites (quartz monzonites) and the lateral change in thickness of sheets at the Dodlin quarry, near Nor ridgewock.

places thin sheets, in others thick sheets, continue downward in alternating vertical zones, and that thin sheets are also apt to occur on both sides of the vertical joints for a few feet. These relations, which are very exceptional in the Maine quarries, may be due to vertical faulting. A horizontal displacement of a foot in a vertical flowstructure band was detected in the working face, evidently due to faulting at right angles to that just referred to. The rift is horizontal-that is, at right angles to the flow structure. The grain is vertical with course N. $45^{\circ} \mathrm{E}$., parallel to the jointing. The northsouth pegmatite dilie, up to 4 inches thick, dips $20^{\circ} \mathrm{S}$.; the other is vertical and an inch thick. They are garnetiferous. Sap 6 inches thick occurs at the top and bottom of sheets, and "shakes" occur along the sheets near headings. (See p. 40.) Knots, both dark and white, occur but rarely.

The plant consists of 10 derricks, 3 hoisting engines, and 3 steam drills. 
Transportation is effected by cartage one-fourth mile to a siding of Somerset Railroad.

The product is used mainly for buildings. Specimen buildings: The post-office at Muskegon, Mich.; the Merrill Library at Norwood, Mass.; the Catholic Church at Lewiston, Me., and the court-house at Bangor, Me. Contract in 1905: Annex to insane asylum at Augusta, Me.

The Lawton quarry is in the town of Norridgewock, on the northwest side of Dodlin Hill and $2 \frac{1}{2}$ miles south-southwest of Norridgewock. Operator, F. S. Lawton, Norridgewock.

The rock is a quartz monzonite of medium-gray and light-gray shade and medium and porphyritic texture, identical with that of the Dodlin quarry just described.

The quarry, opened before 1845 , consists of two openings 'measuring 200 by 100 and 300 by 200 feet by from 5 to 10 feet in depth. The loam stripping does not exceed 3 feet.

R o ck structure: The same flow structure occurs as at Dodlin quarry, on the other side of the hill. The sheets, up to 5 feet thick, average from 3 to 4 feet and roll over the hill with a dip of $10^{\circ}$ both north and south. Between some of the ordinary sheets there are unusual ones, one-half inch in

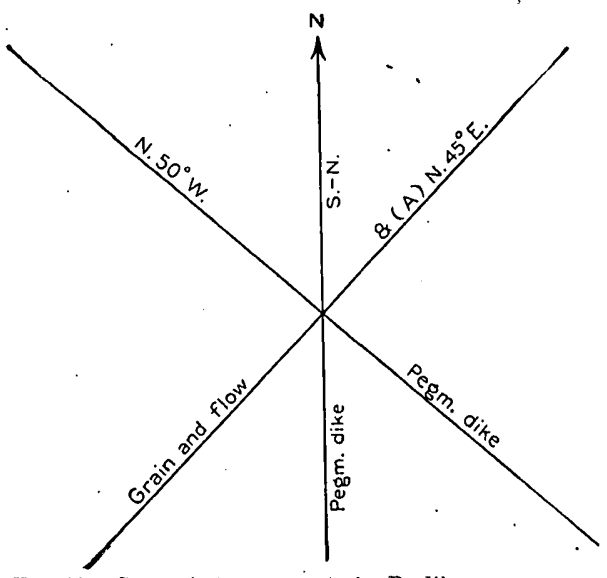

FIG. 33.-General structure at the Dodlin quarry, near Norridgewock.

thickness, which in large slabs are flexible. Whether this was in part due to incipient disintegration was not determined. The lenticular form of the sheets gives them the appearance of being very irregular in thickness. Vertical joints, striking N. $60^{\circ}-65^{\circ} \mathrm{E}$., recur at intervals of 10 to 50 feet. The rift is horizontal and grain vertical, with course N. $60^{\circ} \mathrm{E}$. Knots, both light and dark, are rare. Sap occurs along the sheets up to 6 inches in thickness. There is a 6 -inch dike of white aplite striking $\mathrm{N} .80^{\circ} \mathrm{W}$., glaciated with the granite at the surface (specimen $116 \frac{1}{2}, c$ ).

The plant consists of 3 hand derricks.

Transportation involves a cartage of 3 miles to railroad at Norridgewock.

The product is used for buildings, bridges, and monuments to sup- 
ply local demands. Contract in 1905: The town bridge at Bingham, Me.

The Emmons Taylor quarry is in the town of Norridgewock, on Dodlin Hill, about one-fourth mile north of Lawton quarry. Operator, Emmons Taylor, Norridgewock.

The granite (specimen 117,a) is a biotite-muscovite granite of light-gray color and very fine even-grained texture. The particles range from 0.11 to $1.1 \mathrm{~mm}$., exceptionally $2.19 \mathrm{~mm}$., and average about $0.50 \mathrm{~mm}$. They consist, in descending order of abundance, of a slightly bluish milk-white potash feldspar (microcline and orthoclase), clear quartz, soda-lime feldspar (oligoclase), black mica (biotite), and very little white mica (muscovite), together with accessory magnetite and apatite.

This is a very small opening, from which stone is obtained occasionally for monumental purposes.

WALDO COUNTY.

The quarries in Waldo County are in the towns of Frankfort, Lincoln, Searsport, and Swanville.

The Mosquito Mountain quarry is in the town of Frankfort, on top of Mosquito Mountain, 2 miles S. $10^{\circ}$ E. of Frankfort village. This mountain is a granite dome rising 545 feet above tide water, close by, with a steep east face shown in Pl. III, $B$. Operator, Hayward Peirce, Frankfort, Me.

The granite (specimen $52, a$ ) is a hornblende-biotite granite of general medium-gray shade and of porphyritic texture, with milkwhite feldspar crystals from one-half inch to $1 \frac{1}{2}$ inches in diameter in a gray matrix of medium texture, with black minerals up to onetenth inch. It consists, in descending order of abundance, of milkwhite potash feldspar (orthoclase and microcline), smoky quartz, a milk-white soda-lime feldspar (oligoclase), black hornblende, and black mica (biotite), together with accessory titanite, magnetite, apatite, and a little secondary chlorite, epidote, and carbonate (calcite or dolomite). The porphyritic feldspars are generally twins. Mr. E. C. Sullivan, of the United States Geological Survey, finds that this granite contains 0.1 per cent of $\mathrm{CO}_{2}$ (carbon dioxide) and that warm dilute acetic acid extracts 0.07 per cent of $\mathrm{CaO}$ (lime) and a trace of $\mathrm{MgO}$ (magnesia). Figuring the $\mathrm{CO}_{2}$ to both $\mathrm{CaO}$ and $\mathrm{MgO}$, this would give 0.13 per cent of $\mathrm{CaCO}_{3}$ (lime carbonate) and 0.08 per cent of $\mathrm{MgCO}_{3}$ (magnesium carbonate). The microscopic examination corroborates the occurrence of carbonate.

A test of the compressive strength made of this granite in connection with its use for the United States dry docks at Kittery, Me., reported to the writer by Mr. Hayward Peirce, the owner of the 
quarry, gives it an ultimate crushing strength of 32,635 pounds per square inch.

The quarry was opened before 1837 on the east side of the mountain. The later opening on the top measures 1,000 feet by 500 , with a depth ranging up to 25 feet. There is no drainage problem nor stripping.

Rock structure: The sheets, from 6 inches to 15 feet thick, dip gently northwest and east from the summit of the dome, and below, on the east side, they $\operatorname{dip} 45^{\circ}$, as shown in Pl. III, B. Some of the upper sheets taper out at the sides. (See, further, p. 34.) Vertical joint courses and dike courses are shown in fig. 34. The rift is horizontal and the grain vertical, with course N. $80^{\circ}-85^{\circ} \mathrm{W}$. Some of the joint surfaces are coated with chlorite and pyrite of secondary origin. A dike of quartz monzonite, 10 feet thick, dips $40^{\circ} \mathrm{E}$.

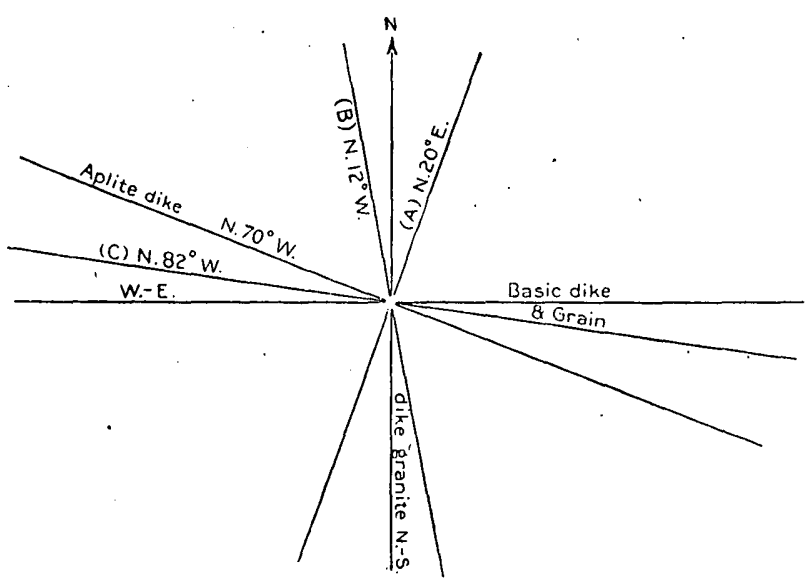

Fig. 34-Dtructure at the Mosquito Mountain quarry, Frankfort.

This is described on page 48 . There are branching dikes of aplite from 1 to 3 feet thick. At the south end of the quarry is a diabase dike 7 feet thick, crossing from east to west. This is described more fully on page 48. Somewhat abundant knots up to 12 inches in diameter and of circular or elliptical cross section occur. Sap measures up to 12 inches in thickness in the upper sheets, but is absent lower down.

The plant consists of 7 derricks and 3 engines, 1 traveling steam crane, 1 compressor (with capacity of 640 cubic feet of air per minute), 2 steam drills, 10 pneumatic plug drills, 3 surfacers, and 25 pneumatic hand tools.

Transportation is effected by about 7,000 feet of track, and gravity cars from quarry to cutting shed and wharf on Marsh River (South Branch stream), which admits schooners of 14 feet draft. 
The product is used for bridge work, and the small sheets and waste go into paving blocks. The chief markets are New York and Philadelphia. Specimen structures: The post-office at Lynn, Mass., and part of that at Chicago, Ill.; the New York Central Railroad bridge across Harlem River. Contracts in 1905: The Manhattan anchorage of one of the new New York suspension bridges.

The Mount Waldo quarry is in the town of Frankfort, on the north spur of Mount Waldo, 660 feet above sea level, one-third mile southwest of Frankfort village. The geographical relations of Mosquito Mountain and Mount Waldo to the Penobscot River are shown on the Bucksport sheet of the United States Geological Survey's topographic map of the United States, published in 1902. This quarry is operated by the Mount Waldo Granite Works, Albert Peirce, treasurer, Frankfort, Me.

The granite (specimen $53, a$ ) is a biotite granite of medium-gray shade and fine even-grained texture, with feldspar up to one-fifth inch and biotite scales up to one-tenth inch. The finer particles range from 0.36 to 1.46 millimeters in diameter It consists, in descending order of abundance, of gray potash feldspar (orthoclase and microcline), smoky quartz, gray soda-lime feldspar (oligoclase), and black mica (biotite), together with accessory magnetite, titanite, and secondary chlorite. The oligoclase is partly altered to kaolin and a white mica. A coarser and lighter granite (specimen $53, b$ ) from the same quarry is a biotite granite of light-gray shade and medium (inclining to fine) even-grained texture, with feldspars up to three-tenths inch, and biotite scales up to one-tenth inch, consisting, in descending order of abundance, of white potash feldspar (orthoclase and microcline), smoky quartz, white soda-lime feldspar (oligoclase), and black mica (biotite), together with accessory magnetite, titanite, and secondary chlorite. The oligoclase is partially altered to kaolin and a white mica. This variety is in places coarsely porphyritic. Dr. George P. Merrill refers to the two Mount Waldo granites. ${ }^{a}$ A test of the compressive strength of Mount Waldo granite, made at the United States arsenal at Watertown, Mass., in 1900, yielded the following results with 2 -inch cubes: ${ }^{b}$

a Collection of building and ornamental stones in the United States National Museum : Ann. Rept. Smithsonian Inst., 1889, pt. 2, p. 415.

${ }^{b}$ Reilly, J. W., Ordnance Rept., Tests of Metal, etc. (1900), 1901, p. 119. 
T'est of Mount Waldo granite.

\begin{tabular}{|c|c|c|c|c|c|}
\hline Number of test. & Direction of pressure. & $\begin{array}{l}\text { Specific. } \\
\text { gravity. }\end{array}$ & $\begin{array}{c}\text { First } \\
\text { crack. }\end{array}$ & $\begin{array}{c}\text { Total } \\
\text { pressure } \\
\text { applied. }\end{array}$ & $\begin{array}{l}\text { Ultimate } \\
\text { strength } \\
\text { per } \\
\text { square } \\
\text { inch. }\end{array}$ \\
\hline $\begin{array}{c}\cdots \\
11055 \ldots \ldots \\
11056 \ldots \ldots \\
11057 \ldots \ldots \\
11058 \ldots \ldots\end{array}$ & 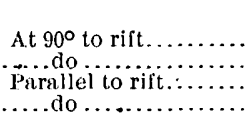 & $\begin{array}{l}2.637 \\
2.655 \\
2.662 \\
2.649\end{array}$ & $\begin{array}{r}\text { Pounds. } \\
120,000 \\
123,300 \\
-107,400 \\
112,600\end{array}$ & $\begin{array}{r}\text { Pounds. } \\
128,400 \\
132,500 \\
122,600 \\
117,900\end{array}$ & $\begin{array}{r}\text { Pounds. } \\
31,782 \\
32,635 \\
30,197 \\
.29,183\end{array}$ \\
\hline
\end{tabular}

The quarry, opened before 1851 , measures 800 feet from north to south by 400 feet from east to west and from 10 to 30 feet in depth. There is no drainage problem nor stripping.

Rock structure: There is a vertical dike of the coarser and lighter. granite (specimen 53, 6 ) 200 feet or more wide, having a course $N$. $20^{\circ} \mathrm{W}$., with the darker granite (specimen 53,a) on both sides of it, the relations indicating vertical flow structure. The longer axes of

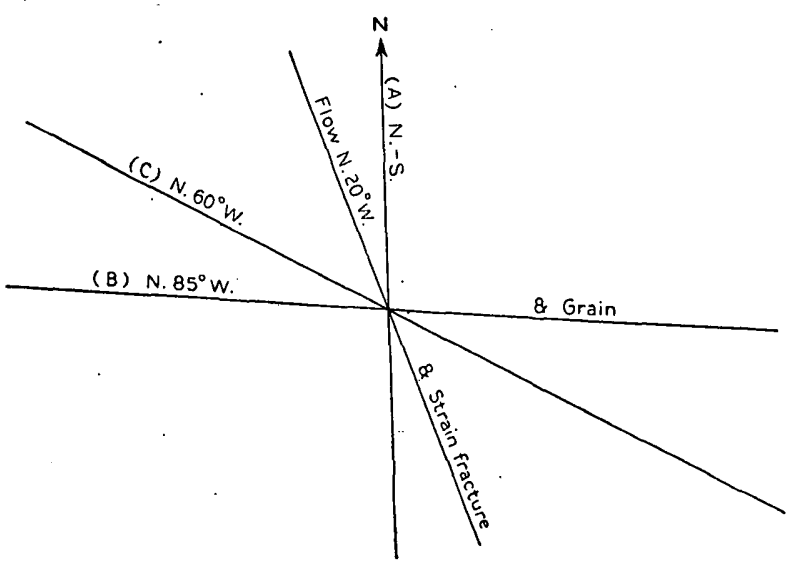

FIG. 35.-Structure at the Mount Waldo quarry, Frankfort.

many of the feldspars lie about north-south. The sheets, from 8 inches to 8 feet thick and lenticular, dip $10^{\circ} \mathrm{E}$. The joint courses are shown in fig. 35. There is only one joint of A. Joint B recurs at intervals of 40 feet; $\mathrm{C}$ at intervals of 20 to 40 feet or more. The rift is horizontal and the grain vertical, trending $\mathrm{N}$. $85^{\circ} \mathrm{W}$. The granite is under compressive strain from east-northeast to west-southwest, causing north-northwest to south-southeast vertical fissures the entire length of the quarry. This fissuring has occurred in summer time and has been accompanied by an explosive noise. The sheets are very free from sap. Knots are exceptional, but one near the junction of the fine and medium granites measures 6 feet by 3 feet and consists of a medium gray aplite, with porphyritic whitish twinned feldspars up to three-fourths inch in length and biotite scales up to one-twentieth inch. 
The plant consists of 10 derricks, 6 hoisting' engines, 1 traveling crane, 1 locomotive crane, 2 compressors (capacity 925 and 500 cubic. feet of air per minute), 6 steam drills, 1 channeler, 12 pneumatic plug drills, 10 surfacers, 60 pneumatic hand tools, and 1 steam pump.

Transportation is effected by two graded tracks, each 1,200 feet long, operated by gravity from the quarry part way down the hill to the power house, thence by a cable road (Roebling engine) $1 \frac{1}{4}$ miles long, to the wharf, which is accessible to schooners of 15 -feet draft. Heretofore the stone destined for the West has had to be transferred to cars at Bucksport, on Penobscot River, 7 miles distant, but the new Northern Maine Seaport Railroad, a branch of the Bangor and Aroostook, which passes at the foot of the hill, will obviate this reshipment.

Some of the stone quarried at the Mosquito Mountain quarry is finished here.

The product is used for buildings, and has of late found its chief market in the West. The small sheets and waste are made into paving blocks. Specimen buildings: Milwaukee and Indianapolis post-offices, Philadelphia mint. Contract in 1905: Cleveland, Ohio, post-office.

The Fernald quarry is in the town of Lincoln, near the north end of Lake Megunticook. Operator, E. H. Fernald Granite Company; address, Lincolnville R. F. D.

The granite (specimen 50,a) is a muscovite-biotite granite of light-gray shade and fine (inclining to medium) even-grained texture, with feldspars up to 0.2 , muscovite to 0.15 , and biotite up to 0.1 inch. The finer particles range from 0.18 to $1.83 \mathrm{~mm}$. in diameter. The rock consists, in descending order of abundance, of slightly bluish-white potash feldspar (orthoclase and microcline), smoky quartz, whitish soda-lime feldspar (oligoclase), white mica (muscovite), and still less of black mica (biotite), together with accessory apatite. The oligoclase is much altered to kaolin. The feldspars generally are intergrown with quartz in particles that are circular in cross section. The stone takes a fair polish with a bluish tinge, although the size of the muscovite plates is against the great durability of the polish under outdoor exposure.

The quarry, opened about 1875, measures 100 by 50 feet, and has a maximum depth of 28 feet. Drainage is effected by pumping on the average half a day per week. The water thus obtained supplies the boiler. The stripping in places measures up to 6 feet.

Rock structure: The sheets, from 6 to 15 feet thick, dip $25^{\circ} \mathrm{S}$. Vertical joints, striking N. $60^{\circ}-65^{\circ} \mathrm{W}$, recur at intervals of 8,14 , and 23 feet; also a joint striking $N .60^{\circ}-65^{\circ}$ E., but not recurring. Another one strikes N. $60^{\circ}$ W., and dips $60^{\circ}$ SE. The rift is verti- 
cal, with course N. $60^{\circ}-65^{\circ} \mathrm{W}$. Sap is faint, and from 4 to 8 inches thick along the sheets. Knots, up to 8 by one-half inch, are rare.

The plant consists of 5 derricks, 1 hoisting engine, 1 steam drill, and 2 pumps.

Transportation is by cartage 5 miles to electric railroad, then 8 miles to Maine Central Railroad. The quarry is 50 feet above Megunticook Lake, and a gravity track could be laid one-third mile to the lake, where boats could bring the stone within $2 \frac{1}{2}$ miles of Camden, on Penobscot Bay, thus reducing the cartage, which at present is the chief obstacle.

The product is used for monuments and buildings to supply local demands. Specimen buildings and monuments: The trimmings to Carlton Block; in Rockport, Me.

The Heal black-granite quarry is in the town of Lincoln, about 2 miles from bridge over outlet to Tilden Pond, and about $3 \frac{1}{2}$ miles from shore of Penobscot Bay. Operator, A. S. Heal, of Heal \& Wood; office, Bridge street, Belfast, Me.

This rock is an olivine norite of black shade, with glistening surfaces and of medium texture: The polished surfaces show a brilliant dark olive-greenish mineral. Under the microscope this rock consists of interlacing slender crystals of a translucent lime-soda feldspar (labradorite, with 10 to 14 per cent of lime), the spaces between which have been filled with the following minerals, in descending order of abundance: Greenish hypersthene (see p. 57), black hornblende, greenish olivine, black mica (biotite), and magnetite, with accessory pyrite and secondary chlorite and serpentine. The stone takes a brilliant polish and under sunlight shows the greenish hypersthene. The hammered or cut surface is very light.

The quarry, opened in 1903, measures 30 by 40 feet and about 10 feet in depth. It is worked only occisionally. There is no machinery. The stone is now carted 7 miles to Belfast to be cut. It is used for dies and tablets for local demand and is admirably adapted for these purposes.

The Bog Hill quarry is in the town of Searsport, on Mount Ephraim (Bog Hill), about 5 miles north-northwest of Searsport village and 2 miles east of Swanville. Operator, Herbert Black, North Searsport.

The granite (specimen 51, a) is a biotite granite of light-gray shade and porphyritic texture, with feldspars up to $1 \frac{1}{2}$ inches in diameter, in a groundmass of medium texture, with biotite scales up to one-fifth inch. It consists, in descending order of abundance, of a whitish potash feldspar (orthoclase and microcline), smoky quartz, whitish soda-lime feldspar (oligoclase), and black mica (biotite), together with accessory magnetite, titanite, zircon, apatite, and secondary chlorite and epidote. The porphyritic orthoclase crystals, 
generally twinned, are intergrown with oligoclase and quartz. Some have a zonal structure indicated by inclusions of quartz and oligoclase. The oligoclase is partially altered to kaolin and a white mica.

The quarry is 200 feet from north to south by 50 feet from east to west, and averages about 5 feet in depth.

Rock structure: The sheets, from 1 to 4 feet thick, dip $10^{\circ} \mathrm{S}$. $30^{\circ} \mathrm{E}$., and are crossed by joints that strike N. $75^{\circ} \mathrm{W}$. and dip $65^{\circ}$ $\mathrm{N}$. and $65^{\circ} \mathrm{S}$., forming headings at the south side and one in the center. Black knots up to 2 inches across occur here and there; also pyrite crystals on the joint faces.

This stone has been used for monuments and buildings in Belfast and for paving blocks, but the quarry has not been in operation for five years. The product had to be carted 5 miles to Searsport.

The Oak Hill quarry is in the town of Swanville, on Oak Hill, about 6 miles north-northwest of Belfast. Operator, Oak Hill Granite Company, Belfast, Me. .

The granite (specimen $49, a$ ) is a biotite granite of slightly bluish dark-gray color and fine even-grained texture, with particles ranging generally from 0.25 to $1 \mathrm{~mm}$. in diameter and an occasional feldspar up to $2.5 \mathrm{~mm}$. or one-tenth inch. It consists, in descending order of abundance, of slightly bluish-white potash feldspar (microcline and orthoclase), smoky quartz, slightly bluish-white soda-lime feldspar (oligoclase), and black mica (biotite). The feldspars are intergrown with quartz and the oligoclase is here and there partially altered to a white mica. The stone takes a very finc polish to the durability of which the fineness of the mica contributes.

The quarry, which was opened about 1872 , consists of several openings, the largest of which is 175 by 100 feet, with a working face 60 feet high.

Rock structure: The sheets, from 1 to 4 feet thick, dip $10^{\circ} \mathrm{W}$. Vertical or steep joints, striking N. $80^{\circ} \mathrm{W}$., recur at intervals of 10 and 20 feet, and form headings on the north side. Sap 2 inches thick occurs along the sheets. Knots up to 2 inches in diameter occur occasionally.

There is no machinery at the quarry at present. The only work being done is the making of paving blocks at one of the openings.

Transportation was by cartage one-fourth mile to a siding running from Sargents Crossing on the Maine Central Railroad.

The product is particularly adapted to monumental uses. The stone is the darkest of the fine-textured granites of the State (compare Freeport, p. 77 ; Pownal, p. 79 ; and Sherwood, p. 105) and is finer textured than the blue Westerly, R. I., granite. This quarry was formerly leased to the New England Granite Company, of Westerly. 
The quarries in Washington County are in the towns of Addison, Baileyville, Calais, Jonesboro, Jonesport, Marshfield, and Millbridge.

The Pleasant River black-granite quarry is in the town of Addison, at Dalotville, on the east side of Pleasant River Bay. Operator, Pleasant River Granite Company, Addison, Me.

This rock (specimen $93, a$ ) is an hypersthene-olivine gabbro of almost black shade and of medium ophitic texture, with black particles up to half an inch and slender whitish crystals. The polished surface is jet-black mottled with a little white. Under the microscope this rock consists, in descending order of abundance, of slender whitish transparent crystals of a feldspar (with both lime and soda, andesine-labradorite) intricately interlaced, the spaces between which are filled with a dark-brownish diallage (see p. 57), black mica (biotite), a little hypersthene, and greenish olivine, together with secondary magnetite, a white mica, and calcite. The diallage is altered along its edges to hornblende. The stone takes a very fine polish, and the hammered or cut surface is almost white. It is referred to by George P. Merrill ${ }^{a}$ and by John E. Wolff. ${ }^{b}$ It $^{\cdot}$ was reported to the company by John S. Newberry in October, 1890, as withstanding a pressure of 22,410 pounds per square inch. Its weight is given by the firm as 184 pounds to the cubic foot."

The quarry, opened about 1885 , measures 75 by 50 feet and has a working face about 50 feet high. It is on the south side of a ridge 70 feet high, extending east-west, the upper 5 to 10 feet of which consist of morainal sand and bowlders. (See Pl. X, A.)

Rock structure: The sheets, from 3 to 17 feet thick, undulate from the horizontal to a dip of $10^{\circ} \mathrm{E}$. Vertical joints, striking N. $80^{\circ} \mathrm{E}$., recur at intervals of 5 to 10 feet and form a heading on the south; a set, striking N. $35^{\circ} \mathrm{W}$., recurs at intervals of 20 to 30 feet, forming a heading on the west. There are also several irregular fractures. The rift is vertical east-west, and the grain is horizontal. There are 10 feet of stained and fractured rock at the top, but sap is usually hardly an inch in thickness. Dikes of whitish quartz monzonite, described in detail on page 61 , measure from 1 to 14 inches in thickness. There is also a more or less horizontal light and dark banding, due to alternating changes in the amount of feldspar. This is shown in Pl. X, $A$, as are also the dikes, sheets, joints, and one of the headings.

The plant consists of 3 derricks and 2 hoisting engines, 1 steam drill, 1 compressor, 2 pneumatic hand tools, 2 polishers, 1 polishing

a Tenth Census, vol. 10, 1S\$4, p. 24.

'Ibid., p. 116.

e Professor Newberry's report will be found in the Eighteenth Aun. Rept. U. S. Geal. Survey, pt. 5, continued, 1897 , p. 961 . 
lathe for stones 12 by 4 feet, 1 gang of steam saws, and 1 single steam saw for use with steel shot.

Transportation is effected by cartage on a track 300 feet from quarry to mill and 300 feet thence to wharf on Pleasant River Bay.

The product is used for monuments and interior decorations and finds market in the cemeteries of Brooklyn, Boston, Chicago, Louisville, Denver, and other cities. As will be noticed from the spacing of the joints and sheets, the dimensions of the blocks are limited. The usual sizes shipped measure 2 feet 6 inches by 2 feet 6 inches by 1 foot and also 3 to 6 feet by 1 foot by 1 foot. The largest block shipped measured 6 feet by 4 feet 6 inches by 4 feet 6 inches. During the writer's visit in August, 1905, the men were endea voring to quarry a block which measured 17 feet by 9 feet, the third dimension of which was still uncertain.

Specimen work: Base of wainscoting in the city hall at Philadelphia; tablet with Welsh incription in Washington Monument at Washington, D. C.; Danforth monument at Morristown, N. J.; Zeller monument at Lewisburg, Pa.; center monument at Greenwood Cemetery, Brooklyn, N. Y.; and mantlepiece in public library at Machias, Me. Contract in 1905, memorial to Architect French in New York.

The Thornberg black granite quarry is in the town of Addison, 3 miles south of Addison village. Operator, A. M. Thornberg, Addison, Me.

The rock (specimens 94, $a$ and 94, $a a$ ) is a hypersthene-gabbro of almost black shade and of medium ophitic texture. There are two varieties-a dark one, which is externally identical with that examined from the Pleasant River quarry, and a lighter one, in which the white mottling due to the feldspar is a little more abundant. Under the microscope this stone is generally identical with that of the Pleasant River quarry, except that in the thin section of this one the feldspar is labradorite and there is no olivine. This, however, may not be characteristic of the rock as a whole. A little accessory pyrite and apatite and a good-sized particle of secondary epidote were also found in the Thornberg gabbro. The stone takes a very fine polish and the hammered or cut surfaces are almost white.

The Black Diamond Granite quarry is in the town of Addison, on Yoho Bay. Owned by Black Diamond Granite Company of New York; address, Basin, Me., or care H. Donald, tax collector, Addison, Me.

The rock (specimen 91, a) is a hypersthene gabbro of very darkgray shade, with slight brownish tinge and of fine to medium ophitic texture, consisting, in descending order of abundance, of a whitish soda-lime feldspar (andesine) in not greatly elongated crystals, 
brownish diallage (partially altered to hornblende), black mica (biotite), a little hypersthene, and quartz, together with accessory magnetite. This rock turns a little brownish on continued exposure and weathers spheroidally. A polished block, reported as from this quarry and shown to the writer in a stonecutter's yard at Quincy, Mass., had become pitted from exposure.

The quarry, opened in 1883 and abandoned in 1902, is 200 feet square and from 10 to 20 feet deep. It has a track 300 feet long to a wharf which admits schooners of 11 feet draft. Although the rock has been here worked down to sea level, there is, a few hundred feet east, on the property of William $N$. Carver, a rising ridge of the same rock which is as yet untouched.

Rock structure and variations: The sheets, from 3 to 8 feet thick; are horizontal or dip $20^{\circ} \mathrm{N}$. Vertical joints, striking N. $80^{\circ}$ E., recur at intervals of 5 to 20 feet, and a set, striking N. $30^{\circ} \mathrm{W}$, recurs at intervals of 2 to 10 feet. There is rarely a. set striking N. $45^{\circ}-50^{\circ} \mathrm{W}$. A 1-inch dike of pegmatite strikes N. $30^{\circ} \mathrm{W}$.

The Hall black-granite quarry is in the town of Baileyville, at the north edge of Meddybemps Lake, 5 miles southwest of Baring, on Washington County Railroad, about 7 miles southwest of Calais. Operator, F.. H. Hall, Calais, Me.

The rock (specimens $98, b, d$ ) is a norite of brilliant luster, very dark gray shade (without any yellowish tinge), and of coarse texture and marked rift, with jet-black particles up to one-half inch in diameter in a network of translucent whitish feldspar. Under the microscope it consists, in descending order of abundance, of elongated transparent crystals of feldspars (with both soda and lime, andesine-labradorite) interlaced, but parallel in the flow and rift direction, with the intervening spaces filled with hypersthene (partially altered to brown hornblende), magnetite, and black mica (biotite), together with accessory calcite and a white mica derived from the partial alteration of a few of the feldspars. The hypersthene and hornblende constitute the conspicuous black particles seen with the unaided eye. In the lighter bands of the rock the feldspar largely crowds out the hypersthene. The content of magnetite is so great that large blocks of the rock deflect the magnetic needle: Mr. Hall states that the stone endures the fire and water test very well; that its compressive strength, as determined by the Watertown Arsenal testing machine, is 22,500 pounds to the square inch, and that an assay by Carmichael, of Boston, shows it to contain a small percentage of gold. The papers giving formal evidence of these results having, unfortunately, been misplaced, can not be cited here. The stone takes a high polish and the hammered and cut surface is almost white. It is very tough, but splits with facility along the rift. 
The quarry, opened in 1902, consists of two adjacent openings on the northeast side of a northwest-southeast ridge over one-fourth mile long and about 50 feet high. These openings measure 60 by 25 feet and 35 feet in depth and 50 by 20 feet and 20 feet in depth, respectively.

Rock structure: The upper 8 feet of the working face are traversed by light-gray more feldspathic bands from one-fourth to 2 inches in thickness, constituting a flow structure parallel to the sheets, which are from 1 to 6 feet thick and dip about $15^{\circ} \mathrm{SW}$. Vertical joints, striking northeast-southwest, cross the ridge at intervals from 6 inches to 7 feet, and form a heading in the smaller northwesterly opening. The rift is parallel to the sheets. As will be noticed by comparing the descriptions of the rock structure at the other blackgranite quarries, the structure along this ridge is unusually favorable for quarrying.

The plant consists of 1 power and 1 hand derrick and 1 engine and 1 steam drill.

Transportation is effected by cartage of 5 miles to Baring on the Washington County Railroad.

The quarry was not in operation in 1905 .

The product is used for tablets and monuments, and has found a market in New York, Boston, Philadelphia, Baltimore, Virginia, Nebraska, Dakota, and California.

Specimen monuments: A monument erected by Stephen A. Lovejoy, of Melrose, Mass., at Melrose Cemetery; also several monuments at the cemetery in Calais, Me.

The Tarbox black-granite quarry is in the town of Baileyville, about 900 feet northeast of the Hall quarry described above, at the north edge of Meddybemps Lake, 5 miles southwest of Baring, on the Washington County Railroad, and about 7 miles southwest of Calais. Lessee, O. S. Tarbox, Redbeach, Me.; owner of mineral right, F. H. Hall, Calais.

This rock is a norite identical with that of the Hall quarry described above. It appears to belong to an outcrop northeast and parallel to the ridge referred to.

The plant consists of 1 derrick.

Gardner's black-granite prospect is in the town of Calais, on St. Croix River, 6 miles south of Calais, north of road to Redbeach. Owner, Lorenzo Gardner, Calais, Me.

This rock (specimen 100,a) is a quartz diorite of very dark gray (not bluish) shade and fine, even-grained texture, consisting, in descending order of abundance, of a whitish soda-lime feldspar (andesine) considerably altered to a white mica, hornblende partly altered to chlorite, quartz, black mica (biotite), and magnetite, together with accessory titanite, pyrite, apatite, and secondary cal- 
cite. It takes a high polish, and the hammered and cut surfaces are very light. The stone is suitable for monumental work. Dr. George Otis Smith, who visited the Gardner prospects in 1903, states that "pink granite occurs intrusive in the dioritic rock in such a manner that both kinds of stone could be quarried from the same opening." One part of the dioritic rock he found in thin section to be in reality a diabase.

Mingo, Bailey \& Company's black-granite quarry is in the town of Calais, about 6 miles south of Calais, on the southwest side of the road to Redbeach, on the north side of an east-west ridge, near top. Operator, Mingo, Bailey \& Co.; office, Redbeach, Me.

The rock (specimen 103,a) is a norite, of almost black with slightly greenish tinge and fine to medium even-grained ophitic texture, consisting, in descending order of abundance, of a whitish soda-lime feldspar (andesine) considerably altered to a white mica, hypersthene (some of it partially or entirely altered to fibrous actinolite), magnetite, and black mica (biotite), with accessory pyrite. The stone takes a fine polish and affords a very light hammered or cut surface.

The quarry measures 50 by 15 feet and up to 20 feet in depth. The sheets are about 10 feet thick. Vertical joints, striking about east to west, recur at intervals of 1 to 3 feet.

There is one derrick. The quarry is worked only occasionally, and the stones are carted to the company's cutting shed, near Redbeach, on the St. Croix River.

The Beaver Lake black-granite quarry is in the town of Calais, near the north end of Beaver Lake, 4 miles west of Redbeach village. Operator, Maine Red Granite Company; office, Redbeach, Me.

The rock (specimen $96, g$ ) is a mica-quartz diorite of general darkgray shade (black mottled with white and gray) and of coarse to medium porphyritic texture, with feldspars up to one-half inch in diameter. It consists, in descending order of abundance, of a grayish feldspar containing both soda and lime (andesine-labradorite), black hornblende, black mica (biotite), magnetite, and a little quartz, together with accessory pyrite, calcite, and apatite. The feldspar is partly altered to kaolin and a white mica, producing the milky-white parts of the feldspars seen in the polished specimen, and some of the hornblende is fibrous. The stone takes a high polish and when hammered or cut has a very light surface.

The quarry, opened in 1885, measures 250 feet from north-northeast to south-southwest by 75 feet across, and has a working face on the east 30 feet in height. Its drainage requires the use of pumps in spring.

Rock structure: The sheets, from 6 inches to 7 feet 6 inches thick, $\operatorname{dip} 15^{\circ} \mathrm{W}$., and are lenticular in form. The upper 10 feet of the face 
consist of shattered surface rock and include a bed a foot thick of sand, due to interstitial weathering. The courses of joints and dikes are shown in fig. 36 . A recurs at intervals of 2 to 10 feet, $B$ at intervals of 10 feet, $\mathrm{C}$ still less frequently. There are also irregular joints, which break the rock up into irregular blocks.

A dike of pinkish aplite, described on page 61 , from 4 to 8 feet thick, runs the entire length of the quarry on the west. A 1-inch dike of white aplite dips $15^{\circ} \mathrm{S}$. Similar ones recur at frequent intervals. Some strike northward and curve. A dike of olivine basalt, referred to on page 61 ; occurs also on the west side or front of the quarry, and is crossed by branches from the large pinkish aplite dike. The rift is horizontal and the grain vertical; trending north-northeast to south-southwest. Thus, altogether, the structure and injections are complex and render the quarrying of large blocks difficult.

Notwithstanding this, blocks 9

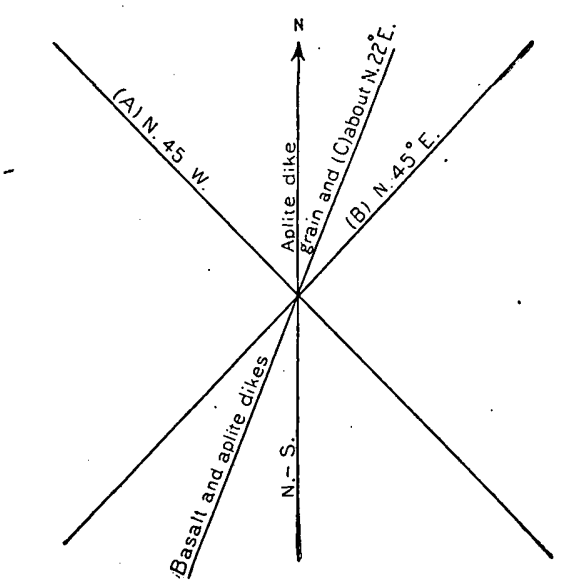

FIG. 36.-Structure at the Beaver Lake diorite quarry, Calais. by 9 feet by 20 inches have been obtained, and one 12 by 12 by 6 feet was in sight in 1905 .

The plant consists of a derrick, engine, and pump.

Transportation involves cartage of 4 miles to the company's cutting mill at Redbeach and a further cartage of one-fourth mile to wharf on St. Croix River.

The product is used entirely for monuments, of which the soldiers' monument at Calais is a specimen.

The Shattuck Mountain quarry is in the town of Calais, 3 miles west-southwest of Redbeach village, on Shattuck Mountain. Operator, Maine Red Granite Company; office at Redbeach, Me.

The granite (specimen $104, b$ ) is a biotite granite of dark reddishgreenish gray color and medium to coarse even-grained texture, with feldspars up to one-half inch and sparsely disseminated biotite under one-tenth inch. It consists, in descending order of abundance, of a reddish potash feldspar (orthoclase), smoky quartz, greenish sodalime feldspar (oligoclase), and black mica (biotite), together with accessory magnetite, apatite, and secondary chlorite. The oligoclase is here and there partially altered to a white mica. The smallness and sparseness of the micas are favorable to the durability of its polish.

The quarry, opened in 1890 , consists of three openings on the south side of an east to west ridge. The principal one of these measures 
50 by 25 feet and from 10 to 20 feet in depth. The sheets, from 5 to 7 feet thick, are horizontal or dip south at a small angle. Joints, striking N. $25^{\circ}$ E. and dipping $70^{\circ} \mathrm{NNW}$, recur at intervals of 10 to 22 feet and form headings on the north and south sides of the quarry. Another set, striking N. $40^{\circ} \mathrm{W}$., dips $65^{\circ} \mathrm{W}$., forms a heading on the east side and recurs in middle of quarry. The 22 -foot column referred to under "product" came from a 6 foot 6 inch sheet between the first set of joints. The heading of that set on the north is about 6 feet thick and includes a bed of clayey sand 8 inches thick. It has three sets of subjoints, one striking N. $40^{\circ}$ E. and dipping $55^{\circ}$ SE., spaced 2 to 12 inches; another striking N. $50^{\circ} \mathrm{W}$., vertical, and spaced 6 inches to 2 feet, and another striking N. $60^{\circ}$ E., vertical, and spaced 4 to 12 inches. The rock has no rift. The weathering of this granite has been referred to on page 55 .

The plant consists of a derrick.

Transportation is by cartage of 3 miles to Redbeach, on the St. Croix River.

The product is used for ornamental and monumental work. Specimens: Four fluted columns 22 feet by 3 feet, for the court-house at Marquette, Mich:

Mingo, Bailey \& Company's red-granite quarry is in the town of Calais, $1 \frac{1}{2}$ miles north-northwest of Redbeach. Operator, Mingo, Bailey \& Co., Redbeach; Me.

The granite (specimen 102, $\succ$ ) is a biotite granite of dark-reddish color speckled with pale greenish and of medium even-grained texture, with feldspars up to two-fifths inch and sparse biotite under one-tenth inch. It consists, in descending order of abundance, of a dark-pinkish potash feldspar (orthoclase), very smoky quartz, a pale yellowish-greenish soda-lime feldspar (oligoclase) considerably altered to a white mica, black mica (biotite), and accessory magnetite and zircon. The rock takes a high polish that exhibits marked contrasts between the two feldspars and the smoky quartz. The smallness and sparseness of the biotite scales favor the durability of the polish. The stone is of a lighter red than that of the Shattuck Mountain quarry, but is darker than that of the Maine Red Granite Company's "old quarry."

The quarry is 25 feet square by 8 feet deep, and is without machinery.

The company has at its cutting shed 1 derrick, 1 engine, and 1 polisher.

Transportation. is had by cartage $1 \frac{1}{2}$ miles to wharf at Redbeach.

The product is used entirely for monuments.

The Maine Red Granite Company's red-granite quarry is in the town of Calais, three-fourths mile west of Redbeach. Operator, Maine Red Granite Company; office, Redbeach, Me. 
The granite (specimen $97, a$ ) is a biotite granite of general brightpinkish color and medium even-grained texture, with feldspars up to two-fifths inch and sparse biotite scales under one-tenth inch. It consists, in descending order of abundance, of a pinkish potash feldspar (orthoclase), smoky quartz, cream-colored soda-lime feldspar (oligoclase), and black mica (biotite), together with accessory magnetite and zircon. The oligoclase is partially altered to kaolin and a white mica. The stone takes a high polish, the durability of which is favored by the sparseness and smallness of the mica scales. In weathering about the quarries the feldspars whiten from increasing kaolinization. The contrasts are chiefly between the two feldspars and the smoky quartz. This type of "red granite" is the brightest of those occurring in Maine.

The quarry consists of two openings, one known as the "old quarry," opened in 1876, and a new one adjacent to it. The new one is about 150 feet square by 20 to 50 feet deep.

Rock structure: The sheets, from 6 inches to 5 feet thick, dip $10^{\circ}-$ $30^{\circ}$ SE. Joints, striking N. $80^{\circ} \mathrm{W}$. and dipping steep to the north, recur at intervals of 1 to 5 feet. Others, striking N. $40^{\circ}$ E. and dipping $80^{\circ} \mathrm{SE}$., recur at intervals of 6 inches to 5 feet. The faces of this set are coated with calcite and epidote. There is no rift. whatever. It is evident from the frequent recurrence of both sets of joints and the limited range in thickness of the sheets that the conditions are not favorable for quarrying large blocks. Prof. John E. Wolff refers to the structure of Redbeach granite. ${ }^{a}$

The plant consists of a derrick.

Transportation involves cartage of three-fourths mile to wharf on St. Croix River.

The product is used entirely for monumental and ornamental work and finds a market all over the United States.

The Maine Red Granite Company's granite works are in the town of Calais, one-fourth mile west of Redbeach.

The red-granite quarries operated by this company at Shattuck Mountain, near Redbeach, have already been described and also its. . black-granite quarry at Beaver Lake.

This company not only finishes the product of its own quarries, but has the most extensive plant for polishing granite in the State and receives granite for finishing from the Stonington, Mount Desert, and North Jay quarries. It makes a specialty of columns, panels; and wainscoting.

The plant is run partly by water power obtained from a stream flowing into the St. Croix River and partly by an auxiliary 150-horsepower engine. It includes 1 derrick and 3 hoisting engines, 1 steam crane (with a capacity of 25 tons), 4 cutting lathes (for stones of 
25 by 4,15 by $2 \frac{1}{2}$, and 10 by $1 \frac{1}{2}$ feet), 4 polishing lathes for smaller stones, 7 "Jenny Lind" polishers, 2 vertical polishers for small work, 2 pendulum polishers, 1 saw (for use with steel shot) with 2 blades, 23 feet long, and a Donald cutting machine for smaller stones, 20 by 6 feet.

Specimens of polished work done by this company: Four fluted columns (22 by 3 feet) of Shattuck Mountain red granite for the court-house at Marquette, Mich.; balusters of gray granite (Goss Crotch Island quarry) for Kansas City court-house; vault of gray granite for Marinoni grave at cemetery in New Orleans, La. The soldiers' monument, of Beaver Lake black granite, at Calais, Me., was also finished here.

The Redbeach Granite Company's quarry is in the town of Calais, on Cooks Mountain, 8 miles southeast of Calais, about 1,000 feet southwest of road to Redbeach. Operator, O. S. Tarbox, Redbeach, Me.

The granite is a biotite granite of general bright pinkish color and medium even-grained texture like that of the Maine Red Granite Company's quarry near Redbeach, described on page 166, and of the abandoned Bodwell Granite Company's quarry on Cooks Mountain.

The quarry, opened in 1895 , is 50 by 25 feet and from 5 to 20 feet deep. The sheets, up to 5 feet thick, dip north at low angle. Vertical joints strike N. $80^{\circ}-90^{\circ}$ E., forming numerous headings. There is no rift.

The plant consists of 1 derrick and 1 hoisting engine.

Transportation involves cartage of over one-half mile to wharf on. St. Croix River at Redbeach.

'The product is used for buildings and monuments. Specimen structures: The red granite in two corner wings of the American Museum of Natural History, in New York; the perlestal to General Grant's monument, at Galena, Ill.

The Horsebrook Mountain quarry is in the town of Jonesboro, at Quarry siding, about 2 miles east of Jonesboro station, on the Washington County Railroad. This quarry was opened in 190: by Cyrus F. Stackpole, of Bangor, Me., and furnished a "pink granite" for the Roman Catholic Church, the Commercial block, and the Pierce block, at Oldtown, Me., and the new schoolhouse at Great Works, Me. These facts were submitted by Samuel S. Kimball, of: Bangor, to the State Survey Commission. The quarry was not in operation in 1905, and specimens of the stone were not obtainable for description in this report.

The Fish quarry is in the town of Jonesboro, 1 mile northwest of Jonesboro village. Owner, N. W. Fish, Jonesboro, Me.

The granite (specimen $87, b$ ) is a biotite granite of lavender medium-gray color and medium, even-grained texture, with feldspars 
generally up to two-fifths inch (exceptionally one-half inch) and sparsely disseminated biotite up to one-tenth inch. It consists, in descending order of abundance, of a pale lavender-colored potashfeldspar (orthoclase), smoky quartz, milk-white soda-lime feldspar (oligoclase), and a little black mica (biotite), together with accessory magnetite and secondary epidote, zoisite, and calcite. The feldspars are considerably altered to white micas, and the biotite is also largely altered to chlorite. This stone resembles that of the Goss and Ryan-Parker quarries of Crotch Island in the lavender tint of its orthoclase, but its texture is finer. Their resemblance may be found to be still greater in lower and fresher sheets.

The quarry, a small opening about 300 feet northwest of Mr. Fish's house, has been worked only occasionally. The sheets are up to 5 feet thick and lie horizontal.

The Bodwell-Jonesboro quarry is in the town of Jonesboro, 2 miles east of Jonesboro village. Operator, Bodwell Granite Company; office, Rockland, Me.

The granite (specimen $86, h$ ) is a biotite granite of general grayishpink color and of coarse (inclining to medium), even-grained texture, with biotite sparsely disseminated and up to one-twentieth inch in diameter. It consists, in descending order of abundance, of a pinkish potash feldspar (orthoclase), smoky quartz, cream-colored sodalime feldspar (oligoclase), and a little black mica (biotite), together with accessory magnetite and secondary white mica, kaolin, and chlorite. The orthoclase is intergrown with plagioclase, and the oligoclase is here and there largely altered to a white mica and kaolin and the biotite to chlorite. The contrasts are chiefly between the two feldspars and the smoky quartz. The stone takes a fine polish, the durability of which is favored by the smallness of the biotite scales.

The quarry, opened about 1875 , measures about 700 feet N. $80^{\circ}$ E.S. $80^{\circ} \mathrm{W}$. by 200 feet from north to south, and has a depth of 10 to 33 feet. Its area is irregular, as shown in fig. 37. Its drainage requires occasional pumping.

Rock structure: This quarry shows a greater variety of dike courses than any other of the Maine quarries. The sheets, from 6 inches to 5 feet thick, are horizontal, with slight undulations. The joint and dike courses are shown in fig. 37. A recurs on the north and south sides of quarry and in middle, and forms a heading on the south; $\mathrm{B}$ forms a heading on the northwest side; $\mathrm{C}$ appears on the south wall, intersecting the heading; D dips steep south, and also intersects the south wall. The rift is vertical, with course $\mathrm{N} .70^{\circ} \mathrm{W}$. There are two dikes of reddish aplite $(a)$, one 6 feet thick, another 4 feet thick; a third (b), also reddish, is from 3 to 6 feet thick; a grayish aplite dike $(c)$, from 1 to $1 \frac{1}{2}$ inches thick, can be traced from 200 to 300 feet, cutting all the other dikes. Thin sections of $a$ are 
described on page 43 . Knots occur up to 12 by 8 inches, but rarely. There are geodes and short veins, containing quartz, epidote, and calcite. (See p. 50.) The sheet surfaces are in places coated with epidote from the alteration of feldspar. Prof. John E. Wolff has referred to the Jonesboro "red granite" and some of its peculiarities. $^{a}$

The plant consists of 4 derricks, 2 hoisting engines, 2 steam drills, and 1 steam pump.

Transportation involves cartage of a mile to the wharf on Englishmans Bay. The stone is shipped to Vinalhaven for finishing.

The quarry was not in operation in 1905 for want of demand for "red granite."

The product was used for buildings. Specimen buildings made of granite from this quarry: Custom-house and post-office at Buffalo,

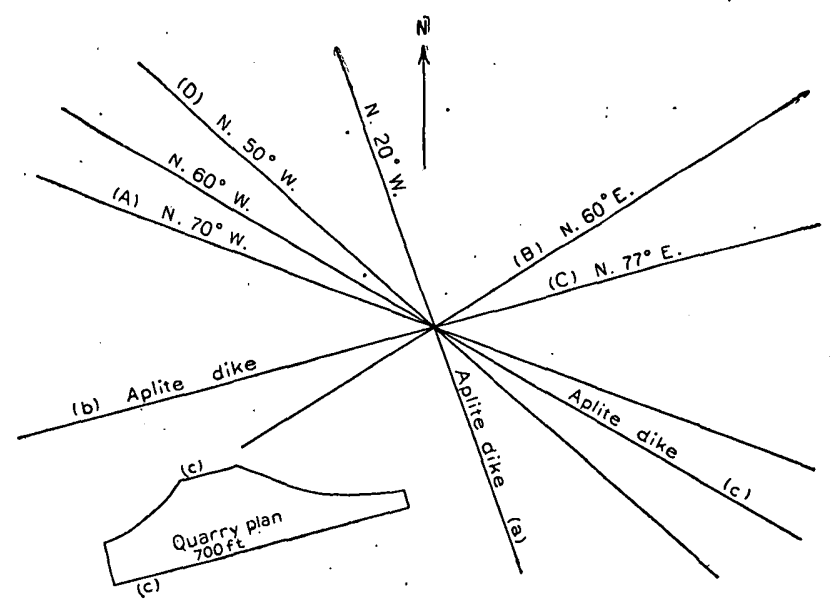

Fra. 37.-General plan and structure at the Bodwell quarry, Jonesboro.

N. Y.; Methodist Book Concern building and Havemeyer residence,. Fifth avenue and Sixty-sixth street, New York; custom-house and post-office at Fall River, Mass.; town buildings at Peabody, Mass.; Western Savings Bank building, Philadelphia.

The Booth Brothers Jonesboro. quarry, in the town of Jonesboro, is $1 \frac{1}{4}$ miles east of Jonesboro village. Operator, Booth Brothers \& Hurricane Isle Granite Company; office, 207 Broadway, New York; Maine office, Rockland, Me.

The granite (specimen $85, .6$ ) is a biotite granite of general pinkishgray color and coarse, inclining to: medium, even-grained texture; with sparsely disseminated biotite up to one-twentieth inch in diameter. It consists, in descending order of abundance, of a pinkish potash feldspar (orthoclase), a little less pink than that of specimen 
$86, h$, from the Bodwell quarry, smoky quartz, cream-colored sodalime feldspar (oligoclase), and black mica (biotite), together with accessory magnetite and secondary white micas, zoisite, and chlorite. The orthoclase is here and there intergrown with a plagioclase. The oligoclase is largely altered to a white mica and kaolin and the biotite to chlorite. The contrasts are between the two feldspars and the smoky quartz. The stone takes a high polish, the durability of which is favored by the smallness of the biotite plates. Its general color is not quite so pinkish as that of the Bodwell quarry.

The following chemical analysis of this granite was made by Ricketts \& Banks, of New York (No. 16072), and is given here merely for purpose of reference:

Analysis of granite from Jonesboro quarry.

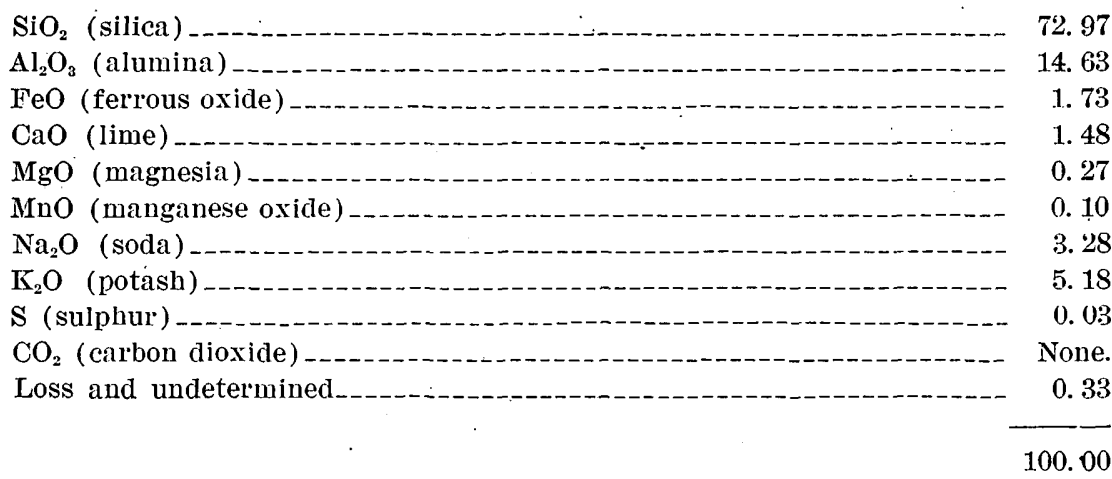

The quarry is of triangular area, about 10 by 75 by 75 feet and 30 feet deep. It is or can be drained by siphoning. The stripping consists of 3 to 5 feet of till.

Rock structure: The sheets, from 5 to 10 feet thick and lenticular, lie horizontal or dip $5^{\circ} \mathrm{NW}$. or $5^{\circ} \mathrm{SE}$. A vertical joint striking N. $60^{\circ} \mathrm{W}$. forms the wall on the southwest. A set striking N: $35^{\circ}-$ $50^{\circ} \mathrm{E}$. forms headings on the northwest and southeast and recurs at intervals of $5,10,20$, and 70 feet. Its faces are coated with hematite. The rift is vertical, with course N. $60^{\circ} \mathrm{W}$. The grain is horizontal. Knots are small and infrequent. Sap up to 3 inches thick is confined to the headings. The structural conditions are favorable for quarrying large blocks.

The plant consists of 1 derrick.

Transportation is effected along a track one-third mile to wharf on Englishmans Bay.

The quarry was idle in 1905 .

The product is shipped to the company's works on Hurricane Island to be finished and is used for building. 
The Minerva Cove quarry is in the town of Jonesport on the north side of Head Harbor Island, which lies about $3 \frac{1}{2}$ miles southeast of Jonesport. Operator, Metropolitan Granite Company ; office, Jonesport, Me.

The granite (specimens $88, a$, and $88, b$ ) is a biotite granite which in the lower sheets is of general dark reddish-gray color, with both a pinkish and a greenish feldspar, but in the upper sheets has a white instead of a greenish feldspar. It is of coarse, even-grained texture, the feldspars measuring up to an inch in length and the biotite up to one-fifth inch. It consists, in descending order of abundance, of a pinkish potash feldspar (orthoclase with a little microcline), smoky quartz, a dull greenish or a milk-white soda-lime feldșpar (oligoclase) and black mica (biotite) in conspicuous flakes, together with accessory magnetite, pyrite, titanite, and apatite. The orthoclase, generally in twins, is intergrown with a plagioclase. The oligoclase is largely altered to a white mica and kaolin, particularly in the upper sheets, where it has passed from green to a white. The quartz is cloudy from the presence of multitudes of irregular bubbles, the largest of which measure $0.01 \mathrm{~mm}$, or about 0.0004 inch in length. It is also traversed by irregular fissures containing sericite. Some of the pinkish orthoclase is rimmed with white or greenish oligoclase or completely envelopes a greenish oligoclase crystal. The contrasts in the granite of the lower sheets are feeble, owing to the darkness of the oligoclase and quartz, but is marked in that of the upper sheets, the four minerals all differing in shade.

The quarry consists of five openings: (1) 100 by 25 and 14 feet deep; (2) 50 by 25 and 40 feet deep; (3) 300 by 70 and 35 feet deep; (4) triangular; 100 by 150 by 75 feet deep, with working face 35 feet high, and (5) 50 by 25 and 20 feet deep. In places there are 3 feet of "till" stripping. There is no drainage problem, but the opening at the wharf can be operated only at low tide.

Rock structure: The sheets at the upper opening from 2 to 22 feet thick, but usually from 5 to 15 feet, dip $10^{\circ}$ NE. Vertical joints striking $\mathrm{N} .10^{\circ} \mathrm{E}$. or north form a heading on the east and recur at intervals of 5 to 10 feet. Another set strikes east-west and dips $60^{\circ}$ S., and one which may belong to it strikes N. $80^{\circ} \mathrm{W}$., dips $90^{\circ}$. The rift is horizontal, the grain vertical, trending north-south. Dikes of aplite up to an inch thick have N. $60^{\circ} \mathrm{E}$. courses.

The plant consists of 3 derricks worked by horses.

Transportation is effected by cartage of 700 feet and 50 feet down grade from upper opening to wharf. From the opening at the wharf stones are loaded by derricks directly on to schooners.

The product is used for buildings and monuments. Specimen structures: Colorado Building, at Fourteenth and G streets, Washington, D. C.; State armory at Providence, R. I.; power house of the 
Metropolitan Street Railway (Interurban), Ninety-fifth to Ninetysixth streets and First avenue to Hudson River, New York.

The New England granite quarry is in the town of Jonesport, on the south side of Head Harbor Island (Hacketts Harbor). Owner, New England Granite Company, Jonesport, Me.

The granite (specimen $89, a$ ) is a biotite granite of general dark reddish-gray color, with both a pinkish and a whitish feldspar, and of coarse, somewhat porphyritic texture, with feldspars up to an inch in diameter and biotite under one-fifth inch. It consists of the same minerals as the granite of the north side of the island, described above. The only perceptible difference is that here the spaces between the feldspars, instead of being filled with quartz, seem to be occupied by a mixture of quartz and fine pinkish orthoclase, and the rock is thus slightly porphyritic. The effect is to diminish the contrast between the quartz and the orthoclase.

The quarry measures 200 by 100 , and up to 20 feet in depth.

Rock structure: The sheets, from 3 to 8 feet thick, dip $10^{\circ}$, and are crossed by vertical joints striking N. $10^{\circ}$ E., spaced 20 feet or more; also by a set striking east-west and spaced in the same way.

The plant consists of 2 derricks and 2 hoisting engines.

Transportation was effected by means of a track 3,000 feet long to a wharf in Hacketts Harbor.

No work has been done since 1897.

The Hardwood Island quarry is in the town of Jonesport, on Hardwood Island, which lies $3 \frac{1}{2}$ miles southwest of Jonesport village. Operator, Rockport Granite Company, Rockport, Mass.

The granite (known commercially as "Moose-a-bec red") is a biotite granite of general dark reddish-gray color, with a white and a pinkish feldspar, and of coarse, even-grained texture, like that of specimen 88, a, from Head Harbor Island, described on page 171, but with an occasional isolated feldspar.

The Rosiwal method of determining approximately the proportions of the chief mineral constituents was applied to a specimen of this granite having a polished face measuring 5 by 3 inches. The size of mesh was 0.9 inch; total length of lines, 40.20 inches. Owing to the irregular massing of the feldspars in the specimen a second test was made with the short set of lines shifted one-fourth inch, and the long set adjusted accordingly. The results of both tests were averaged for the final estimate. 
Sizes and percentages of minerals in granite from Hardwood Island, as determined by the Rosiwal method.

\begin{tabular}{|c|c|c|c|c|}
\hline Mineral. & First test. & $\begin{array}{l}\text { Second } \\
\text { test. }\end{array}$ & \multicolumn{2}{|c|}{ Averages. } \\
\hline 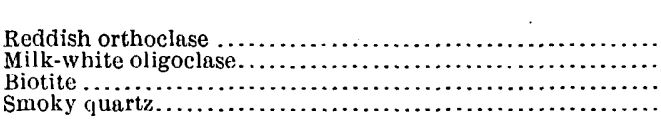 & $\begin{array}{r}\text { Inches. } \\
10.12 \\
8.00 \\
1.72 \\
20.36\end{array}$ & $\begin{array}{r}\text { Inches. } \\
12.46 \\
8.24 \\
1.54 \\
17.96\end{array}$ & $\begin{array}{r}\text { Inches. } \\
11.29 \\
8.12 \\
1.63 \\
19.16\end{array}$ & $\begin{array}{r}\text { Per cent. } \\
28.85 \\
22.45 \\
4.05 \\
44.65\end{array}$ \\
\hline Total. & 40.20 & 40.20 & 40.20 & 100.00 \\
\hline
\end{tabular}

Percentage of both feldspars, 51.30.

This granite takes a fine polish, in which the contrasts between the pinkish and white feldspars and the black mica stand out on the background of smoky quartz. Some of the pinkish feldspars are bordered by the white. The large size (usually one-tenth inch) of the biotite scales is against the durability of the polish under longcontinued outdoor exposure.

The quarry measures 150 by 60 feet, and 15 feet in depth, but its bottom is between tide levels. There is no stripping.

Rock structure: The sheets, from 2 to 10 feet thick, are horizontal, but in places curve seaward. Joints striking N. $75^{\circ} \mathrm{W}$., and dipping $65^{\circ}$ S. recur only at rare intervals. Others, striking N. $45^{\circ} \mathrm{W}$. and vertical, recur at intervals of 18 feet and over. The rift is vertical with course N. $10^{\circ} \mathrm{E}$. Dikes of aplite up to 6 inches thick strike N. $25^{\circ} \mathrm{W}$.

The plant consists of 1 derrick. The cutting plant is at Rockport, Mass.

Transportation is effected by lifting the blocks onto the wharf, which is 125 feet from the quarry.

The product is used for buildings and finds a market in Philadelphia, New York, and Baltimore. Specimen buildings: The wainscoting and stairway in main entrance to Suffolk County courthouse in Boston; the American Baptist Publication Society building in Philadelphia, and 25 columns in the Catholic cathedral in Newark, N. J.

The Marshfield quarry is in the town of Marshfield, 3 miles north of Machias. Operator, Machias Granite Company, Machias, Me.

The granite (specimen $84, b$ ) is a biotite granite of pinkish-gray color and of medium to fine even-grained texture, with feldspars . from one-tenth to two-fifths inch and sparsely disseminated biotite under one-tenth inch in diameter. It consists, in descending order of abundance, of pinkish potash feldspar (orthoclase), smoky quartz, cream-colored soda-lime feldspar (oligoclase), and a little black mica (biotite), together with accessory magnetite, titanite, and zircon and secondary kaolin, white micas, and chlorite. The orthoclase is inter- 
grown with plagioclase, the oligoclase is much altered to kaolin and a white mica, and the biotite is partly chloritized. Molybdenite occurs here and there. The granite is slightly less pinkish than that from the quarry of Booth Brothers at Jonesboro (specimen 85, $b$ ). The contrasts are also reduced by the greater fineness of the particles. It takes a fine polish, the durability of which is favored. by the sparseness and smallness of the biotite scales.

The quarry, opened in about 1894, measures 200 by 150 feet and from 2 to 10 feet in depth. There is no serious drainage problem and only 2 feet of soil stripping.

Rock structure: The sheets, from 1 to 8 feet thick, dip irregularly as high as $10^{\circ} \mathrm{SW}$. and $10^{\circ} \mathrm{NW}$. Vertical joints, striking N. $55^{\circ} \mathrm{E}$., form headings on the north and south sides. Another set, striking N. $60^{\circ} \mathrm{W}$., dips $70^{\circ} \mathrm{SW}$. to $90^{\circ}$, forms headings near the east side, and recurs at intervals of 10 to 50 feet. A third and diagonal set, striking N. $85^{\circ}$ E., dips $55^{\circ} \mathrm{N}$. and recurs irregularly. There is some "toeing in" of sheets, probably owing to faulting along the set of joints striking N. $55^{\circ}$ E. The faces of the second set are coated with epidote and those of the third with pyrite. The rift is horizontal. There are geodes (up to 6 inches thick) of orthoclase and oligoclase, smoky quartz, amethyst, and pyrite filled with calcite, epidote, and chlorite. Sap is 2 inches thick in the upper sheets only.

The plant consists of 2 derricks ( 1 horse and 1 hand).

Transportation is by cartage of 3 miles to railroad or wharf at Machias.

The product is used for monuments and buildings and finds a market in the Middle West, New York, and Pennsylvania. Specimen buildings: Basement front and steps of E. S: Draper residence, on Beacon street, Boston, Mass. In 1905 the quarry was producing monuments for local demand and for Boston.

The Millbridge quarry is in the town of Millbridge, near Millbridge village, in the southwestern part of Washington County. Operators, Swanton \& Wallace, Millbridge, Me.

The granite (specimen 143,a) is a biotite granite of somewhat dark buff color and of medium, even-grained texture, with feldspars up to three-tenths inch (exceptionally one-half inch) and biotite scales under one-tenth inch, consisting, in descending order of abundance, of - a buff-colored potash feldspar (orthoclase), smoky quartz, very slighty greenish white soda-lime feldspar (oligoclase), and black - mica (biotite), together with accessory magnetite and apatite. The quartz has numerous very irregular bubbles up to 0.028 millimeter in length. The orthoclase is intergrown with a plagioclase. Granulation ("crush borders") occurs along the contacts of the feldspars with one another. The stone takes a high polish, the durability of which is favored by the smallness of the biotite scales. 
Some tests of a Millbridge granite, quarried at White Rock Mountain by S. L. Treat \& Co., were made in 1895 by the United States Ordnance Department at the Watertown Arsenal. ${ }^{a}$ These give it a shearing strength of 2,820 pounds, a transverse strength of 2,069 pounds, and a compressive strength of 19,917 pounds, all per square inch.

The Millbridge quarry was not visited by the writer, and the firm failed to reply to questions as to dimensions of quarry, plant, and product.

\section{YORK COUNTY.}

The granite quarries in York County are in the towns of Alfred, Berwick, Biddeford, Hoilis, Kennebunkport, and Wells.

The Bennett quarry is in the town of Alfred, 1 mile southwest of Alfred village, south of Portland and Rochester Railroad, at the north foot of a 480-foot hill. Operator, Bennett Brothers (John H. and Edward), Alfred, Me.

The rock (specimen 153,a) is a quartz diorite of slightly greenish dark-gray color, with conspicuous black mica, and of medium, evengrained texture, with feldspars up to one-fourth inch and biotite scales under one-fifth inch. It consists, in descending order of abundance, of a grayish soda-lime feldspar (oligoclase), black mica (biotite), quartz (smoky or milky), dark hornblende and magnetite, with accessory titanite, zircon, apatite, and secondary epidote and a white mica. The oligoclase is often in good-sized twins and is intergrown with orthoclase and quartz, and generally cloudy and altered by a white mica. The only contrast in this stone is that between the gray of the feldspar and quartz and the black mica. After one or two years' exposure the feldspar loses its slightly bluish tinge and assumes a greenish one, which is attributed to the oxidation of its ferrous oxide. (See on this subject p. 54.)

The quarry, opened prior to 1875 , measures 60 by 150 and is up to 30 feet in depth.

Rock structure: The sheets, measuring up to 12 feet in thickness and inclined, are crossed by vertical joints striking N. $70^{\circ} \mathrm{E}$., recurring at intervals of 10 feet and forming a heading 8 feet wide in center of quarry. Another set, also vertical, and striking N. $20^{\circ}-25^{\circ}$ W., recurs at intervals of 20 feet. The rift is horizontal and the grain vertical, with course N. $70^{\circ} \mathrm{E}$. The sap is 2 inches thick along the sheets. A vertical bed of sand, 6 inches thick, lies in the central heading.

The plant consists of 1 hand derrick.

Transportation is effected by cartage of a mile to Alfred railroad station.

a Rept. of tests of metals, etc., for 1895 (1896), pp. $319,325,344,409$. 
The product is used for curbing and buildings, and finds a market in Rochester, N. H. The Parsons Memorial Library, of Alfred village, is built of this stone.

The Spence \& Coombs black-granite quarry is in the town of Berwick, $1 \frac{1}{2}$ miles southeast of North Berwick village and station. Operator, Spence \& Coombs, Berwick, Me.

This rock (specimen 139, $a$ ) is a gabbro of very dark olive-brownish color and medium ophitic texture, consisting, in descending order of abundance, of longitudinal crystals of grayish olive-brownish limesoda feldspar (labradorite) between which are particles of diallage, black mica (biotite), magnetite, and a little pyrite, together with secondary hornblende, analcite, zoisite, and calcite. The freshly quarried stone becomes somewhat brownish on exposure. It takes a high polish and the cut or hammered surface is almost white.

The quarry consists of two openings, about 25 feet square by 5 to 10 feet deep.

Rock structure: The sheets, from 6 to 8 feet thick, lie nearly horizontal, and are crossed by vertical joints striking N. $25^{\circ}-30^{\circ} \mathrm{W}$. and by another set striking $\mathrm{N} .45^{\circ} \mathrm{E}$. and dipping $65^{\circ} \mathrm{SE}$. and recurring at intervals of 6 to 20 feet.

The plant consists of 2 derricks.

The quarry is worked only occasionally and the stone is used entirely for monuments. In 1905 a carload of it was shipped to Concord, N. H. A monument made of this gabbro for a Mr. Johnson was erected in 1885 in a cemetery at Somersworth, N. H., and is reported to be in as good condition now as then.

The Ricker quarry is in Biddeford city, at 19 Granite street. Operator, Charles Ricker, 19 Granite street, Biddeford.

The granite (specimen 129, a) is a biotite granite of general lightgray shade with conspicuous smoky quartz and slightly bluish white feldspar and of coarse, even-grained texture, with feldspars. up to 0.75 inches and biotite under 0.2 inches. It consists, in descending order of abundance, of a slightly bluish milk-white potash feldspar (microcline and orthoclase), quite smoky quartz, milk-white sodalime feldspar (oligoclase), and black mica (biotite), together with accessory magnetite, zircon, and apatite, and secondary white mica and kaolin, derived from the alteration of the oligoclase. The contrasts in this granite are unusually brilliant. They are between the white of the feldspars, the gray of the very vitreous quartz, and the black of the mica. The stone takes a fine polish, but the largeness of the biotite scales does not favor its durability under exposure to the weather.

The quarry, opened in 1865 , is 100 by 50 and from 5 to 25 feet deep. There is no drainage problem nor stripping. 
Rock structure: The sheets, up to 12 feet thick, are crossed by joints striking $\mathrm{N} .50^{\circ}$ E., and dipping $55^{\circ} \mathrm{NW}$., which recur at intervals of 2 to 20 feet, and by a set striking N. $45^{\circ} \mathrm{W}$., and dipping $60^{\circ} \mathrm{SW}$., which recur at intervals of 2 to 10 feet and over.

The plant consists of 5 derricks and 1 engine.

Transportation involves cartage of 1 mile to railroad.

The product is used for monuments, etc.

The Gowen Emmons quarry is in Biddeford city, at 17 Granite street. Operator, Gowen Emmons \& Co., 17 Granite street, Biddeford.

The granite (specimen 12S, $a$ ) is a biotite granite of general lightgray shade, with conspicuous smoky quartz and slightly bluish white feldspar, and of coarse even-grained texture, with feldspars up to three-fourths inch and biotite under one-fifth inch. It is

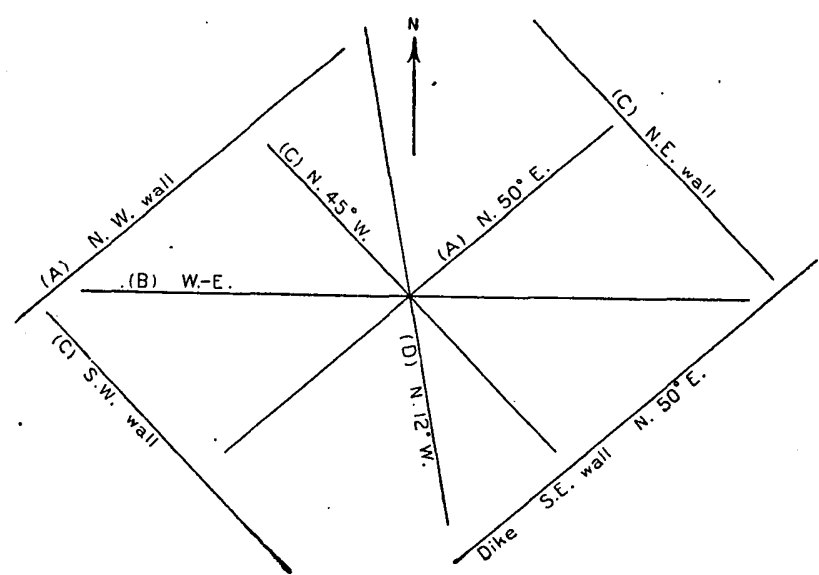

Fig. 38.-Structure at the Gowen Emmons quary, Biddeford.

identical with that of the Ricker quarry (specimen 129, a), described above. In the sheets that lie nearer the surface the feldspar has lost its bluish tint and is slightly grayish or greenish, which has the effect of diminishing the contrasts. Specimen 128, $a$ is not so brilliant as $129, a$.

The quarry, opened about 1865 , consists of 2 openings, an old one 200 feet from northeast to southwest, by 100 feet across, and from 30 to 70 feet deep, and a new one, 250 feet from northeast to southwest, by 200 across, and from 10 to 60 feet in depth. There is no drainage problem.

Rock structure: The sheets, from 1 to 12 feet 6 inches thick, increasing in thickness downward, undulate horizontally. The joint courses are shown in fig. 38. A dips $55^{\circ} \mathrm{NW}$., and recurs at intervals of 2 to 20 feet; $\mathrm{B}$ dips $70^{\circ} \mathrm{S}$., and occurs exceptionally; C dips 
$60^{\circ} \mathrm{SW}$., and forms the northeast and southwest walls, and recurs at intervals of from 2 to 10 feet or more; D dips $65^{\circ} \mathrm{E}$., and occurs exceptionally. The rift is vertical, N. $60^{\circ} \mathrm{W}$.; grain is horizontal. On the southeast wall there is a basic dike up to 1 foot thick and nearly parallel to joints A. Black knots occur up to 6 inches across. Sap measures 6 inches on both sides of upper sheets but diminishes below.

The plant consists of 5 derricks, 2 hoisting engines, and 2 polishers, run by an 8 -horsepower engine.

Transportation involves cartage of 1 mile to railroad.

The product is used for buildings and monuments, and finds a market in the State and also in the West. Specimen monument: The Lincoln monument, erected at Springfield, IIl., in 1868. Contract in 1905: A hospital at Dover, N. H.

The Marcille \& Wormwood quarry is in the town of Biddeford, $1 \frac{1}{4}$ miles southwest of Biddeford city, in West Biddeford. Operator, Marcille \& Wormwood, Biddeford.

The granite (specimen 130, $a$ ) is a biotite granite of general mediumgray pinkish-buff color and of coarse, even-grained texture, with feldspars up to three-fourths inch and biotite up to three-twentieths inch. It consists, in descending order of abundance, of a pinkish-buff potash feldspar (microcline and orthoclase), dark smoky quartz, cream-white soda-lime feldspar (oligoclase), black mica (biotite), and a very little muscovite, together with accessory magnetite and secondary epidote, chlorite, kaolin, and white micas. The oligoclase is considerably altered to kaolin, a white mica, and epidote, and the biotite to chlorite. The contrasts in this stone are chiefly between the pinkish-buff and the white feldspars and the smoky quartz, to which the black mica adds another element. As some of the potash feldspars are more pink and others more buff, it has in all five colors and shades.

The quarry is 40 by 20 feet and from 6 to 8 feet deep. There is little or no stripping.

Rock structure: The sheets, 7 feet thick (increasing to 15 feet lower down the hill), are crossed by vertical or very steep joints, striking N. $80^{\circ}-85^{\circ}$ W., which recur at intervals of 20 feet, also striking N. $40^{\circ}$ E., and recurring at intervals of 35 feet with headings. Sap, 1 to 2 inches thick, occurs along the top sheet, but along the headings it is 4 inches thick. A bunch of knots up to 8 inches thick and of egg-shaped outline was noticed.

The plant consists of 3 derricks.

Transportation involves a cartage of 1 mile to railroad siding.

The product is used for buildings. Specimen building: The trimmings on St. Joseph's Church, at Biddeford. (Material for the Charlestown, Mass., dry dock was quarried at an old opening adjacent 
to this.) In 1905 the quarry was producing trimmings for St. Mary's Convent, at Biddeford.

The Andrews \& Perkins quarries are in the town of Biddeford, about $1 \frac{1}{2}$ miles southeast of Biddeford city and one-half mile south of Saco River. Operator, Andrews \& Perkins, 18 Middle street, Biddeford.

The granite (specimien $133, a$ ) is a biotite granite of general lightgray color, with conspicuous black mica, and of coarse, even-grained texture, with feldspars up to three-fourths inch and biotite up to one-fifth inch. It consists, in descending order of abundance, of a bluish, translucent white potash feldspar (microcline and orthoclase), - smoky quartz (not so dark as that of the Ricker quarry, specimen 120 , a) milk-white soda-lime feldspar (oligoclase), and black mica (biotite), together with accessory magnetite, titanite, zircon, and apatite and secondary kaolin and a white mica derived from the alteration of the oligoclase. The feldspars are considerably intergrown with quartz, some particles of which are circular in cross section. The contrasts are chiefly between the feldspars, quartz, and mica. The feldspar is more bluish than that of the Ricker and Gowen Emmons quarries.

The quarries, opened in 1862, and again in 1895, consist of six small openings of various dimensions, only one of which-a " bowlder quarry"-is worked at present.

Rock structure: The rift is horizontal, the grain vertical, striking northwest-southeast, but the difference between them is not marked. The jointing permits the quarrying of blocks up to 25 feet square. Sap is 2 inches thick. Knots in some of the openings measure up to 3 and even 10 feet in length.

The plant consists of 10 derricks, 3 hoisting engines, 4 steam drills, and 4 pumps.

Transportation involves cartage of one-half mile to Saco River, or of 2 miles to railroad at Biddeford.

The product is used for buildings and monuments. Specimen buildings: Tribune Building, New York; General Dix monument at Fort Monroe, Va.; foundation and trimmings of Watson \& Miller building at Portland, Me. This quarry has furnished granite for the Delaware and Saco River breakwaters. In 1905 the quarry was supplying curbing for Dover and Rochester, N. H.

The Goodwin quarry is in the town of Biddeford, about $1 \frac{1}{2}$ miles southeast of Biddeford city and one-half mile south of Saco River, a little southeast of Andrews \& Perkins quarry. Owner, Goodwin heirs, Biddeford. The quarry is not in operation.

The granite is a biotite granite, identical with that of the Andrews \& Perkins quarry, described above. 
The quarry consists of two openings, one 150 feet square and 10 to 25 feet deep, another 200 by 150 feet and from 10 to 40 feet deep.

Rock structure: The sheets, from 1 to 10 feet thick, are horizontal, undulating, or dip up to $15^{\circ} \mathrm{SE}$. with a 3 -inch bed of sand in upper part.' Joints, striking N. $45^{\circ} \mathrm{E}$. and dipping $65^{\circ} \mathrm{NW}$., form a heading in the newer opening, and in the older one recur at intervals of 1 to 5 feet. Another set, confined to the newer opening, striking N. $50^{\circ} \mathrm{W}$, and dipping $90^{\circ}$, forms the northeast and southwest walls of the quairy and a 10-foot heading in the middle. Knots are somewhat plentiful. An 18-inch basic dike strikes northeast.

The plant consists of 4 . derricks and 1 hoisting engine.

The Bear Hill quarry is in the town of Hollis, on Bear Hill, 1 mile west-southwest of Bradbury station (Hollis Center), on the Portland and Rochester Railroad. Operator, E. M. Bradbury, Hollis Center, Me.

The granite (specimen $136, a$ ) is a biotite-muscovite granite of medium-gray shade with a slight greenish tinge, evenly spangled with black and white mica, and of medium (inclining to fine) evengrained texture, with feldspar up to three-tenths and mica up to onetenth inch. It consists, in descending order of abundance, of a grayish potash feldspar (orthoclase and microcline), slightly smoky quartz, grayish soda-lime feldspar (oligoclase), black and white mica (biotite and muscovite), with accessory apatite and a secondary white mica. As the quartz is about of the same shade as the feldspar the only contrast is between the gray ground and the micas. In the stone at the smaller openings the feldspars are milk-wbite translucent, with a very slight bluish tinge, which gives the granite a general light-gray shade. .

The quarry, opened in 1901 (although stone had been taken out as early as 1855), consists of an older opening of irregular shape, from which about 700 cubic yards have been quarried and an acre stripped, and of a newer opening 50 feet square and 5 to 10 feet deep. The stripping consists of 1 foot of soil (woods).

Rock structure: The sheets are lenticular, up to 6 feet thick, and horizontal. Vertical joints strike N. $55^{\circ} \mathrm{W}$., and form a heading on the southwest; joints also strike N. $30^{\circ}-35^{\circ}$ E., recurring at intervals of 30 feet or more. The rift (horizontal) is marked, and the grain is vertical, striking east and west. Pegmatite dikes, up to 6 feet thick, strike N. $10^{\circ}-20^{\circ} \mathrm{W}$., recurring at intervals of 30 feet or more, and in places branching. They consist of quartz, feldspar, biotite, and muscovite. A basic dike, from 1 to 12 inches thick and with a course N. $30^{\circ} \mathrm{E}$., traverses the entire quarry, crossing the pegmatite dikes and dying out on the northeast. The sap is marked on upper sheet and also along the joints and up to 6 inches in thickness.

The plant consists of 3 derricks and 1 ditch hand pump. 
Transportation involves a cartage of one-fourth mile to railroad, but the present contract for dam on Saco River involves a cartage of 3 miles.

The product is "random stone." The quarry is now producing stone for the foundation of a pulp mill (Bar Mills) and for a dam on the Saco River.

The Day quarry is in the town of Kennebunkport, 3 miles southwest of Biddeford. Operator, A. H. Day, Biddeford.

The granite (specimen 131,a) is a biotite-muscovite granite of medium-gray shade with conspicuous black mica and of coarse evengrained texture, with feldspars up to an inch across and biotite scales up to one-fifth inch. It consists, in descending order of abundance, of a gray (very slightly buff-pinkish in places) potash feldspar (microcline and orthoclase), very smoky quartz, milk-white soda-lime feldspar (oligoclase), black mica (biotite), with a little white mica (muscovite). The contrasts in this granite are marked.

The quarry, opened about 1899, is 50 feet square and 25 to 30 feet deep. The stripping consists of 3 feet of gravel. .

Rock structure: The sheets, from 4 to 14 feet thick, dip $10^{\circ} \mathrm{E}$.; joints, striking north and dipping $60^{\circ} \mathrm{W}$., form a heading on the west, and recur at intervals of 30 feet or more. One striking northwest dips $80^{\circ} \mathrm{SW}$.; another strikes N. $80^{\circ}$ E., and still another strikes northeast and dips $40^{\circ} \mathrm{SE}$. This is a bowlder quarry. The rift is horizontal and grain N. $70^{\circ}-75^{\circ} \mathrm{W}$., but they are not marked. Sap, from 2 to 3 inches thick, occurs along the joints.

The plant consists of 6 derricks and 1 hoisting engine.

Transportation involves cartage of 1 mile to a railroad siding.

The product is used for bridge work, and some of it was used in the Kittery, Me., dry dock. In 1905 the quarry was doing bridge work for the Boston and Maine Railroad.

The Ross quarry is in the town of Kennebunkport, $3 \frac{1}{2}$ miles southwest of Biddeford. Operator; Ellis \& Buswell; office at Woburn, Mass.

The granite (specimen 132, a) is a biotite granite of general lightgray shade with translucent milky-white feldspars, dark, smoky quartz and black mica, and of coarse, even-grained texture with feldspars up to 1 inch across and biotite scales under one-fifth inch. It is similar to that of the Ricker and Gowen Emmons quarries, described on pages 175,176 .

The quarry, opened in 1887, is about 200 feet square and 35 feet in depth. Its drainage requires pumping after each rain and for a month in the spring before starting up. The stripping consists of 2 to 3 feet of loam.

Rock structure: This is a typical "bowlder quarry," with irregular joints, shown in fig. 39. The sheets, from 14 to 22 feet thick, 
are horizontal or dip $30^{\circ} \mathrm{E}$., but irregularly. A basic dike 10 inches thick forms the northwest side of the quarry and is said to continue for one-fourth mile in a direction N. $50^{\circ} \mathrm{E}$. The joints run in four directions, none of them at right angles to another and none of them vertical. Sap measures from 3 to 6 inches thick along the sheets. Knots up to 6 inches thick are not abundant.

The plant consists of 6 derricks, 2 hoisting engines, 2 steam drills, and 2 steam pumps.

Transportation involves cartage of one-third mile to a siding on the Boston and Maine Railroad.

The product is used mostly for bridge work. Specimen structures: The gateway at Hope Cemetery, in Kennebunk (except the balls on the posts) and the Renwick tomb at cemetery near Kittery, Me. Contract in 1905: Railroad bridge at Haverhill, Mass.

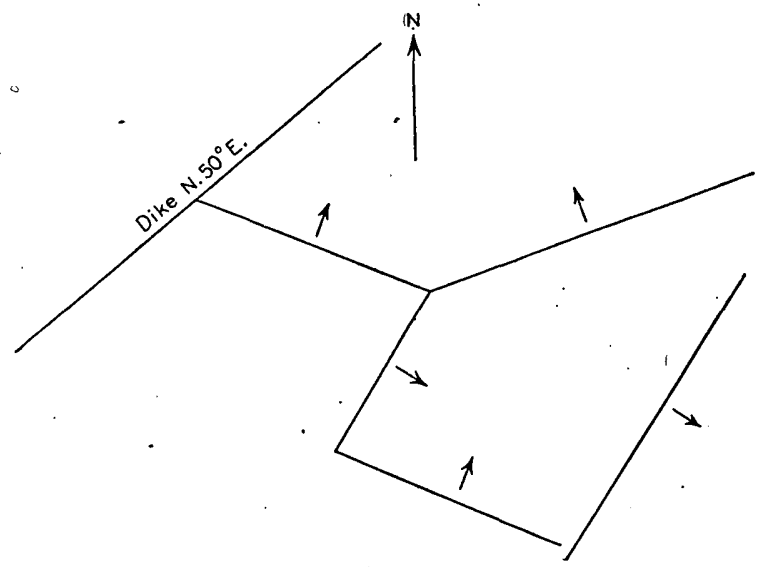

Fig. 39.-Approximate structure at Ross (Ellis \& Buswell) "bowlder quarry," Kennebunkport. The small arrows show the direction of dip of joints.

The Lord prospect is in the town of Wells about 1 mile east-northeast of Wells Depot on the Boston and Maine Railroad (eastern division), near a schoolhouse at a road fork. Owners: Granville W: and H. E. Lord (of one opening). These, associated with L. A. Stevens, are owners of another opening. Address, Wells Depot, Me.

The granite from the first opening (specimen 138, $a$ ) is a biotite granite of light pinkish-gray shade, with sparsely disseminated conspicuous biotite, and of medium to coarse, even-grained texture, with feldspars up to one-half inch and biotite scales up to one-fifth inch in diameter. It consists, in descending order of abundance, of a delicate pink potash feldspar (microcline and orthoclase), with slightly smoky quartz, cream-white soda-lime feldspar (oligoclase), and black mica (biotite), together with accessory magnetite and zircon and secondary white mica and chlorite. The potash feldspars are both intergrown with plagioclase. The oligoclase is intergrown with 
quartz in particles that are circular in cross section and is partly altered to a white mica and the biotite to chlorite.

The stone takes a good polish, but the large size of the biotite scales is not favorable to the durability of the polish in outdoor exposure. The contrasts are chiefly between the grayish-pinkish ground and the black mica.

The openings are small. The stripping consists of 3 feet of sand. The sheets, from 1 to 3 feet thick, are horizontal. Vertical joints strike N. $10^{\circ}$ E. and N. $70^{\circ}$ W. The rift is horizontal. Sap 2 inches thick occurs along the sheets.

\section{STATISTICS OF EQUIPMENT AND INVESTMENT.}

In order to ascertain the amount of capital invested in the Maine granite industry, the operators were asked to submit, in confidence, conservative estimates of the value of their quarries and plants and of an amount of capital sufficient for working the same on their present scale. Figures were obtained from all but a few very small concerns, and in their cases estimates were made by the writer based on the size of the quarries and plants and the number of men employed and on the returns from the other firms. The figures for 82 operators aggregate $\$ 3,531,000$, but four of these operators are simply owners of idle quarries. As their value was estimated at $\$ 73,500$, that amount should perhaps be deducted from the aggregate, which would make the investment represented by the Maine granite industry $\$ 3,467,000$, or, in round numbers, $\$ 3,500,000$.

\section{STATISTICS OF PRODUCTION FOR 1905.}

By Alitha T. Coons.

The following table shows the production of granite in Maine in 1905, clạssified by counties and by uses:

Production of granite in Maine in 1905, by counties and uses.

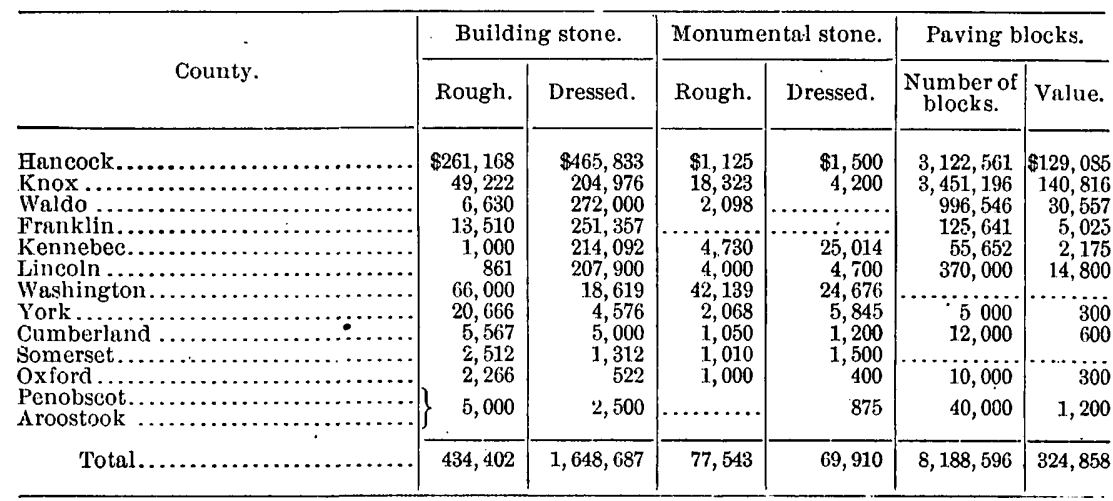


Production of granite in Maine in 1905, by counties and uses-Continued.

\begin{tabular}{|c|c|c|c|c|c|c|c|}
\hline County. & Curbing. & $\begin{array}{l}\text { Flag- } \\
\text { stone. }\end{array}$ & $\begin{array}{l}\text { Crushed } \\
\text { stone. }\end{array}$ & Rubble. & Riprap. & Other. & Total. \\
\hline 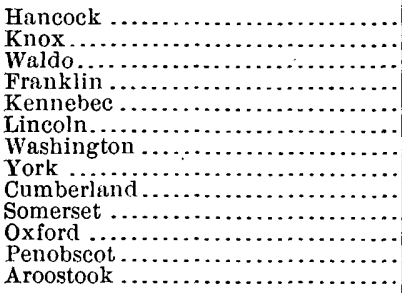 & 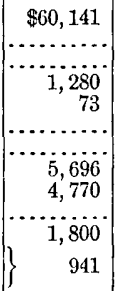 & 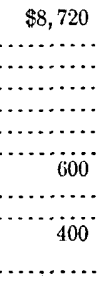 & $\begin{array}{r}\$ 724 \\
875 \\
6,016 \\
\ldots .495 \\
2,49 \\
10 \\
100 \\
9 \ldots\end{array}$ & $\begin{array}{r}\$ 710 \\
\cdots \ldots \ldots \\
1,975 \\
2,538 \\
\cdots \ldots \ldots \\
\cdots \ldots \ldots \\
\cdots \ldots \ldots \\
\cdots \ldots \ldots \\
\cdots\end{array}$ & 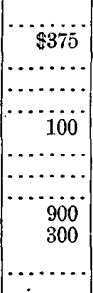 & $\begin{array}{r}\$ 1,300 \\
23,140 \\
10,523 \\
\ldots \ldots \ldots \\
943 \\
430 \\
10,000 \\
4,172 \\
800 \\
4,452 \\
1,000\end{array}$ & $\begin{array}{r}\$ 928,872 \\
442,486 \\
322,683 \\
279,163 \\
250,565 \\
235,286 \\
161,434 \\
43,933 \\
19,097 \\
11,686 \\
8,084 \\
10,516\end{array}$ \\
\hline 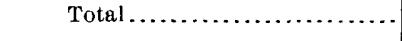 & $74 ; 701$ & 9,720 & 10,316 & $5 ; 223$ & 1,675 & 56,760 & $2,713,795$ \\
\hline
\end{tabular}

\section{BIBLIOGRAPHY OF ECONOMIC GEOLOGY OF GRANITE.}

Buckley, Ernest B. Building and ornamental stones of Wisconsin : Bull. Wisconsin Geol. and Nat. Hist. Survey, No. 4, Madison, Wis., 1898. Granite, pp. \$8-100, 107-115, 121-160 ; tests, pp. 46-74, 358-415.

Buckley, Ernest B., and Buebler, H. A. The quarrying industry of Missouri : Missouri Bureau of Geol. and Mines. 2d series, vol. 2. 1904. Granite, pp. $60-85$.

Coons, Altha T. The stone industry in 1904: Min. Res. U. S. for 1904. 1905. Granite, pp. 17-32.

Daw, A. W. and Z. W. The Blasting of Rock in Mines, Quarries, and Tunnels [etc.]. Pt. I: The Principles of Rock Blasting and their General Application. London. 1898.

Day, William C. Stone: Min. Res. U. S. Twenty-first and prior Ann. Repts. U. S. Geol. Survey. Granite.

Gillette, H. P. Rock Excavations: Methods and Cost. New York. 1904.

Gilmore, Q. A. Report on the comparative strength, specific gravity, and ratio of absorption of building stones in the United States. Official report Chief of Engineers, 1875.

Guttman, Oscar. Handbuch der Sprengarbeit. Braunschweig, 1892.

Harris, G. F. Granite and our Granite Industriess. London, 1888.

Henning, G. C. Diamond tools. Trans. Am. Soc. Mech. Eng., vol. 26, 1904, pp. 409-417.

Herrmann, O. Steinbruchindustrie und Steinbruchgeologie. Berlin, 1899.

Herrmann, O. Technische Verwerthung der Lausitzer Granite. Zeitschr. prak. Geol., November, 1895 (II), pp. 433-444.

Hull, Edward. A Treatise on the Building and Ornamental Stones of Great Britain and foreign countries. London, 1872.

Julien, Alexis A. Building stones; elements of strength in their constitution and structure: Jour. Franklin Inst., Pennsylvania, vòl. 147, No. 4. April, 1899, pp. 257-442.

Julien, Alexis A. Comparison of methods of graphic analysis of rocks. Bull. Geol. Soc., America, vol. 14, pp. 460-468. 1903.

Lundbohm, Hjalmar. Summary of his various papers on granite and granite quarrying in Europe, by William C. Day: Min. Res. U. S. for 1893. U. S. Geol. Survey, 1894. 
Mathews, Edward B. The granite quarries of Maryland: Rept. Maryland Geol. Survey, vol. 2, 1898, pp. 136-160.

Mathews, Samuel W. The granite industry of Maine: Sixteenth Ann. Rept. Bureau of Industrial and Labor Statistics for the State of Maine, 1902, pp. $7-51$.

Merrill, George P. On the collection of Maine building stones in the United States National Museum : Proc., U. S. Nat. Mus., vol. 6, 1883, pp. 165-1.83.

Merrill, George P. Collection of building and ornamental stones in the United States National Museum: Ann. Rept. Smithsonian Inist., 1886, pt. 2, 1889.

Merrill, George P. Physical, chemical, and economic properties of building stones: Rept. Maryland Geol. Survey, vol. 2, 1898, pp. 47-123.

Merrill, George P. Stones for Building and Decoration, 3d ed. New York, 1903.

Merrill, George P. Stone (granite): Special reports of the Census Office, Twelfth Census; mines and quarries. (1902.) 1905.

Perkins, George H. Report on the marble, slate, and granite industries of Vermont, 1898. Granite, pp. 51-68.

Perkins, George H. Report of State Geologist on the mineral resources of Vermont, 1899-1900. Granite, pp. 5i-iT.

Perkins, George H. Report of State Geologist on the mineral industries and geology of certain areas of Vermont, 1903-4. 1904. Granite, pp. 23-44.

Reusch, Hans. Granite industrien ved Idefjorden, etc. Norges geologiske undersögelse: Aarbog for 1891. Kristiania; 1891.

Riiber, Carl C. Norges granit industri : Norges geologiske undersögelse No. 12 : Aarbog for 1893, with English summary.

Rich, George. The granite industry of New England: New England Magazine, February, 1892, p. 742.

Rosiwal, August. Ueber geometrische Gesteinsanalysen. Ein einfacher wer zur ziffermässigen Feststellung des Quantitiits verhältnisses der Mineralbestandtheile gemengter Gesteine: Verh. der K.-K. geol. Reichcsinstalt, vol. 32,1898 , pp. 143-175.

Rosiwal, August. Ueber einige neue Ergebnisse der technischen Untersuchung von Steinbaumaterialen. Eine neue Methode \%ur Erlangung zahlenmässiger Werte fur die "Frische" und den "Verwitterungs grad" der Gesteine: Verb. der K.-K. geol. Reichsanstalt, vol. 33, 1899, pp. 204-225.

Rosiwal, August. Ueber weitere Ergebnisse der technischen Untersuchung Erlangung zahlenmässiger Werte fur die "Zähigkeit" der Gesteine: Ver. K.-K. geol. Reichsanstalt, 1902, pp. 234-246.

Smith, Walter B. Methods of quarrying, cutting, and polishing granite. Mineral Industries: Eleventh Census, U. S. (1892), pp. 612-61.8. Also Sixteenth Ann. Rept. U. S. Geol. Survey, pt. 4, pp. 446-456.

Speer, F. W. Quarry methods: Tenth Census, U. S., vol. 10, 1888, pp. 33 et. seq.

Tarr, Ralph S. Economic Geology of the United States, with Briefer Mention of Foreign Mineral Products, 2d ed., New York, 1895.

Watson, Thomas Leonard. A preliminary report on a part of the granites and gneisses of Georgia: Bull. 9 A, Georgia Geol. Survey, 1902. 
Watson, Thomas Leonard, and Laney, Francis B., with the collaboration of George P. Merrill. The building and ornamental stones of North Carolina: Bull. North Carolina Geol. Survey No. 2, 1906.

Williams, Ira A. The comparative accuracy of the methods for determining the percentages of the several components of an igneous rock: Am. Geologist, vol. 35, January, 1905.

Wolff, Johnु E. Details regarding quarries (granite) : Tenth Census, vol. 10, 1888.

See also the successive reports of the tests of metals and other materials for industrial purposes made at Watertown Arsenal, published by the United States War Department.

The German periodicals named below also give results of tests of granite:

Mitteilungen der technischen Versuchsanstalten zu Berlin.

Mitteilungen der Anstalt zur Prüfung von Baumaterialien am Polytechnikum in Zürich.

Mitteilungen aus dem mechanisch-technischen Laboratorium der Königlichen technischen Hochschule in Mïnchen.

The substance of the paper by Merrill in rol. 10 of the United States Tenth Census, 1888, and by Merrill in the proceedings of the U. S. National Museum, vol. 6,1883 , several times referred to, has reappeared in more modern form in his other works or is given in this report.

\section{GLOSSARY OF SCIENTIFIC AND QUARRY TERMS.}

- Accessory minerats in granite are original constituents of the rock, found only in small, often only in microscopic quantity. "(See p. 17.)

AnTrcline. A term applied to granite sheets or sedimentary beds that form an arch.

APLiTE. Fine-grained granite, usually occurring in dikes and containing little mica and a high percentage of silica.

BAsIc. A term applied to rocks in which the iron-magnesia minerals and feldspars with lime and soda predominate, such as diabase or basalts.

BowLDER QUARrY. One in which the joints are either so close or so irregular that no very large blocks of stone can be quarried.

Channel. A narrow artificial incision across a mass of rock, which, in the case of a granite sheet, is made either by a series of contiguous drill holes or by blasting a series of holes arranged in zigzag order.

Cleavage, when applied to a mineral, designates a structure consequent upon the geometrical arrangement of its molecules at the time of its crystallization.

Close-Jointed. A term applied to joints that are very near together.

Crush-Border. A microscopic granular structure sometimes characterizing adjacent feldspar particles in granite in consequence of their having been crushed together during or subsequent to their crystallization.

CUT-OFF. Quarrymen's term for the direction along which the granite must be channeled, because it will not split. Same as "hard-way."

Dike. A mass of granite, diabase, basalt, or other rock which has been erupted through a narrow fissure.

Dimension stone. A term applied to stones that are quarried of required dimensions. 
Dir. The inclination from the horizon, given in terms of degrees, of a sheet, joint, heading, dike, or other structural plane.in a rock.

Drift. Sand and bowlders deposited by the continental glacier.

ERosion. The wearing away of portions of a rock by such natural agencies as stream or ice action.

IAxfoliation. The peeling of al rock surface in sheets owing to changes of temperature or other causes.

Faultivg. The slippage of a rock mass or masses along a natural fracture. (See p. 40.)

Fow structure. The parallel arrangement of the minerals in granite or other igneous rock in the direction of its flowage during its intrusion. (See p. 25.$)$

Geode. A rock cavity lined with crystals. Geodes in granite are attributed to steam or gas bubbles. (See p. 50.)

Grain in granite is practically the direction in which the stone splits "next easiest," the "rift" being that in which it splits most readily. (See p. 26.)

Grour. A term applied to the waste material of all sizes obtained in quarrying stone.

Grow-on. Quarrymen's term to designate the place where the sheet structure dies out, or the place where two sheets appear to grow onto one another.

HARD-way. The direction at right angles to both rift and grain in which granite does not split readily. (See Cut-off.)

Heabing. A collection of close joints. (See p. 39, and Pls. VIII, A, IX, B.)

Heading-seam. See Joint.

Hematite. An oxide of iron $\left(\mathrm{Fe}_{2} \mathrm{O}_{3}\right)$ which when scratched ur powdered gives a cherry-red color.

Igneous. A term applied to rocks that have originated in a molten condition.

Jornts. More or less steeply inclined fractures which cross the granite sheets and which are attributed to various stresses. (See p. 38.)

KaOLIN. A hydrous silicate of alumina derived from the alteration of feldspar.

Kaolinization. The process by which a feldspar passes into kaolin. (See p. 55.)

KNots. A term applied by quarrymen to dark gray or black objects, more or less oval or circular in cross-section, which are segregations of black mica or hornblende formed in the granite while in a molten state. (See p. 49.) English quarrymen call them "heathen."

KNox HoLe. A circular drill hole with two opposite vertical grooves which direct the explosive power of the blast.

LEWIS HOLE. An opening made by drilling two or three holes near together and chiseling out the intervening rock.

Lrmonite. A hydrous oxide of iron $\left(2 \mathrm{Fe}_{2} \mathrm{O}_{3}, 3 \mathrm{H}_{2} \mathrm{O}\right)$; a hydrated hematite, which, when scratched or powdered, gives a brownish rust color.

MAtrix. The general mass of a rock which has isolated crystals; sometimes called groundmass.

Millimeter. French decimal lineal measure, the thousandth part of a meter or the tenth part of a centimeter. It is equivalent to nearly 0.04 inches, the meter being $39 \frac{10}{27}$ inches.

Monoliter. A column or monument of one stone. 
Mórion. A term used in granite regions to designate small paiving-block quarries. (See Pl. XII, B.)

Opнiтic. A term applied to microscopic rock texture to designite a mass of: longish interlacing crystals, the spaces between which bave been filled with minerals of later crystallization.

Pegmatite. A very coarse granite occurring in irregular dikes or lenses in granites and some other rocks. (See p. 44.)

Plagloclase. A term applied to all those feldspars that are not potash feldspars.

Polarized light. Light whose vibrations, unlike those of ordinary light, which are in all directions, are in only one plane. Polarized light is used in the microscopic study of rocks.

Porphrritrc. A term applied to rock texture to designate the presence of isolated crystals in a general mass (matrix or gronudmass) of finer material. (See p. 20.)

Random stone. A term applied by quarrymen to quarried blocks of any dimensions. (See definition of dimension stone.)

RIFT. A quarrymen's term to designate an obscure microscopic cleavage in granite which greatly facilitates quarrying. (See p. 26 and tig. 28.)

SALT-HoRse. Quarrymen's term for aplite.

SAP. Quarrymen's term for ferruginous discoloration along sheet or joint surtfaces.

Schrst. A rock made up of flattish particles arranged in rough parallelism, some or all of which have crystallized under pressure.

Schistositr. The quality of being like a schist.

Seam. Quarrymen's term for joint.

Secondary minerals. Minerals whose presence is due to the alteration of the original minerals.

Sedmentary. A term designating those rocks that consist of particles depos-

- ited under water.

Segregatron. The scientific term for "knot;" a collection of material separated from other material.

Sericite. A more or less fibrous form of muscovite (potash mica), often resulting from the alteration of feldspar:

Shakes. Quarrymen's term to designate a somewbat minute close-joint structure, which forms along the sheet surface as a result of weathering. (See p. 40.)

SheET QUARRY. A quarry in which the granite lies in sheets, crossed by widespaced steep joints.

Sutckensmes. The polished and grooved faces of a joint or bed caused by motion and friction.

SPECIFIC GRAVITY. The weight of a rock or mineral compared to that of a body of distilled water of the same bulk. (See p. 21.)

STRATIFIED. 'A term applied to rock consisting of originally horizontal beds or strata.

STRIKE. The direction at right angles to the inclination of a plane of bedding. a sheet, or joint, etc.

Strmping. The material (sand, clay, soil, etc.) overlying a rock of economic value, which must be removed before quarrying. 
SUbJoint. Minor joints diverging from or parallel to the regular joints. (See p. 41.)

Syncrine. A geological term for the trough part of a wavelike sheet or bed of rock.

Tur.. A mixture of clay and bowlders deposited by glaciers.

Toerng-IN. Quarrymen's term for the wedging in of the end of a granite sheet under an overhanging joint, probably in consequence of the faulting of the sheets along the joint. It is also applied to the overlapping of lenticular sheets.

TWIN cristals. Two adjacent crystals which have formed with the poles of their main axes in opposite or different directions. (See p. 20.)

Weathering. The decomposition of a rock owing to the action of the weather. (See p. 54.) 



\section{INDEX.}

A. Page.

Abbott (Alonzo) quarry (Franklin), description and product of........... 92-93

Accessory minerals, definition of......... 186 occurrence of ........................ 17

Addison Town, quarries in............ 159-161 See also following quarries: Pleasant River, Thornberg, Black Diamond.

Alfred Town, quarries in

$175-176$

Allanite, occurrence of, in granite........ 17,18

Allen, M. L., quarries of. See Snowflake quarry, Allen quarry.

Allen quarry (Mount Desert), description. and product of............... 100

dikes on ....................... 47, 100

plate showing.................... 44

faulting at......................... 40

plate showing................... 44

American granites, analyses of............ 19

American Stone Company's quarry, description and product of........

flow structure at................. 26, 83

Ames, Calvin, quarry of. See Calvin Ames quarry.

Andalusite schists, occurrence of ...........

Andrews \& Perkins-quarries (Biddeford), description and product of .... 179

granite of, classification of............ 73

knots at........................... 50,179

Anticline, definition of .................. 186

A patite, occurrence of, in granite.......... 17, 18

$\Lambda$ plite, analyses of ...................... 44

definition of ....................... 186

dikes $n$, occurrence and character of. 42-44,61

A rmbrust,' J. P., quarry of. See Armbrust quarry.

A rmbrust quarry (Vinalhaven), description and product of....... 129,135-136

granite of, classification of............ 73

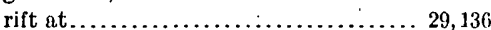

A roostook Co., production of granite in.. 183-184

A rsenal, U. S., tests of granite by......... 21-22,

$81,84,154-155,161,175$

Augite, description of .................. 17 occurrence of, in granite............ 14, 17, 18

\section{B.}

Babbage, Seth, quarry of. See Babbage quarry.

Babbage quarry (Mount Desert), description and product of. See arso quaries in .......... 161-162 See also Fall black-granite quarry: Tarbox black-granite quarry.

Baird (Mathew) Contracting Co., quarry of. See Baird quarry.

Baird quarry (Swans Island), description and product of.............. 114-115

granite of, classification of............ 73

Baker, J. H., quarry of. See Hartland quarry.

Banding in black granite, occurrence of .... $60-61$ plate showing....................... 60

Bangor, quarry near.................... 147

Bartlett, F. L., work of ................ 78

Bartlett, W. C., on expansion in granite ... 22 .

Bascom, Florence, on Johns Bay dikes..... $\cdot 61$

Basic, definition of..................... 186

Bastin. E. S., work of ................. 9,127

Batholith, probable existence of.......... 10-11 . roof of ........................... 11,15

Bear Hill quarry (Hollis), description and product of ................. 180-181

Beaver Lake black-granite quarry (Calais), description and product of ... 163-164

dikes at........................... 61

granite of, classification of........... 75

stracture at, figure showing........... 164

Becker, G. F., on joints................. 38

on sheets ........................ 32

Bennett Brothers, quarry of. See Bennett quarry.

Bennett quarry (Alfred), description and product of ............... 175-176

discoloration in ..................... 54

granite of, classification of........... 74

Berwick Town, quarries in .............. 176

See also Spence \& Coombs black-granite quarry.

Bibliography of granites............. 62, 184-186

Biddeford Town, quarries in............ 176-180

See also following quarrics: Ricker;

Gowen Emmons; Marcille \& Wormwood; Andrew \& Perkins; Goodwin.

Biotite, description of $\ldots \ldots \ldots \ldots \ldots \ldots \ldots \ldots, 17$

occurrence of, in granite........... 17, 18, 57

Biotite granite, definition of.............. 24

Biotice-hornblende granite, definition of ... 24

Biotite-muscovite granitc, definition of $\therefore \quad 24$

Black, Herbert, quarry of. See Bog Hill quarry.

Black, J. S., quarry of. See Black (Pleasant River) quarry. 
Black Diamond Granite Co., quarry of. See Black Diamond quarry.

Black Diamond quarry, description and product of ...... $160-161$

Black granite, banding in. banding in, plate showing. chemical composition of............ 57-58 classification of . . . . . . . . . . . . contacts of .................... 61-62 definition of. $. \ldots \ldots \ldots \ldots \ldots \ldots \ldots .14,56-j 7$ dikes in, plates showing........... 60,62 granite and, distinction between ...... 58 joints in ....................... 60 plate showing $\ldots \ldots \ldots \ldots \ldots \ldots \ldots \ldots .62$ minerals in ..................... 57-58 physical properties of . . . . . . . . . . . 58-59 quarries of, descriptions of ..... 114,126-127, $136,139-140,143-144,157,159-164,176$

distribution of 60,62

plates showing . . . . . . . . . . . 60, 62

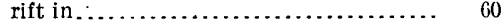

sheets in......................... 60

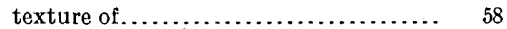

uses of . . . . . . . . . . . . . . . . . 58-59,67

variations in. .................... $60-62$

varieties of .

- See also Granite; Gabbro; Diabase; Diorite; Norite.

Black Island Granite Co., quarries of. See Black Island quarries.

Black Island quarries (Long Island), description and product of...... 96-97

granite of, classification of . . . . . . . . . .

Black (Pleasant River) quarry (Vinalhaven), description and product of . . . . . . . . . . . 134-135

granite of, classification of .......... 73

Blaisdel! ( $\mathrm{T}$. M.) quarry (Franklin), description and product of ....... 93-94

granite of, classification of ...........

structure at, figure showing..........

subjoints in.

Blaisdell (W. B.) \& Co. quarry (Franklin), description and product of . . . . 94-95

granite of, classification of........... joint faces in, minerals on . . . . . . . . . . structure at, figure showing ........... subjoints in. .

Bluehill G ranite Co.'s quarry (Bluehill), description and product of .......

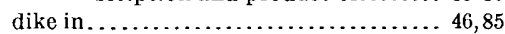

Bluehill Town, quarries in............. 84-88

See also following quarries: White Bluehill Granite Co.'s; Chase Collins Granite Go.'s; Howard.

Bodwell black-granite openings, description

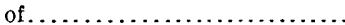

granite of, classification of ............

Bodwell Granite Co., quarries of. See following quarries: Sprucehead; Wildcat; Bodwell-Jonesboro; Sands; Palmer; Duchane Hirge Harbor; Bodwell.

Bodwell-Jonesboro quarry (Jonesbc scription and product

geodes in

Bodwell-Jonesboro quarry, granite of, clas-

sification of . . . . ..............

structure at, figure showing. .......... 169

Bog Hill quarry (Searsport), description and product of ............ 157-158

granite of, classification of........... 74

Booth Brothers and Hurricane Isle Granite Co., quarries of. See following quarrics: Long Cove; Pequoit; Hurricane Island; Waldoboro; Booth Brothers; Jonesboro.

Booth Brothers Jonesboro quarry (Jonesboro), description and product of . ....................... 169-170

granite from, analysis of ............ 170 classification of . ............... 73

Bowlder quarry, character of .......... 39

definition of . . . . . . . . . . . 186

Bradbury, E. M., quarry of. See Bear Hill quarry.

Bradbury (F.) \& Sons quarry (Franklin), description and product of . . . . 95-96

granite of, classification of.......... 74

Bragdon, Fernald \& Gordon quarry (Franklin), description and product of.

structure at, figure showing

Branner, J. C., on sheets............... 31

Bristol Town, quarries in ............... 139

See also Round Pond quarry.

B rooksville Town, quarries in . . . . . . . . . 88-89

See also following quarries: Bucks Harbor; Westcott; Maine Lake Ice Co.'s; Herrick's; Sargent's.

Brown, C. W., work of . . . .............

Brown, David, quarry of. See Brown quarry.

Brown quarry (Dedham), description and product of . . ............... $89-90$

granite of, classification of........... 74

structure at, figure showing.......... 90

Brunswick Town, quarries in........... 76-77

See also Grant quarry.

Bryant Pond quarry (Woodstock), description and product of.......... 146-147

dikes at....................... 48, 147

granite of, classification of ........... 74

joint faces in, minerals on . . ......... 52, 147

Buckley, E. B., on physical properties of granite............ 21, 22, 23,65, 66

Bucks Harbor, quarries at . . . . . . . . . . . . . 88-89

See also Bucks Harbor quarries; Westcott quarry; Maine Lake Ice Co.'s quarry.

Bucks Harbor Granite Co., quarry of. See Bucks Harbor quarries.

Bucks Harbor quarries (Brooksville), description and product of....... 88-89

granite of, classification of .......... 73

Building stone, production of ........... 183 $\therefore$

C.

Calais Town, quarries in . . . . . . . . . 162-167

See also following quarries: Gardner's; Beaver Lake; Shattuck Mountain; Mingo, Bailey \& Co.; Maine Red Granite Co.; Redbeach Granite Co. 
Page. Calvin Ames quarry, description and product of ..................... 109-110

Campbell \& Macomber quarry (Mount Desert), description and product of.

dikes in............ 48,99

granite of, classification of ............ 73

structure at, figure showing........... 99

Carbonic acid, presence of, evidence from .. 14-15

Carroll, John, quarry of. See Carroll quarry.

Carroll quarry ('Tremont), description of... granite of, classification of.............

Carving, examples of, plates showing ...... 70,72

Channels, cutting of ..................... 71 definition of ..................... 186

Chapman, W. G., receivership of.......... 77

Chase quarries (Bluchill), description and product of .................. 80 80 87

dikes at............................ 40

granite of, analysis of ............... 86

classification of.................. 73,74

Chase Quarries Co., quarries of. See Chase quarries,

Chemical composition of granites, description of...................... 18-20

determination of .................... 63

Chlorite, occurrence of, in granite......... 17

Clark Island quarry (St. George), description and product of .......... 125-126

dikes at.......................... 45, 126

granite of, classification of........... 74

sheeting at....................... 37,126

Classification of granites, methods of...... 23-24 of Maine granites, schemes of......... 24-25,

$59-60,72-75$

Cleavage, definition of.

Close-jointed, definition of................. 186

Cohesiveness of granite, data on......... 21

Collins Granite Co.'s quarry (Bluehill), description and product of........ granite of, classification of ............

Color of granites, classification by. description of

Colorado, sheeting in .........................

Commerce, Bank of, carved panel at, view of.

Compression, joints due to................ sheeting due to................. 32, 35, 36-37

Concord, N. H, rift at . ................ 27 strain at ......................... 36-37

Contact of granite with country rock, character of . . . . . . . plates showing................. 42, 46, 62

Contraction, sheeting due to........ 30,31, 35, 36

Cooks.Mountain, quarry on ............. 167

Coons, A. T., granite statistics by ..... 14, 183-184

Cores, crushing of

Crabtree \& Harvey quarry (Sullivan), description and product of........., 110 granite of, classification of ............ 74 knots in ......................... 49,110 plate showing................... 38 sheets at............................ 34

plate showing.................... 38

Crawford, J. J., on sheeting.............. 30

Crosby, W: O., on jointing. 38
Crotch Island, joints on ............... Page.

joints on, plate showing ............. 32 quarries on ...................... 101-106

See also Ryan-Parker quarry; Goss quarry; Sherwood quarries.

sheets on ................. 33-34,35, 36, 101

plate showing.................. 32

view of ........................... 32

water supply on..................... 69

Crown Granite Works, quarry of. See McConchie black-granite quarry.

Crush-border, definition of .............. 186

Crystallization of granite................. 15

Cumberland Co., production of granite in. 183-184 quarries in .........................

Curbing, production of ................. 184

Curved joints, occurrence of ............... 39

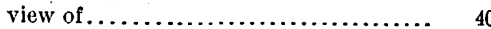

Cut-off, definition of .................... 180 view of .......................... 40

Cutting, H. A., on vitreousness of granites.. 23

\section{D.}

Dalotville, quarry at................... 159

Daly, R. A., on discoloration............. 54,63 Day, A. H., quarry of. See Day quarry.

Day quarry (Kennebunkport), description and product of .............. 181

- granite of, classification of ............ 73

Decomposition, deseription and cause of... 54

Dedham Town, quarries in .............. 89-90 See also Brown quarry.

Deer Isle, quarries on . ................ 108-110

See also Settlement quarry; Hagan and Wilcox quarry; Calvin Ames quarry.

Definitions of terms............... 14, 186-189

Devonian period, intrusions in ........... 11

Diabase, composition of ................... 58

origin of $\ldots \ldots \ldots \ldots \ldots \ldots \ldots \ldots \ldots \ldots \ldots \ldots, 57$

utilization of .....................

Dike, definition of .................... 186

Dikes, basic, occurrence and description of . 47-49 plate showing...................... 44 utilization of ........................ 72

Dikes, granitic, occurrenco and description of $. . \ldots \ldots \ldots \ldots \ldots \ldots \ldots \ldots . \ldots 2-46,61$ plates showng..................... 10,62

Dimension stone, definition of ............ 186

Diorite, composition of ............... $\quad 57$ quarries of ..... 25, 114,139-140,143-144, 162-164 plates showing................60,62 varieties of ........................ 59

Dip, definition of ..................... 187 Discoloration, occurrence and origin of..... 52-54 test for ......................... 63

Distribution of granite in Maine......... 7-9 map showing ...................... Pocket Dix Island quarries (Muscle Ridge Plantation), description and product of ......................... 123-124

rite of, classification of ............ 73

Dodli "ranite Co., quarry of. See Dodlin ci: iduarry.

Dodlin $\mathrm{H}_{2}$. 
Dodlin quarry (Norridgewock), contact in, figure showing............... 150 description and product of........... 149-151 faulting at..........................40,150 figure showing.................. 150 flow structure at................. 25, 150 granite of, classification of.......... 73,74 structure at, figure showing.......... 151

Domes, origin of $\ldots \ldots \ldots \ldots \ldots \ldots \ldots \ldots \ldots \ldots \ldots \ldots$ view of $\ldots \ldots \ldots \ldots \ldots \ldots \ldots \ldots \ldots \ldots \ldots \ldots, 34$

Drift, definition of .................... 187

Duchane Hill quarry (Vinalhaven), description and product of.

granite of, classification of.............

Dunbar, Harvey, quarry of. See Harvey Dunbar quarry.

Dunbar Brothers' quarry (Sullivan), description and product of........ dike in .......................... 48,113

Dwyer, Thomas, quarries of. See Dix Island quarries.

E.

Eagle Gray Granite Co., quarry of. See Eagle Gray quarry.

Eagle Gray quarry (Fryeburg), description '. and product of .............. 144-145

dikes in .......................... 45, 144

granite of, classification of..

45,144

structure at, figure showing............ 145

East Franklin, quarries in............... 93

East Sullivan, quarries near.............. 114

Economic aspects of granites, discussion of 63-189

Économic classification, methods of...... 24

Edwards, Edwin, quarry of. See Flat Ledge quarry.

Elasticity of granite, data on............ 21-22

Ellis \& Buswell, quarry of. See Ross quarry.

Emmons (Gowen) \& Co., quarry of. See Gowen Emmons quarry.

Emmons, S. F., on sheets................

Emmons - Taylor quarry (Norridgewock), description and product of.....

dikes at. ...

granite of, classification of. .

gidote, oceurrence of, in granite.

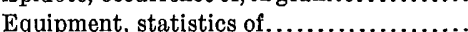

Erosion, definition of .................... process of

European granites, analyses of............

Exfoliation, definition of..................

Expansibility of granite, data on...........22, 66

Expansion, joințs due to............... 38

sheeting due to................ 31,32,35, 36

Explosives, use of ..................... 69-71

\section{F.}

Faulting, definition of

Faults, occurrence of ................... 40

Feldspar, color of, cause of............... 18

description of....................... 16 occurrence of, in granite......... 14, 16, 18, 56 mode of ......................... 20

Fernald (E. H.) Granite Co., quarry of. See Fernald quarry.
Fernald Brothers and Higgins quarry Mount Desert), description and product of....................

Fernald quarry (Lincoln), description and product of ................. 156-157

granite of, classification of............ 74

Finland, quarrying in.................. 71

Fire, effect of, on granite............... 66

Fish, N. W., quarry of. See Fish quarry.

Fish quarry (Jonesboro), description and product of ............... 167-168

granite of, classification of............ 73

Flagstone, production of............... 184

Flat Ledge quarry (St. George), description and product of ................ 127

Flexibility of granite, data on........... 22

Flow gneiss, definition of ................. 20

Flow structure, definition of............. 187

nature and direction of .............. 25-26

Fluorite, occurrence of, in granite........ 17

Foliation, occurrence and character of..... $40-41$

Foster and Sargent, quarry of............ 89 See also Maine.Ice Co.'s quarry.

Fox Islands, map of .................... 130

quarries in........................ 129

Foxcroft, quarry near................. 148

Fractures, microscopic, occurrence and character of ..................... 40-41

sap and, relations of ................. 41

Fractures, recent, occurrence and description of........................ 42

view of......................... 42

Frankfort Town, quarries in. ...........152-154 See also Mosquito Mountain quarry; Mount Waldo quarry.

Franklin County, production of granite in . 183-184 quarries in ........................ 80-83

Franklin Town, quarries in.............. 90-96 See also following quarries: Bragdon, Fernald \& Gordon; Robertson \& Havey; Abbott (Alonzo); Blaisdell ('T. M.); Blaisdell (W: B.) \& Co.: Bradbury (F.) \& Sons.

Freeport Granite Co., quarry of. See Freeport quarry.

Freeport quarry (Freeport), description and product of................ 77-79

granite of, classification of............ 74 inclusions at...................... 50,51,78 plate showing ................... 42 structure at, figure showing............ 78

Freeport Town, quarries in............... 77-79 See also Freeport quarry.

Freezing, effect of, on granite........... 66 Fryeburg, dikes at...................... 45, 48 Fryeburg Town, quarries in............. 144-145 See also Eagle Gray quarry.

G.

Gabbro, banding of, view of.............. 60 composition of ....................... 57 quarries of .................... 159-161,176 varieties of...................... 59

Gardner, Lorenzo, quarry of. See Gardner's black-granite prospect. 
Gardner's black-granite prospect (Calais), description of ................ 162-163 granite of, classification of............. 75

Garnet, occurrence of, in granite......... 17

Geikic, $\Lambda$., on weight of granite............ 21

Geodes, definition of ................... 187 occurrence and description of......... 50

Geographic distribution of granite........ $7-9$ map showing...................... Pocket

Geologic history of granite intrusions...... 10

Geologic relations of granite............. $9-11$

George Gins quarry, description and product of ..................... 136-137

Georgia granites, analyses of . ............. 19 description of ...................... 31 structure of, plate showing............ 42

Gilbert, G. K., on sheeting............ 32-33, 36 photograph by..................... 42 work of ........................... 14

Gins, George, quarry of. See George Gins quarry.

Glossary of granite technology. $186-189$

Gneiss, definition of.

Goodwin heirs, quarry of. See Goodwin quarry.

Goodwin quarry (Biddeford), description and product of............. 179-180

Goss, John L., quarries of. . See Goss quarry; Moose Island quarry.

Goss quarry (Stonington), description and product of.................. 104-105

dike at.......................... 43

granite of, classification of............ 73

sheets at....................... 34, 101, 104

plate showing................... 32

structure at, figure showing.......... 104

view of $\ldots \ldots \ldots \ldots \ldots \ldots \ldots \ldots \ldots \ldots ., 32$

Gowen Emmons quarry (Biddeford), description and product of ....... 177-178

granite of, classification of............ 73

structure at, figure showing............ 177

Grain, character of. . . ................... 20 .

definition of.......................... 26, 187

direction of .......................... 29

discusssion of ........................ 26-29

Grand Trunk Railway, quarry of. See Bryant Pond quarry.

Granite, analyses of . . 19, 63, 81, 86, 122, 137, 141, 170 bibliography of ................... 184-186 black granite and, distinction between. chemical composition of ............. 18-20 classification of ....... 23-24, 24-25, 59-60, 72-75 crystallization of ..................... 15 definition of ......................... 14

dikes of ............................. $45-46$

discoloration of ...................... 52-54

test for $\ldots \ldots \ldots \ldots \ldots \ldots \ldots \ldots \ldots, 63$

expansibility of .................... 22, 66

fire test of ............................ 66

freezing on, effect of ................ 66

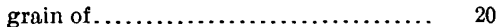

hardness of ...................... 22,64-65

joint faces in, minerals on ............ 51-52

lime carbonate in.................... 63

mineral composition of ....... 14, 16-18, 63-64
Page.

Granite, minerals in, occurrence of, mode of. 20-21 organ of . . . . . . . . . . . . . . . . . . physical properties of................ 21-23 polish of ............................ 64 porosity of ..........................22-23, 65 saturation of ...................... speciffe gravity of. ................... 66,188 strength of........................ 65 synthesis of, attempted reproduction of 15-16 technology of, glossary of.......... 186-189 tests of .............. texture of...................... 19-20, 25 uses of.......................... 67,72

weight of $\ldots \ldots \ldots \ldots \ldots \ldots \ldots \ldots \ldots \ldots, 21,66$

Grant quarry (Brunswick), description and product of ................... 76-77

flow structure at................... 25,76

granite of, classification of............ 74

structure at, figure showing........... 77

Graves Brothers quarry (Mount Desert), description and product of.... 100-101

Gray, Wm. \& Sons, quarry of. See High Isle quarry.

Green Island, joints on . ............... 38, 129

joints on, plate showing.............. 32

quarries on ............... 106, 129, 136-137

See also Latty Brothers quarry.

Gregory, H...., work of.................

Grout, definition of $\ldots \ldots \ldots \ldots \ldots \ldots \ldots \ldots, 187$

Grow-on, definition of ................. 187

Guilford Town, quarries in............... 148

See also Queen City Granite Co.

Gundelow quarry, description of......... 136

H.

Hagen and Wilcox quarry (Stonington), description and product of...... 109

granite of, classification of............ 73

Hall, C. J., quarry of ................. 115

Hall, F. H., quarry of. See Hall blackgranite quarry.

Hall black-granite quarry (Baileyville), banding in.................6, 60,162

description and product of .......... 161-162

granite of, classification of............. 75

tests of ...................... 161

sheets in ...........................6, 60,162

Hall Quarry, quarries at and near... 97, 98, 99, 100

Hallowell Granite Works, quarries of. See Stinchfield quarry; Longfellow quarry.

Hallowell Town, quarries in. 117,121

See also Stinchfield quarry; Longfellow quarry; Tayntor quarry.

Hancock County, granite contacts in...... 9-10

production of granite in ............ 183-184

quarries in...................... 84-117

Hanson, H. F., quarry of. See Hermon Hill quarry.

Frarbor quarry (Vinalhaven), description and product of.............. 129, 136

Hardness of granite, data on.......... 22,64-65 Hard-way, definition of................. 187

Hardwood Island quarry (Jonesport), description and product of...... 172-173 
Hardwood Island quarry, granite of, classification of..............................

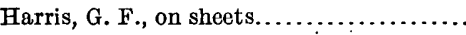
Hartland quarry (Hartland), description and product of................. granite of, classification of..............

Hartland Town, quarries in............... See also Hartland quarry.

Harvey Dunbar quarries (Sullivan), description and product of......... 113-114

Havey, W. 'T., quarry of. See Whalesback quarry.

Hawes, G. W., on hardness of granite......

Head Harbor Island, granite of, classification of ....................... quarries on ..................... 171, 172 See also Minerva Cove quarry; New England Granite quarry.

Heading-seam, definition of.............. 187

Headings, decomposition due to........... 40

definition of......................... 187

description of ...................... 39-40

intersection of, plate showing ......... 46

origin of ............................ 40

plates showing. ...................... 44, 46

Heal, A. S., quarry of. See Heal blackgranite quarry.

Heal black-granite quarry (Lincoln), description and product of ........

75

Heat, sheeting due to ................. 33, 35-37

Hematite, definition of................. 187

Herrmann, O., on crushing strength of granites.........................

on joints.......................... on rift.

on sheets......................... 30-31

Hermon Hill quarry, description and product of ..................... 147-148 granite of, classification of........... 75

Hermon Town, quarries in ............. 147-148 See also Hermon Hill quarry.

Heron Neck, joints at, plate showing....... view of. ............................

Herrick, E. H., quarry of................. See also Herrick's quarries.

Herrick's quarries (Brooksville), description and product of .............

High Isle quarry, description and product of ........................ 122-123

granite from, analysis of............. classification of ................... 73 thin section of, figure showing......

heading at, plate showing............. sheets at............................ plate showing............................ structure at, figure showing............ water supply of.......................

Hitchock, C. H., on sheets................. work of...

Hodsdon, W. I., quarry of. See Hodsdon quarry.

Hodsdon quarry (Fryeburg), description and product of............... 145

Hollis Town, quarries in. See also Bear Hill quarry.
Page.

Hooper, Havey \& Co.'s quarry (Sullivan), description and product of...... 112

fracture at........................ 42,112

Hopewell quarry (Sullivan), description and product of .................. 111

granite of, classification of. ........... 74

sap at............................. 53

Hopewell Stone Co., quarry of. See Hopewell quarry.

Hornblende, description of .............. 17

occurrence of, in granite......... 14, 17, 18, 57

Hornblende-biotite granite, definition of ... 24

Hornblende granite, definition of .......... . .24

Horsebrook Mountain quarry (Jonesboro), description and product of..... 167

Howard, W. M., quarry of. See Howard quarry.

Howard quarry (Bluehill), description and product of ....................

granite of, classification of..............

Howe, Ernest, experiments of .............

Hudson, C. E., quarry of. See Weskeag quarry.

Hurricane Island, quarries on....... 129, 137-138

Hurricane Island quarry (Vinalhaven), description and product of...... 137-138

granite of, analysis of................ 137 classification of ................... 73

sheets at.......................... 34

plate showing.................... 36

structure at, figure showing.......... 138

I:

Igneous, definition of ................... 187

Igneous intrusions, period of ............ 11

See also Intrusions.

Ilmenite, occurrence of, in granite........ 17

Inclusions, occurrence and description of... 50-51

India, artificial production of sheets in.... 33

Intrusion of granite, evidences of......... $9-10$

history of .......................... 10

period of $. . . . . \ldots \ldots \ldots \ldots \ldots \ldots \ldots \ldots, \quad 11$

laceration by....................... 15-16

Investment, amount of ................. $\quad 183$

Irish granite, gas in.................. 19

Jackson, C. $\mathbf{T}$. , work of .................. 9

Jay Town, quarries in............... 80-83

See also Maine and New Hampshire

Granite Co.'s quarries; American Stone Co.'s quarry.

Jewett, E. C., quarry of. See Jewett's black-granite quarry.

Jewett's black-granite quarry (Whitefield), description and product of... 143-144

granite of, classification of............. 75

Johannsen, Albert, work of.............. 13-14

Joint faces, minerals on................. 51-52

Joints, courses of ........................ $\quad 39$

definition of....................... 187

origin and description of............... $38-39$

plates showing............... 32,36, 40,60

sheet structure and intersection of..... 38 intersection of, plates showing. .. $36,40,60$ 
J oints, spacing of... Page. See also Subjoints.

Jonesboro Town, quarries in ............ 167-170 See also following quarries: Horsebrook Mountain; Fish; Bodwell-Jonesboro; Booth Brothers Jonesboro.

Jonesport Town, quarries in........... 171-173

See also Minerva Cove quarry; New England granite quarry; Hardwood Island quarry.

\section{K.}

Kaolin, definition of.

occucrence of in granite.

17

Kaolinization, definition of .

Kemp, J. F., work of

Kennehec County, production of granite in ...................... 183-184 quarries in....................... 117-121

Kennebunkport Town, quarries in...... 181-182

Knight, 0 . W., on platinum in granite.... 147

Knots, definition of .................... 187 occurrence and description of......... 49-50

Knox County, production of granite in .. 183-184 quarries in ......................... 122-139

Knox holes, definition of ............... 71, 187

\section{L.}

Latty Brothers quarry (Stonington), description and product of ...... 106-107 granite of, classification of ........... 73

Lawton, F. S., quarry of. See Lawton quarry.

Lawton quarry (Norridgewock), description and product of......... 151-152

Lewis holes, definition of ............... 71,187

Lime carbonate, occurrence of, in granite... 63

Limonite, definition of ................ 187

Lincoln County, production of granite in. 183-184 quarries in ........................ 139-144

Lincoln Town, quarries in........... 156-157 See also Fernald quarry; Heal blackgranite quarry.

Literature, list of : $62,184-186$

Lit-par-lit injections, occurrence of........ 9, 10

Long Cove quarry (Tenants Harbor), description and product of...... 128-129 granite of, classification of............ 74 methods at ......................... 71

Long Island Town, quarries in .......... 96-97 See also Black Island quarries.

Longfellow quarry (Hallowell), description tion and product of .......... 117-120

dike at............................. 44

granite of, classification of............ $\quad 74$

strength of...................... 118

headings at, plate showing............ 46

structure at, figure showing ........... 118

Lord, G. W. and H. E., quarry of. See Lord prospect.

Lord prospect (Wells), description and product of ................ 182-183

granite of, classification of.
M.

Page.

Macadam, manufacture of ................ 72

McConchie, George, quarry of. See McConchie black-granite quarry.

McConchie black - granite quarry (St. George), description and product of ................... 126-127

granite of, classification of............ 75

McMullen (Arthur) \& Co., quarry of. See McMullen quarry.

McMullen quarry (Mount Desert), description and product of.......... 97-98

granite of, classification of............. 74

joint faces in, minerals on............ 52

structure at, figure showing........... 98

Machias Granite Co., quarry of. See Marshfield quarry.

Magnetite, occurrence of, in granite.... 17, 18, 57

Maine and New Hampshire Granite Co.'s quarries (Jay), description and product of ................... 80-83

dikes in .......................... 45,82

granite of, analysis of................ 81

classification of .................. 74

macadam made at.................. 72

structure at, figure showing........... 82

Maine Coast Granite Co., quarry of....... $\quad 89$

See also Westcott quarry.

Maine Lake Ice Co.'s quarry (Brooksville), description and product of .....

granite of, classification of.............

Maine Red Granite Co., quarries of. See Beaver Lake. black-granite quarry; Shattuck Mountain quarry; Maine Red Granite Co.'s quarry and works.

Maine Red Granite Co.'s quarry and works (Calais), description and product of .................... 165-167

granite of, classification of ............ 73

joint faces in, minerals on .......... 51,166 Maine State Survey Commission, cooperation with................. 11

Map showing distribution of granite.... Pocket Marcille \& Wormwood quarry (Biddeford), descriptíon and product of . . . 178-179

granite of, classification of............ 73

Marshfield quarry (Marshfield), description and product of.............. 173-174

geodes in ...................... 50,174

granite of, classification of............ 73

Marshfield Town, quarries in............ 173-174

Matrix, definition of ..................... 187

Meddybemps Lake; quarries near ..... 60, 161, $162^{\circ}$

Megunticook Lake, quarry near .......... 156

Melvin quarry. See Tayntor quarry.

Merrill, G. P., on contrast in granite....... 59

on physical properties of granite...... 22-23

on sheets.......................... 31

on weathering...................... 56

work of $\ldots \ldots \ldots \ldots \ldots, \ldots \ldots \ldots \ldots \ldots \cdot 14,18$

Merriman farm, quarry on. See Grant quarry.

Merrithew, $\longrightarrow$ photographs by .........68,70

Metamorphosed rocks, occurrence of........ 8 
Metropolitan Granite Co., quarry of. See Minerva Cove quarry.

Mica, occurrence of, in granite.. See also Muscovite; Biotite.

Microcline, occurrence of, in granite.

Milford, N. H., fractures at

Mill Cove, quarries near.

Millbridge quarry, description and product

of ....................... 174-175

granite of, classification of............ 74

Millbridge Town, quarries in........... 174-175 See also Millbridge quarry.

Millimeter, definition of ............... 187 Minerals in granite, determination of...... 63-64,

forms of

genesis of $20-21$

occurrence of ........................ 16-18

Minerals on joint faces, occurrence and description of ................. 51-52

Minerva Cove quarry (Jonesport), description and product of.

Mingo, Bailey \& Co.'s black-granite quarry (Calais), description and product of .........................

granite of, classification of ............

Mingo, Bailey \& Co.'s red-granite quarry (Calais), description and product of ........................

granite of, classification of ...........

Molybdenite, occurrence of, in granite..... 17, 18 Monolith, definition of .................. 187

Monumental stone, production of........ 183

Moose Island, quarry on. See Moose Island quarry.

Moose Island quarry (Stonington), description and product of.......... 107-108

granite of, classification of ........... 73

Mosquito Mountain, sheets at.......... 33, 34, 37

sheets at, plate showing............. 34

Mosquito Mountain quarry (Frankfort), description and product of ... 152-154

dikes at...................... 46, 48, 153

granite of, classification of............ 74

structure at, figure showing........... 153

Motion $\Lambda$, definition of ............... 72, 188

view of $\ldots \ldots \ldots \ldots \ldots \ldots \ldots \ldots \ldots \ldots .68$

Mount Desert town, quarries in.......... 97

See also following quarries: McMullen;

Campbell \& Macomber; Snowflake; Allen; Babbage; Richardson Brothers; Fernald Brothers \& Higgins; Graves Brothers.

Mount. Waldo Granite Works, quarry of. See Mount Waldo quarry.

Mount Waldo quarry (Frankfort), description and product of.......... 154-156

dikes at........................... 46, 155

flow structure at.................. 25, 155

fracture at......................34, 42,155

granite of, classification of.

tests of.

29,154

knots at

50,155

rift at ............................ 29,155

sheets at.......................... 34,155

structure at, figure showing.
Page.

Mount Waldo quäry, tests of.......... 154-155

Muscle Ridge Plantation, quarries in...... 122

See also High Isle quarry; Dix Island quarries.

Muscovite, description of ................ 17

occurrence of, in granite............ 17,18

Muscovite-biotite granite, definition of..... 24

\section{N.}

New England Granite Co., quarry of. Sec New England Granite quarry.

New England Granite quarry (Jonesport), description and product of ..... 172

New England Granite Works (Concord, N. H.), quarry of, strain in.... 36-37

New York hall of records, statue at, view of:. 72

Norite, quarries of.... 126-127, 136, 157, 161-162, 164

Norridgewock Town, quarries in ......... 149-152 Sce also Dodlin quarry; Lawton quarry; Emmons Taylor quarry.

North Berwick, quarries near............ 176 North Carolina, quarrying in............ 37,71 North Jay, quarries at................... 80,83 North Sullivan, quarries at............ 111, 112 Northeast Harbor, quarry at........... 100

\section{0 .}

Oak Hill Granite Co., quarry of. See Oak Hill quarry.

Oak Hill quarry (Swanville), description and product of .............. 158

granite of, classification of ............ 74

Oligoclase, occurrence of, in granite......... 18

Ophitic, definition of................... 188

Orland quarry, location of .............. 117

Orthoclase, occurrence of, in granite...... 16

Oxford County, production of granite in. 183-184 quarries in ...................... 144-147

Oxford Town, quarries in ............... 146 See also Roy quarry.

$P$.

Palmer quarry (Vinalhaven), decomposition at.................... 55, 133

description and product of ....... 129, 132-134 granite of, classification of............ 73 columns of, plate showing......... 70

knots at.......................... 49,133

Paragonite, occurrence of, in granite...... 17

Paving stones, manufacture of............ 72

production of ...................... 183

quarry of, plate showing............. 68

Pegmatite, definttion of.................. 188 dikes of, occurrence and character of . 44-45, 61 plate showing.................. 60

origin of ........................... 45

Penobscot County, prodaction of granite in ...................... 183-184

quarries in....................... 147-148

Pequoit quarry (Vinalhaven), description and product of................. 135

granite of, classification of............ 74

Pettee, J. A., quarry of. See Pettee blackgranite quarry.

Pettee black-granite quarry (Sullivan), description $a$ and product of........

granite of, classification of 
Pierce, Hayward, quarry of See Mosquito Mountain quarry.

Piscataquis County, quarries in.

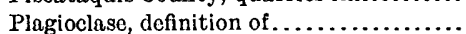
description of ....................... occurrence of, in granite................

Pleasant River, quarry on................ Pleasant River Bay, quarry on............ Pleasant River black-granite quarry (Addison), description and product of ....................... 159-160 granite of, classification of........... $\quad 75$ sheets in .......................... 159

plate showing..................

Pleasant River Granite Co., quarry of. See Pleasant River black-granite quarry.

Polarized light, definition of.............. 188

Polish, susceptibility of granite to........ 64

Porosity of granite, data on............... 22-23 test for.

Porphyritic, definition of ............... 188 Pownal Granite Co.'s quarry (Pownal), description and product of....... 79-80

flow structure at $\ldots \ldots \ldots \ldots \ldots \ldots \ldots \ldots 26,79$

granite of, classiffcation of............ 74

Pownal Town, quarries in .............. 79-80

See also Pownal Granite Co.'s quarry.

Pride, J. H., quarry of .................. 80

Pride's quarry (Westbrook), description and product of ............. 80

Production of granite, statistics of .... 12, 183-184 Pyrite, occurrence of, in granite.......... 17, 18 Pyroxene, occurrence of, in black granite... $\quad 57$

\section{Q.}

Quarries, accessibility of................ 12, 68 description of ....................... $76-183$ distribution of $\ldots \ldots \ldots \ldots \ldots \ldots \ldots \ldots, 75-76$ drainage of ..................... 68-69 equipment of, and investment in ...... 183 operation of ........................ 69-71

figure showing.................. 70 value of, factors in ................. 12, 68 waste from ......................... 72 Quartz, occuirrence of, in granite .. 14, 16-17, 18, 56

Quartz diorite, definition of ............. 25 quarries of ..... 25, 114, 139-140, 143-144, 162-164 plates showing ................. 60,62

Quartz monzonite, definition of.......... 24

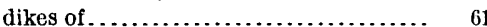

plate showing................... 60 quarries of ...........................

Queen City Granite Co., quarry of. See. Queen City granite quarry.

Queen City granite quarry (Guilford), description and product of ......... granite of, classification of ..............

Quincy, Mass., headings at................ rift at.................................. 27,28 sheeting at....................... 30

\section{$\mathrm{R}$.}

Random stone, definition of .

Redbeach, quarries at and near.......... 162-167 quarries at and near, rift at.
Redbeach Granite Co.'s quarry (Calais), description and product of.........

granite of, classification of .............

Redcliff opening. See Black Island quarries. Redstone, N. H., rift at................. Richardson Brothers quarry (Mount Desert), description and product of.

Ricker, Charles, quarry of. See Ricker quarry.

Ricker quarry (Biddeford), description and product of .................176-177

granite of claśsification of ............ 73

Rift, definition of ..................... 26, 188

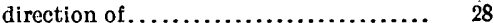

discussion of .......................... 20-29

Riiber, C. C., on rift ................... 27

Riprap, production of................... 184

Roberts Harbor, quarry on............ 135

Robertson \& Havey quarry (Franklin), description and product of........ 90-92

dikes in ........................ 43, 48,91

effect of, on granite............... 43

granite of, classification of ............ 74

structure at, figure showing.......... 91

Rock Chapel Hill, Ga., structure at, plate showing.................... 42

Rockland, qun rries near............ 122, 124, 125

Rockland region, granite contacts in...... 9

Rockport Granite Co., quarry of. See Hardwood Island quarry.

Rodgers, J. C., quarry of. See Clark Island quarry; Settlement quarry.

Rogers, E. T., analysis by .............. 81

Rosiwal, August, method of, for determining minerals in granite. ...... 172-173

on minerals in granite................ 64

Ross quarry (Kennebunkport), description and product of ............ 181-182

granite of, classification of............ 73

joints in.......................... 39, 181

figure showing................. 182

structure at, figure showing........... 182

Round Pond quarry (Bristol), contacts in.......................61-62, 139

description and product of .......... 139-140

dikes at......................... 48, 61, 139

plates showing.................60,62

granite of, classification of............ 75

structure at, figure showing........... 140

Rowe, B. E., quarry of. See Toothachers Cove quarry.

Roy quarry (Oxford), description and product of ....................... 146

granite of, classification of........... 74

joint faces in, minerals on.............. 52

Rubble, production of .................. $\quad 184$

Rutile, occurrence of, in granite........... 17

Ryan-Parker Construction Co., quarry of. See Ryan-Parker quarry.

Ryan-Parker quarry (Stonington), description and product of ......... 101-103

granite of, classification of........... 73

rift at.............................. 28

view of ......................... 32

sheets at............................ 34, 101

plate showing................... 34 
Ryan-Parker quarry, structure at, figure showing .

view of.

S.

Saco River, quarries near.................

St. Croix River, quarry on................

St. George Town, quarries in............. See also following quarries: Sprucehead; Clark Island; McConchie; Flat Ledge.

St. John the Divine Cathedral, granite for. 133-134 granite for, plate showing ............ 70

Salt horse, definition of ................ 42, 188

Sand Cove, quarry on................ 129, 136 Sands quarry (Vinalhaven), description and product of ................. 129-132

dike at............................ 43,132

granite of, carving in, plate showing ... $\quad 70$ classification of.................... 73

joint faces in, minerals on ............ 51, 131 knots at...................... 49-50,132 structure at, figure showing........... 131 sheets and joints at, plate showing.... $\quad 40$

Sap, definition of ..................... 188

fractures and, relations of............

headings and, relations of............ 52 plate showing.................. 46

importance of .................... 12

occurrence and origin of .............. $52-54$ utilization of..................... 72

view of ............................. 46

See also Discoloration.

Sargent, H. W., quarry of. See Sargent's quarry.

Sargent (W. G.) Co., quarry of............ 101 Sargent's quarry (Brooksville), description and product of.

Schaller, W. T., work of.............. 14,46,131

Schist, contact of, plate showing.......... 62 definition of ....................... 188

inclusions of, plate showing........... $\quad 42$

Schistosity, definition of ............... 188

Scientific aspects of granite, discussion of.. 14-62 Scope of report....................... 11-12,13

Scotch granites, gas in................. 19-20

Seal Cove quarries (Tremont), description and product of............... i17

granite of, classification of........... 74

Seam, definition of .................... 188

Searsport Town, quarries in............ 157-158 See also Bog Hill quarry.

Secondary minerals, definition of......... 17,188

Sedgewick quarries (Sedgewick), descripand product of ..................

granite of, classification of ............ 74

Sedgewick Town, quarries in. See Sedgewick quarries.

Sedimentary rocks, definition of ........... 188 intrusion of granite into.............. 9

Segregations, definition of ............... 188 occurrence and description of........... 49-50

Sericite, definition of.................. 188 nccurrence of, in granite............ 17,46-47 Settlement quarry (Stonington), descriptionuand product of .......... 108-109
Page.

Settlement quarry, dikes $n t . . . \ldots . . . . . . .46,109$ granite of, classification of ............ 73 strength of.................... 108 structure at, figure showing.......... 108

Shakes, definition of ................. 40-41,188 origin of .......................... 55

Shaler, N. S., on sheets.................. 30

Shattuck Mountain quarry (Calais), decom-. position at................... 55 description and product of .......... 164-165 granite of, classification of............ 73 subjoints in .................... 41-42,165

Sheet quarry, definition of.............. 188

Sheet structure, artificial production of.... 33

continuity of ....................... 38

description of ........................ 30,31

imbrication of ...................... 31

joints and, intersection of............. 38

intersection of, plates showing $\ldots . .$.

origin of ............................ 30-38

plate showing................. 42

percolation of water along............. 38

plate showing................. 40

plates showing..... $32,34,36,38,40,42,44,60,62$

rock surface and, relations of........ $30,32,37$

Sherwood (S. Clinton) Co., quarries of. See Sherwood quarries.

Sherwood quarries (Stonington), description and product of...... 101,105-106

dikes in ............................ 46

flow structure at................... 25

granite of, classification of.......... 73,74

varieties of .................... 105 figure showing ............... 105

Silica. Sce Quartz.

Silurian period, intrusions in ............. 11

Sinclair black-granite prospect (Sullivan), description of ................ 114

Slickensides, definition of ................ 188

occurrence of....................... 40

Smith, George Otis, introduction by, on occurrence of granite in Maine.. 7-12

on diabase......................... 57

on Gardner prospects................ 163

work of........................... 9

Snowflake quarry (Mount Desert), description and product of.......... 99-100

granite of, classification of........... 74

Solar heat, sheeting due to ..... 30,31,33,35,36,37 Somerset County,production of granite in. 183-184

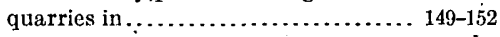
Somes Sound, quarries on............... 100 quarries on, view of ................. 44 Sound, quarry near..................... 100 South Thomaston Town, quarries in..... 127-128 See also Weskeag quarry.

Southwest Harbor, quarry a.t........... 116

Specific gravity of granite, definition of ... 66,188 Spence \& Coombs black-granite quarry (Berwick),description and product of. $\quad 176$ granite of, classification of........... 75

Sprucehead-Clark Island a rea, granite contacts in .....................

Sprucehead quarry (St. George), description and product of.............. 124-125

dikes at........................... 43-44 
Sprucehead quarry, granite of, classification of $\ldots \ldots \ldots \ldots \ldots \ldots \ldots \ldots \ldots \ldots . .74$

sheets at........................ 37,124

structure at, figure showing........... 125

Spruce Island, quarries on............. 107

See also Stonington quarry.

Stackpole, C. F., quarry of. See Horsebrook Mountain quarry.

Starks Hill, quarries near............. 144,145

Stevens, I. A., and others, quarry of. See Lord prospect.

Stevenson, T., on weight of granite........

Stimson, Mrs. C. A., quarries of. See Stimson quarries.

Stimson quarries (Sullivan), description and product of.................. 111-112

granite of, classification of........... 74

inclusions at...................... 50

Stinchfeld quarry (Hallowell), description and product of ............. 117-120

granite of, carving of, plate showing ... 72

classification of ................... 74

strength of ..................... 118

sheets at...................... 34,118-119

plate showing.................. 36

structure at, figure showing........... 118

Stone Mountain, Ga., granite at .......... 31

Stonington quarry (Stonington), description and product of .......... 107

granite of, classification of ........... 74

Stonington Town, quarries in.......... 101-110

quarries in, map showing............ 102

See also following quarries: Ryan-Parker; Goss; Sherwood; Latty Brothers; Stonington; Hagan \& Wilcox; Settlement; Calvin Ames.

Strain sheets, description of .............. 36-37

Stratified, definition of ................... 188

Strength of granitc, tests for............... 65

Strike, definition of .................... 188

Stripping, definition of .................. 188

Structure of Maine granites, character of.... 25-42

Subjoints, definition of ................. 189

occurrence and character of ...........41-42

Sullivan, E. C., work of .......... 14,17, 51 , $94,102,117,120,126,130,140-141,152$

Sullivan Town, quarries in............ 110-114

See also following quarries: Crabtree \& Havey; Hopewell; Stimson; Hooper, Havey \& Co.; Whalesback; Dunbar Brothers; Harvey Dunbar; Taylor; Pettee; Sinclair.

Swans Island town, quarries in...........114-116

See also Baird quarry; Toothachers Cove quarry.

Swanton \& Wallace, quarry of. See Milbridge quarry.

Swanville town, quarries in..............

See also Oak Hill quarry.

Swenson (Peter) \& Co., quarry of. See Round Pond quarry.

Syncline, definition of

189
$\mathrm{T}$.

Page.

Tarbox, 0. S., quarries of. See Tarbox black-granite quarry; Redbeach Granite Co.'s quarry.

Tarbox black-granite quarry, description of ......................... 162

Tarr, R. S.,.on rift and grain............... 26-27 on uses of granite................... 67

Tassin, Wirt, work of.............. 14,46-47

Taylor, Emmons, quarry of. See Emmons Taylor quarry.

Taylor, Harry, quarry of. See Taylor quarry.

Táylor quarry (Sullivan), description and product of ................. 113-114

granite of, classification of ............ 74

Tayntor quarry (Hallowell), description and product of .............. 120-121

flow structure at................. 25, 120

fracture at......................... 42,121

knots in......................... 50,121

sap in.......................... 53,121

structure at, figure showing .......... 121

Tayntor (C. E.) \& Co., quarry of. See Tayntor quarry.

Technology of granite, glossary of........ 186-189

Tenants Harbor Town, quarries in...... 128-129.

Texture, character of ..................... 25

classification by ..................... 24

definition of ......................... 20

description of ...................... 20-21, 58

Thornberg, A. M., quarry of. See Thornberg black-granite quarry.

Thornberg black-granite quarry (Addison), description and product of...... 160

granite of, classification of........... 75

Thurlow Head, quarries at............ 101,104 sheets at............................ $33-34$

plate showing ................... 34

Till, definition of ..................... 189

Titanite, occurrence of, in granite......... 17, 18

Toe nails, description of .................. 39

Toeing in, cause of ....................... 40

definition of ...................... 189

Toothachers Cove quarry (Swans Island), . description and product of.... 115-116 granite of, classification of............ 73

Tortion, joints due to $\ldots \ldots \ldots \ldots \ldots \ldots \ldots . \quad 38$

Tourmaline, occurrence of, in granite ..... $\quad 17$

Transportation, cheap, importance of...... 68

Tremont Town, quarries in ............. 116 See also Seal Cove quarries; Carroll quarry; Orland quarries.

Turner, H. W., on sheets................ 32

Twin crystals, definition of.............. 189

V.

Van Hise, C. R., on sheets............... 33

Variations in granite, occurrence.of........ 42-52

Veins, occurrence and description of....... 46-47

Vinalhaven Island, quarries on.......... 129-137 
Vinalhaven Town, quarries in

See also following quarries: Sands; Palmer; Webster; Black (Pleasant River); Pequoit; Duchane Hill; Armbrust; Harbor; Bodwell black granite; George Gins; Hurricane Island.

Vitreousness of granite, data on........... Vogt, J. H. L., on sheets

\section{W.}

Waite, E. L., quarry of. See Stonington quarry.

Waldo County, production of granite in.. 183-184 quarries of ..................... 152-158

Waldoboro quarry, contact at.......... 51,142 figure and plate showing........... 46,142 description and product of.......... 140-143 dikes at.......................... 45, 142 granite from, analysis of ............ 141 classification of .................. 74 schist inclusions at, figure showing..... 142 sheets at........................... 35,142 plate showing ................... 46

Waldoboro Town, quarries in ........... 140-143 See also Waldoboro quarry.

Warth, H., on artificial production of sheets. Washington County, production of granite in ......................... 183-184 quarries of ......................... $\quad 159$

Waste, utilization from.................. 72

Water, expansive freezing power of, quarry-

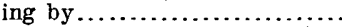
supply of .

Watertown, arsenal at. See Arsenal.

Weathering, definition of. 189 sheet structure due to $31,35,36,37$ stages of ......................... $55-56$

Webster, A. M., quarry of. See Webster quarry.

Webster quarry.(Vinalhaven), description and product of ............. 129,134

granite of, classification of ............ 73

knots at....................... 50,134

view of ............................ 68

Weight of granites, data on ............. 21, 66

Wells Depot, quarry near .............. 182

Wells Town, granite of, classification of .... 73 quarries in

182-183
Weskeag quarry (South Thomaston), description of.............. 127-128

granite of, classification of ........... 73

rift at............................. 27-28

figure showing................... 28

'West Biddeford, quarries in.............. 178

West Franklin, quarries at...............

West Sullivan, quarries at............. 111,113

Westbrook Town, quarries in ............ 80

See also Pride's quarry.

Westcott quarry (Brooksville), description and product of ................ 89

Whalesback quarry (Sullivan), description and product of ............. 112-113

dikes in.......................... 48,113

Wharff quarry. See Palmer quarry.

White horse, description of................

White Granite Co., quarry of. See White quarry.

White quarry (Bluehill), description and product of................. 84-85

granite of, classification of ........... 73

joints in .......................... 39,85

plate showing................... 40

sheets at........................... 34

plate showing ................... 40

structure at, figure showing.......... 84

Whitefield Town, quarries of ............ 143

See also Jewett's black-granite quarry.

Whitney, J. D., on sheets................. 30

Whittle, C. L., on rift and grain........... 27

Wildcat quarry, dike at.................. 45

Willard Point quarry, dike at............. 45

Willcutt (L. D.) \& Son, quarry of......... \&

Williams, J. F., on hardness of granite..... 65

Wilson Granite Co., development by....... 88 granite of, classification of........... 88

Woodstock Town; quarries in........... 146

See also Bryant Pond quarry.

Woodworth, J. B., on subjoints........... 42

Woolson, I. H., tests by .............. 137,141

Y.

Yoho Bay, quarry on................. 160

York County, production of granite in ... 183-184 quarries in...................... 175-183

$\mathrm{Z}$.

Zoisite, occurrence of, in granite.......... 17

Zircon, occurrence of, in granite.......... 17, 18 